\title{
THE IMPACT OF PAC POLICY ON PACIFIC WOMEN'S HEALTH AND WELLBEING: THE EXPERIENCES OF KIRIBATI MIGRANTS
}

\author{
Rose Namoori-Sinclair \\ A thesis submitted to Victoria University of Wellington in fulfilment of the \\ requirements for the degree of Doctor of Philosophy
}

Victoria University of Wellington

2020 



\section{Keywords}

\section{Kiribati words}

boua ni kaua: Young men in te maneaba setting.....................................................4 47

bururu ma beroro: Rumours and unofficial conversation in te maneaba ............... 49

inaomata: Same meaning as toronibwai .............................................................. 55

kakawakin te aomata: Respect for the right of the individual .................................. 64

kieia ataei: Mats for children, which symbolises the kindness of the people to

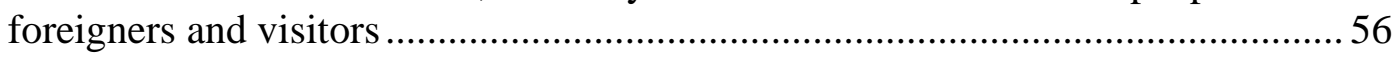

maroroakina: To share or discuss ....................................................................... 75

maungatabu: Formal meeting .............................................................................. 47

onean te rau: Replacing the thatched roof ........................................................... 49

rorobuaka: Young men .................................................................................. 48

tabakeauea: Another word for unimane that is not commonly used in today's

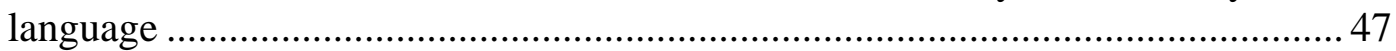

taburoroko: Forbidden, embarrassing and not culturally acceptable ........................51

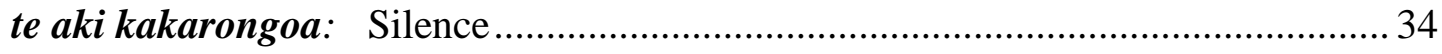

te akoi: Kindness ............................................................................................. 57

te aoa onoua: A disciplinary action ordered by unimane .......................................... 51

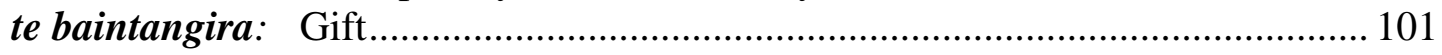

te boti: Sitting space in te maneaba ………………………………………........... 46

te bowi: A meeting ........................................................................................... 51

te bubuti: A request ………………………………………………………. 99

te bukarere: Veranda of te maneaba …………………………………………..... 49

te inaki: Portion under the roof allocated to each kainga ........................................ 47

te kaawa: Village ..................................................................................... 3

te kainga: Extended family............................................................................. 3

te kakairua: Hospitality - way in which foreigners or visitors are welcomed with

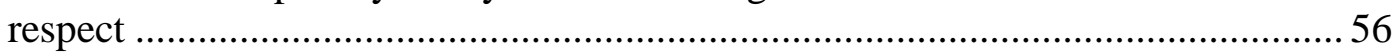

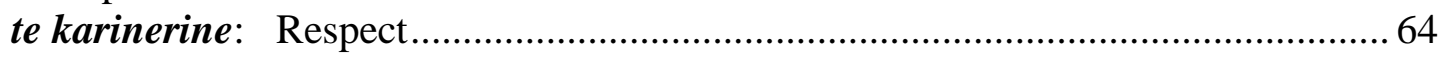

te karinrin: Traditional engagement ceremony ……………………………….......5 57

te kawawa: A cultural form of mobilising social capital or resources for helping

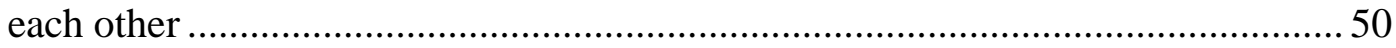

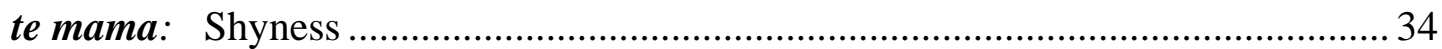

te maneaba ni Maungatabu: House of parliament ....……………………………... 63

te maneaba: A cultural meeting hall .................................................................... ii

te maroro: An exchange of stories or ideas..........................................................iii

te moanibwai: First important person or family in te maneaba cultural setting ..... 49

te mweaka: A formal gift................................................................................. 47

te nei ni kauatabakea: Sacred space surrounded by tabakeauea ............................... 47

te otabwa: Fiancée …………………………………………………………....5

te tangira: Love ............................................................................................ 57

te tangobwai: A form of borrowing ................................................................. 79

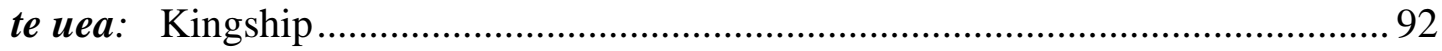

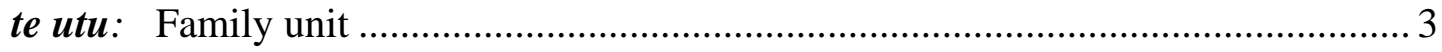

toronibwai: Well functioning and productive to make their own living without

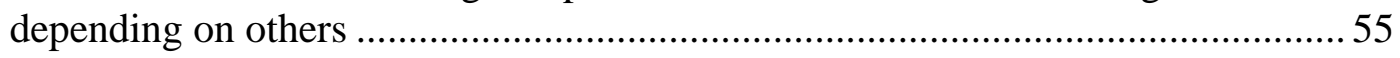




\section{Abstract}

This research examines in-depth the health and wellbeing experiences of 30 Kiribati migrant women navigating their way to achieve New Zealand permanent residency under the Pacific Access Category (PAC) policy. The political and economic rationality underpinning PAC was to meet New Zealand's labour demand for industrial growth. It also provides successful applicants with the opportunity to work, live and study in New Zealand indefinitely. The purpose of the research was two-fold. Firstly, to assess the health and wellbeing experiences of migrant women who travelled to New Zealand under the PAC scheme, using Kiribati women as a case study to comment on issues of responsibility for healthcare and wellbeing. Secondly, to identify gaps in personal and policy-related aspects of healthcare and wellbeing, and determine how access to appropriate healthcare and social services for PAC migrant women can be facilitated.

The experiences of these migrant women indicated shortcomings in provision of health and social services that this thesis terms the 'PAC gap'. Although the PAC policy offers them the opportunity to live permanently in New Zealand, the current state of the PAC policy features gaps in service provision that result in gender and health inequality, financial hardship and stress, poor housing, unemployment and poverty. The health and wellbeing impact of the existing conditions of the PAC policy was exacerbated by the contrasting influence of neoliberalism as a policy, ideology, and a form of governmentality in the New Zealand environment (Larner, 2000a; Suaalii, 2006), and the markedly different maneaba system that is central to the social and political life in Kiribati (Tabokai, 1993; Uakeia, 2017; Whincup, 2009). Te maneaba is a traditional meeting hall, where communal meetings take place, and unimane (male elders) make decisions for the governing and wellbeing of the village people (Tabokai, 1993). It is a form of governmentality that shapes and influences how an I-Kiribati thinks and acts (Foucault, 1991). This system is at odds with a neoliberal approach that stresses self-responsibility and individualism. These contrasting forms of governmentality 'talk past each other' or are totally different (Metge \& Kinloch, 1984).

I recruited 30 I-Kiribati women who were successful PAC migrants: six from Auckland, six from Hamilton, and eighteen from Wellington. These women were 
selected in different years from 2012 through to 2015. To identify the PAC gaps, I employed an indigenous research method called te maroro/talanoa (to exchange ideas and experience freely and openly), complemented by the use of the feminist oral history method that transfers the needs and voices of women from the margin to the centre. This thesis draws on Foucault's governmentality theory, a critical discourse on neoliberalism, and research on migration and the colonial history of Kiribati. It also draws on work by both Pacific and non-Pacific scholars that articulate how health and wellbeing are rooted in our lived culture and values. This thesis also stresses the need for cultural competency and integration of policy, service provision and community engagement. These materials have all guided my analysis to unpack the women's health and wellbeing experiences.

The research findings on the drawbacks of neoliberal governmentality and maneaba governmentality, and understanding of te maneaba system in a new way, strengthen Pacific studies. These contribute to the literature on Kiribati's indigenous knowledge and cultural values and Kiribati migration as well as to the impact and effectiveness of the PAC policy for Kiribati and Pacific migration. This thesis demonstrates the need to extend the engagement of Pacific indigenous knowledge and values to the design and implementation of policies at national, regional and global levels. This thesis recommends a hybrid neoliberal-maneaba residential model to address the issues of the current system, such as stress and difficulty finding a job offer, and close PAC gaps. The new model entails a more open and transparent communication between both the New Zealand and Kiribati governments when designing a cultural competent and coherent strategic framework. By working in the best interests of all parties (i.e. New Zealand and the Kiribati governments and PAC migrant groups) this would support future successful PAC applicants to settle well in New Zealand. This would contribute to improved health outcomes for these women, their utu and kainga, without undermining the richness and values of Kiribati's culture rooted in te maneaba system. These stories articulate a consistent requirement for a hybrid neoliberal-maneaba system, to create a residency model that works for successful PAC applicants, the government of New Zealand and Kiribati, and Kiribati families living in both countries. This would avoid repeating the stress and pain most of these PAC migrant women had experienced because of lack of government support as perceived under te 
maneaba system. The recommended residency model would also benefit other eligible countries (Fiji, Tonga, and Tuvalu) participating in the PAC scheme. 


\section{Table of Contents}

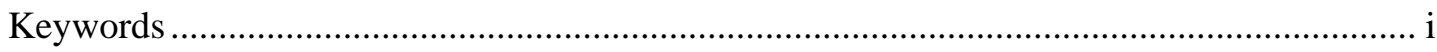

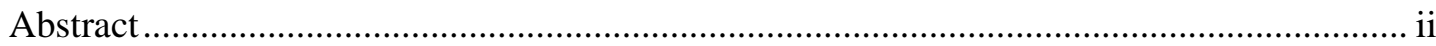

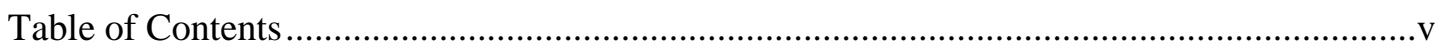

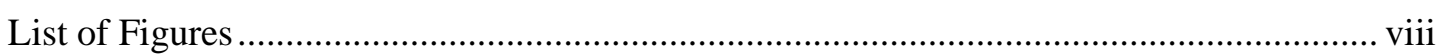

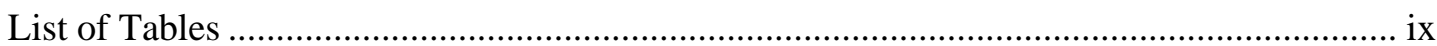

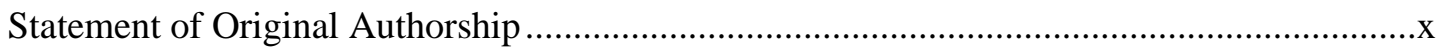

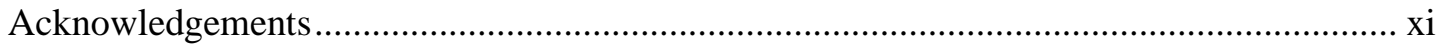

Chapter 1 Introduction............................................................................................................... 1

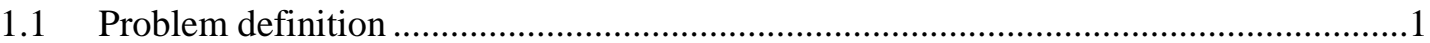

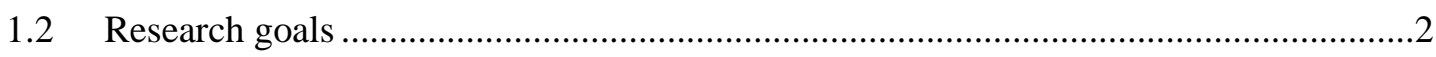

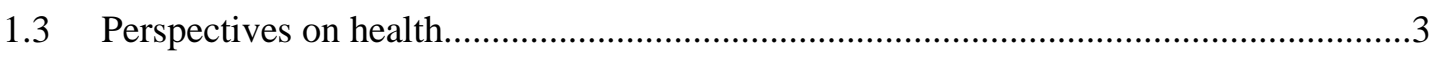

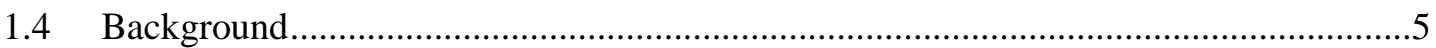

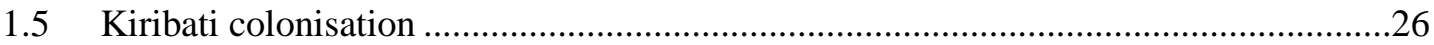

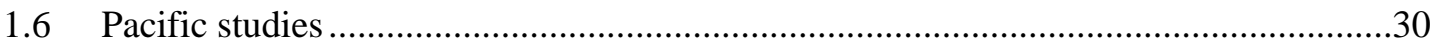

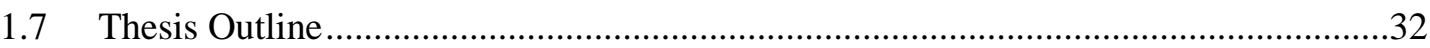

Chapter 2 Literature review on conceptual framework.................................... 37

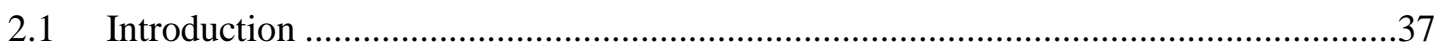

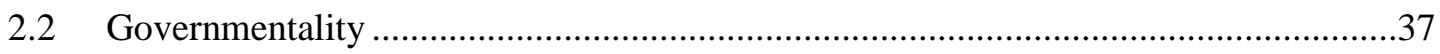

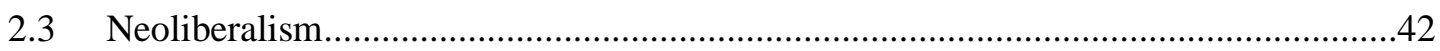

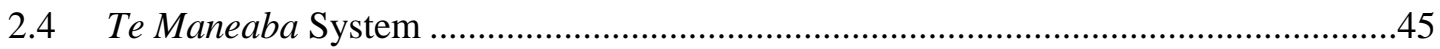

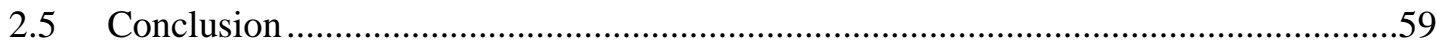

Chapter 3 Research methodology .............................................................................60

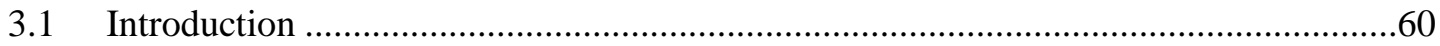

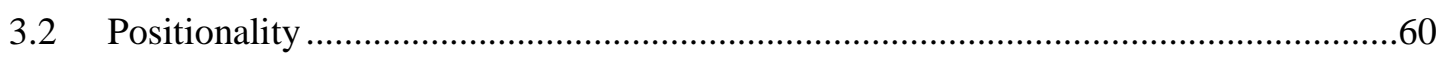

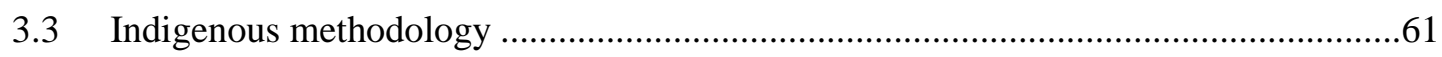

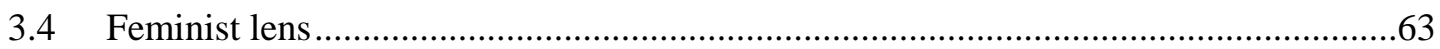

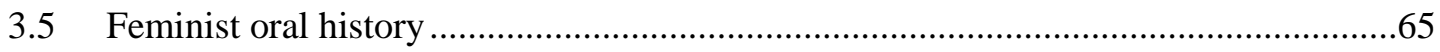

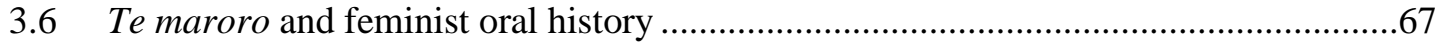

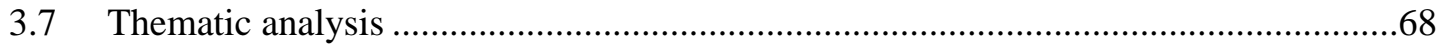

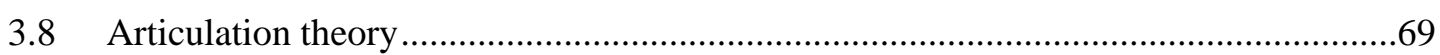

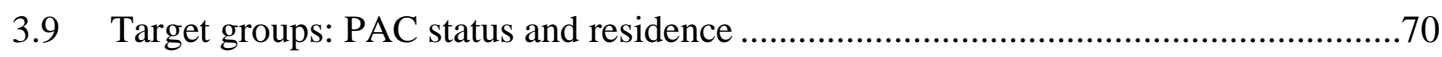

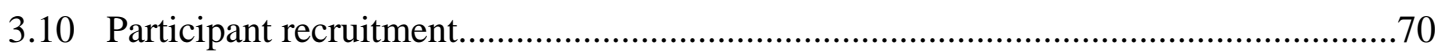

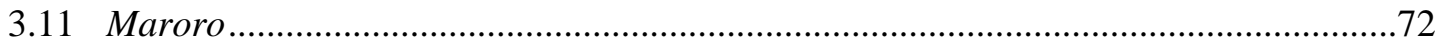

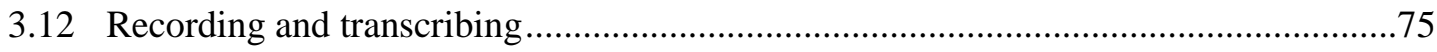




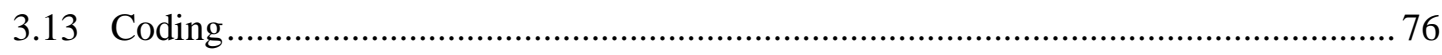

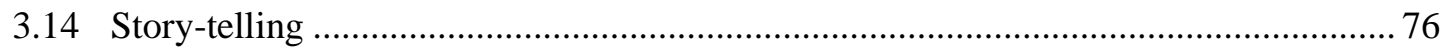

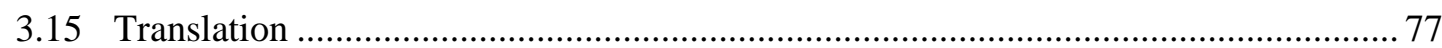

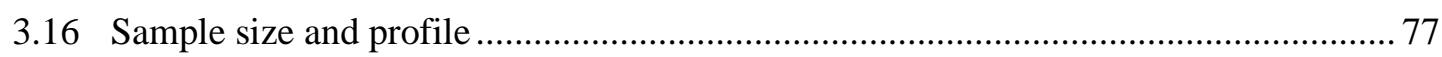

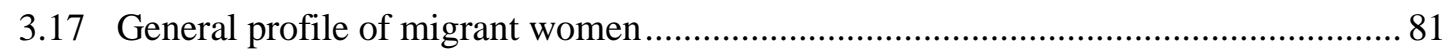

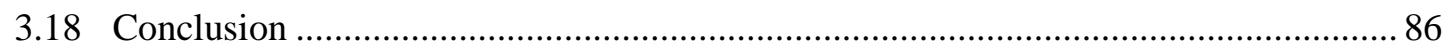

Chapter 4 Differing world views: neoliberal and te maneaba systems............. 89

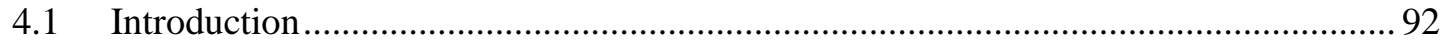

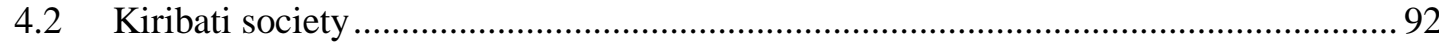

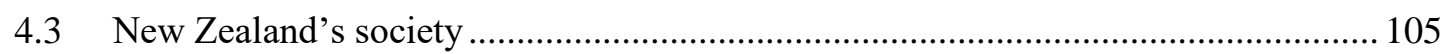

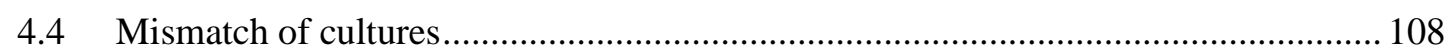

4.5 Lack of support from staff within Immigration New Zealand ................................... 109

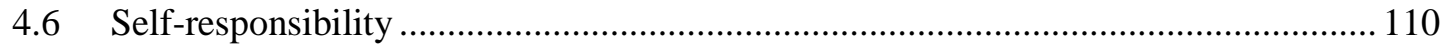

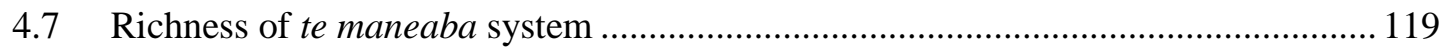

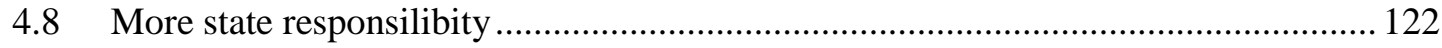

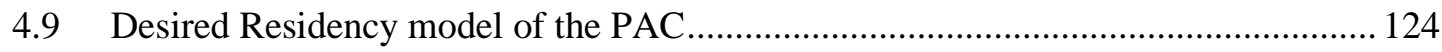

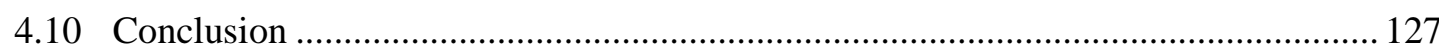

Chapter 5 New responsibility for Kiribati families in New Zealand in bridging the PAC gaps............................................................................................. 131

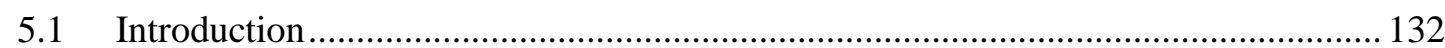

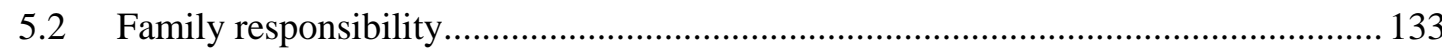

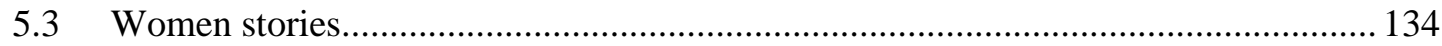

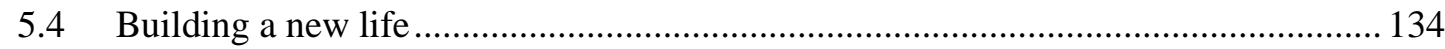

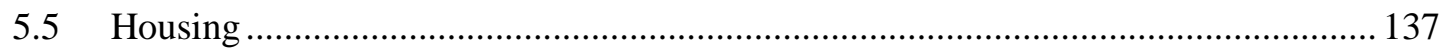

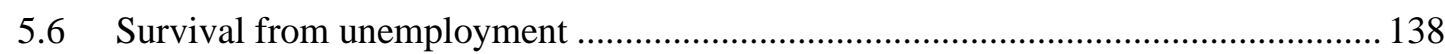

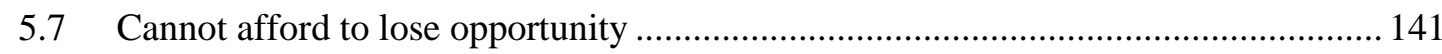

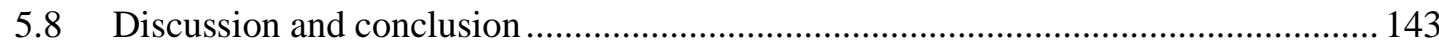

Chapter 6 Cultural barriers: language, te mama (shyness), and te aki kakarongoa (silence) .......................................................................................... 149

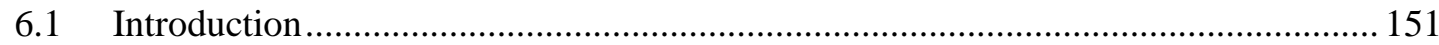

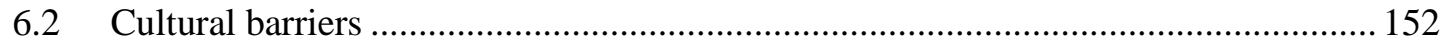

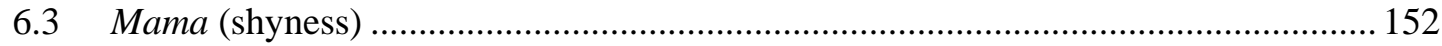

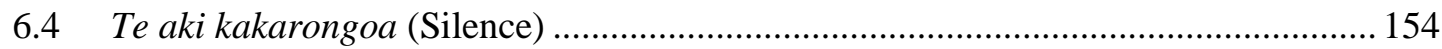

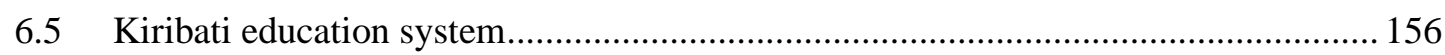

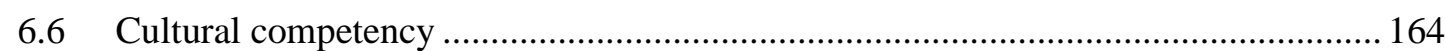

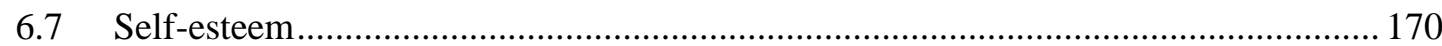

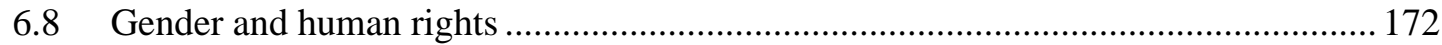

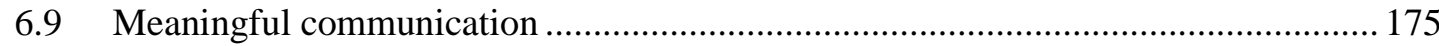




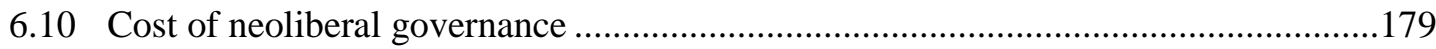

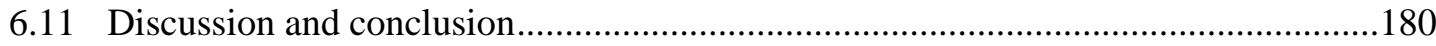

Chapter 7 Risk of self-responsibility for healthcare and wellbeing ................ 189

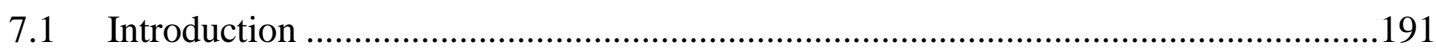

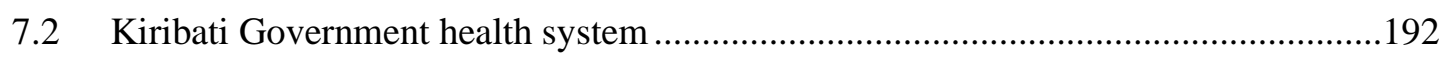

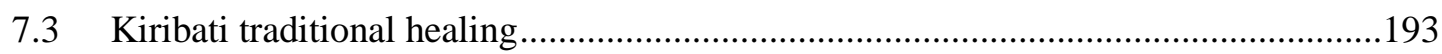

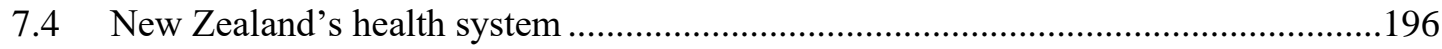

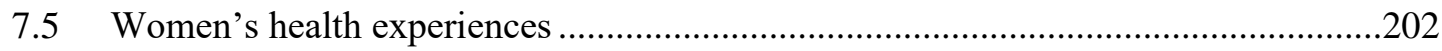

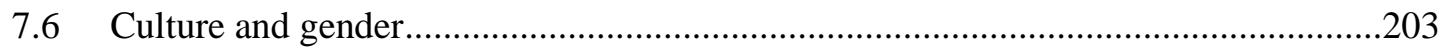

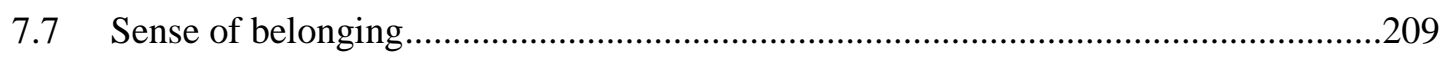

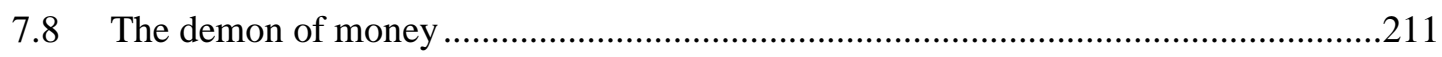

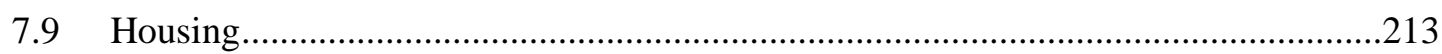

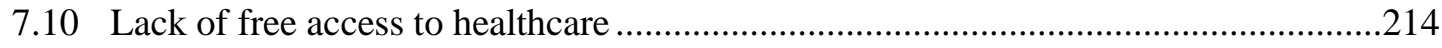

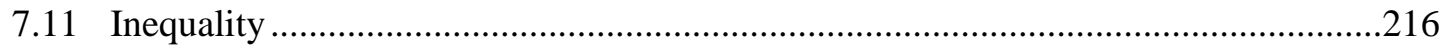

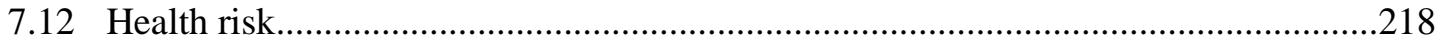

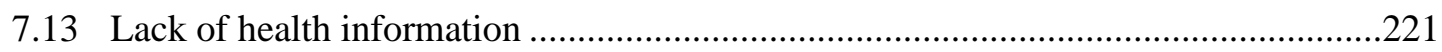

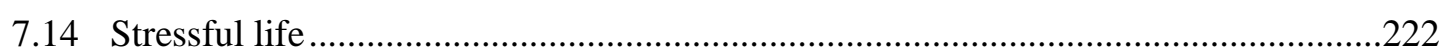

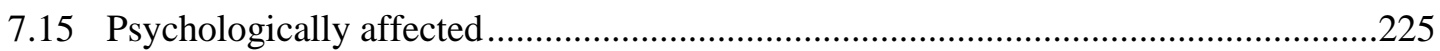

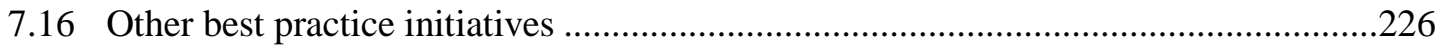

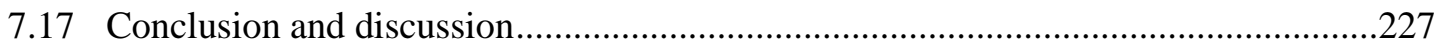

Chapter 8 Conclusions, limitations and recommendations............................. 233

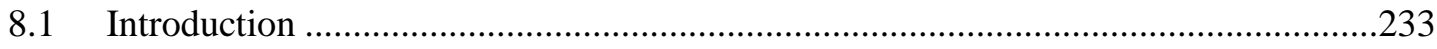

8.2 Drawbacks of the political and economic systems ................................................233

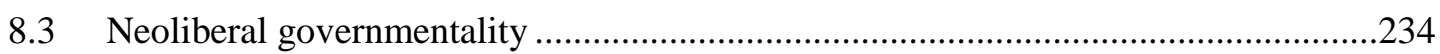

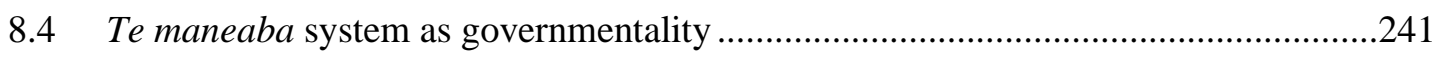

8.5 Aspects of te maneaba that relate to wellbeing (traditional setting) ...........................245

8.6 Neo-maneaba health and wellbeing model in the New Zealand society ....................245

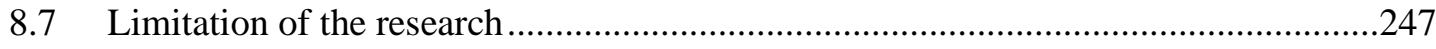

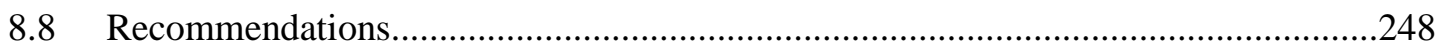

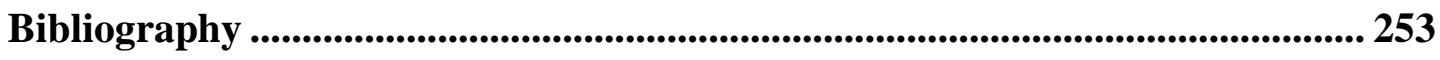

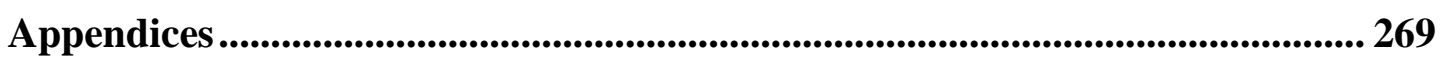




\section{List of Figures}

Figure 1.1: Pacific residence approvals by visa stream, 2013-2017 financial years.

Figure 1.2: Pacific residence approvals under the International/Humanitarian sub-streams by financial year.

Figure 1.3: Residence approvals under the Pacific Access Category by financial year.

Figure 1.4: Approved temporary workers from the Pacific by work visa policies.

Figure 1.5: New Zealand's population by ethnicity and gender, census years 2001-2013.

Figure 1.6: Household crowding by ethnicity. 18

Figure 1.7: Permanent residence visa sub-streams most commonly granted to Kiribati migrants, financial years 2009-2018. 19

Figure 1.8: Kiribati population in New Zealand by gender, 2013. 20

Figure 1.9: Distribution of the Kiribati population by New Zealand region, 2013. 21

Figure 1.10: Age distribution of the Kiribati population in New Zealand, 2013....... 21

Figure 1.11: Map of the Republic of Kiribati........................................................... 22

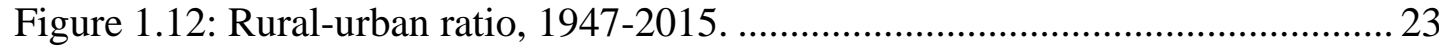

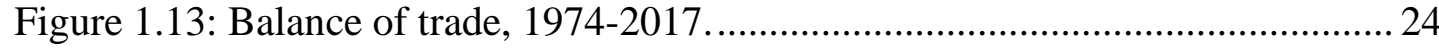

Figure 1.14: Economic growth and real income per capita....................................... 25

Figure 2.1: Photo of a maneaba (Taratabito) in my home village of Tanaeang

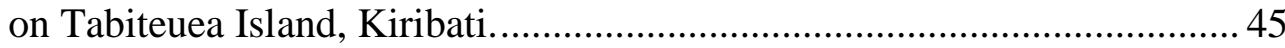

Figure 2.2: Photo of the inside of a maneaba (Taratabito)....................................... 48

Figure 2.3: Te maneaba system and its core values..............................................5

Figure 7.1: Ambulatory Sensitive Hospital admissions.......................................... 198

Figure 8.1: Neo-maneaba health and wellbeing model. ...................................... 246 


\section{List of Tables}

Table 1-1: Permanent residence visa policies most commonly granted to Pacific migrants.

Table 1-2: Kiribati residence approvals under the PAC, 2009-2018 financial years.

Table 1-3: Population 15 years and over by island and work status - 2015.............. 25

Table 3-1: Level of education achieved by age group........................................... 77

Table 3-2: Overseas experience by age group. .................................................... 78

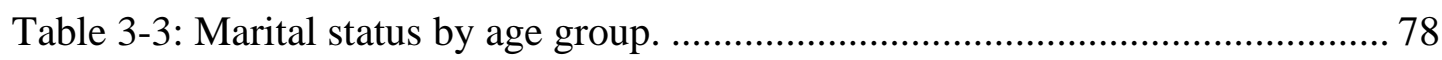

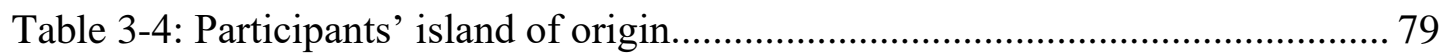

Table 3-5: Year participants were selected under the PAC. .................................... 80

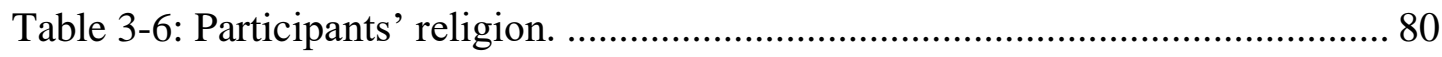

Table A-1: Temporary work and study visa policies most commonly granted to

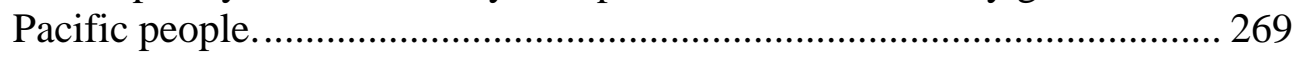

Table A-2: Pacific residence approvals by stream............................................. 269

Table A-3: Approved temporary workers from the Pacific by work visa policies

Table A-4: Recognised Seasonal Employer work visa approvals by eligible country.

Table A-5: Key economic data for Kiribati. 


\section{Statement of Original Authorship}

The work contained in this thesis has not been previously submitted to meet requirements for an award at this or any other higher education institution. To the best of my knowledge and belief, the thesis contains no material previously published or written by another person except where due reference is made.

Signature:

Date: 


\section{Acknowledgements}

I wish to acknowledge and thank the following people for their contributions to the formation of this thesis.

First and foremost, the 30 Kiribati women who participated in this research, in sharing their health and wellbeing experiences of migrating to New Zealand under the PAC policy. I also thank everyone else who have so kindly shared their stories. The information is insightful and contributes to knowledge to inform future research and immigration and health policies for the wellbeing of future PAC migrants from Kiribati and the Pacific.

My primary supervisor, Professor Brigitte Bonisch-Brednich for her guidance, support and patience throughout this research. Her wealth of knowledge in migration studies, words of encouragement and wisdom have inspired me to successfully complete this research in spite of the many obstacles encountered.

The late Dr Jenny Neale for her wealth of knowledge, which has provided me with invaluable insights into the health and gender aspects of my research.

Dr April Henderson for her wealth of knowledge, which has provided me with insights in Pacific studies to strengthen this thesis.

My internal examiner Dr Aliitasi Tavila-Su'a (VUW Faculty of Health), New Zealand examiner Dr Maria Borovnik (Development Studies, Massey), and overseas examiner Dr Petra Autio (Social and Cultural Anthropology, U Helsinki) for their critique and insightful suggested changes to strenghten this thesis.

The late Dr Teresia Teaiwa and Dr Sailau Suaalii-Sauni for their guidance and support during the initial phase of this research.

Dr. Takuia Uakeia for his sound advice on the strategic direction of this thesis and words of encouragement, which have motivated me to complete this research.

Fr Tikoua Kautu, Fr Michael Mackenzie, Fr Iona Tatau and the late Fr Ruatamaki Ambo for sharing their indigenous knowledge on Kiribati culture that added value to this research. 
I am indebted to my husband Joseph, son Stewart and his partner Wendy, my daughter Celine, grandchildren Thomas and Charlotte, my sisters Kaewanang, Teiaia and Tekeua, and brothers Kabuati and Teikake, and the rest of my kainga for their support, prayers and patience whilst I carried out this research. 


\section{Chapter 1 Introduction}

\subsection{PROBLEM DEFINITION}

As a Kiribati national who migrated to New Zealand under the Skilled Migrant Category in 2001, I have since worked closely with a number of people within Kiribati communities across New Zealand. Many of them recently migrated to New Zealand under the Pacific Access Category (PAC). Each year, the PAC allows a number of Fijian, Kiribati, Tongan and Tuvaluan citizens selected by ballot to be considered for New Zealand residency, provided they meet the required criteria. Applicants whose registration is drawn from the ballot and are invited to apply for residence are referred to as 'PAC successful applicants'. Most PAC successful applicants come to New Zealand on a visitor visa or receive a work visa of one year or less before they are granted a resident visa.

The New Zealand Ministry of Health's eligibility criteria for publicly-funded health and disability services entitles a work permit holder of two years or more and their dependent children aged 17 years or younger, to access these services (Ministry of Health, 2011). Whilst waiting for their residency application to be processed, PAC successful applicants who are on a visitor visa or short-term work visa of less than 2 years, experience difficulty accessing healthcare services under the existing health policy. Some may not prioritise their health needs and avoid visiting a General Practitioner (GP) or hospital because of the high costs as well as other economic, social and cultural factors. These factors are identified and examined in later chapters on how the health of these migrants is negatively affected. In addition, PAC migrants do not have free access to education, daycare and other social services, which further constrain their health and wellbeing. I wanted to contribute positively to the life of New Zealand migrants by advocating for improved conditions under the PAC policy.

It was an expectation of this research that the current conditions of the PAC policy create stress on the health and wellbeing of migrant women and their children, and this is the primary interest of this thesis.

The rest of this chapter discusses the significance of this research, defines health from the Kiribati, Pacific and global perspectives, and provides an overview of Pacific 
migration to New Zealand as well as immigration policies such the PAC (the primary focus of this thesis) and other schemes that facilitate migration. I also introduce Kiribati and I-Kiribati (a citizen of Kiribati) people residing in New Zealand and discuss the relevance of Pacific Studies to this thesis. I conclude this chapter by providing a research outline for the rest of the thesis document.

\subsection{RESEARCH GOALS}

This research focuses on the impact of PAC policy on Pacific women's health and wellbeing, focusing on the experiences of Kiribati migrant women in the period following their arrival in New Zealand, but before they obtain New Zealand residency. I engaged 30 Kiribati migrant women who have settled in New Zealand under a PAC resident visa and examined ways in which access to appropriate healthcare and social services for PAC migrant women could be facilitated. The research is situated within the field of Pacific Studies. This field involves the study of the Pacific and Pacific peoples using appropriate theories and methods. It also acknowledges the importance of the research in engaging communities, taking into account Pacific voices, perceptions and epistemologies, and using appropriate language to demonstrate respect for our lived cultures.

My $\mathrm{PhD}$ research focuses on the following goals:

- Assess the health and wellbeing experiences of PAC migrant women, using Kiribati women as a case study, to comment on issues of responsibility for healthcare and wellbeing.

- Explore personal and policy-related aspects of healthcare and wellbeing that directly impact on these women, and how access to appropriate healthcare and social services for PAC migrant women can be facilitated.

To achieve these research goals, I explored the following key questions:

- What was the main reason underlying the initiation of the PAC policy?

- What kind of healthcare and social services are being provided for PAC migrant women, to support them during initial settlement?

- What did the Kiribati PAC migrant women experience when coming from Kiribati to Aotearoa New Zealand under the PAC Scheme? 
- How did they receive information about what they need to know about the lifestyle in Aotearoa New Zealand?

- Did they have work set up before they came?

In working towards these research goals and questions, I have gathered relevant cases that identify (1) key economic, political, social and cultural barriers to accessing appropriate healthcare services, and why they have become barriers for these women; (2) reasons that inspired them to settle in New Zealand despite such barriers; (3) responsibility issues in the context of the health and healthcare of migrants; and (4) what the PAC policy could entail to support good health outcomes for these women and their children. By engaging research participants and reviewing relevant immigration policies and the literature relevant to healthcare, I collected information about the PAC policy (its criteria, history, political and gendered context and background) and its gaps particularly in relation to the health and healthcare of migrants.

\subsection{PERSPECTIVES ON HEALTH}

\subsubsection{Kiribati health view}

From the Kiribati indigenous perspective, the concept of health is embedded in the Kiribati traditional blessing of Te Mauri (Health), Te Raoi (Peace) ao Te Tabomoa (Prosperity). This is further elaborated as "Te Mauri - good health, good life, protection from harm; Te Raoi - peace, calmness; and Te Tabomoa-prosperity, place of honour, primacy. To attain prosperity, one must have good health and peace" (Ministry of Social Development, 2016, p. 4). Clearly, health from the Kiribati indigenous perspective is embedded in its culture of respect and reciprocity, rooted in te maneaba system. The term maneaba is made up of manea (embrace) and te aba (land and people) (Whincup, 2009). Te maneaba is a traditional cultural hall that provides a sense of belonging to everyone in the village, and where the heart of culture is placed and practised. The broader social and political system of governance associated with te maneaba, what this thesis terms te maneaba system, will be explained in more detail in Chapter 3. As an influence of te maneaba system, te utu (the family unit), te kainga (the extended family) (Ministry of Social Development, 2015 , p. 5) and te kaawa (the village) are responsible for the health and wellbeing of individual members, thus putting the wellbeing of the family at the centre. Te kainga 
also refers to "old site of the mwenga of the utu or the clan" (Uriam, 2017, p. xii). For instance, traditional healers are not only responsible for themselves and their $u t u$, but are compelled to provide healthcare and treatment to members of their kainga or kaawa without expecting to be paid in return.

Strong extended family ties extend within and outside Kiribati. This is the same across the Pacific. The New Zealand Treasury (2018, p. 10) noted that "Pacific worldviews are fundamentally central to how Pacific understand their wellbeing and prosperity, with enduring cultural norms and values such as respect and reciprocity". In Kiribati, the state is responsible for delivering healthcare for its citizens. This is also the case for New Zealand. Based on strong Kiribati family ties, it is often considered the responsibility of more fortunate family members to help disadvantaged members if the government is not able to meet the cost of their health needs. There is also a strong cultural expectation on extended family members living in New Zealand to support Kiribati PAC migrants. This is reflected in the women's stories presented in Chapter 5 .

\subsubsection{Pacific health view}

Health is affected by the interaction between personal and environmental factors. Environmental influences include physical, socio-economic, cultural and political factors as well as the availability of health services. It is generally accepted that the socio-economic factors - especially education and income - are the most important determinant of population health status. Poor people with limited education generally have poor health (Tukuitonga, 2012, p. 4).

Pacific researchers (e.g. Apelu, 2008; Bush, Collings, Tamasese, \& Waldegrave, 2005;

Masoe \& Bush, 2009; Su'a, 2017) have argued that health is embedded in culture, meaning that any initiatives set up for Pacific people need to have the cultural knowledge and background to meet the Pacific people's health needs. Apelu (2008) argues that the term 'by Pacific for Pacific' recognises a Pacific cultural identity and knowledge in order to meet Pacific peoples' mental health needs. Bush et al. (2005, p. 612) added that "Pacific Island mental health services would allow culture-specific concepts central to an understanding of mental health to be embedded in service delivery". While these two examples refer to mental health services, the same approach of integrating Pacific cultural values should be applied to the PAC policy to address the needs of the member countries. 


\subsubsection{Global health view}

From a global perspective, the World Health Organisation's (WHO) definition of health is "a state of complete physical, mental and social wellbeing and not merely the absence of disease or infirmity" (Svalastog, Donev, Kristoffersen, \& Gajović, 2017, p. 432). This is a widely accepted definition that was included in its constitution at the time of its establishment in 1948 (Svalastog et al., 2017). Since then there have been amendments to the definition of health showing there is no one size fits all definition to suit different social situations and cultures. Svalastog et al. (2017, p. 433) added that " $[\mathrm{t}]$ he Ottawa Charter from the first international conference in Health Promotion held in Ottawa, Canada [in] 1986 says that health is created in the context of everyday life and environment, where people live, love, work and play". Over the last few decades, the WHO definition of health has been amended to include a fourth dimension, spiritual health, which involves a sense of fulfilment and satisfaction with many aspects of life including our own lives, values or beliefs and attitudes and successful way of managing our daily life (Svalastog et al., 2017). WHO adds that "the enjoyment of the highest attainable standard of health is one of the fundamental rights of every human being without distinction of race, religion, political belief, economic or social condition" (Ghebreyesus, 2017, p. 1). This principle affirms my main argument in this thesis that New Zealand's PAC policy, which is arguably driven by neoliberalism disarticulates the humanitarian principles of health and wellbeing of migrants, and rearticulates in unfair principles of self-responsibility, which actually disadvantage Pacific migrants. This is evidenced by my research participants' stories in Chapters 3 to 6. As Labonté and Stuckler (2016) argued, people have been living in poor conditions of inequality not because of the scarcity of economic resources, but rather driven by neoliberal-influenced policy.

\subsection{BACKGROUND}

\subsubsection{Pacific migration to New Zealand}

New Zealand's relationship with the Pacific is based on constitutional and colonial history, and shared Pacific interests on issues including climate change, education, maritime and regional security, sustainable development, and trade (Ministry of Business, Innovation and Employment, 2018). Broadly speaking, this relationship also reflects the long history of Pacific migration into New Zealand dating back to 1300AD 
when the first settlers arrived by canoe from Polynesia. Section 4.3.1 provides further discussion.

Several significant eras of migration from different parts of the Pacific have followed throughout the years. Polynesian, Melanesian and Micronesian peoples who explored and settled in New Zealand have played a pivotal role in the development of New Zealand and its friendship and partnership with the Pacific. However, stories of their contributions to New Zealand especially prior to the Second World War have not been well acknowledged in New Zealand history books. In the book titled "Tangata o le Moana: New Zealand and the People of the Pacific" edited by Mallon, Māhina-Tuai, and Salesa (2012), a collection of informative essays produced by Pacific, Māori and Pākehā authors have helped bridge information gaps about migration of Pacific peoples and their contributions, particularly in the $19^{\text {th }}$ and early $20^{\text {th }}$ centuries. The essays by Peter Adds and Janet Davidson reviewed the connections between Māori ancestry and the Pacific. Both authors acknowledged the amazing indigenous navigational skills of Pacific peoples who travelled across 'a sea of islands' - a term coined by the late Epeli Hau'ofa, without the use of modern navigational technologies. The authors concluded that New Zealand was settled by peoples from the eastern Pacific and regular return voyages to their home islands were unlikely. Māhina-Tuai (2012) reviewed the contributions of Pacific peoples who served in the New Zealand armed forces in both world wars. Geoff Bertram's essay covers New Zealand's economic relationship with the Pacific in key industries including phosphate and sugar. The development of the phosphate industry in the Pacific notably benefitted farmers from Australia and New Zealand. By contrast, Pacific land owners received low returns and their islands were severely damaged as a result of mining (Bedford, 2015; Mallon, Māhina-Tuai, \& Salesa, 2012).

Migration to New Zealand from the Pacific has become increasingly popular, with Auckland being the main centre for the largest urban concentration of Pacific Islanders (Bedford, 1994). This is driven by close family linkages, marriages and employment opportunities as well as New Zealand's commitment to support labour mobility to address domestic labour shortages whilst supporting its Pacific neighbours (Ministry of Business, Innovation and Employment, 2018).

New Zealand has established migration agreements with some Pacific countries reflecting shared history and mutual interests. The Cook Islands, Niue and Tokelau 
have been part of the Realm of New Zealand since the early $20^{\text {th }}$ century, so their citizens have open access to New Zealand. Samoa and New Zealand have had a close relationship right from the First World War. Following its independence in 1962, Samoa signed the Treaty of Friendship with New Zealand. This paved the way for the Samoan Quota Scheme, which, since 1970, enables up to 1,100 Samoan citizens to be granted residence in New Zealand each year, provided they have a job offer and meet other requirements. The Citizenship (Western Samoa) Act of 1982 further extended New Zealand citizenship to many Western Samoan citizens then resident in New Zealand. Similar to the Samoan quota scheme though involving proportionally fewer numbers, the Pacific Access Category has provided a pathway since 2002 for eligible citizens of Fiji (250), Kiribati (75), Tonga (250) and Tuvalu (75) to migrate and settle in New Zealand each year, provided they meet the conditions of the scheme (New Zealand Government, 2001). In addition, Pacific people have migrated to New Zealand temporarily to work under the Recognised Seasonal Employer scheme (RSE) since 2006. Partnership and Essential skills immigration categories also offer opportunities to Pacific people to live in New Zealand.

In the post-war period, strong economic growth resulted in significant labour shortages. New Zealand's Pacific neighbours were an important source of labour. Over the years, New Zealand has implemented measures that support labour shortfalls in key industries. For instance, on 11 November 2004, the New Zealand government announced at the Northern Business and Employment Law Conference that various measures would be applied to address labour shortages (New Zealand Government, 2004b). These included the use of holiday working schemes, variation of conditions of visitors already in the country, and recruiting labourers under the Samoan and PAC quotas. This was followed by the announcement of a series of measures to enable the Pacific Island quotas to be filled (New Zealand Government, 2004a). Arguably, these improvements to the quota system were initiated to help New Zealand in terms of filling labour shortages, particularly at a time of low unemployment, whilst benefiting Pacific nations.

Pacific people wishing to migrate permanently to New Zealand can apply for residency through one of the three residence streams of the New Zealand Residence Programme. These streams are Skilled/Business; Family; and International/Humanitarian (see Table 1-1). Under each stream, there are multiple sub-stream visas. For instance, the 
PAC resident visa, discussed in the next section, falls under the International/Humanitarian stream.

Table 1-1: Permanent residence visa policies most commonly granted to Pacific migrants.

\begin{tabular}{|c|l|}
\hline $\begin{array}{c}\text { Business/Skilled Visa } \\
\text { Stream }\end{array}$ & $\begin{array}{l}\text { - Skilled Migrant category resident visa } \\
\text { - Resident from work visa }\end{array}$ \\
\hline Family Visa Steam & $\begin{array}{l}\text { - Partner of a New Zealander resident visa } \\
\text { - Dependent child resident visa }\end{array}$ \\
\hline $\begin{array}{c}\text { International/Humanitarian } \\
\text { Stream }\end{array}$ & $\begin{array}{l}\text { - Samoan quota resident visa } \\
\text { - Pacific Access Category resident visa }\end{array}$ \\
\hline
\end{tabular}

Source: Ministry of Business, Innovation and Employment (2018).

Figure 1.1 presents the number of Pacific people who have been granted permanent residence during the 2013 to 2017 financial years (see also Table A-2 in the Appendix). Most resident migrants from the Pacific were approved under the Family stream followed by the International/Humanitarian and Business/Skilled streams. The total number of Pacific residence approvals remained stable since 2013, only increasing by 4 percent from 5,027 in 2013 to 5,243 in 2017. The gap between total approvals under the Family and International/Humanitarian streams noticeably reduced, from 17 percent in 2013 to 6 percent in 2017. This was primarily due to an increase in the Samoan Quota and PAC approvals that make up the majority of Pacific residence approvals under the International/Humanitarian stream (see Figure 1.2). Immigration policies such as the Samoan Quota and the PAC offer more relaxed requirements for entry into New Zealand, as they do not require for instance specialised skills and qualifications compared to other visa policies.

It is evident from the migration figures that the Family and International/Humanitarian streams, particularly the Samoan Quota and PAC sub-streams have a significant influence on Pacific migration and the growing Pacific population in New Zealand. Thus, there is a need to have a good social and economic infrastructure in place to support their health and wellbeing in order for them to become productive New Zealand citizens. 
Figure 1.1: Pacific residence approvals by visa stream, 2013-2017 financial years.

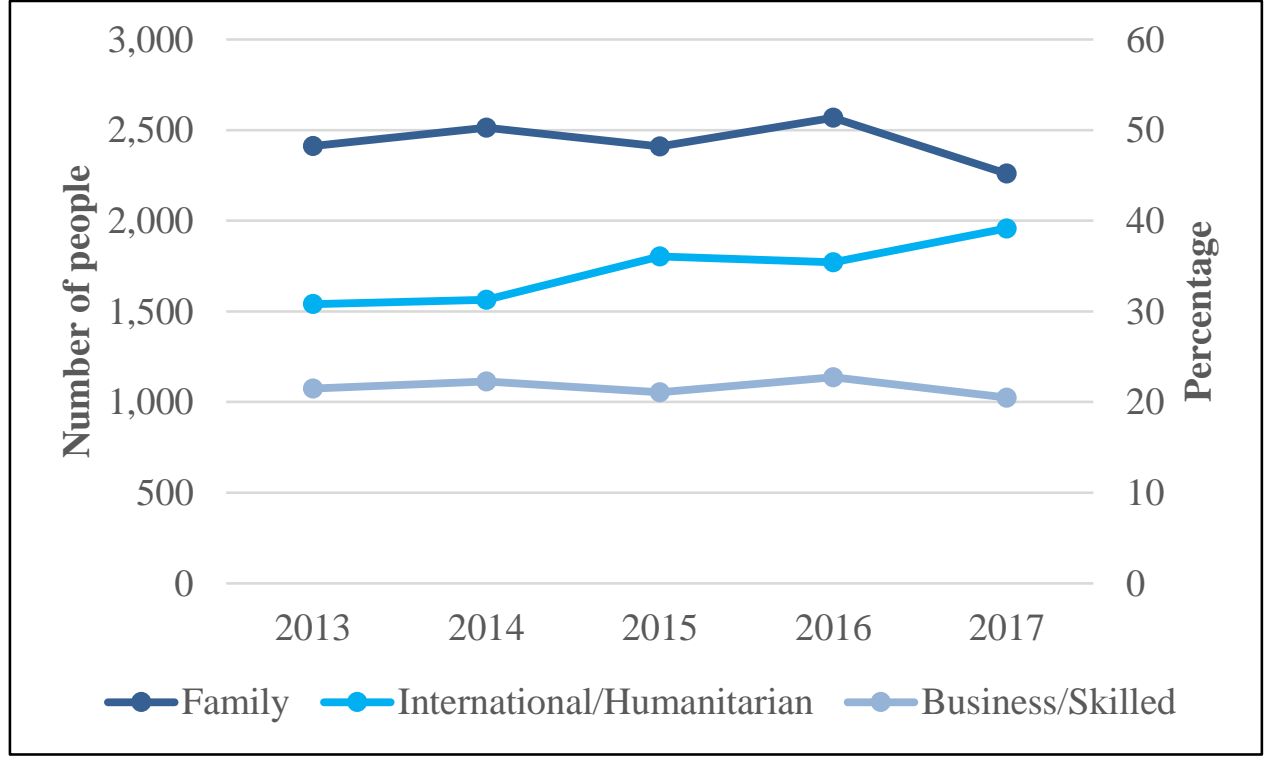

Source: Ministry of Business, Innovation and Employment (2018).

Figure 1.2: Pacific residence approvals under the International/Humanitarian substreams by financial year.

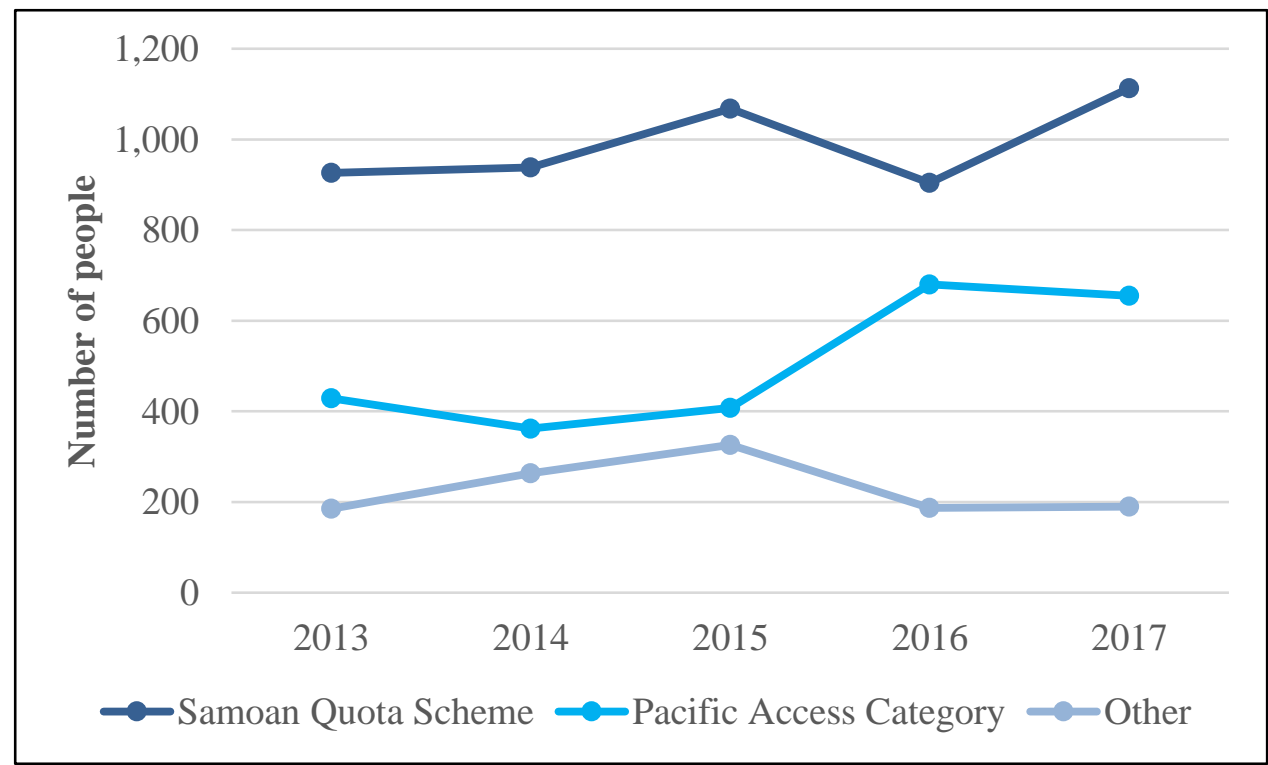

Source: Ministry of Business, Innovation and Employment (2018). 


\subsubsection{Pacific Access Category}

Announced on 20 December 2001 by New Zealand Government Ministers ${ }^{1}$, the Pacific Access Category (PAC) opened a new channel in 2002 for eligible Pacific Island people from Fiji, Kiribati, Tonga and Tuvalu to migrate and settle in New Zealand (New Zealand Government, 2001) ${ }^{2}$. Applicants must first register with the scheme and if their registration is successfully drawn from the ballot, applicants are then invited to apply for the PAC resident visa and include every immediate family member in their application. To meet the residence eligibility criteria, the principal applicant must be (i) a citizen of either Fiji, Kiribati, Tonga or Tuvalu; (ii) have registered for the annual PAC ballot and been successful in the pool draw; (iii) be aged between 18 and 45; (iv) have an acceptable job offer from any employer in New Zealand, or have a partner included in their application who has an acceptable job offer; (v) demonstrate a minimum level of English language skills; (vi) meet the minimum income requirement; (vii) meet health and character requirements, which also applies to a partner and dependent children if they are included in the application; (viii) lodge their application for permanent residence under the PAC within eight months of the date when they received an invitation to apply for permanent residency from Immigration New Zealand. The instructions for processing and managing the PAC, including further explanation of the above criteria are contained in S1.40 of the Immigration New Zealand (2018b) Operational Manual. Extractions relevant to the health, character and employment requirements are presented in Section A.3 of the Appendix. The total number of residence approvals under the PAC policy by eligible Pacific Islands between 2009 and 2018 are shown in Figure 1.3. Tonga has the highest residence approvals because it has the largest quota of 250 per year. Fiji is also allocated the same quota but due to the 2006 military coup its participation was suspended from 2006 to 2015. Residence approvals for Fiji from 2009 to 2015 are related to applicants who were accepted to submit their residence application prior to Fiji's suspension (Ministry of Business, Innovation and Employment, 2018). Since the PAC was re-opened for Fijian nationals in 2015, Fiji has shown similar PAC approval

\footnotetext{
${ }^{1}$ Ministers Phil Goff, Lianne Dalziel and Mark Gosche.

${ }^{2}$ The PAC replaced previous work schemes with Tuvalu and Kiribati.
} 
numbers as Tonga. On the other hand, Kiribati and Tuvalu residence approvals have been stable throughout 2009-2018 except for a notable decline in 2010 .

Figure 1.3: Residence approvals under the Pacific Access Category by financial year.

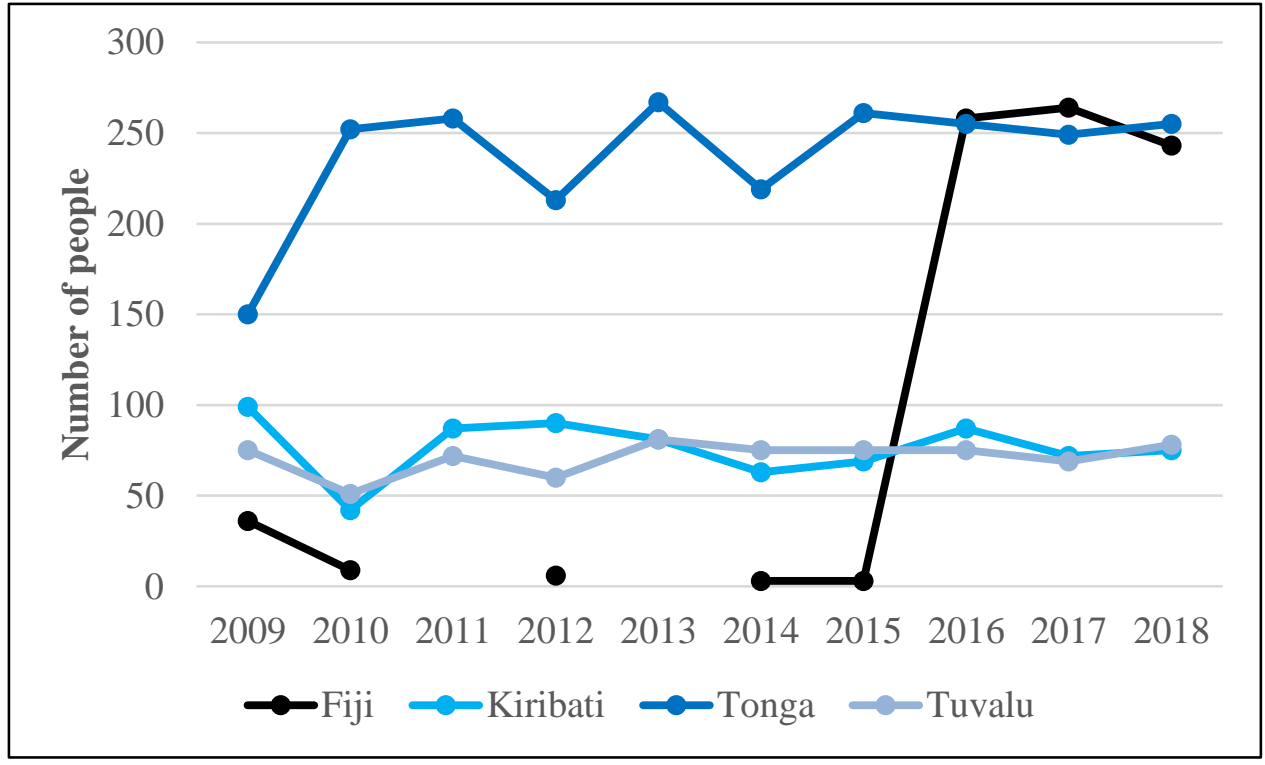

Source: Ministry of Business, Innovation and Employment (2019).

Table 1-2: Kiribati residence approvals under the PAC, 2009-2018 financial years.

\begin{tabular}{|c|c|c|c|c|c|c|c|c|c|c|}
\hline \multirow{2}{*}{$\begin{array}{l}\text { Ballot } \\
\text { year }\end{array}$} & \multicolumn{10}{|c|}{ Financial year decided } \\
\hline & 2009 & 2010 & 2011 & 2012 & 2013 & 2014 & 2015 & 2016 & 2017 & 2018 \\
\hline 2006 & 6 & & & & & & & & & \\
\hline 2007 & 21 & 6 & 9 & & & & & & & \\
\hline 2008 & 72 & 6 & 9 & & & & & & & \\
\hline 2009 & & 30 & 57 & & 6 & & & & & \\
\hline 2010 & & & 12 & 66 & 15 & & & & & \\
\hline 2011 & & & & 24 & 18 & & & & & \\
\hline 2012 & & & & & 39 & 24 & & 3 & & \\
\hline 2013 & & & & & & 42 & 21 & & & \\
\hline 2014 & & & & & & & 48 & 30 & & \\
\hline 2015 & & & & & & & & 57 & 9 & \\
\hline 2016 & & & & & & & & & 66 & 27 \\
\hline 2017 & & & & & & & & & & 48 \\
\hline
\end{tabular}

Notes: Ballot year refers to the year in which an applicant's PAC registration was successfully drawn from the ballot. Financial year decided refers to the year in which an applicant was granted permanent residency.

Source: Ministry of Business, Innovation and Employment (2019).

In the case of Kiribati, Table 1-2 shows a clear time-lag between the time Kiribati PAC applicants are invited to submit their residence applications and the time they are 
granted residency. For example, six applicants were invited in 2006, but waited for three years before receiving residency in 2009. Similarly, six applicants were granted residency in 2013, four years after being invited to apply in 2009. These applicants would have remained in New Zealand on a temporary work or visitor visa and face difficulty accessing publicly-funded health services.

Whilst the PAC is a limited access programme for residents of the Pacific nations concerned, the (New Zealand Government, 2001) reported at the time of announcing the PAC policy that the scheme was a positive step towards providing assistance and certainty for these Pacific countries. Ramasamy, Krishnan, Bedford, and Bedford (2008) added that the PAC as well as other work schemes operating since the 1970s represent the special relationship between New Zealand and its Pacific neighbours. Ramasamy et al. (2008, p. 174) also noted that these immigration policies supported New Zealand's strategy to address the fact that "local labour supply, including traditional sources, were not sufficient to meet the demand". In the case of Kiribati, its strong links to New Zealand, according to Bedford and Hugo (2008), came about largely as a result of the now exhausted phosphate deposits on Banaba (Ocean Island, see Figure 1.11) that were so important for agricultural development in New Zealand as well as in Australia (Bertram, 2012). This is explored further in Section 1.5.

Other researchers (e.g. Koser, 2012; Simati, 2009) have argued that the establishment of the PAC was in response to Pacific countries that are vulnerable to the impacts of climate change. For instance, Simati (2009, p. 4) noted that "Tuvalu's lobbying and concern over climate changes affecting its nine atoll islands is partially responsible for its inclusion in the development of the PAC scheme". Sharing similar geographical characteristics and environmental challenges, it could also be argued that Kiribati was included in the scheme partly because its thirty-three low-lying atolls are vulnerable to climate change. Nonetheless, the scheme targets countries, such as Kiribati, Tonga and Tuvalu, that are vulnerable to sea-level rising and extreme weather events, and "arguably provides a basis for admitting people from these islands on environmental grounds" (Koser, 2012, p. 11). According to McAdam (2009), the PAC was primarily a labour migration initiative rather than an instrument for humanitarian protection. It is clear from the New Zealand government policy initiative that the PAC is primarily an economic incentive to address labour shortages in the domestic market, while helping its neighbouring Pacific countries (New Zealand Government, 2004a, 2004b). 
International studies on migration by Carballo and Mboup (2005) and Glasford and Huang (2008) argue that on the whole, immigration policies negotiated between nation-states are making migration more complicated and difficult for the migrant and generate social and economic environments unfavourable to their health and welfare. In line with this argument, this thesis finds that the current regulation and conditions of the PAC policy create a gap in service provision that negatively impacts on migrants, especially mothers and children, who come under this scheme. For the purpose of this research, I will call this social gap, the 'PAC gap'. The women's stories and the analysis of their stories in Chapters 3 to 6 explain what this PAC gap entails. The next two sections discuss the RSE and Refugee policies to provide a useful comparison for understanding the immigration situation of PAC migrants.

\subsubsection{Recognised Seasonal Employer scheme}

Established in 2006, the Recognised Seasonal Employer Scheme (RSE) allows workers from eligible Pacific Forum countries ${ }^{3}$ to work in New Zealand for a shortterm period of up to seven months ${ }^{4}$ each year in the horticulture and viticulture industries (Ministry of Business, Innovation and Employment, 2018). The Kiribati and Tuvalu workers receive a special favour to work for up to nine months because of the high return airfare to New Zealand. This is to give them enough time to recover their travel costs. The scheme provides an economic infrastructure to support these industries and regional economic development. Preference is given to employers who have evidence that they (i) could not find New Zealanders to fill labour shortages, (ii) have available accommodation to support RSE workers, and (iii) are committed to providing pastoral care and acceptable employment conditions (New Zealand Government, 2018).

Figure 1.4 shows that there has been a notable increase in the number of RSE visa approvals since 2013. In 2017, 60 percent of Pacific temporary workers were approved under the RSE work visa category, compared to 49 percent in 2013 (for corresponding numbers, refer to Table A-3 in the Appendix). Annual increases in RSE work visa approvals were a result of increases in the cap on the number of RSE places available for each season, which were driven by increased demand from employers (Ministry of

\footnotetext{
${ }^{3}$ Fiji, Kiribati, Nauru, Papua New Guinea, Samoa, Solomon Islands, Tonga, Tuvalu and Vanuatu.

${ }^{4}$ Nine months for workers from Kiribati and Tuvalu.
} 
Business, Innovation and Employment, 2018). Almost half the number of Pacific workers approved under the RSE scheme were from Vanuatu followed by 20 percent from Tonga and 19 percent from Samoa (see Table A-4 in the Appendix). Despite the number of Kiribati workers increasing from 42 in 2009 to 243 in 2018, Kiribati's share of total RSE work visa approvals amounted to only 2 percent during this period.

Figure 1.4: Approved temporary workers from the Pacific by work visa policies.

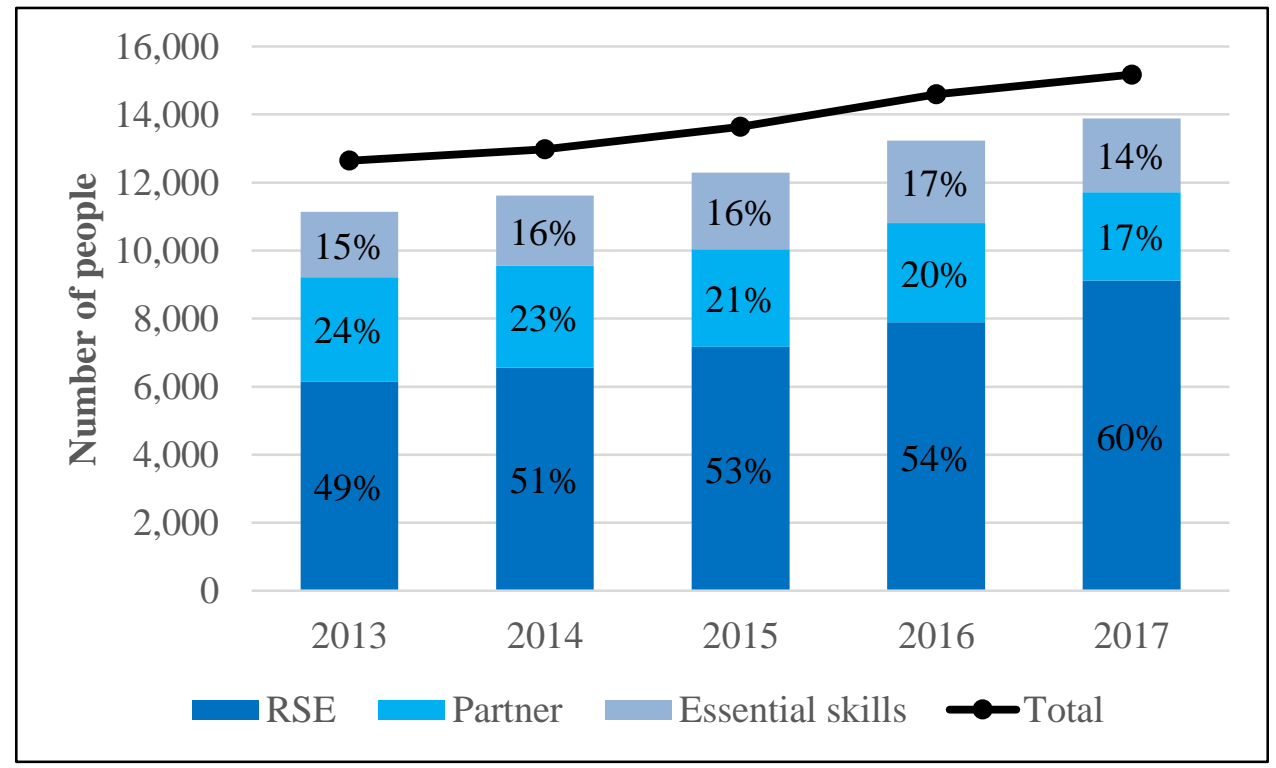

Source: Ministry of Business, Innovation and Employment (2018).

A number of studies have examined the RSE scheme. For instance, Ramasamy et al. (2008) reviewed the RSE in line with the objective of meeting the seasonal labour shortages in New Zealand's horticulture and viticulture industries and contributing to New Zealand's objectives of encouraging economic development, regional integration and stability within the Pacific. Whilst it was too early at the time of the report to articulate outcomes of the scheme, there were a number of positive aspects about the RSE scheme.

For instance, it was noted that the RSE policy is unique in terms of New Zealand's immigration policies in that it was a collaborative programme between the Department of Labour (now part of the Ministry of Business Innovation and Employment), the Ministry of Social Development and the New Zealand Agency for International Development. The Department of Labour created Labour Inspector positions to monitor and ensure that workers are well looked after as far as their health and safety are concerned and that workers are not exploited. Employers are also expected to work 
closely with Pacific Liaison officers. These positions were created to assist employers in ensuring that they meet the pastoral care needs of the workers. In addition, Pacific Liaison officers act as a conduit for exchange of information between Pacific workers and their employers, and help with resolving any issues (Ramasamy et al., 2008). Employers also arrange health insurance coverage for their workers, so when anyone is endangered by any health issue, their hospitalisation, treatments and other healthcare related costs are covered.

Williams (2010) conducted qualitative research to understand and gain an in-depth appreciation of the cultural perspectives of Ni-Vanuatu temporary migrant workers in Te Puke. One of the findings of the study is that the cultural shift from Vanuatu to New Zealand was a real challenge for Ni-Vanuatu workers, who found it difficult to understand and adapt to the New Zealand culture. The cultural difference between the New Zealand culture and that of Ni-Vanuatu was found to be frustrating at times (Williams, 2010). Pre-departure training and the role of liaison officers as mentioned earlier are key components of the RSE programme that manage such issues. Nevertheless, while such supporting facilities are available, it is still challenging to address cultural challenges in a short time frame. It requires concerned parties to be well trained in each other's culture to avoid any misunderstandings and miscommunication. Similar issues also affect PAC migrants and these are discussed in Section 5.8.

\subsubsection{Refugee status in New Zealand}

Being one of the 26 countries participating in the United Nations High Commissioner for Refugees' Program, New Zealand supports 1,000 refugees settle in New Zealand every year, with new refugees being well cared for by the Mangere Refugee Resettlement Centre for the initial six weeks. During this time, they are provided with shelter and treated for any personal health conditions to protect the health of the wider community. The centre is funded by the Ministry of Health to provide healthcare services such as health screening (Auckland Regional Public Health Service, 2019).

The study by Mortensen (2011) on refugees in New Zealand identified the types of health benefits refugees receive and noted some of the challenges they face. Mortensen (2011) examined the role of New Zealand's public health system and the integration of refugees. This was achieved by exploring available health services and health programmes, and investigating how they responded to the needs of refugees. Services 
that were available to refugees included health promotion, mental health, communitybased health, and cultural diversity training. New Zealand accepts immediate responsibility for the healthcare of refugees as part of its obligations to the 1951 United Nations Convention, the 1967 Protocol Relating to the Status of Refugees, the 1984 Convention against Torture, and 1966 Covenant on Civil and Political Rights (Immigration New Zealand, 2019b). These responsibilities are specified in Section 124 of the Immigration Act 2009. In addition, the New Zealand government has implemented a strategy for integrating refugees into New Zealand society. This strategy focuses on five areas: i) self-sufficiency - all working-age refugees are in paid work or are supported by a family member in paid work; ii) participation - refugees actively participate in New Zealand life and have a strong sense of belonging here; iii) health and wellbeing- refugees and their families enjoy healthy, safe and independent lives; iv) education - English language skills help refugees participate in education and daily life; and v) housing - refugees live in safe, secure, healthy and affordable homes without needing government housing assistance (Immigration New Zealand, 2018b).

There is no similar strategy for integrating PAC residents into New Zealand society. To provide further context to this thesis, in the next section I examine the size of the Pacific population including Kiribati people in New Zealand, and how Pacific population numbers will continue to grow under the PAC and other visa streams.

\subsubsection{Pacific people in New Zealand}

Pacific people are the fourth-largest (7 percent) major ethnic group in New Zealand, behind European, Māori and Asian ethnic groups (see Figure 1.5). The Pacific ethnic population in 2013 was 295,941, up by 28 percent compared to 2001. About two-thirds of Pacific people were born in New Zealand. The Pacific population is projected to be 590,100 by 2038 , representing 10 percent of the New Zealand total population (Ministry of Business, Innovation and Employment, 2018). About a third of the Pacific ethnic group is made up of immigrants and includes people originally from Samoa, Cook Islands, Niue, Tonga, Tokelau, Papua New Guinea, Vanuatu, Fiji, Solomon Islands, Tuvalu, Kiribati, Nauru, and French Polynesia (Statistics New Zealand, 2013b). 
Figure 1.5: New Zealand's population by ethnicity and gender, census years 20012013.

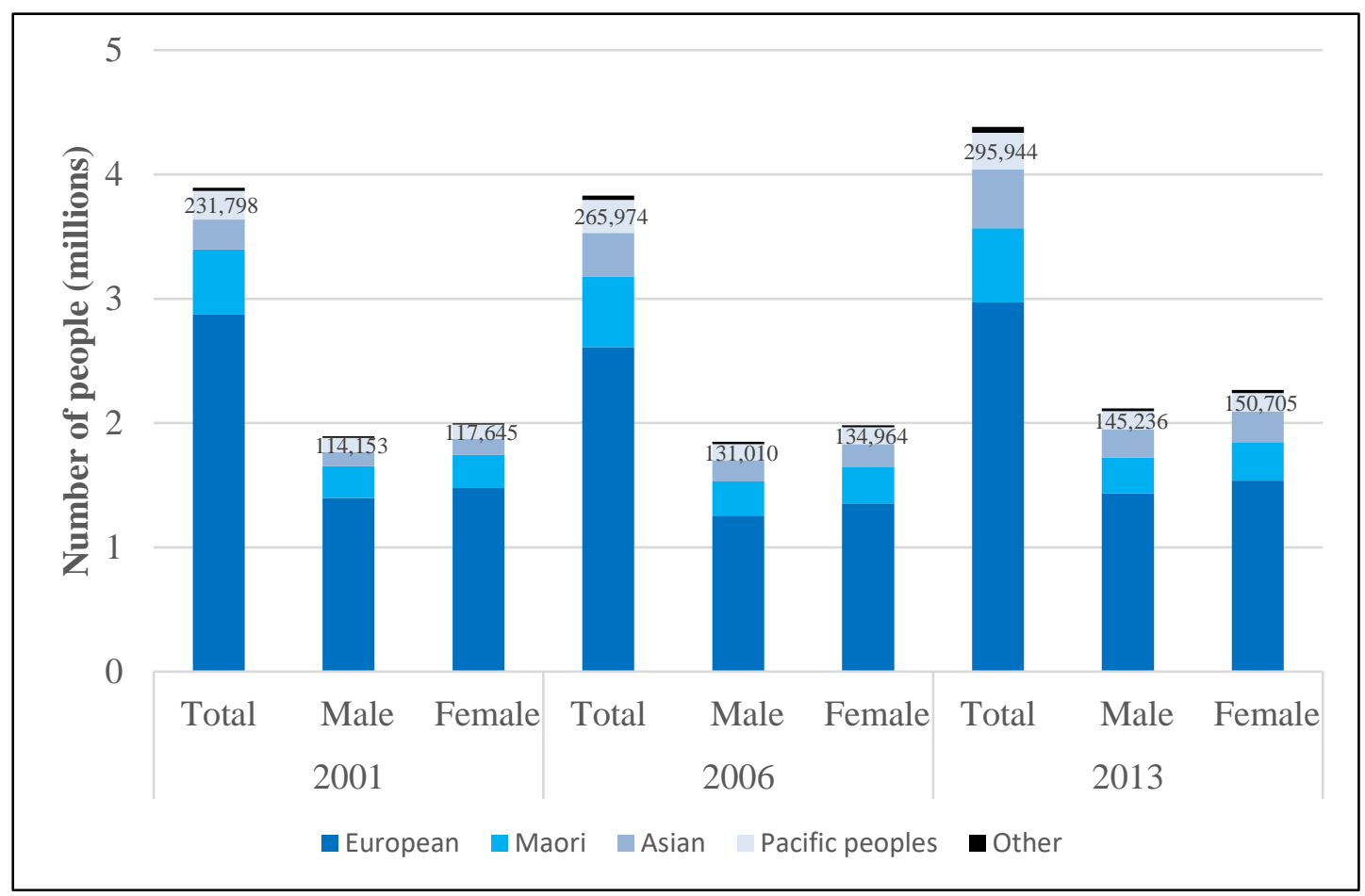

Source: Statistics New Zealand (2019b).

Originally, New Zealand sourced immigrants from the UK, Western Europe and North America. Over time, this changed to a specific preference for labour characteristics, initially cheap labour and then more skilled labour (Bauer, Lofstrom, \& Zimmermann, 2001). In 1946, New Zealand's Dominion Population Committee recommended a policy to fill labour shortages created by its expanding secondary and tertiary industries. This resulted in the adoption of short-term immigration programmes to meet labour shortages. The New Zealand government at the time used internal Māorirural-urban migration as well as cheap labour from the neighboring Pacific Islands to meet its needs for unskilled workers (Ongley \& Pearson, 1995). Krishnan, Meleisea, and Warren (1994, p. 21) state that by the early 1970s, the newly migrant Pacific people had filled most of the unskilled jobs offered by New Zealand employers at the time. Pacific people remain over-represented in low skilled jobs. New Zealand's RSE, Samoan Quota and the PAC schemes will continue to recruit Pacific people from eligible Pacific countries. The PAC offers a significant route to New Zealand residence for Kiribati nationals and contributes to the growing Kiribati population living in New Zealand. 


\subsubsection{Overcrowded housing}

Figure 1.6: Household crowding by ethnicity.

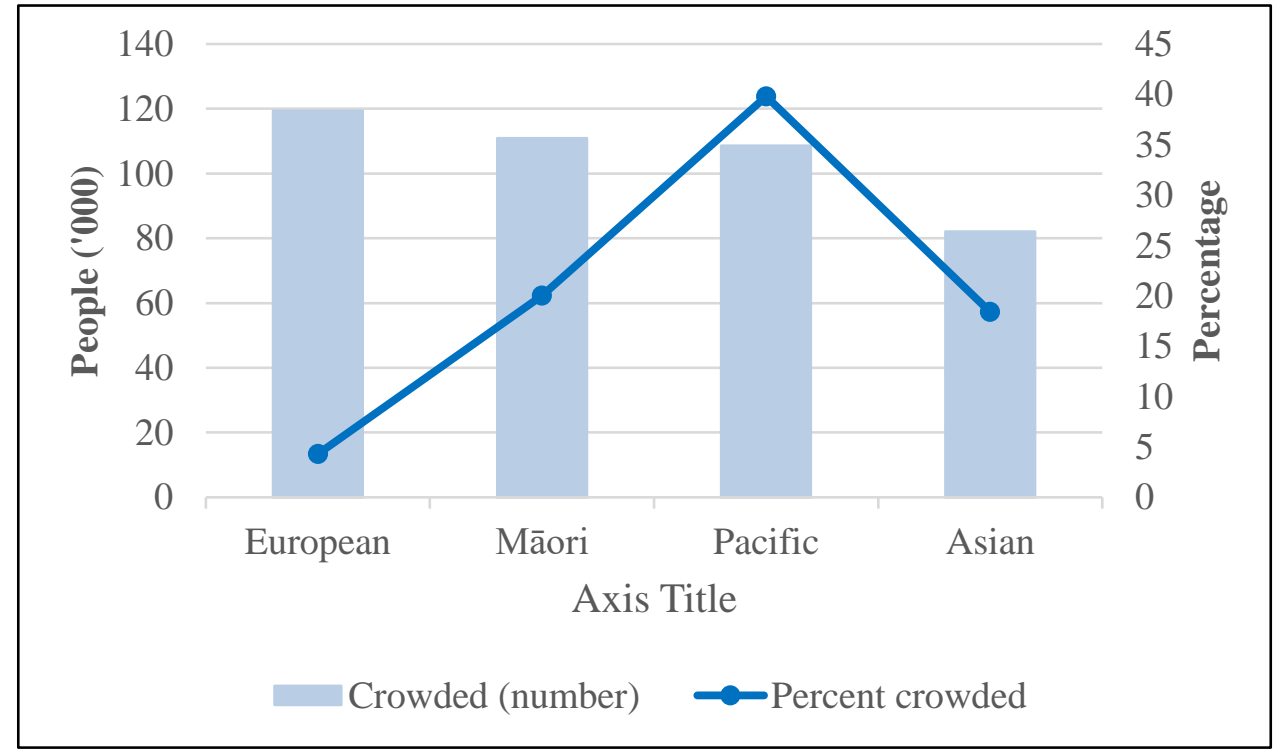

Source: Ministry of Health (2014b).

Migration to New Zealand is also another contributing factor to over-crowding for some ethnic groups. Ministry of Health (2014b, p. 2) adds that "factors such as limited stock of large sized housing, cultural living arrangements and low incomes all compound crowding in these groups". Overcrowded housing also poses public health risks. For instance, Baker, McDonald, Zhang, and Howden-Chapman (2013, p. 11) stated that "household crowding is a very important risk factor for transmission of most major categories of close-contact infectious diseases". Studies have shown that Māori and Pacific peoples in New Zealand live in overcrowded homes compared to other ethnic groups (Baker et al., 2013; Ministry of Health, 2014b). At this time, for instance, approximately 40 percent of Pacific peoples of all ages lived in crowded households compared to 20 percent of Māori, 18 percent of Asians and 4 percent of Europeans (see Figure 1.6). Ministry of Health (2014b) figures show that in the case of households with children aged 0-4 years, the Pacific population has the highest level of overcrowding with 45 percent compared to Māori (26 percent) and Asians (20 percent). According to Statistics New Zealand (2019c), the average number of Pacific 
people living in 'Usually Resident Multi-family Households' was 6.98 compared to 6.14 (Māori), 6.08 (Asian), and 5.57 (European) $)^{5}$.

\subsubsection{Kiribati migration to New Zealand}

Figure 1.7: Permanent residence visa sub-streams most commonly granted to Kiribati migrants, financial years 2009-2018.

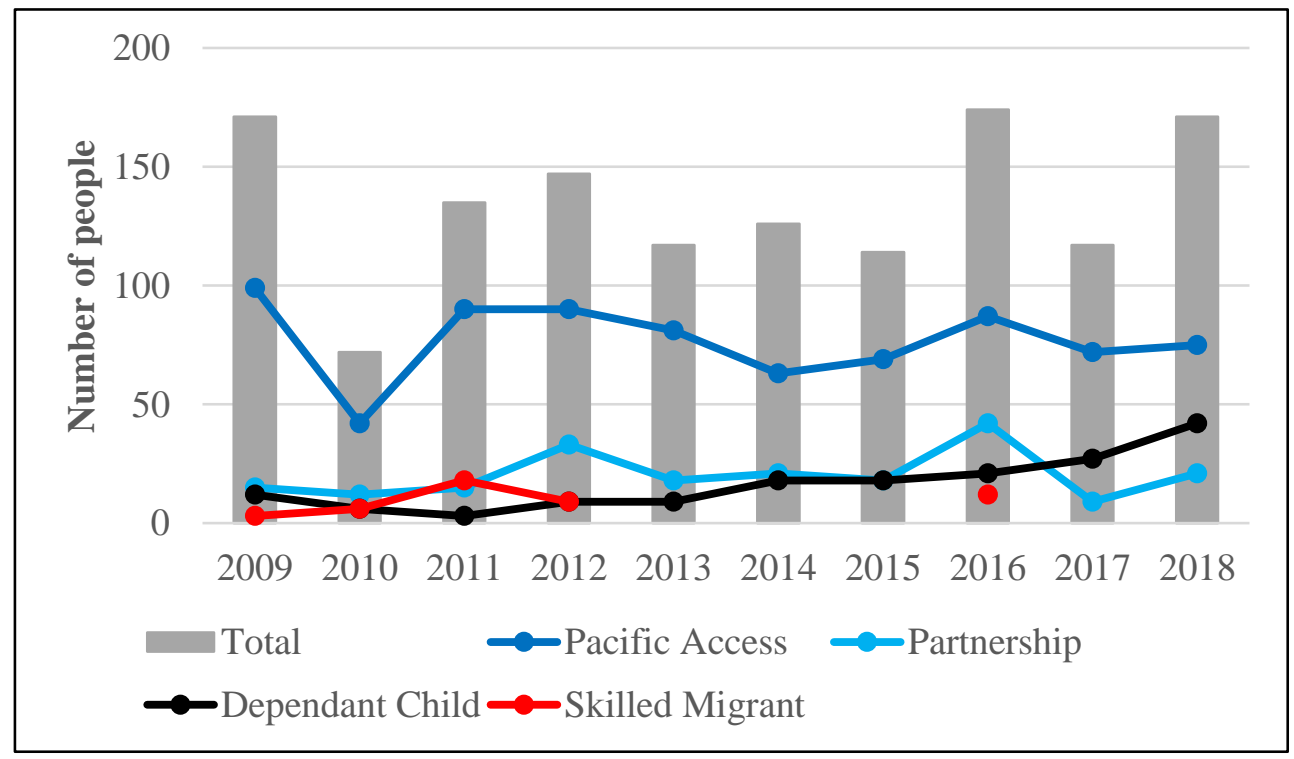

Source: Ministry of Business, Innovation and Employment (2019).

Compared to other Pacific ethnicities, Kiribati people migrated much later to New Zealand following the 1986 work schemes offered to Kiribati and Tuvalu (Bedford \& Hugo, 2008, p. 9). Many of these workers managed to progress their work visas to permanent residency and most of them settled in Auckland. The introduction of the PAC, which replaced the earlier work schemes, contributed largely to the rapid growth of the Kiribati population in New Zealand. In the period 2009-2018, over half of Kiribati migrants were granted permanent residency under the PAC followed by the Dependent child, Partnership and Skilled migrant categories. The Kiribati population in New Zealand is expected to increase rapidly in the near future given the increasing number of residence approvals under the PAC. Residence approvals are also expected through other channels such as the Family and Business/Skilled streams, though on a much lower scale (refer to Figure 1.7). Given that the requirements under the PAC are

\footnotetext{
${ }^{5}$ Usually Resident Multi-family Households are defined as including two-family households (with or without other related or non-related people), and excludes one-family households (with or without other related people), and non-family households (Statistics New Zealand, 2019c).
} 
more relaxed compared with requirements under the Skilled Migrant Category, it is expected that people with work experience and qualifications will still choose to apply for residency under the PAC.

Figure 1.8: Kiribati population in New Zealand by gender, 2013.

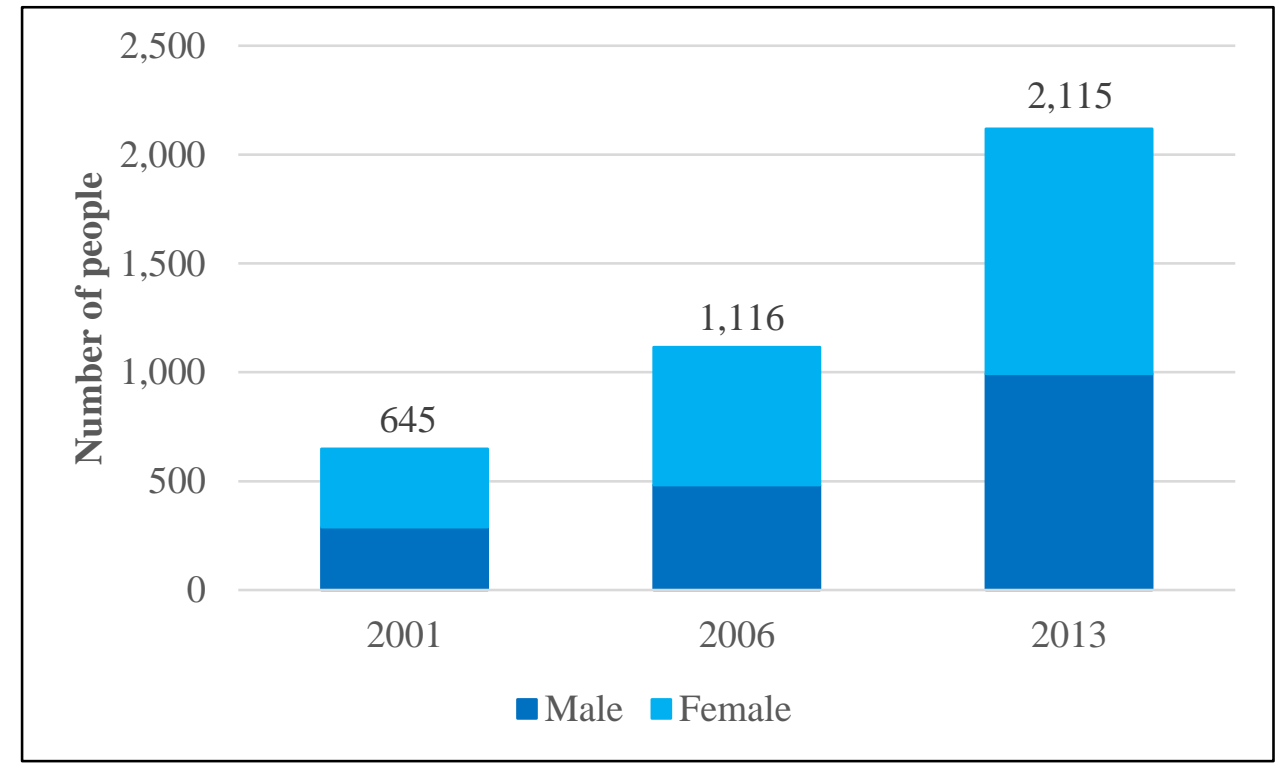

Source: Statistics New Zealand (2019b).

According to Statistics New Zealand (2019b), the total number of Kiribati people living in New Zealand in 2013 was 2,115 compared to 645 in 2001, and females make up over half of the total population (see Figure 1.8). The distribution of the Kiribati population across New Zealand regions is presented in Figure 1.9. The majority of Kiribati people (about 93 percent) reside in the North Island of which almost half live in Auckland (48 percent), followed by Waikato (19 percent) and Wellington (15 percent). About two-third of the Kiribati population were born in Kiribati and onethird were born in New Zealand. About 78 percent of the population aged 15 years and over have a formal qualification. The median income for those aged 15 years and over is $\$ 14,700$ (Statistics New Zealand, 2019a). 
Figure 1.9: Distribution of the Kiribati population by New Zealand region, 2013.

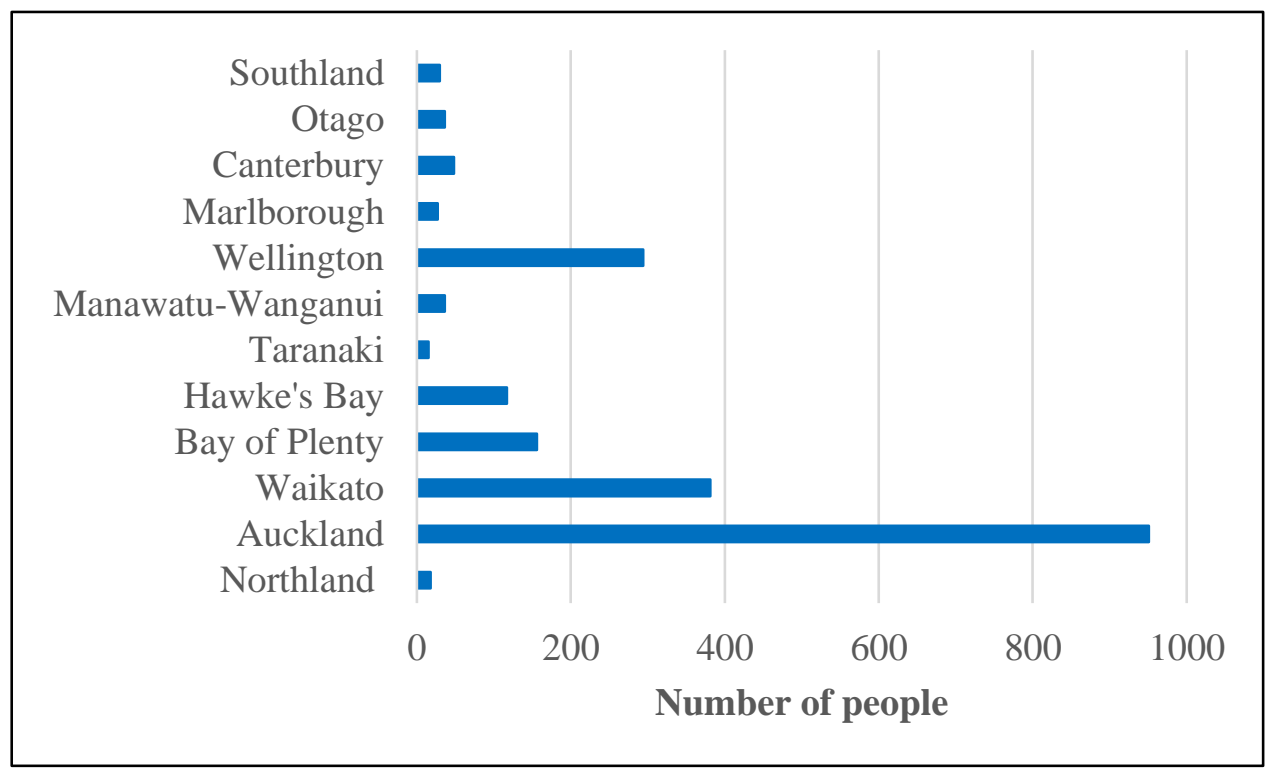

Source: Statistics New Zealand (2019b).

Like other Pacific ethnic groups, Kiribati people are both communal and religious. According to Statistics New Zealand (2013b), 94 percent of the Kiribati people living in New Zealand declared that they have a religion. The majority were Catholic (45 percent) followed by Presbyterian, Congregational and Reformed (18 percent), and Latter-day Saints (10 percent).

Figure 1.10: Age distribution of the Kiribati population in New Zealand, 2013.

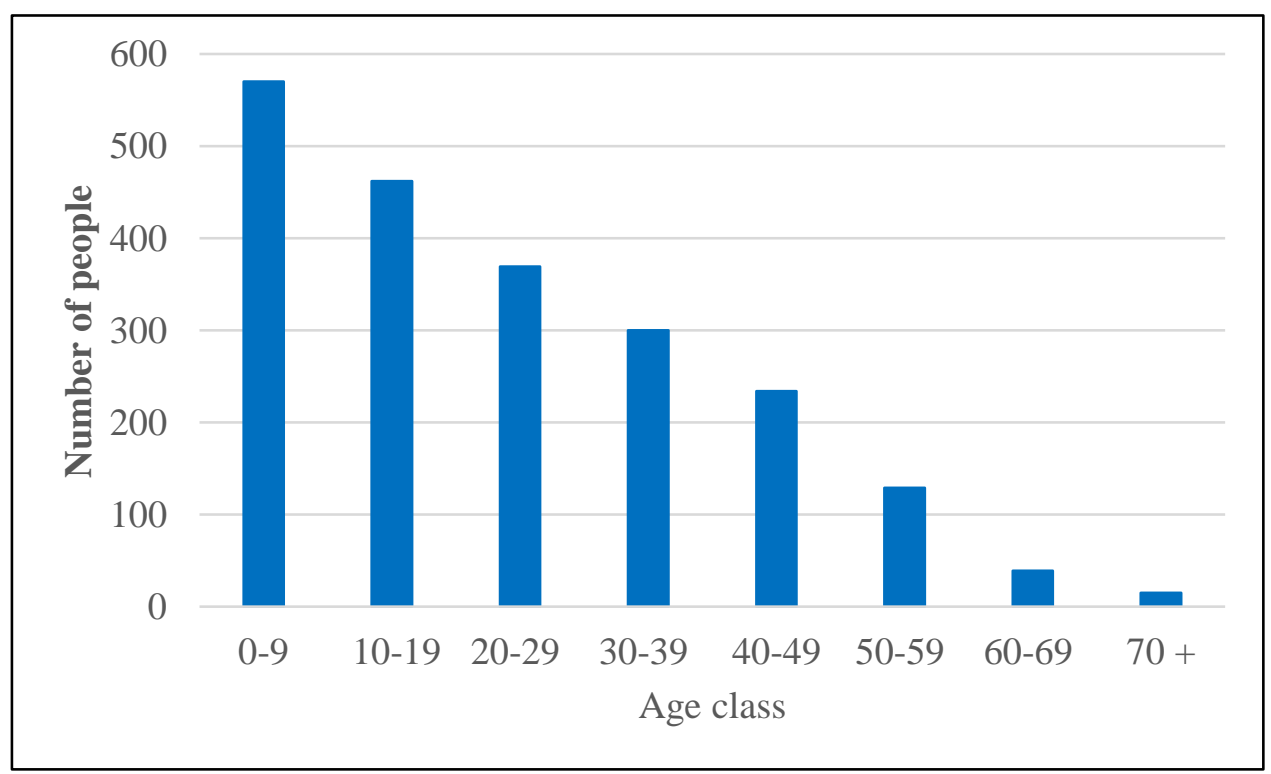

Source: Statistics New Zealand (2019b). 
The rapid population growth is also supported by the fact that the Kiribati population in New Zealand is young with a low rate of mortality and high rate of fertility, similar to other Pacific Island groups. According to Statistics New Zealand (2013a), the median age was 20.6 years and 80 percent of the population is aged under 40 years (see Figure 1.10).

\subsubsection{Kiribati home country}

Figure 1.11: Map of the Republic of Kiribati.

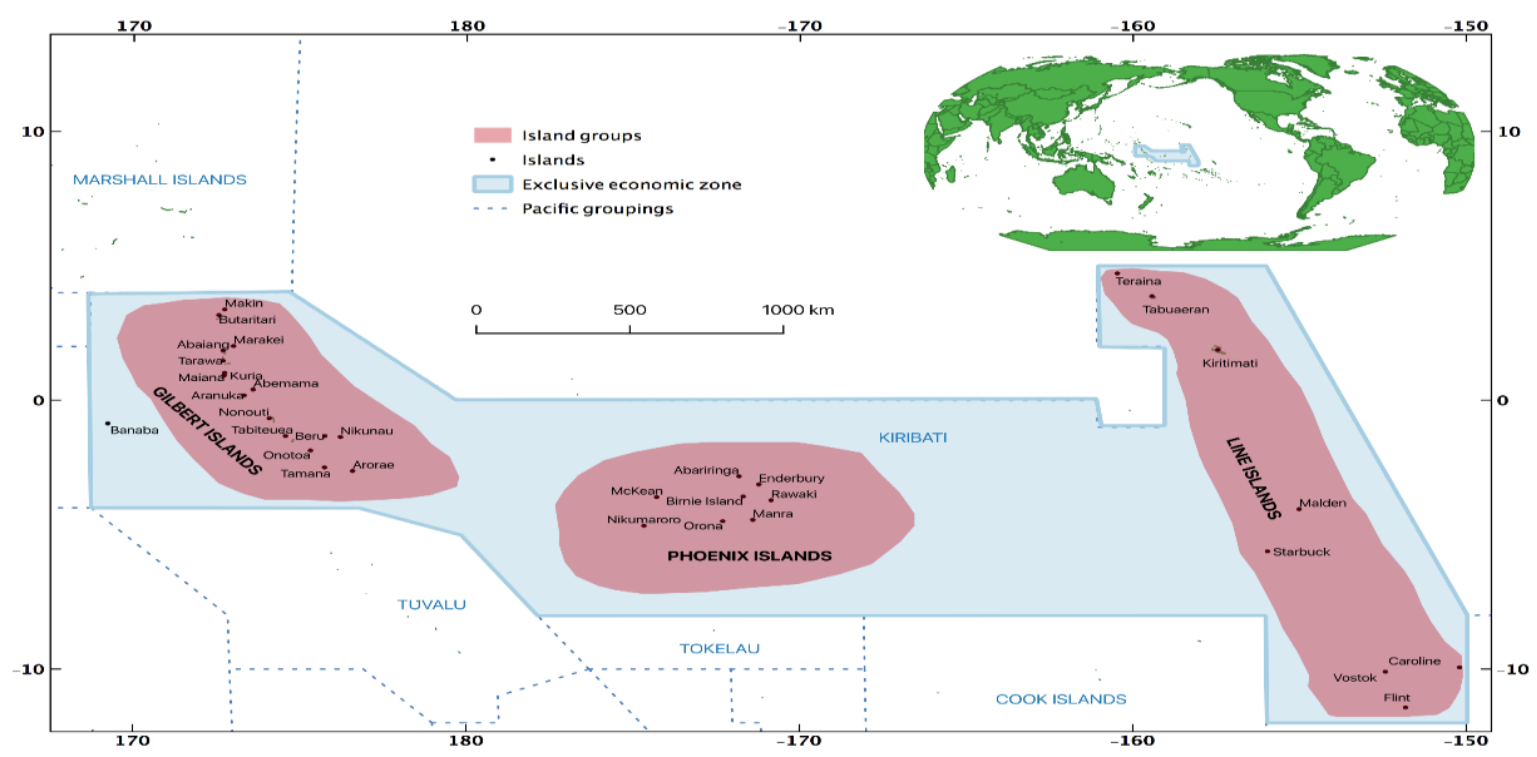

Source: Constructed using GIS data from Natural Earth (2018).

Kiribati is located in the central Pacific and consists of 33 islands divided into three main island groups (Gilbert Islands, Phoenix Islands and Line Islands, see Figure 1.11). Most of these 33 islands are low-lying coral atolls, except for Banaba (Ocean Island), which is a raised atoll island. Although the total land area is only 810 square kilometres, Kiribati's exclusive economic zone (EEZ) is vast, covering an ocean area of 3.5 million squared kilometres. The capital island of Kiribati is Tarawa, which is comprised of South Tarawa (urban) and North Tarawa (rural).

The total population of Kiribati was 110,136 in 2015 compared to 92,533 in 2005 (Ministry of Finance and Economic Development, 2018). Refer also to Table A-5 in the Appendix. During this period, Kiribati experienced steady population growth with an average annual growth rate of 1.8 percent (Asian Development Bank, 2018). Being small in terms of land mass, Kiribati's population density is significantly high, 
particularly in urban areas. About 50 percent of the total population live on South Tarawa with a land area of just 15.76 square kilometres (Ministry of Finance and Economic Development, 2018). Figure 1.12 shows that the urbanisation trend for Kiribati has not slowed down since the 1940s. The Urban population was about 60 percent in 2015 compared to under 40 percent in 1990. Increased urbanisation coupled with steady population growth notably raises multiple challenges for both the Kiribati government and its people.

Figure 1.12: Rural-urban ratio, 1947-2015.

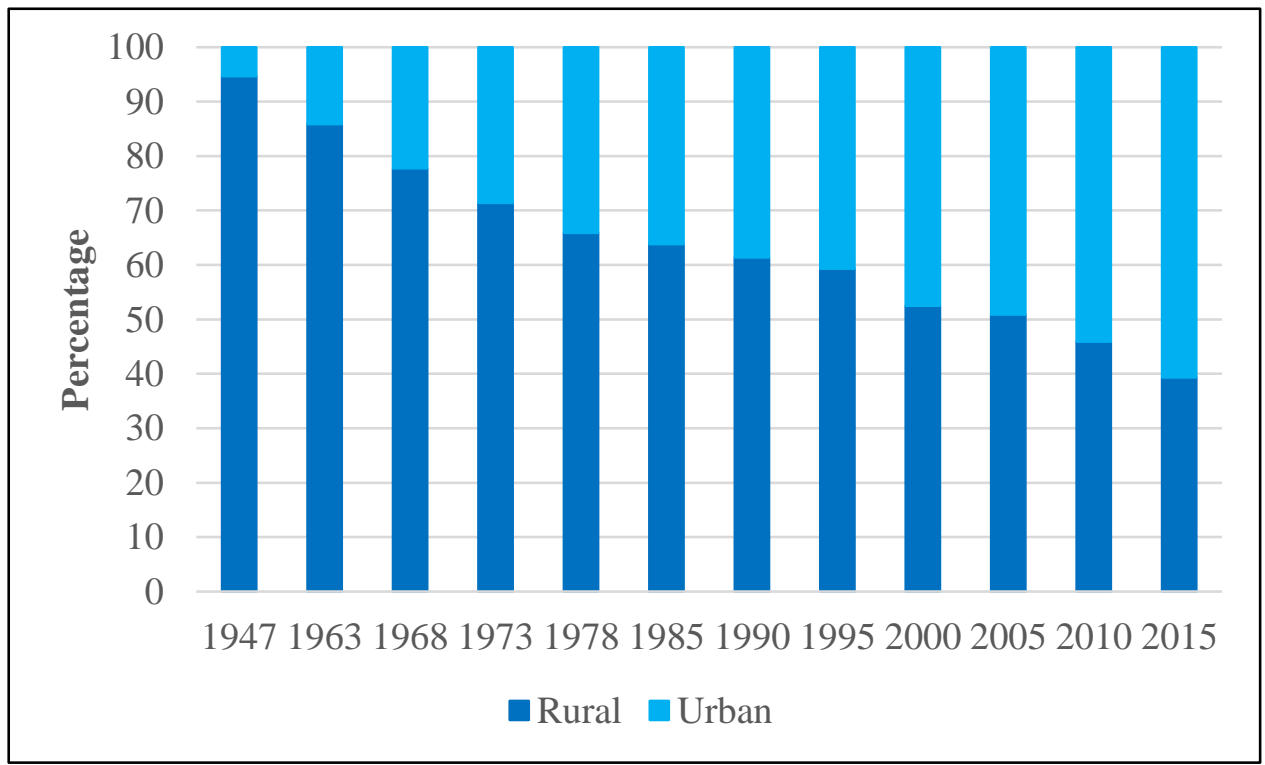

Source: Ministry of Finance and Economic Development (2018).

The people of Kiribati are known as kain Kiribati or I-Kiribati. There is only one language, so although English is taught in school as the official language, the people converse in their own language. Land and agricultural resources are limited. The soil is infertile and water resources are limited. The people mainly live on fish as the main source of protein, and other staple food sources including bwabwai (giant taro), breadfruit, coconut and pandanus.

Kiribati's production and export base is narrow, mainly limited to tuna fishing and copra. Fish and coconut products make up almost all of Kiribati's exports, so the population is dependent on imported foodstuffs and fuel (International Monetary Fund, 2019). This has resulted in a widening trade balance deficit since the 1980s (see Figure 1.13). Despite this, Kiribati's current account has been in surplus since 2012 (see Table A-5 in the Appendix). This is a result of earning high revenue from selling fishing 
licenses to foreign-owned vessels fishing in Kiribati waters under the Vessel Day Scheme (International Monetary Fund, 2019). Kiribati also relies heavily on overseas donors' grants, which amounted to about 40 percent of Gross Domestic Product (GDP) on average between 2013 and 2017 (International Monetary Fund, 2019). In addition, Kiribati has a sovereign wealth fund - the Revenue Equalising Reserve Fund (RERF) - which was established in 1956 from profits from mining phosphate deposits on Banaba. Mining ceased in 1979 and in recent years, fishing revenues have been used to replenish the fund (International Monetary Fund, 2019). The RERF plays two key roles: (i) serves as a capital base for future generations; and (2) provides a financing function for recurrent deficits (Government of Kiribati, 2016b). As of August 2018, the RERF's net worth value rose just above $\mathrm{A} \$ 1$ billion, a target that was expected to be reached in 2020 - making it the largest sovereign wealth fund in the Pacific (International Monetary Fund, 2019).

Figure 1.13: Balance of trade, 1974-2017.

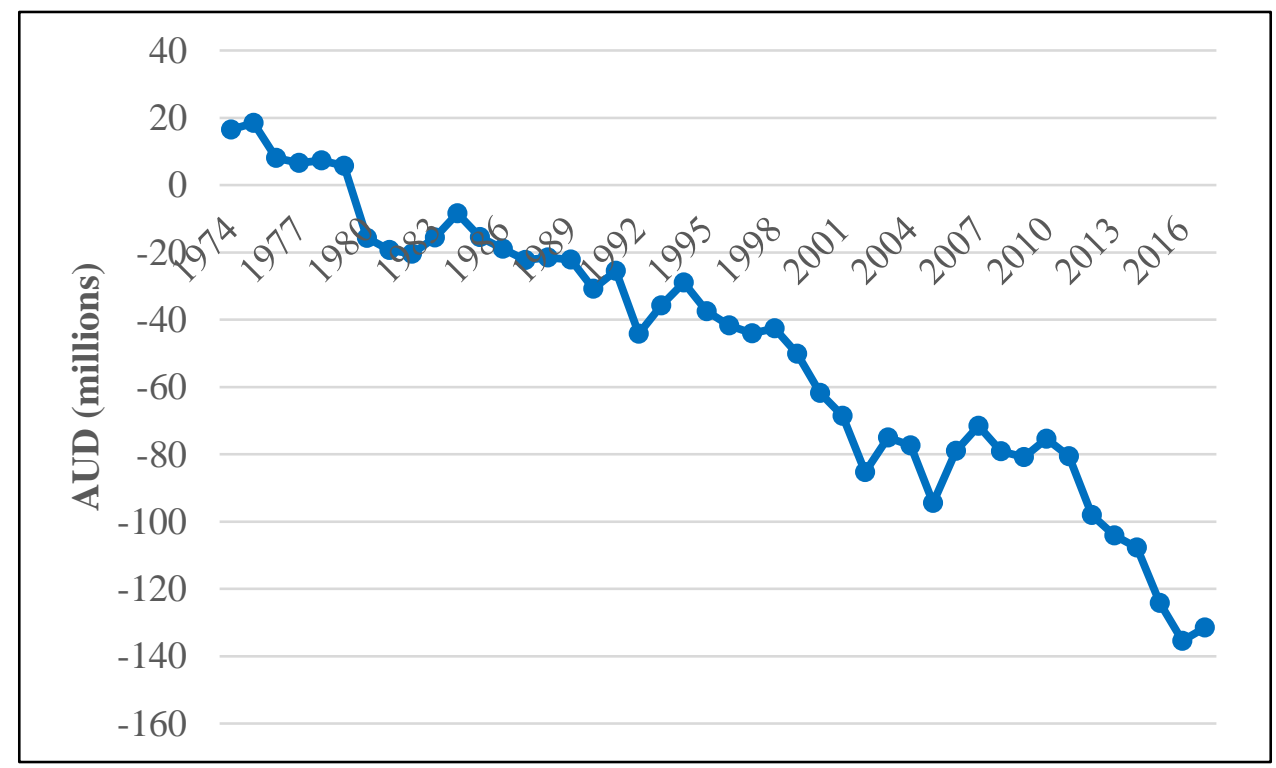

Source: Ministry of Finance and Economic Development (2018).

Despite notable economic volatility, Kiribati's economy grew at an average annual rate of 5.3 percent in the $2015-17$ period, compared to 1.5 percent in the $2005-14$ period (see Figure 1.14 and Table A-5). The stronger economic growth in recent years is supported by higher public spending financed by fishing revenue and donorfinanced infrastructure spending (International Monetary Fund, 2019, p. 7). In 2017, real GDP per capita was only A $\$ 1,656$. This was the lowest in the Pacific region (International Monetary Fund, 2019, p. 24). The public sector (26 percent) and the 
agriculture and fishing industries (31 percent) contributed to over half of GDP in 2017 (Ministry of Finance and Economic Development, 2018).

Figure 1.14: Economic growth and real income per capita.

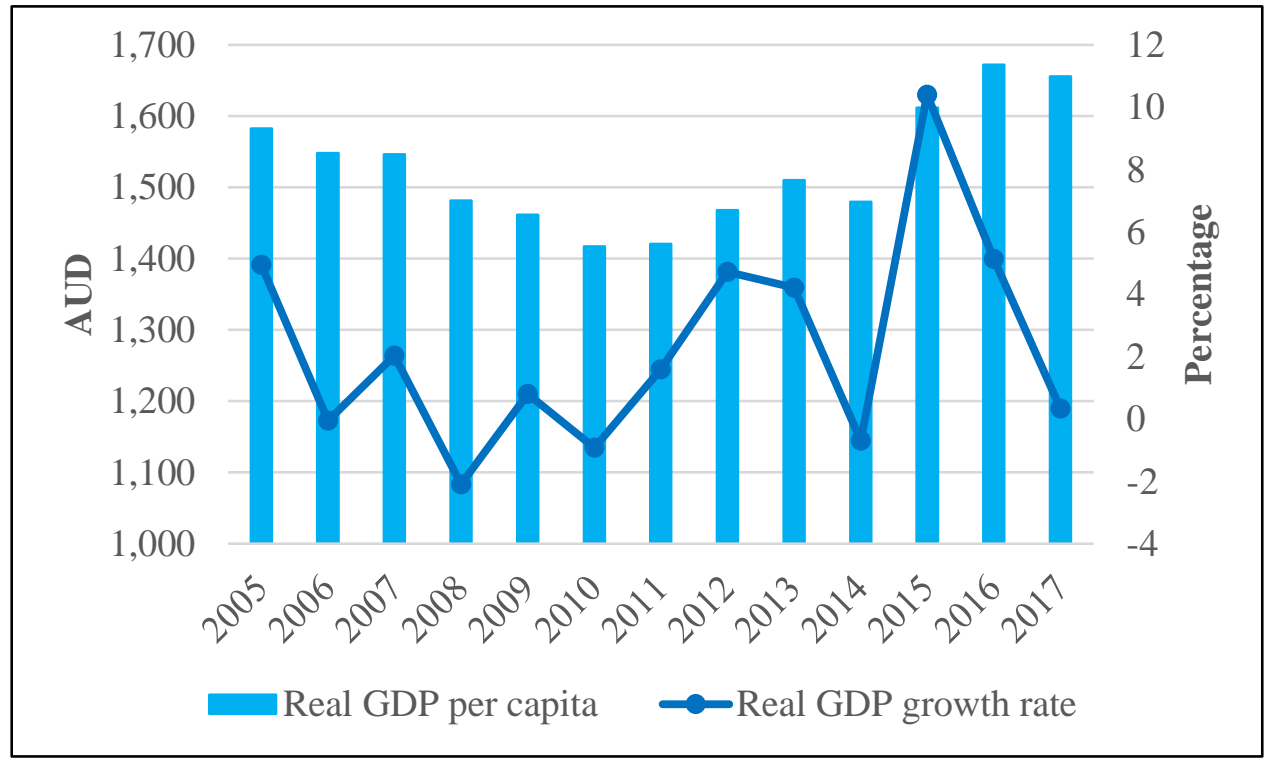

Source: Ministry of Finance and Economic Development (2018).

Table 1-3: Population 15 years and over by island and work status - 2015

\begin{tabular}{|l|r|r|r|r|}
\hline & \multicolumn{2}{|c|}{ South Tarawa } & \multicolumn{2}{c|}{ National } \\
\cline { 2 - 5 } & Number & \multicolumn{1}{c|}{ Percentage } & Number & \multicolumn{1}{c|}{ Percentage } \\
\hline Total & 38,078 & & 71,698 & \\
Employee & 11,116 & 29.2 & 15,731 & 21.9 \\
Self-employed & 2,505 & 6.6 & 9,292 & 13.0 \\
Employer & 109 & 0.3 & 143 & 0.2 \\
Subsistence & 737 & 1.9 & 2,788 & 3.9 \\
Not Employed & 23,604 & 62.0 & 43,540 & 60.7 \\
Not Stated & 7 & 0.02 & 204 & 0.3 \\
\hline
\end{tabular}

Source: Ministry of Finance and Economic Development (2018).

According to the 2015 census records on the general working-aged population (15 years and older, see Table 1-3), 22 percent were employed, 13 percent self-employed, 4 percent depended on subsistence economy, and 61 percent were unemployed. Similar statistics were observed for the same demographic group on Kiribati's capital of South Tarawa, i.e. 29 percent were employed, 7 percent self-employed, 2 percent lived on subsistence economy, and 62 percent were unemployed. High unemployment rates put pressure on employed members of the family unit to support unemployed 
family members. In spite of these pressures, Kiribati culture is built on a strong extended family and closeness of members of the family unit. Similar to other Pacific cultures, no one works just for themselves - everyone is expected to support each other, particularly the most vulnerable and those in need.

Being the main source of employment, the public sector is not keeping up with the demands of the growing numbers of young people completing secondary and tertiary education. According to the 2010 census, about 54 percent of the population aged between 15 and 24 years were unemployed, indicating limited economic activities that generate job opportunities to meet the demand for work (Government of Kiribati, 2016b). There is a need amongst young people to seek job opportunities outside Kiribati. Since the establishment of the Marine Training Centre in Kiribati (see Section 6.5.1), many young Kiribati men have worked abroad as seafarers returning remittances to support their families. Remittances from seafarers have been an important traditional source of overseas income, peaking at 18 percent of GDP in 1990 - a period when there were a high number of overseas seafarers (Government of Kiribati, 2016b). Remittances amounted to A $\$ 16$ million (7 percent of GDP, see Table A-5 in the Appendix) in 2017 and have now been diversified with additional sources from the seasonal worker schemes in New Zealand and Australia, the PAC scheme, and other Kiribati citizens working abroad. Thus, the PAC scheme is very important as one way to address the population and youth unemployment issue in Kiribati. It is therefore important to understand Kiribati migrant women's health experience for future improvements to the PAC policy.

\subsection{KIRIBATI COLONISATION}

According to Bedford, Macdonald, and Munro (1980, p. 202), between the 1820s and 1830s Kiribati was in regular contact with Europeans. This was initiated by whalers seeking trading opportunities, followed by beachcombers and resident traders. In the 1870s, the London Missionary Society began its operation in Kiribati. These contacts with outsiders created opportunities for Kiribati people to be taken for work outside Kiribati. Between 1847 and 1895 approximately 9,300 adults from Kiribati were recruited for work in New South Wales, Reunion Island, Peru, Fiji, Samoa, Tahiti, Hawaii, Central America, and Queensland (Bedford et al., 1980, p. 217). The first formal recruitment was made in 1847 when 22 men were taken from Arorae and Tamana to work on Benjamin Boyd's sheep and cattle stations in New South Wales, 
Australia. In the 1850s French recruiters took some people from Kiribati to Reunion Island, others probably to New Caledonia (D. Shineberg personal communication to B. K. Macdonald) (Bedford et al., 1980, p. 213). "The main sources of recruits between 1875 and 1895 were Beru and Tabiteuea, where over 350 and 200 respectively are known to have worked in Fiji. Nikunau, Onotoa and Arorae provided between 100 and 150 over the same period while Abaiang, Maiana, Abemama, Nonouti and Tama provided fewer than 100 each" (Bedford et al., 1980, p. 215). An interesting feature of overseas labour migration from these islands in the 19th century was the involvement of entire families: "On 24 of the 35 voyages to Fiji between 1876 and 1895, for example, there were about as many women and children (475) on board as there were adult males (481)" (Bedford et al., 1980, p. 217). Between 1877 and 1887 Kiribati was the main source of potential immigrants to Hawaii, with some 1,500 adults and 300 children going to Hawaii (Bedford et al., 1980, p. 216). At the end of this overseas labour migration, further labour migration began for the economic development of Kiribati and Tuvalu. Labourers were recruited from other islands within Kiribati to work on Government-owned plantations on Fanning and Washington, parts of Kiribati. In 1900, Albert Ellis's discovery of phosphate on Ocean Island resulted in migration to Banaba from other Kiribati Islands and Tuvalu, and this labour migration was later extended to Nauru to work on phosphate mining there (Bedford \& Macdonald, 1982, p. 217).

Chapter 4 provides further discussion on pre-colonisation and colonisation in Kiribati. In her recent article, Teaiwa (2018) reminded us that decades of phosphate mining on Banaba (during colonisation), ending in the late 1970s, resulted in the removal of 22 million tons of land (about $90 \%$ of the island's surface). The island was not rehabilitated and many Banabans were resettled on Rabi Island in Fiji. Arguably, at the time Kiribati's relationship with its developed neighbours did not result in a winwin outcome for Banabans. Phosphate mined by the British Phosphate Commission was sold to Australia and New Zealand at relatively low prices between one-half and one-third of the world market prices (Bertram, 2012). In addition, phosphate mining adversely resulted in the involuntary relocation of Banabans, being removed from a source of wealth, their rich culture and identity. Teaiwa (2018) argues that the experience of Banaban resettlement foreshadows future inevitable relocations that many Pacific islanders will face due to climate change. 
Unfortunately, the resettlement of Banabans on Rabi island was not the first time a group of Kiribati people had to experience the ordeal of resettlement. Between 1938 and 1940, the people from the southern Gilbert Islands were relocated to the Phoenix Islands. Both island groups belong to Kiribati (see Figure 1.11). Even in other parts of the Pacific and the globe, relocation of people from their native lands to a foreign home due to various social, economic and political reasons, is not new (Tabe, 2011).

According to Maude (1952), Captain M Baker first landed on one of the Phoenix Islands to bury a member of his crew, when he accidently discovered phosphate guano deposits. This resulted in the commencement of work in most of the Phoenix islands except Hull (Orona), which were bonded under the 1856 American Guano Act confirming that the guano there was found by an American citizen. Workers and supplies as well as many large vessels were taken to the islands four times a year. Future research will be necessary to find out to which countries these phosphate guano deposits were taken to. Work on these islands continued until 1877. Later came $\mathrm{Mr}$ John T Arundel, a British national with interests in coconut plantations and guano mining. Mr Arundel and his company proceeded with the work on guano mining and planting coconut trees on the islands in the Phoenix Group. In September 1937, Mr Maude was given the responsibility under the British administration to undertake a feasibility study in the Phoenix Islands to see if it was viable for colonisation. Following his work, the Phoenix resettlement was approved and he was assigned to manage the scheme. The Phoenix scheme aimed to relieve overpopulation and land shortage in the southern Gilbert group including Nonouti, Tabiteuea (my home island), Beru, Onotoa, Tamana and Arorae by relocating some of the locals from their home islands to the uninhabited Phoenix Islands. This relocation was done on a voluntary basis (Tabe, 2011). However, the song included below, composed by the people from Beru islands, shows that the natives were guided wrongly and left in the dark; they were taken to an unknown place that has no connection to their ancestral land. The key message from this song articulates that Kiribati people have a lot of respect and trust in people with authority. They expressed their appreciation to the person in charge of the Phoenix scheme, trusting that the relocation would provide them with a better future, even though they were not given the opportunity to see the place first to decide if it was somewhere they would like to live permanently. 
In 1954, the people in the Phoenix Islands suffered from a drought that affected many crops and water supplies. According to Tabe (2011), the elders proposed that the British administration relocate them to Kiritimati Island, another island in the Line Islands group. Instead, they were involuntarily relocated to the Solomon Islands, a different country with a contrasting geographical environment and people who differed from I-Kiribati in their culture and multiple languages. Based on stories told by Tabe's informants, it was suspected that the British atomic bomb testing on Christmas Island, which they witnessed to be a significant test with a bright light in the sky, might have caused many of their food crops to die and affected their water supply (Tabe, 2011). Between 1957 and 1958, Britain performed nine hydrogen and atomic bomb tests at Malden Island and Christmas Island (Kiritimati) both belong to the Line Islands in Kiribati. In 1962, the United States carried out 24 atmospheric nuclear tests at Kiritimati (Christmas Island) (Maclellan, 2017). They also undertook "five atmospheric airbursts and nine high-altitude nuclear tests, with warheads launched on missiles from Johnston (Kalama Atoll) and submarines" (Maclellan, 2017, p. xv). Arguably, the relocation of the Kiribati people from the Phoenix to the Solomon Islands during British colonisation was involuntary, and probably resulted from the environmentally destructive activities of the British and United States. Whilst there is limited literature documenting the effects of the British atomic work on Christmas Island, Tabe was able to document the informants' (who were relocated to the Solomon Islands) stories.

E a katau te nako Orona $(A k a u, 1946)^{6}$

E a katau te nako Orona bwa ti na nako $n$ roko iai Te aba ae I aki ataia ngai Ao a aki ataia tibu.

Chorus: $N$ na iririko ni boborau

$N$ nna iririko ni boborau

N na iri $N$ na iri

$N$ na iriko $N$ na iriko

E rabwa Iuta n arona

Ngke karekea te iango aei

Are ti na kabwaia iai

Ma raora ni kabane iai.

\footnotetext{
${ }^{6}$ Orona is one of the islands in the Phoenix group, see Figure 1.11. This song was composed in 1946. The exact composer is unknown, but credit is given to Iuta Akau and the people of Beru Island.
} 
E a tau an tai manga rairaki

$N$ tara abam ae nangi tiku

E a tau teirake ti a nako

Bwa Ti nang kitana BERU.

[English translation by Researcher]

It is about time to travel to Orona

The island that I don't know

And even my ancestors did not know.

Chorus: I will follow you to travel

I will follow where you travel

I will come I will come

I will come with you I will come with you.

Thank you Iuta

For initiating the idea

That will bring us prosperity

Everyone of us.

Don't turn back

To look at your home island which will stay behind

Stand up lets go

We will leave Beru Island.

The next section discusses the importance of my thesis to Pacific Studies, and how it will contribute to knowledge that will benefit future immigration policies impacting on the health and wellbeing of Pacific migrants residing in New Zealand.

\subsection{PACIFIC STUDIES}

My philosophy of research in the Pacific is that it should involve the study of fundamental problems affecting the Pacific and Pacific people using appropriate theories and methods. I also believe that research should be guided by theory that helps to improve the situation and provides direction on appropriate methods of analysis, resulting in a contribution to knowledge in general. Pacific Studies literature (e.g. Teaiwa \& Henderson, 2009; Wesley-Smith, 1995) acknowledges that most of the research on the Pacific to date has been conducted by outsiders to the region. What Wesley-Smith described as the pragmatic and laboratory rationales for the development of Pacific Islands Studies some sixty years ago in metropolitan countries, emerged from a desire to influence and administer the Pacific and its people. While it is widely acknowledged that work by outsiders is valid for informing sectoral policies, it is about time that Pacific people conduct their own studies of their communities and 
environments in line with the aim of 'Pasifika research' in New Zealand, which exemplifies an 'empowerment' rationale for Pacific Studies (Wesley-Smith, 1995). Teaiwa and Henderson (2009) also acknowledge the importance of Pacific research involving engagement with communities, taking into account Pacific voices, perceptions and epistemologies and using appropriate language to demonstrate respect for our lived cultures. This assists in preparing the research to be more responsive to the needs of Pacific people. As a Kiribati woman engaging Kiribati women in my research, with the aim of incorporating their perceptions and voices into my analysis, I see myself as working within the frame of the empowerment rationale and hope to contribute knowledge that will inform immigration policies for the benefit of future migrants.

Whilst it is vital to incorporate indigenous voices and cultural values, it is also important not to exclude Western theories that are useful for analysing issues and concerns of the Pacific people. Teaiwa (2014) acknowledged the work of a number of Western authors who had produced important research for the Pacific people. In "Rethinking Pacific Island Studies", Wesley-Smith (1995), an Irish-born male author based in Hawaii, produced outstanding research which describes the rationales for the establishment of Pacific Studies. Maude (1961) provided a record of cultural protocols related to the significant role of te boti (an allocated space for families in te maneaba) in social and political lives of Kiribat people. Whincup (2009) published documents such as "Bwai ni Kiribati Artefacts of Experience" entailing key aspects of a social life in the village, which were primarily based on our traditional knowledge and skills. These included traditional dance, fishing, weaving and cutting today, which support the health and wellbeing of I-Kiribati. Finnish researcher Petra M. Autio's doctoral research "Hard Custom, Hard Dance" (2010) contains significant information on the Kiribati culture, using Tabiteuea Island as a case study. My own doctoral research privileges the voices of I-Kiribati participants, drawing on my own and other Kiribati people's cultural knowledge alongside relevant research from Pacific and non-Pacific scholars.

My research explored Kiribati women's health experiences since they migrated from their home island to New Zealand under the PAC. It will not only inform immigration policy, but it will also contribute to the literature on the settlement of Kiribati PAC migrants, who are a minority in New Zealand. Whilst there is ample literature on 
Kiribati and Kiribati labour migration, there are only a few theses that I know of which come out of interdisciplinary Pacific Studies or similar programmes. Katerina Teaiwa's MA thesis on "Tirawa irouia: Re-presenting Banaban stories” (1999), from the Center for Pacific Island Studies at the University of Hawaii, describes the experiences of ancestral Banabans who were relocated to Rabi Island in Fiji. The relocation was done by the British following the cessation of phosphate mining, which was in operation between 1900 and 1980. Tammy Tabe's MA thesis "Sapon riki kain Toromon: A study of the I-Kiribati community in Solomon Islands" (2011), also from the Center for Pacific Islands Studies, looks at the history and experiences of Kiribati communities. They were relocated by the British in the mid $20^{\text {th }}$ century from the Phoenix Islands in Kiribati to the Solomon Islands, where they have become a minority group in a Melanesian society. Holly Mansfield's MA thesis on "Discourses of Vulnerability: Kiribati, I-Kiribati Women and Forced Migration Due to Climate Change" (2013), completed in Pacific Studies at Victoria University of Wellington, examines how language about "vulnerability" is used in debates about forced migration (as a possible outcome of climate change), including in the articulations of I-Kiribati people being described in this way. In addition to these Pacific Studies theses, Maryanne Thompson's $\mathrm{PhD}$ thesis on "Settlement experiences of Kiribati Migrants Living in New Zealand" (2016) in Public Health from the University of Otago, reveals some common themes that influence the settlement experience of these migrants and their families. My thesis complements these studies by focussing primarily on the impact of the PAC policy on the health and wellbeing of Kiribati migrant women and children.

\subsection{THESIS OUTLINE}

This thesis comprises seven chapters.

- Chapter 1: Introduction.

This chapter defines the research problem and rationale for undertaking this research. It provides background information on Kiribati including its geographical location and its economy, the Pacific people including I-Kiribati living in New Zealand, and Pacific migration by category, one of which is the Pacific Access Category. The trends of migration from Kiribati to New Zealand under this policy, and other policies which 
are useful for comparison in understanding the immigration situation of PAC migrants are included.

- Chapter 2: Literature review on conceptual framework

This chapter explains key concepts that together form the conceptual framework of this research. Elaborated in this chapter are Foucault's theory of governmentality; feminist approaches to research; the concept and features of neoliberalism; and te maneaba system (encompassing the Kiribati cultural protocols): together, these guide my research methods, analysis and presentation of my research findings. These approaches helped me, with different lenses, to understand and interpret the voices of my research participants.

- Research methodology.

This chapter explains the theories and literature that underpin the research methods applied to my thesis topic. My research engages indigenous methodology as researchers (e.g. Pe-Pua, 2006; Prescott, 2009; Smith, 2004; Tamasese, 2005) argue that social science methods are inadequate to capture the indigenous experiences of the world. However, Pacific Studies scholars assert that it is important not to ignore Western theories which equip researchers with a different lens to analyse world problems (Teaiwa, 2014). I employed a combination of the Kiribati indigenous method, te maroro (talanoa) (exchange of stories or ideas) and the feminist oral history method to gather 30 Kiribati PAC women's rich stories. Ethical consideration, processes for recruiting research participants, signing of the consent and confidentiality forms, transcribing and thematising information using NVivo are included.

- Chapter 3: Differing world views of neoliberalism and te maneaba system.

This chapter explains governmentality theory to help analyse what lack of government support means, as it emerged as one of the key themes from the women's stories. It also discusses te maneaba system in Kiribati which is the rock and foundation of Kiribati culture and values that influence how these women view the world. The shift in power and governing in New Zealand from welfarism to neoliberalism, marked rolling back the state or encouraging self-responsibility. It is these expectations of selfresponsibility that these women interpreted as 'lack of government support'. The analysis of the women's experiences showing how te maneaba system and 
neoliberalism talk past each other. Discussion of how this impacted on the lives of these women and their children is included.

- Chapter 4: New responsibility for Kiribati families.

This chapter continues the discussion of the risks of neoliberalism by relating to selfresponsibility that has led to the emergence of collective effort and responsibility by Kiribati families in New Zealand. These earlier migrants are shouldering the responsibility and acted as a welfare state agency to bridge the PAC gaps in providing housing, seeking job offers, providing healthcare, and other services to most Kiribati immigrants.

- Chapter 5: Cultural barriers: language, shyness and silence.

The chapter discusses how the lack of experience in using English for day-to-day activities, te mama (shyness), and te aki kakarongoa (silence) have made life very difficult for the migrant women. The women's stories demonstrate these challenges, and highlight areas for improvement in the PAC policy relating to cultural competency, self-esteem, gender and human rights, and meaningful communications.

- $\quad$ Chapter 6: Risk of self-responsibility on healthcare and wellbeing.

Differing world views of te maneaba system and neoliberalism, families shouldering responsibility, and the rich Kiribati culture becoming a barrier to successful migration help make sense of why and how these women experience health and healthcare issues. This chapter provides an account of the women's health experiences that fits well with my main argument in this thesis, that the New Zealand PAC policy disarticulates the humanitarian principles of health and wellbeing from migration policy, and results in unfair expectations of self-responsibility that disadvantage migrants. The information collected from these women's health experiences contribute to knowledge in the area of how the PAC policy has impacted on the health and wellbeing of the Kiribati migrants. The story of a woman experiencing stillbirth, for example, is evidence of how the PAC has created unnecessary inequality, hardship and poverty. The women's stories demonstrate that experiences of health are embedded in culture and gender. I also examine how the PAC policy could improve the health outcomes of immigrants. 
- Chapter 7: Conclusions, limitations and recommendations.

This chapter summarises the main conclusions drawn from Chapters 3 to 6 , the limitations of the research which create opportunities for future research to contribute to new knowledge, and suggests future policies to support the health and healthcare of migrants. The concluding chapter also provides recommendations around the improvement of the PAC policy conditions, and proposes a residency model that balances the PAC's purpose for economic growth with humanitarian principles of health and wellbeing for migrants drawn from te maneaba system. 



\section{Chapter 2 Literature review on conceptual framework}

\subsection{INTRODUCTION}

As discussed in Chapter 1, my philosophy on Pacific research is that it should be motivated by the fundamental issues affecting Pacific people using appropriate conceptual frameworks to provide direction on appropriate methods of analysis. This will result in research that is not just relevant to its Pacific context, but will also make a contribution to knowledge in general. Anae (2010, p. 2) argues that " $[t]$ here is a need for a comprehensive conceptual framework for research with Pacific communities which offers holistic, theoretical foundations to improve and enhance the quality and quantity of evidence". It was also argued in the previous chapter that whilst it is important to use indigenous knowledge and values to analyse Pacific issues, western theories are also important and add value to the analysis. This chapter discusses governmentality as a conceptual framework to analyse how two forms of economic and political systems - te maneaba governmentality and neoliberal governmentality impact on the health and wellbeing of Kiribati women who migrate and settle in New Zealand under the Pacific Access Category.

\subsection{GOVERNMENTALITY}

In Foucault's theory of governmentality, “[g]overnmentality (gouvernmentalite) refers to the conduct of conduct, especially the technologies that govern individuals. It captures the way governments and other actors draw on knowledge to make policies that regulate and create subjectivities" (Bevir, 2010, p. 423). The governmentality lens helps make sense of the tactics of government employed by agents of the New Zealand nation-state in the design and implementation of the PAC, and how these disadvantage Kiribati PAC migrant women, given their differing world views of New Zealand and Kiribati societies. For example, one of the tactics or strategies of Immigration New Zealand's PAC policy is to ensure that successful applicants have an acceptable job offer. This thesis wanted to explore how and why this condition created social struggles for my research participants. 
Michael Foucault, a French thinker, first introduced the idea of governmentality in his lectures at the Collège de France between 1977 and 1984, the latter being the year when he died. The word 'governmentality' comes from the French word gouvernemental - concerning government (Lemke, 2007).

Foucault coins the concept of "governmentality" as a "guideline" for the analysis he offers by way of historical reconstructions embracing a period starting from Ancient Greece through to modern neo-liberalism (Foucault 1997b, p. 67). The semantic linking of governing ("gouverner") and modes of thought ("mentalité") indicates that it is not possible to study the technologies of power without an analysis of the political rationality underpinning them (Lemke, 2002, p. 2).

In his review of the literature on government, Foucault (1991) explains that the transition that took place in $18^{\text {th }}$ century in Europe from an art of government (referred to as general government) to a new science of government, involved changes in governmentality - changes in governing mentalities. The general problem of government broke out in the sixteenth century. The problem of government refers to issues relating to "how to be governed, by whom and how we accept to be governed, how to be the best possible governor" (Bulley, 2014, p. 1). The word government in Foucault's thesis of governmentality "did not refer only to political structures or to the management of states, rather, it designated the way in which the conduct of individuals or groups might be directed - the government of children, of souls, of communities, of the sick" (Bulley, 2014, p. 2). Foucault was particularly interested in governmentality as the "conduct of conduct" or regulation of behaviours, or a form of action that influences, guides or affects the conduct of some persons (Gordon, 1991; Lemke, 2002). Foucault's teaching materials on the subject of governmentality have contributed knowledge and guidance to subsequent researchers (Bevir, 2010). This thesis uses the governmentality framework for uncovering the health and wellbeing experiences of Kiribati PAC migrant women. Foucault's governmentality framework guides my analysis of te maneaba system (discussed further in this chapter) as governmentality from the Kiribati perspective, focusing on Kiribati women who also have a position in te maneaba system, and have migrated to New Zealand under the PAC scheme.

Throughout the 17th to the beginning of the 18th century, the art of government that was based on a sovereignty model of government and "an economy of enrichment is still based on a model of the family" (Foucault, 1991, p. 98). This government of 
family, termed economy, refers to "the correct manner of managing individuals, goods and wealth within the family (which a good father is expected to do in relation to his wife, children and servants) and of making the family fortunes prosper - how to introduce this meticulous attention of the father towards his family into the management of the state" (Foucault, 1991, p. 92). This family model was not able to respond to the new shifts in the problem of government, i.e. government of population - the new political unit for governing focussed on the needs of voting citizens who comprise a population or populations.

It was through the development of the science of government, that the notion of the economy came to be re-centred onto that different plane of reality which we characterize today as the 'economic', and it was also through this science that it became possible to identify problems specific to the population... The perspective of population, the reality accorded to specific phenomena of population, render possible the final elimination of the model of the family and the re-centring of the notion of economy (Foucault, 1991, p. 99).

Under the new science of government, Foucault argued that population became the unit of analysis that replaced the family as a model. The family is no longer a model, but a segment or an instrument for the government of the population. This analysis of a shift in the art of government to the new science of government, which Foucault also termed political economy (Foucault, 1991), is what is of interest in this thesis, especially when analysing trends in nation-state governing of immigration and health policies in New Zealand. For example, I was interested in knowing how the PAC policy supports the health and wellbeing of Kiribati PAC migrant women who came on a visitor visa prior to obtaining their permanent residency. How did these women access healthcare services when they were sick or how did the women with children access healthcare services when their children were sick? Have there been any changes in the conditions of policies for PAC migrants over the years since the PAC scheme's inception in 2001 ?

Governmentality as conduct of conduct entails "power and knowledge as an integral part of the other" (Stehr \& Adolf, 2018, p. 193). Based on Foucault's theory, power that depends on knowledge, shapes subjects and subjectivities. Power mainly affects individuals' daily lives, their attitudes, communication and ability to learn (Stehr \& Adolf, 2018). Power that is being referred to in Foucault's governmentality theory "refer[s] to the way in which contingent historical backgrounds impact on individuals, 
influencing their subjectivity and their actions" (Bevir, 2010, p. 433). Power also comes from tradition that helps "explain why people hold the beliefs they do, and because beliefs are constitutive of actions, they also help to explain actions" (Bevir, 2010, p. 434). Foucault's governmentality framework (Burchell, Gordon, \& Miller, 1991) is a useful tool for analysing the wellbeing of the Kiribati PAC migrants, who come from a society with a differing world view, beliefs and values. For example, governmentality helps explain why most of them have struggled to meet the requirements of the PAC policy in a new environment with a different culture.

Other scholars such as Ludwig and Stefanie (2009) have used a governmentality framework from a feminist perspective to analyse and understand the dominant forms of governmentality that affect vulnerable women. For example:

[T] he feminist critique and the women's movement in the 1970s and 1980s have fought for a new definition of what can be considered as private (like the struggles about the definition of domestic violence or unpaid housework) and what should become part of the state's and/or public responsibility... On a theoretical level, this means that governmentality is not only a description of macro-political technologies and technologies of the self, but also analyses the construction of norms, divisions of the public and private, representations, questions of sovereignty, of law, discipline and the technologies of security as different aspects of the technologies of power because they are also part of these social struggles (Foucault, 1984; Dean, 1999; Lemke, 2000). These norms, representations etc. are not gender neutral but (re-)produce a gendered social order (Ludwig \& Stefanie, 2009, p. 9).

From a feminist perspective, Foucault's governmentality is a useful tool to analyse dominant forms of governmentality that create social struggles for women. My thesis uses a feminist lens to understand the world views of the Kiribati PAC migrant women, what they experienced under the PAC policy, and what changes they hope to see for future migrants.

Many scholars have, as this thesis seeks to do, extended and applied a governmentality framework in non-Western societal contexts. Sigley (2006) used the governmentality conceptual framework to understand forms of government in contemporary China, and how it is played out in a non-liberal context. "There are, nonetheless, crucial differences between how the 'conduct of conduct' [regulation of behaviours] has been played out in different societies" (Sigley, 2006, p. 493). "Chinese socialist governmentality differs from liberal western variants in its perception of the limits to 
what one can know about the object to be governed. Liberal reasoning, growing out of a critique of police, maintains a certain scepticism regarding the ability to know the object to be governed in detail and thereby employs an array of more 'indirect' methods of shaping conduct" (Sigley, 2006, p. 494). Sigley's research contributes to knowledge on studies of governmentality in non-Western and non-liberal settings. Raymond (2006) developed the notion of 'environmentality' based on Foucault's governnmenality framework to explore how the Indian state leaders had finally made Kumaon (a province of India) to become a model of 'community-based conservation'. Since the early twentieth century there was high resistance amongst the locals against new regulations on forest management. The author's "[e]xplanation unfolds as a complex series of causal factors, including new forms of knowledge, new political relationships, and new institutional arrangements. But the most interesting (and important) change Agrawal identifies is in the beliefs of the Kumaonis themselves" (Raymond, 2006, p. 261). When the locals were given authority to manage and make decisions of forest management, the change Agrawal calls an example of 'governmentalized localities', this had made local residents become environmental subjects - individuals with a commitment to protect their environment.

Rudnyckyj (2004) employed a governmentality conceptual lens to understand the political and economic processes that enable the transnational movement of migrant labourers from Indonesia to wealthier countries in the Indian and Pacific Ocean regions. The study resulted in the identification of technologies that would enhance the safety and wellbeing of migrants. Suaalii (2006, p. 17) employed the governmentality framework to explore the conditions and tactics of government affecting Samoan youth offenders, rendering them subject to the various spirits of governing available. Analysing the government of the ethnic minority youth group was of interest in her thesis. My thesis uses a governmentality lens to analyse the forms of power/knowledge operating under te maneaba and neoliberal systems, to also identify drawbacks for the health and wellbeing of the Kiribati PAC migrant women affected by both systems as they processed their application for residency, and how both New Zealand and Kiribati governments could assume more responsibility for rectifying shortcomings in service provision.

Governmentality is a theoretical framework used to critique neoliberalism on three bases. 'First, neoliberalism is treated as a manipulative 'wrong knowledge' of a society 
and economy" (Lemke, 2002, p. 6). It is thus crucial that governmentality is interested not only "to see if neo-liberal rationality is an adequate representation of society, but also how it functions as a 'politics of truth' producing new forms of knowledge, inventing new notions and concepts that contribute to the 'government' of new domains of regulation and intervention" (Lemke, 2002, p. 7). "Second, critics see neoliberalism as the extension of economy into the domain of politics, the triumph of capitalism over the state, the globalisation that escapes the political regulations of the nation-state" (Lemke, 2002, p. 6). Third, critics see neoliberalism that promotes "individualisation endangering collective bonds, the imperatives of flexibility, mobility and risk taking that threaten family values and personal affiliations: neoliberalism as practical antihumanism" (Lemke, 2002, p. 6). The use governmentality as a theoretical framework to critique neoliberalism is of interest to this thesis, as it is assumed that the PAC policy is theoretically underpinned by the neoliberal approach. In this research, I wanted to assess how PAC policy impacted on the health and wellbeing of Kiribati migrant women, who are coping with New Zealand's contrasting environment compared to Kiribati economic, social and political cultures.

\subsection{NEOLIBERALISM}

According to Martinez and Garcia (1997, p. 1), neoliberalism originates from the ideology of economic liberalism in the 1800s and early 1900s that believed in removing government control and intervention to encourage entrepreneurship. The liberal school of economics was famous following the publication of a book called 'The Wealth of Nations' in 1776 by Adam Smith, a Scottish economist (Martinez \& Garcia, 2001). According to these economists, the government should not intervene in the market as they believed that the market determines demand and supply to encourage capitalists to make their own choices to grow their profits and develop the economy (Martinez \& Garcia, 1997). The Great Depression in the 1930s gave rise to the ideology of John Maynard Keynes, arguing that the solution to the economic crisis following the Great Depression was for governments and central banks to intervene to develop businesses and generate employment opportunities (Martinez \& Garcia, 1997). The capitalist crisis in the 1970s that was caused by declining profits, motivated owners of companies to revive economic liberalism. Neoliberalism refers to 'neo' or new liberalism, which is the revival of economic liberalism (Martinez \& Garcia, 1997). 
Larner (2000a) argues that neoliberal policy marks a shift from a Keynesian welfare state policy towards a political agenda that gives a new emphasis on marketisation, which is directly associated with the globalisation of capital. Instead of formulating policies to support full employment and the health and welfare system, governments have focussed on promoting economic efficiency and international competitiveness. This has resulted in the 'rolling back' of state welfare activities, by focusing on the privatisation of formerly 'public' goods and services, and liberalisation of immigration policies. Larner (2000a, p. 4) states that the "five values: the individual, freedom of choice, market security, laissez-faire and minimal state intervention" underpin the neoliberal challenge to Keynesian welfarism and push for deregulation and privatisation. The theoretical focus of neoliberalism then, is to open the market by removing trade barriers to support the development of the private sector. Murray and Overton (2011, p. 1) state the neoliberalism movement is associated with "radical reform, restructuring and diminishing the role of states in order to place the market at the centre of development strategies". Lemke (2002, p. 12) argues that neo-liberalism "entails shifting the responsibility for social risks such as illness, unemployment, poverty, etc, and for life in society into the domain for which the individual is responsible and transforming it into a problem of self-care". These are the types of social risks that I examine in the stories shared by the research participants.

This new intellectual political agenda of neoliberalism has been popularised by experts as a solution to political and economic problems and supported by international organisations such as the International Monetary Fund and the World Bank. Politicians such as Margaret Thatcher, Ronald Reagan and Brian Mulroney were influential in the shift from the Keynesian welfarist government to neoliberal government (Larner, 2000a). Neoliberalism as a new form of governmentality marks the major change from the state's full responsibility for the welfare of its citizens to expectations of selfresponsibility and thus created unnecessary poverty, inequality and hardship (Kingfisher \& Goldsmith, 2001; Larner, 2000a, 2000b; Lemke, 2002; Murray \& Overton, 2011; Suaalii, 2006; Trnka \& Trundle, 2014). Larner (2000a) suggests that neoliberal policies disarticulated state responsibility from welfare concerns and rearticulated it as the primary concern of the citizen or community instead. Larner noted that "[w]hile on one hand neo-liberalism problematizes the state and is concerned to specify its limits through the invocation of individual choice, on the other 
hand it involves forms of governance that encourage both institutions and individuals to conform to the norms of the market" (Larner, 2000a, p. 12). Larner argues that the governmentality literature has inspired innovative analyses of welfare state restructuring to link social policy reform to this new object of governance. The neoliberal strategies or new political technologies are "found in diverse realms including workplaces, educational institutions and health and welfare agencies encourage people to see themselves as individualized and active subjects responsible for enhancing their own wellbeing" (Larner, 2000a, p. 13).

Ludwig and Stefanie (2009, p. 11) argue that "[n]eo-liberalism is a political rationality and strategy which shifts responsibility away from institutions such as the state to individual actors, relying on the resources of the individual to solve their own social "risks" such as unemployment, insurance, pensions, and health". It creates a new belief about self technology, the freedom of the market and the withdrawal of the state from its core function of ensuring certain welfare policies. "Privatization and individualization go hand in hand in this process, creating a new 'truth' that each individual is now personally responsible for social welfare problems" (Ludwig \& Stefanie, 2009, p. 11). Thus, the shift in the state's core welfare function to focussing on neoliberal individualistic ideas, changes the norms of society. Arguably, neoliberal governmentality thus emphasises economic incentives that now drive regulations and the state and the forms of government. Ludwig and Stefanie (2009, p. 12) argue that neoliberal governmentality has led to inequalities especially for certain marginalised women who now work in low skilled jobs. According to Repo (2016, p. 323), gender is being deployed as a 'biopolitical apparatus' the same way as sexuality was deployed in the nineteenth century. Gender cannot be detached from neoliberal governmentality, which shifts the responsibility for governing fertility and economy to individuals themselves. Women in particular are made responsible for both fertility and productivity, and hence, the wellbeing and prosperity of society. Chapter 6 discusses the Kiribati PAC migrant women's experience of taking responsibility for childcare, and working at the same time in a neoliberal society.

Critiques of neoliberalism offer a useful lens to view and unpack the issues of PAC policy expectations for self-responsibility, and the burden of care transferred to Kiribati families in New Zealand. This notion of self-responsibility is a new concept for my research participants, and contrasts with their learned behaviour, actions and 
values acquired from the power and knowledge of te maneaba system - a system which circulates to family, community, church and even to the government. The notion of self-responsibility is new especially to those who have not been in New Zealand or overseas previously, and single girls and young mothers who are still dependent on their parents, or husbands, or family members for support.

\subsection{TE MANEABA SYSTEM}

Figure 2.1: Photo of a maneaba (Taratabito) in my home village of Tanaeang on Tabiteuea Island, Kiribati.

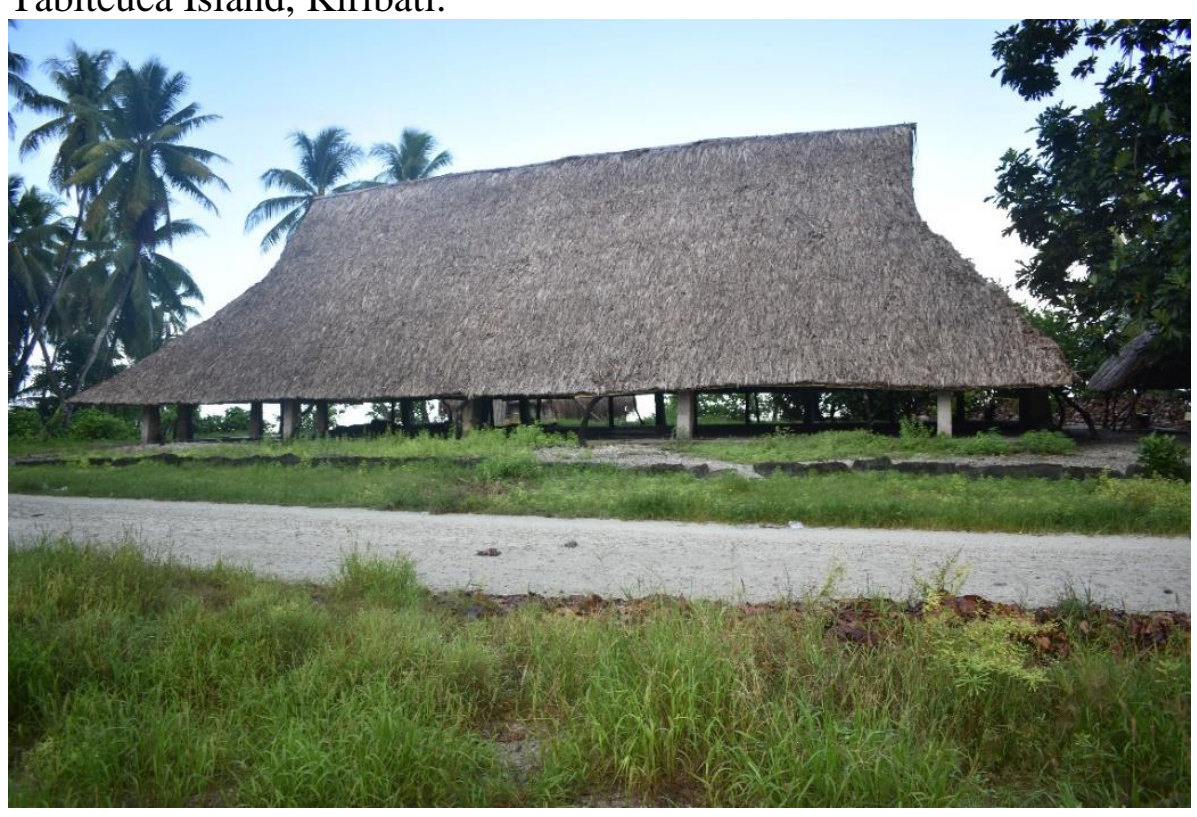

Source: Photograph taken by Rose Namoori-Sinclair on 15 June 2019.

Using the governmentality conceptual framework helps me, as a researcher, to deeply understand that the Kiribati cultural values are the powers and knowledge-also referred to as technologies (Bevir, 2010) of te maneaba system that have been circulated and lived by individuals within te utu, te kainga, te kaawa, te abwamwakoro and even the state.

In this section, I discuss the role, structure and benefit of te maneaba in the traditional cultural setting using my memories as a child brought up in my kainga (Namakauro). I also used knowledge and skills of my families, members of my village (Tanaeang), and the community in Wellington. I also cited other relevant literature with interests in te maneaba system. I have selected Taratabito, which is a traditional maneaba in my home village, Taneang, on the island of Tabiteuea North (see Figure 2.1 above). I am connected to it through my boti, which I have inherited from my parents. This has 
allowed me to draw on my knowledge and familiarity with its structure, the role of unimane, and other cultural values which I have learnt since childhood. However, there are historical practices that are no longer used because the majority of the people in the village are Christians. As discussed in Chapter 1, te maneaba is symbolic of an entire political and social system that structures experiences of governmentality in Kiribati society (Maude, 1961; Uriam, 2017; Whincup, 2009). Te maneaba, a traditional meeting house (see Figure 2.1), is "the largest Kiribati cultural artefact and its size signals its importance within the community" (Whincup, 2009, p. 134). The word maneaba is made up of two words: manea means to bring everyone together, and te aba means the land or the people of the land (Tabokai, 1993; Whincup, 2009). Whincup (2009, p. 134) also states that "[t]he mwaneaba ${ }^{7}$ is central to the I-Kiribati way of life, defining, maintaining, and reflecting attitudes to spirituality, age, hierarchy, communality, patterns of expression and hospitality." As a form of governmentality, te maneaba system remains significant in the lives of the Kiribati people despite major changes through colonisation, independence, and modernisation. Kiribati's unique culture of caring, loving and hospitality is rooted in the traditional maneaba system. Whincup $(2009$, p. 137) describes it as the "social nexus of village life". In the next section, I will discuss its structure and influence on the role of unimane and te kainga in relation to the wellbeing of all members. Renovating the roof and changing the mats are significant events in which te kainga plays a significant part, and highlights that there is also a hierarchical structure in te maneaba system.

Given their significant role in the village as people with the highest authority, unimane are also referred to as tabekeauea (king) (T. Kautu, personal communication, August $28,2019)$. Unimane from the different kainga sit in their respective boti (space) within te maneaba to discuss and make fair decisions pertaining to the wellbeing of te kainga, te kaawa and te abwamwakoro. Te boti provides a space for each kainga to have their voices heard by te unimane, allowing everyone to have a sense of belonging in their kainga, kaawa and te abwamwakoro. Unimane are responsible for governing, maintaining peace, resolving conflicts, and ensuring justice, and that the voices of all members are heard and not dominated by a few (Tabokai, 1993, p. 24).

\footnotetext{
${ }^{7}$ In this thesis, I use 'maneaba' because it is commonly used and widely accepted.
} 
From observation, the role of te boti within te maneaba, extending back to our ancestors, in keeping te kainga, te kaawa and te abwamwakoro connected is very powerful and remains a unique part of the Kiribati identity. No matter where you go within and outside Kiribati, the concept of te maneaba as a place to embrace everyone and create a sense of belonging creates a bond amongst te kainga, te kaawa and te abwamwakoro, to support and look after the wellbeing of each other.

\subsubsection{Structure}

\section{Te inaki and te boti}

In te maneaba, te inaki and te boti are used interchangeably, but the real difference is that te inaki is a portion of the roof for each kainga. Te boti is passed on from the father to the sons. Traditionally, women do not inherit te boti because they depend on their father or husband's boti. Recently, women have been included in the division of te boti within each inaki. This means that they have more flexibility than men as they can sit either in their father, mother or husband's boti. The disadvantage of keeping more than one boti is that there are more maintenance responsibilites, e.g. you might be called upon for contributions in times of maneaba renovation. With the continuous migration from rural to urban areas, there are more spaces within certain inaki for members of te kainga remaining behind. There are also challenges in that those migrating to other islands or abroad may not be able to know their boti or inaki when they return, as information is passed on orally from the elders to the younger generation, with no documentation of the protocol.

Figure 2.2 shows the inner posts that support the roof of te maneaba, and where unimane sit within their boti during community meetings, feasts and other events. Behind unimane, boua ni kaua (young men) sit as observers with the view of taking over when their unimane are not able to participate in any meetings, or have passed away. In a conversation with a Kiribati Catholic priest (T. Tikoua, personal communication, August 28, 2019), he told me that the square in the middle of te maneaba is known as te nei ni kauatabakea (sacred space surrounded by tabakeauea), when unimane have a maungatabu (formal meeting). This space becomes a sacred space and no one is allowed to enter the space, including children. Only certain people such as waen te maneaba (an informant) who has a significant role to present te mweaka (gift) from visitors, or declares the names of people who have completed the required thatch or sitting mats during a roof renovation or the renewal of sitting mats 
is allowed to enter the space. In a conversation with T. Kautu (personal communication, August 28, 2019), he explained that te nei ni kauatabakea can become "te namo ni bure". This means that this sacred space can also be open to certain forms of social entertainment. For example, choirs or dancers are able to perform in the inner centre of te maneaba. "Symbolically, te mwaneaba provides a means for selfexpression and self definition through its building, maintenance and operation" (Whincup, 2009, p. 134). According to Uriam (2017, p. 18), it is affirmed that there are four sectons within te maneaba: there is the open square in the centre, known as te nei ni kauatabakea; the edge of the inner square along which unimane sit facing each other during meetings; behind them sit the rorobuaka, also known as boua ni kaua (young men); and finally the women and children. "So the maneaba was revered by Gilbertese, and all behaviour under its roof had to be seemly, decorous, and in strict conformity with custom, lest [te] maneaba be matauninga (offended) and the culprit maraia (accursed)" (Uriam, 2017, p. 18).

Figure 2.2: Photo of the inside of a maneaba (Taratabito).

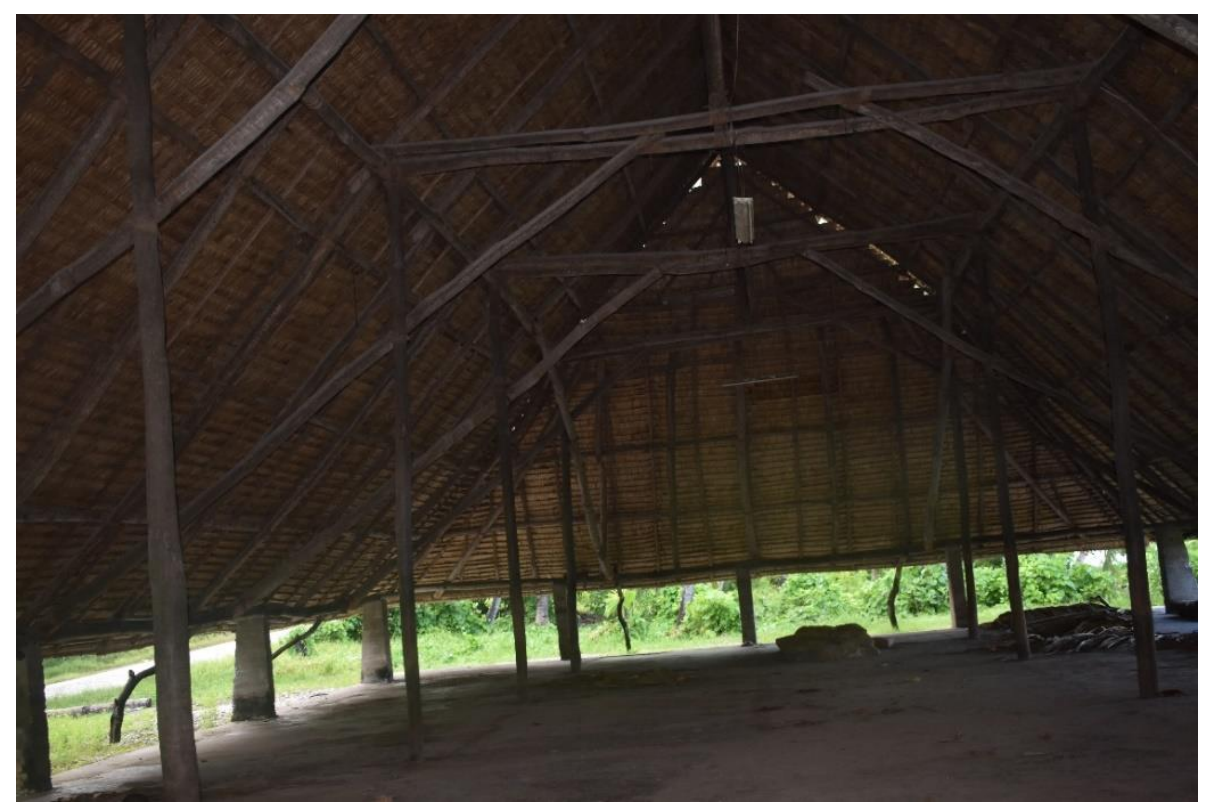

Source: Photograph taken by Rose Namoori-Sinclair on 15 June 2019.

As Maude (1961, p. 43) states, “[m]ost ceremonial meetings, however, were for all the boti in the maneaba, the principal ones being held: (1) on the laying of the ridgecapping; (2) when the first thatch was being cut; (3) when the first inai, or any fresh inai, was being laid; (4) when the maneaba was being re-thatched; (5) at the end of the pandanus harvest". Kazama (2015, p. 608) adds that the importance of the boti is also 
reflected in the ranking of boti as reflected in the order of speech or the organisations of programmes and activities in te maneaba. Each boti is also allocated different responsibilities such as mending of te maneaba; kabaraki (covering the ridge of the top roof), and koro burae (evening out the edge of leaves of the roof). In my conversation with family members, in the South Islands such as Tabiteuea where egalitarianism is practised, in times of important events, one can see that a hierarchy system or protocol must be followed. For example, during te tao inai (mat being laid or renewal of sitting mats) of te maneaba, which is an important event in the life of the people in the village, you cannot place mats in the appropriate boti, until te moanibwai (the first important person/family) has brought their mats to be placed by those responsible. The connectivity of te maneaba and spirituality allows such protocols and hierarchy to be followed. Another interesting custom relating to the preparation of mats is that women having their menstruation are not allowed to weave them. Men are involved in cutting the coconut leaves as it involves climbing a tree, while women lay them out in the sun for a day to make the leaves soft and easy to weave. The completion of te tao inai (mat replacement) or onean te rau (re-roofing) is celebrated with feasts and cultural performance - singing and dancing. In a conversation with a family member (T. Namoori, personal communication, June 15, 2006), she said that in the village of Tanaeang at the completion of one of these events during her childhood, she remembers that there were heaps of whales that landed on the white shores along the sea wall of Taratabito (the traditional maneaba - see Figure 3.1 above). Cressey (1998) provided similar accounts in other Kiribati islands as well as in other parts of Oceania. This shows that the traditional maneaba has a strong connection with power and spirituality. With the coming of Christianity, while the principles of te maneaba system remains practised until the present day, the calling of whales to mark these accomplishments are no longer practised.

\section{Bukarere (veranda)}

According to Whincup (2009, p. 137), te bukarere (veranda) refers to the "inner space of the mwaneaba of which the outer area is reserved for the village people" comprising women, children and other members of te kainga. It is a space for members of te kainga to sit and listen to unimane discussing and debating and making collective decisions for the wellbeing of te kainga, kaawa and abwamwakaro. Anything discussed behind the men is claimed as 'bururu ma beroro' (rumours and unofficial), unless the matter 
is formally discussed by te unimane who are under the roof, which is then claimed as official. To clarify how this works in real life, I will retell a story that was told to me by a family member (T. Namoori, personal communication, June 15,2006 ). It is a story about two men arguing within the bukarere of te maneaba. One of them made a complaint during the formal meeting to te unimane about the misconduct of the other man. The defendant stood up and said, "unimane, ngkai I tei ikai ao a rawaeaki au taeka man te taubuki, ao ngkana I taetae ikai, a raweaki au taeka irouia bururu ma beroro (Dear respected elders, when I talk here [under the roof], my words are recorded from the roof, but when I talk here [under the veranda], my words are not considered important)". In other words, what the defendant was trying to justify to unimane and the public was that anything discussed within a designated boti was significant and warranted unimane's decision, and anything discussed within the bukarere were considered rumours without any evidence to inform te unimane's decision.

\subsubsection{Role of te unimane}

In te maneaba, unimane represent the interests and needs of the people in the village. They have the authority to make decisions and their decisions are respected by everyone. In other words, unimane are perceived to be like parents who govern their families and villages on principles of fairness and collective decision making to ensure that the needs of their people are met. Their role is significant in the social, economic and political life of an I-Kiribati. At this level, whatever matters and decisions being discussed and made, are official and cannot be changed because they have been discussed under the roof of te maneaba. Formal discussion and decisions are conducted orally as written official documentation does not exist in the traditional Kiribati culture. To distinguish what is formal and non-formal in te maneaba system, everything that is discussed by unimane within a designated position within te boti, is considered official. This maneaba-unimane model is applied within te utu and te kainga, where a man is the head of the family and a woman has the subordinate role.

\subsubsection{Benefit of te maneaba}

Te maneaba is commonly used by members of te kainga and te kaawa to gather and plan for activities such as te kawawa (helping each other) involving digging the babai (giant taro) pit and cutting toddy. For example, on any specified week or month depending on the nature of the work, the group might dig a babai pit for one member, 
next they dig another member's babai pit until everyone has a completed babai pit and they are ready to plant their babai plants. It is a way of mobilising social capital, which maintains connectedness within te kainga and te kaawa, and empowering the people to work for a living. In doing this, te maneaba system facilitates sharing of skills and knowledge to members of te kainga, te kaawa and te abwamakoro, as depicted in Figure 2.3 under section 2.4.7.

Te maneaba is also a sacred place with a violence-free policy, where victims especially women seek shelter when they are in a vulnerable situation (Ministry of Social Development, 2015). As soon as the victim enters te maneaba, there is no more fighting. There is a traditional belief that if you do not obey unimane, parents and other people with authority, you will have bad luck.

\subsubsection{Local law and order}

Te maneaba is also comparable with a local traditional judiciary system controlled and run by unimane. Unimane have a significant role as local peace makers to address issues involving youth as well as women and children. For example, if there is a group of young people drinking alcohol and causing offence, the victim would report the perpetrator(s) to waen te maneaba whose role is to contact unimane proposing a bowi (meeting) to discuss such matters. Parents of the offending young people are informed and bring the offenders to te bowi. If the offence relates to sexual misconduct, such as night crawling or rape, which are taburoroko (forbidden, embarrassing and not culturally acceptable), the reported perpetrator is instructed to leave te kaawa by $6 \mathrm{pm}$. This is known as te aoa onoua (an intervention disciplinary action), which is still practised today as a way of preventing family violence. If the perpetrator remains in his house by 6pm, the assigned secret agency, a group of local men, would come and throw stones at the house to get the perpetrator out, and would finally burn the house down as the last attempt to get rid of him. Given the seriousness of the aoa onoua, in most cases, the perpetrator promptly leaves his house before $6 \mathrm{pm}$. No one should be able to identify members of the secret agency, only unimane. While te aoa onoua is against the human rights of an individual, the perpetrator has no power to report the matter to court, demonstrating that unimane are in control of the welfare of te kainga, te kaawa and te abwamwakoro. It also demonstrates that decisions by unimane are respected at the local level. Te aoa onoua has been found to be successful in the islands in the South for keeping peace within te kaawa. 


\subsubsection{Contemporary maneaba system}

Compared to new contemporary maneaba, "several traditional maneaba disappeared in the mid-2000s in Tabiteuea South. Some buildings were abandoned for nearly a decade without being mended" (Kazama, 2015, p. 608). This is common throughout the islands in Kiribati. Following colonisation, Christianity and the coming of whalers, traders and other foreigners, the principles of te maneaba system have remained the same, but with some changes such as the emergence of maneaba for churches, local councils, schools (Kazama, 2015, p. 608), the central hospital, abwamwakoro (members from different islands living on South Tarawa), people with disability and kainga. Te maneaba at the central hospital provides temporary accommodation for families travelling from the outer islands to accompany patients who require intensive care. This means that the government has recognised the value of te maneaba system and has integrated te maneaba principles in its healthcare strategic plan. The government also supported the establishment of te maneaba for each island on South Tarawa to provide temporary accommodation for people from those islands, e.g. teams from the outer islands, coming to participate in national biennial sports competitions on South Tarawa. The provision of temporary accommodation at these maneaba, helped relieve the burden on families living on South Tarawa.

These contemporary maneaba adopt the same principles of the traditional maneaba system of maintaining the unity of members, upholding the welfare of each other and giving them a sense of acknowledgement and belonging to a particular part of society. In these contemporary maneaba, such as the Church maneaba, the seating arrangements are still practised with men seated in the front, women seated at the back and children not supposed to run around in the middle of the maneaba. Since Kiribati gained its independence in 1979, young people taking leadership roles in politics, Churches, or government, despite their age and gender, have been allowed to talk with unimane in te maneaba (Tabokai, 1993). Whilst this was seen as a change in the traditional maneaba structure and system, it has not destroyed, but rather reinforced the values of te maneaba in the contemporary Kiribati society. This has given young people and women the opportunity to improve their confidence in public speaking and leadership. 


\subsubsection{Definition of kainga}

The definition of kainga is determined by te inaki. Underneath te inaki, the floor within te maneaba is subdivided into different boti for each family unit (Autio, 2010; I. Taatau, personal communication, June 6, 2018; B. Tebouaki, personal communication, June 5, 2018). The sitting arrangement within te maneaba indicates your immediate families (te utu), close and distant relatives, all of which comprise te kainga in the Kiribati context (I. Taatau, personal communication, June 6, 2018). In the outer islands where every $u t u$ has sufficient land, each $u t u$ has their own house. It is common that each household comprises a husband and wife, sons (and their wives if married), daughters and grandparents. On South Tarawa, where about half of the total population reside, land is scarce and housing is limited, so each household may comprise a husband and wife, and their children, aunts, uncles, cousins, grandparents and other fictive kin.

When it is time to renovate the roof of te maneaba, women from each inaki or kainga are responsible for preparing the materials including the thatch (made from pandanus leaves) and strings (made from the young coconut husks), and preparing food for the men involved in te maneaba renovation work. Men are responsible for cutting down the mature pandanus and coconut trees, and preparing the wood for renovating the roof. Thus, te maneaba has a significant role in connecting and reconnecting members of te inaki or kainga. The more members there are in the inaki, or kainga, the lighter is the workload. The workload is shared amongst family members.

\subsubsection{Kiribati cultural values}

Figure 2.3 depicts a wellbeing model that strengthens the configuration of individuals, te utu, kainga, kaawa and the abwamwakoro. The model also reflects the important role of the family in bridging the 'PAC gap', which is discussed in more detail in Chapters $4-7$. In what follows, I briefly describe what each core value of te maneaba system in the traditional setting means. All of the core values are interconnected to depict health and wellbeing. I will also explain in detail te karinerine (respect), which is one of the cultural values of te maneaba, how it relates to te tangira (love), and how each is applied. 
Figure 2.3: Te maneaba system and its core values.

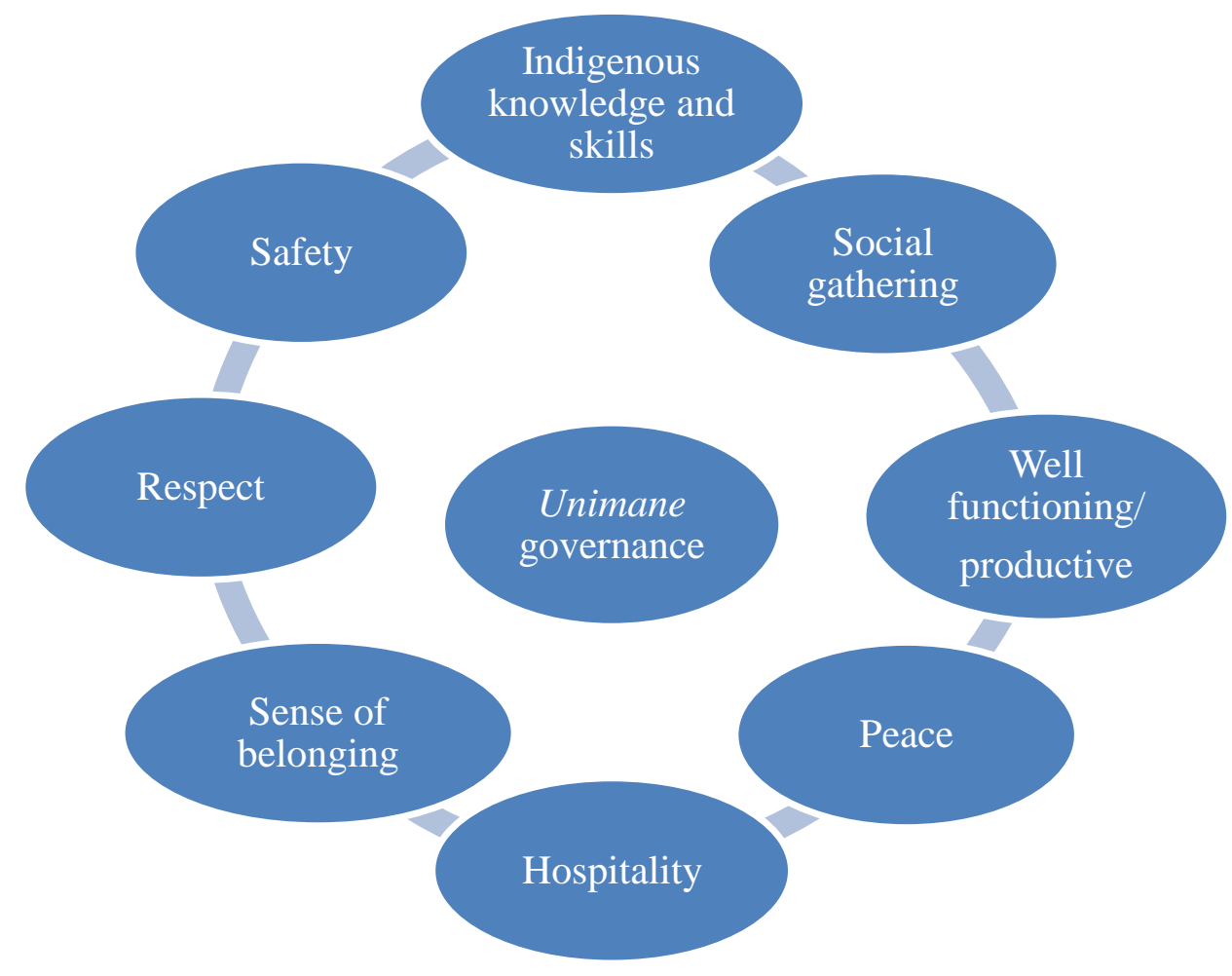

These core values of te maneaba system are interconnected and all lead to the health and wellbeing of I-Kiribati in the cultural setting. 'Health and wellbeing' is reflected in the Kiribati old saying of Te Mauri, Te Raoi ao Te Tabomoa (Health, Peace and Prosperity) as discussed in Chapter 1 . These core values of te maneaba system constitute and define our culture and identity, which we refer to as katei ni Kiribati. In this thesis, I argue that katei ni Kiribati are rooted in the maneaba system.

\section{Indigenous knowledge and skills}

The delivery of activities that each boti is allocated to do, such as changing the thatch roof of te maneaba known as te ono rau, and performing cultural songs and dance during ceremonies is one way of providing knowledge and skills. These are passed on to young people within each boti. Individuals who have traditional health skills are responsible for providing care to sick people from other boti.

\section{Safety}

Te maneaba provides a safe place for members to seek shelter during bad weather or if women experience any form of family violence (Ministry of Social Development, 2015). 


\section{Sense of belonging}

Each kainga is allocated $a$ boti, which gives everyone a sense of belonging without leaving anyone behind. Refer to Section 2.4.6 for futher discussion.

\section{Hospitality}

Te maneaba is a central place to welcome and show respect to visitors, especially people from other islands or from outside Kiribati. The welcoming ceremony is expressed in the form of dancing and singing, providing food and other hospitable entertainment.

\section{Peace}

As discussed in Section 2.4.4, when members cause trouble in the village, they are summoned to te maneaba to face appropriate forms of disciplinary action. Until now, these practices in te maneaba are still maintained as effective strategies to prevent crimes in the village.

\section{Well functioning and productive}

Knowledge and skills acquired from te boti within te maneaba build the capacity of members to become functional and productive known as toronibwai . In the traditional setting, someone who is toronibwai or inaomata has indigenous skills, such as the ability to build a traditional house, canoe, go fishing, work in the babai pit, and cut toddy without depending on others. These are essential for producing wealth for the family and other members of te kainga.

\section{Social gathering}

As discussed in Section 2.4.3 and also articulated by other interested researchers (e.g. Autio, 2010; Whincup, 2009), te maneaba in the Kiribati culture is a central place for everyone to gather and share their skills and knowledge, and celebrate their achievements in many ways. This supports the health and wellbeing of members.

The cultural values of te maneaba system, which give power and knowledge, have been circulated and applied to influence the governmentality of te utu, te kainga, te kaawa, communities and the rest of society. As explained in Section 2.4.1, under the traditional maneaba setting, unimane are the decision makers and women fulfil subordinate roles. Similarly, te maneaba system is also practised within the home where the parents act as unimane in that they make decisions for the health and wellbeing of the family, and children act as boua ni kaua to learn from their parents. 
In the following sections, I discuss other cultural values of te maneaba, namely te karinerine (respect) and te tangira (love). Te tangira is integrated throughout each of the core values of te maneaba.

\section{Te karinerine}

Parents teach their children from an early age to respect their elders. It is taburoroko (forbidden) for a child to answer back to someone older such as parents, older brothers and sisters, uncles, aunties, teachers and anyone with authority. To show respect, when someone with authority talks to you, you bow your head down or you remain silent. Like other Pacific cultures, being silent as a sign of respect also has other complex meanings (Hang, 2011; Singh, 2001), which need to be unpacked to elicit information from the Kiribati migrants coming to New Zealand under the PAC.

As part of te karinerine, I-Matang (foreigners or white people) or guests are considered special and treated with respect by the locals. This is known as te kakairua (hospitality - the way foreigners and guests are welcomed with respect). On my home island of Tabiteuea, when there is an irua (someone from another island or foreign country), the host family organises a welcome feast, which is called te boka ni wae (the washing of the feet).

In an email conversation (R. Ambo, personal communication, January 13, 2019), Fr Ambo explained that,

1. Te tebowae $\mathrm{n}$ te baibara (washing of the feet in the bible):

Washing of the feet in the bible emphasised the point of equality and unity among the disciples - meaning that no one is greater than the other. Each one is invited to wash each other's feet meaning we are to be servants unto one another. It is done within the Eucharist celebration (Last Supper) to highlight the willingness of the disciples to be broken for each other. It is shown by their willingness to wash one another's feet. The whole symbolism of this act of Jesus is about mutual and reciprocal stewardship. It begins with true and genuine humility.

2. Te tebowae irouia kain Tabiteuea Island (washing of the feet on Tabiteuea Island):

Ba are e bon ataaki ba kain Kiribati a rangi $n$ humble and welcoming people. Ma kain Tabiteue ${ }^{8}$ a rangi $n$ kan kinaaki man atongaki riki ba ngaia bon aomata aika a rangin kakairua ao $n$ aki anganga aoia $n$ taekan te kakairua (exemplary) They go the extra mile so to say, Ae

\footnotetext{
${ }^{8}$ In a recent conversation with a Kiribati priest (K. Kautu, personal communication, August 28, 2019), the island of Tabiteuea is also known as 'kieia ataei' (mats for children), which symbolises the kindness of the people from this island to foreigners who visit the island.
} 
ngaia naba kakawakin ae akea te irua ae e aki butimaeaki. - a kaota te sign of deepest acceptance, warmest welcome and utmost respect nakon aia irua are e roko i bataia.

Te symbolism and visual sign are a clean te feet ba a kaotiia ba a kamangoriia i matan te irua ba a teboka te kabanea ni mangori ao $n$ rinano iroun am irua ae waena are e bubu mani bareka. It is the lowering of oneself in front of the guest are e kawariko ni mwengam. which symbolises the lowering of oneself in the washing of the most humble and lowly part of one's guest -that of one's feet.

Kiribati people are known as as being humble and welcoming. The people from the island of Tabiteuea want to set a mark for being known as a welcoming place for guests and foreigners visiting their home, and take pride in being known as a place where they care so much for guests or people from outside the island coming to visit. Washing the guest's feet, the dirtiest part of the body is a symbolic and visual sign of humbleness to guests by lowering oneself in front of the guest who visits your home.

The above explanations for the 'washing of the feet' provided by Fr Ambo Ruatamaki demonstrate that the Church upholds the cultural values of te karinerine, te tangira and te akoi (kindness). The principle of the church of care and creating a sense of belonging by being invited to church services to celebrate the Eucharist, sharing peace with one another, and being encouraged to preach the good news, is about serving and caring for persons in most need. The classic example of the washing of the feet signifies Jesus' humbleness. The naming of this special welcome to our guests, signifies that people from Kiribati are also humble and respectful.

In some islands in the Northern Gilberts, they have certain practices to demonstrate the significance of te karinerine. In a conversation with another Kiribati community member (B. Chung, personal communication, February 10, 2019), she shared her experience of attending the traditional engagement celebration known as te karinrin. The boy was from Maiana Island and in their culture, when a boy and a girl are engaged, the boy's family welcomes the girl to his utu and kainga. To show their deep respect to the girl and her family, and more importantly their love for their son, nephew or a grandson, the boy's aunties wash and use their long hair to dry the feet of te otabwa (the fiancée) and her family accompanying her. In a similar conversation (W. Tekee, personal communication, January 20, 2019), Tekee shared her childhood experience of a formal engagement celebration, where she watched her aunties washing the feet of their niece's fiancé and members of her family, and then dried them with their long hair. This is why keeping Kiribati girls' hair long is significant because it has many 
purposes. The hair is also used to plait the belt for tying the dancing costumes around the boys' or men's waists. Another cultural practice in the Northern Gilberts is for te otabwa to be carried on the shoulder of her fiancé's uncles when she is welcomed to the boy's family. These stories demonstrate the deep respect for girls in the Kiribati culture.

\section{Te tangira}

Te tangira and te karinerine (respect) are interrelated. I-Kiribati people are loving, kind and caring. Te bubuti (request) is part and parcel of te karinerine and te tangira. It is critical in the Kiribati culture to put the needs of others at the centre before they attend to their own needs, even though they might have almost nothing. When a member of your kainga, puts forward a bubuti to you for something important, you are compelled to give. It is for this reason that some businesses close down in Kiribati because when there are special occasions such as weddings, birthdays, and funerals, concerned families bubuti food and buy on credit from grocery owners. If the shop owner is a member of te kainga, they will give the items for free, or be too shy to collect their debts. In other situations, when they have a visiting guest, they ensure there is abundant food and drink to ensure that their guest does not go hungry. It is paramount that the guest is well fed and gains weight before he or she leaves.

The key functions and principles of te maneaba are based on maintaining unity and peace within te utu, te kainga, te kaawa and te abwamwakoro. Te maneaba remains a symbol of the past, in the present and for the future (Tabokai, 1993). This means that the political significance of te maneaba system that is inherited from our ancestors continues today. This section on Kiribati cultural values demonstrates the strong moral economy of sharing family responsibilities that has implications for Kiribati families and communities in New Zealand, who are filling the 'PAC gap' by acting as an informal welfare agency in supporting PAC migrants.

In Kiribati, it is normal to marry young and live with parents. Some women may have not yet worked and others would have, but still live and follow the rules of their parents. While, it keeps te utu and te kainga strong and connected and delivers benefits for elder care, it does not give young couples the experience of living independently and being responsible for their own wellbeing. The other reason is that parents often do not will their property such as land, canoe and bwabwai (giant taro) pit to their children while they are alive. In the past, some parents could also punish any of their 
children who had been disrespectful or neglected them, by not giving them a share of their property, although with the introduction of Christianity and new laws, parents cannot do this anymore. It is thus expected that many successful PAC migrants have not experienced living on their own, and being responsible for their own wellbeing. The neoliberal notion of self-care therefore contradicts the Kiribati value of collectivism. This could explain why many of PAC migrants have struggled with New Zealand's way of life.

\subsection{CONCLUSION}

The governmentality concept provides an analytical framework to understand the forms of power, knowledge and values within the neoliberal and te maneaba political and economic systems, and how these have impacted on the health and wellbeing of PAC migrant women in meeting residency requirements. The governmentality conceptual framework was incorporated into the methodology of this research to inform te maroro (to tell a story, inform, talk, discuss - discussed in the next chapter) to understand Kiribati women's experiences under the two contrasting governmentalities. From a feminist perspective, governmentality is a useful tool to explain how most of the Kiribati women who have migrated to New Zealand under the PAC policy have negotiated their positionalities within the two contrasting political and societal systems. On one hand, women in a neoliberal society are encouraged to enter the labour market, but are still primarily responsible for producing and caring for children and the family. Under te maneaba governmentality, whilst women in the urban area are also encouraged to enter the workforce, they have members of the extended familiy to share the domestic role of looking after the children. The governmentality framework was incorporated throughout Chapters $4-8$ to identify the benefits and drawbacks of both the neoliberal and te maneaba governmentalities. The framework also helps identify and explain who amongst these Kiribati women were the most advantaged and disadvantaged in achieving their New Zealand permanent residency. 


\section{Chapter 3 Research methodology}

\subsection{INTRODUCTION}

This chapter explains the relevant literature that underpins the research methods applied to my thesis topic. My research involved understanding an in-depth experience of thirty (30) I-Kiribati women who came to New Zealand under the PAC. In its design, this thesis used qualitative research as a social science approach. Methodology refers to the philosophical reasons for the research and the rationale. Qualitative research is a design which involves the collection of a variety of empirical materials using different methods that include case studies, personal experience, ethnographic fieldwork, life stories, audio recorded interviews, review of official documents, artefacts, cultural texts, productions, observational, historical, interactional and visual texts (Denzin \& Lincoln, 2005; Hammersley, 2013). Qualitative research has the benefits of reaching the hard to research, and gaining a deep understanding of understudied populations (Maher \& Dertadian, 2018). Like other Pacific cultures, Kiribati culture is complex and requires indigenous research methods to deeply understand the Kiribati women's experience, culture and behaviour. Kiribati people in New Zealand are amongst the minority groups and under-studied population. The research focused on these goals:

- Assess the health experiences of PAC migrant women, using Kiribati women as a case study to comment on issues of responsibility;

- Explore personal and policy related aspects of healthcare that directly impact on these women, and how access to appropriate healthcare services for PAC migrant women can be facilitated.

\subsection{POSITIONALITY}

I was born on Tabiteuea Island, Kiribati. I left my parents at the age of 12 years to attend the Junior Catholic Secondary school on Abaiang Island. I attended the Senior Catholic Secondary school on North Tarawa. I completed my Form 6 at KGV/EBS on South Tarawa. I was then offered a scholarship to do a Bachelor's degree in Economics and Geography at University of the South Pacific in Fiji. After working for the Kiribati 
government for four years at the Ministry of Finance and Economic Planning, I was offered a scholarship to pursue a Master's degree in Economics at the University of New England in Australia. I returned to work for the Kiribati government for a further five years. I then went to work for the Secretariat of the Pacific Community in New Caledonia for three years, before migrating to New Zealand with my family at the end of 2001. I worked for the New Zealand government in various government departments. I also took on a part-time role at Kiribati's Ministry of Employment and Human Resources. My main role was to provide support to RSE Kiribati workers in New Zealand - that is, to advocate their needs to employers and the governments of Kiribati and New Zealand. I also worked on a voluntary basis as an active member and leader within the Kiribati community in Wellington and across New Zealand. My upbringing in Kiribati has cemented my knowledge of the Kiribati culture and language. In addition, my extensive engagements and work with the Kiribati community in New Zealand have driven me to pursue this research that will contribute to the health and wellbeing of not only Kiribati PAC migrants, but all Pacific immigrants especially those who are marginalised.

\subsection{INDIGENOUS METHODOLOGY}

Implicit in other indigenous research (e.g. Pe-Pua, 2006; Prescott, 2009; Smith, 2004; Tamasese, 2005) is the idea that mainstream social science methods have been inadequate for investigating or representing indigenous experiences of the world. Researchers (e.g. Sanga, 2004) argue that research for Pacific people by Pacific people removes language and cultural barriers and uses the indigenous knowledge systems of the Pacific. As Sanga (2004) puts it, research that does not incorporate Pacific thought or philosophy, especially when it comes to policy making will disadvantage Pacific people. The decolonisation project aims to unmask and deconstruct imperialism and colonialism and reclaim knowledge, language and culture. Pacific researchers are increasingly carrying out their research from the perspective of indigenous people as opposed to implicitly furthering colonial ideology and domination (Smith, 2004).

Suaalii-Sauni and Fulu-Aiolupotea (2014) argue that indigenous research involves using the right tools such as Talanoa and Faafeletui that are significant and appropriate for a Pacific indigenous community. Other indigenous research methods include Kakala (Thaman, 2007), Kaupapa Māori (Smith, 2004) and the Philippine pakapakapa (Pe-Pua, 2006) as cited in (Suaalii-Sauni \& Fulu-Aiolupotea, 2014). This 
demonstrates that there is no one size fits all for the different cultural groups, but rather each research method is suited to the needs of the people being studied.

Talanoa is an indigenous method proposed by indigenous scholars (Farrelly \& Nabobo-Baba, 2014; Halapua, 2008; Prescott, 2009; Suaalii-Sauni \& Fulu-Aiolupotea, 2014; Teaiwa, 2010; Vaioleti, 2006). It is a culturally appropriate Pacific research approach for gathering information from indigenous Pacific peoples about an experience affecting them and their lives in the modern context.

Vaioleti (2006) writes that Talanoa is a personal encounter where people story their issues, their realities and aspirations through a conversation, a talk and an exchange of ideas or thinking. Talanoa, in the Tongan language is translated as: "Tala means to inform, tell, relate and command, as well as to ask or apply. Noa means of any kind, ordinary, nothing in particular, purely imaginary or void" (Vaioleti, 2006, p. 23). Thus, Talanoa can either be a casual or formal conversation depending on the topic of discussion and who the listeners are. Vaioleti argues that Talanoa is a method that promotes the removal of the distance between researcher and participant, encouraging the building of a closer relationship at the outset, and providing the latter with a human face they can relate to (Vaioleti, 2006, p. 25). Prescott (2009) supports Vaioleti's claim that Talanoa can achieve the kind of building of trust and relationships between researchers and participants.

There is a similar tool in Kiribati that can be used to understand the Kiribati women's experiences, culture and behaviour. The word 'Te maroro' is consistent with Talanoa, where at least two or more people have the opportunity to tell or share a story about their personal experiences in a particular setting or context. 'Te maroro' is also similar to Talanoa in the sense that it is a tool used to remove barriers between a researcher and a participant, building trust and partnership, having an open and free communication, and developing a good relationship. For the purpose of my research, I have chosen te maroro as an indigenous research method.

\subsubsection{Why use te maroro research method?}

Te maroro creates an open and free environment for participants to share their personal experiences in addressing my research questions. By conducting te maroro in Kiribati, I removed language and cultural barriers and empowered the Kiribati PAC migrant women to openly share their stories. In Kiribati maroro situations, te maroro advocates 
understanding the importance of indirect speech. For example, while stating your point of view directly is appropriate for people from the Southern Gilbert islands, it is considered rude to others in some parts of the Northern and Central Gilbert Islands. Understanding this is important when carrying out a maroro session and how that session is then analysed. Having a good experience of the communication and language context of the Kiribati community is paramount when employing te maroro. In the Kiribati context, a maroro can take place in te maneaba in local villages, or te maneaba ni Maungatabu (house of representatives or parliament). A maroro can be conducted informally or formally, and is an effective means of communicating information to, or collecting information from the hard to research people, especially in villages. Similar to the philosophy of Talanoa and other indigenous research methods, te maroro is an open dialogue allowing people to talk from their hearts without any preconceptions. Talking from the heart leaves room for greater empathic understanding (Farrelly \& Nabobo-Baba, 2014). In addition, Suaalii-Sauni and FuluAiolupotea (2014) argue that having Pacific research methods helps to decolonise Pacific research through developing research tools that can more sensitively encourage meaningful discussions between researchers and participants. Wesley-Smith (1995) talks about how Pacific Studies are empowering Pacific peoples through the development of research approaches that represent their cultural values more appropriately. Teaiwa and Henderson (2009) affirmed this using an experience from a Pacific seminar in Porirua in 2001, when they acknowledged the importance of using indigenous Pacific languages to signal respect and allow Pacific people to engage.

Whilst it is vital to incorporate indigenous voices and cultural values, it is also important to incorporate non-Pacific approaches that support the ability to analyse issues and concerns of Pacific people. This will strengthen the methological position of this research. For example, in my research I want to acknowledge the significance of using a feminist lens for incorporating women's voices and perceptions in my research.

\subsection{FEMINIST LENS}

Using a feminist lens in this research, based on the principle of equity and elimination of inequality to empower women and improve their wellbeing (Woolley, 1993), helps me to question and challenge the PAC conditions that contribute to the Kiribati migrant 
women's disadvantages. There have been many debates about the applicability of the term 'feminism' in Pacific cultural settings. Pacific scholars note that feminism is perceived by some as "a discourse of white Western women that is really about their struggle to have equal status with white Western men" (Hall, 2009, p. 26). The 1987 Pacific women's workshop “Women, Development and Empowerment”, held in Suva, Fiji, had an objective to define feminism that would be meaningful and relevant to women's lives in the Pacific, and contribute to their activities and work (Griffen, 1989, p. 1). Participants were encouraged to talk about their realities in the Pacific, and to discuss what kind of collective dream about society that women wanted to see in the future. Before women could define feminism, they needed to learn to see realities through their eyes without depending on the views of other people. In this way, they would be able to dream of different ways of shaping and doing things to achieve their vision for themselves as women and people in a new Pacific (Griffen, 1989, p. 98). The aim of my research is to understand the kind of struggle that Kiribati PAC migrants have faced while settling in a new society. Whilst feminism is considered primarily a Western concept, there are some elements of the feminist approach that are useful for my research.

In the Kiribati culture, women have a key responsibility for the healthcare of the family. While more and more Kiribati women are engaged in the cash economy, they also have the challenge of taking on the extra load of being responsible for the healthcare of the family. However, with the support of the Kiribati extended family, the responsibility is shared, and women are supported in their jobs whether at work, community or home. In my research, I have personalised feminism to the Kiribati cultural setting of te karinerine (respect), kakawakin te aomata (respect for the right of the individual) and other significant values that recognise rights of Kiribati women in the traditional custom and culture, and the state to access good healthcare. In analysing the women's stories, I paused and thought of how the PAC articulates, disarticulates and rearticulates this responsibility for healthcare and wellbeing for these women and their families. I listened carefully to the women's stories to find empirical evidence of whether the state was responsible for the health and wellbeing of these women and their families, or the women were made self-responsible for their own healthcare and wellbeing needs. I also listened carefully to look for scenarios where the state helped because other women might have persistently asked for health and 
wellbeing support. It is critical that such support systems are in place, especially when Kiribati women have a key responsibility for the healthcare and wellbeing of their families.

\subsection{FEMINIST ORAL HISTORY}

I was particularly inspired to use the feminist oral history approach, which provides a voice for women who have limited opportunities to have their voices heard and histories recorded (Anderson \& Jack, 1991; Reinharz, Davidman, \& Conochie, 1992; Scanlon, 1993). Whilst I am not going to archive my participants' stories, I have used the oral history approach to complement my maroro approach. Anderson and Jack (1991) argue that feminist oral history researchers must attend more to the interviewees' needs rather than their own. In listening attentively to the interviewee, they must begin with the belief that she is the expert on her own experiences. Using the feminist oral history approach, women were encouraged to talk openly so the interviewer could understand their complex feelings and any contradictions behind their stories. This fits well with the philosophy of te maroro, which is not about the person facilitating te maroro, but the method which is designed for everyone to freely and openly share their stories.

Anderson and Jack (1991) articulate important elements of the feminist oral history method in research as an important source of providing rich information and insights about women's experiences or phenomena. I found these useful in guiding my research. Anderson and Jack (1991) highlighted lessons learnt that can help researchers with their interview techniques. One of the important lessons is that "if we want to know how women feel about their lives, then we have to allow them to talk about their feelings as well as their activities. If we see rich potential in the language people use in their daily activities, then we have to take advantage of the opportunity to let them tell us what their language means" (Anderson \& Jack, 1991, p. 15). This fits well with te maroro approach, which allows women to openly tell their stories, and when I saw potential information in their maroro, I had the chance to ask them to explain what they meant. For example, one of my participants experienced financial stress when her child was hospitalised and she was still on a visitor visa. I carefully encouraged her to openly discuss her story and I had the opportunity to ask questions when it was appropriate to uncover further issues. 
Anderson and Jack (1991) highlighted good lessons for researchers from oral interviews on depression among women and on moral reasoning among practicing lawyers. Firstly, the most difficult but important step is "to learn to listen in a new way, to hold in abeyance the theories that told me what to hear and how to interpret what these women had to say" (Anderson \& Jack, 1991, p. 18). This reminded me to listen attentively to my participants who are experts of their own experience, and help them to elicit their personal experience. Secondly, the interviewer also needs to attend to the subject's meta-statements, where people spontaneously pause and reflect on their own thoughts or what they have just said. This helped me to identify whether my participants had a rich story to tell, so I could encourage them to tell their story. Thirdly, it is important to listen and attend to the logic of the narrative in order to note or observe any consistency or inconsistency of the key themes in the women's statements. This is relevant to my research so that I could closely examine consistent or inconsistent messages behind the women's stories and the reasons for the inconsistencies.

As explained in Foucault's governmentality framework, the power and knowledge contained in a language within a society influence an individual's behaviour and action. As Cameron (1998, p. 3) pointed out, 'speech' and 'silence' have been powerful metaphors in feminist discourse. They are used to explore why women are denied the right or the opportunity to express themselves freely. It is further argued that a claim that women are 'silent' or 'silenced' does not mean that they lack the capacity to use the language to speak "which is the inalienable birthright of every human being" (Cameron, 1998, p. 3). In the culture they belong to, women have the linguistic activities to use the language, for example 'gossiping', writing letters or post cards to family members, and many more examples (Cameron, 1998, p. 3). My research aims to empower Kiribati PAC migrant women to have the opportunity to share their stories and voice their experiences and concerns.

The feminist oral history method complements my maroro indigenous research method. In these series of maroro sessions, I learnt to listen carefully to the women's stories to elicit important themes. As Reinharz et al. (1992) pointed out, most oral history feminists share a common goal of enabling women to speak for themselves. Interviews are valuable for uncovering women's perspectives, experiences, and other significant information. As a researcher, it is important to note that what the woman 
has to say during te maroro is respected and honoured. The feminist oral history method is appropriate for Pacific women, especially for Kiribati PAC migrant women, most of whom struggle to have their voices heard in their new society. The feminist oral history approach fulfilled this by assuring them that their stories were treated with respect and recorded using a secure password protected device so no one was able to access their personal information, except the researcher. The stories are a mixture of happiness, sadness, frustrations, homesickness, and personal achievements.

\subsection{TE MARORO AND FEMINIST ORAL HISTORY}

To collect and understand Kiribati PAC migrant women's health and wellbeing experiences, I employed te maroro and feminist oral history research methods. These approaches are relevant as generally, te mama (shyness) and te aki kakarongoa (silence) are common among Kiribati women. This does not mean that women have nothing to contribute, they obviously do, but it could possibly relate the values of te maneaba system as discussed in Chapter 2. Further discussion on te mama and te aki kakarongoa is presented in Chapter 6.

The lack of practice in using English in their day-to-day activities by most of these women and lack of understanding the New Zealand culture, put more pressure on these women. These are obvious in the women's stories in Chapters 4 to 7. Combining te maroro philosophy with feminist oral history offered a methodological approach that was culturally and gender sensitive to my research participants. The research approach addressed such cultural barriers, helped women become engaged, and elicited important information. This approach provided an open environment for women to share their stories that contained prominent information; it also meant acknowledging the importance of equality of voices of participants in my research. The feminist oral history fitted well with te maroro indigenous research method to form my overall research method called 'te maroro feminist oral history'. Using the feminist oral history method, I was able to make women feel that they were the experts of their own experience. This empowered these women to tell powerful stories that contain a mixture of feelings and emotions including pain, empathy, passion to thrive, relief and gratitude. Theobald (2014) argued that the feminist oral history method provides women from the margins with an opportunity to tell their stories and have their voices heard. This means that for me, the feminist oral history approach would result in delivery of rich information by empowering women to tell their stories. During my 
maroro with these women, after explaining the purpose of the research in our own language, they were empowered to tell their stories that would provide information for improving services that will benefit future migrants. This shows that they understood well the benefits of the research for future migrants from Kiribati and other eligible Pacific Islands. The feminist oral history method enabled me as researcher to listen and understand how these women interpret their experiences in navigating their way to New Zealand under the PAC.

As discussed earlier in this chapter, relevant Western theories are important to strengthen the ability to analyse issues and concerns of the Pacific people. In addition to the feminist oral history method, I want to acknowledge the significance of using a governmentality lens for understanding the power of society and how it contributes to the Kiribati women being disadvantaged when settling in New Zealand.

\subsection{THEMATIC ANALYSIS}

Thematic analysis refers to a process of processing data where you identify themes grounded in the data. In this research, I also used thematic analysis to identify patterns in the way my participants shared their stories and coded the common themes of their maroro. Researchers (e.g. Attride-Stirling, 2001; Smith \& Firth, 2011) note that thematic analysis is a widely used method for interpreting data collected through qualitative research such as in-depth interviews, focus groups, or any other field research work, and identifying themes or patterns within the data. The approach was relevant to this research as it involved te maroro with 30 Kiribati PAC migrant women and it was important that I identified key and consistent messages that were significant for my analysis.

To help me identify the themes or patterns, instead of manually doing this, I used NVivo software to code the data. NVivo is an effective way of going back to relevant parts of women's stories, which the researcher might like to quote. For example, one of the common messages from the participants was 'lack of government support'. I coded this as one code, and as I read through the translation, whenever I found these words in the women's stories, I highlighted it and put it in this code. This helped me when identifying women's quotes under 'lack of government support' to support my data analysis. I also employed articulation theory to be able to understand the complex experiences of these women, and the underlying causes of such issues. I wanted to 
know how and why some did not experience any challenges, while most women experienced many difficulties impacting on the healthcare and wellbeing of them and their children.

\subsection{ARTICULATION THEORY}

According to Slack (1996, p. 113), essentialism and reductionism result in ignoring important elements or contexts that may help the researcher better understand a problem, relationship, link, or phenomenon. Articulation theory, she argues, counters such reductionism: "Epistemologically, articulation is a way of thinking of the structures of what we know as a play of correspondences, non-correspondences and contradictions, as fragments in the constitutions of what we take to be unities" (Slack, 2006, p. 112). Another definition is that "articulation is the political connecting and disconnecting, the hooking and unhooking of elements - the series that any sociocultural ensemble that presents itself to us as a whole is actually a set of historical connections and disconnections" (Clifford, 2003, p. 45). Thus, the working definition of articulation theory is that it is an analytical tool to understand a problem, or societal formation, by identifying all its contributing elements and contexts.

In this thesis research, articulation theory helped me think through possible strategies for analysing primary data. Slack (2006) argues that articulation theory helps us to explore what a complex world entails, map out how it works and initiate new ideas to improve it. Slack (2006, p. 277) adds "[a]s Karl Marx has taught us, we make the world, but we do not do so under conditions of our own making. Thinking of the concept of articulation, we map the conditions we inherit as well as envision how we might move on from there". This concept helped me analyse how the socio-economic background of these women, and the political, economic, social and cultural conditions of Kiribati, might have created barriers for them to settle in a new environment. For example, in listening to women's experiences and challenges, I used the Kiribati, feminism and governmentality lenses to help me understand layers of information contributing to these women's issues and how these issues could be better managed. This also helped identify solutions that work best for the Kiribati PAC migrant women, the Kiribati families in New Zealand, and New Zealand government. The benefits will flow to other stakeholders such as Kiribati families in Kiribati and the government of Kiribati. 


\subsection{TARGET GROUPS: PAC STATUS AND RESIDENCE}

My research focused on Kiribati women with families coming to New Zealand under the PAC, because I was interested in exploring issues of family wellbeing, including access to health and maternal care for these families. I was interested in carrying out a maroro with Kiribati PAC migrant women who had recently arrived in New Zealand after being successfully selected in the pool draw, and/or successfully obtained their permanent residency under the PAC. This allowed me to gain an insight into differences in experience of recent Kiribati PAC migrant women compared with notso-recent Kiribati PAC migrant women. By comparing these experiences, I envisaged identifying whether there had been any changes or improvement in the conditions of the PAC policy and determining any further changes needed. Given time and cost constraints, I limited my maroro to women who live in Hamilton, Otaki, Levin, Paraparaumu, Porirua and Pukekohe. I did not include their partners in te maroro given that the primary purpose of the research related to the health experience of women themselves and as primary carers of children.

\subsection{PARTICIPANT RECRUITMENT}

Capitalising on my strong connection with the Kiribati community in Greater Wellington and the rest of the regions in New Zealand, I used community gatherings or events and existing contacts to approach potential participants. The Wellington Kiribati Community, which covers all I-Kiribati living in different areas of Greater Wellington, meet regularly through church activities or general community meetings. Verbal communication is the preferred option rather than written communication, e.g. email or text. For very important maroro such as for my research, the Kiribati people prefer to be properly asked in person, so they feel respected and valued, and more importantly, they understand the important nature of te maroro. If they know that you live far away, they prefer to be asked over the phone as opposed to email, messenger, or text.

I started arranging te maroro with women in Porirua by asking them in person when I could meet with them. Porirua is my previous home town where I lived for over nine years. It was very easy to organise te maroro with women in Porirua, Otaki, Paraparaumu and Levin. As an active member since 2002 of both the Wellington 
Kiribati Community and the Wellington Kiribati Catholic Community covering Greater Wellington, I have strong connections with the Kiribati people in these areas.

I applied snowball sampling (Atkinson \& Flint, 2001) in arranging my maroro with women in Pukekohe. This approach was effective in expanding my network for recruiting other research participants. It is a good option to apply in places where contacting many unknown people is difficult. Using this approach, I initially contacted someone in Pukekohe who I knew well back in Kiribati. She came to New Zealand under the PAC, so I asked her to invite five additional Kiribati women who also came under the PAC. When the six women confirmed their availability, I booked my flight from Wellington to Auckland to maroro with them for this research. Of these six women, it was the first time I had met four of them, and I already knew the other two. In arranging my maroro with the women in Hamilton, I asked a Kiribati friend from the South Island for a contact in Hamilton, who came under the PAC. It happened that I already knew this person, but I did not have her contact details. I asked her to identify five other women who also came to New Zealand under the PAC. Again, it happened that I already knew the other five women through my strong involvement with the Kiribati Community in New Zealand, and my lead role in the Kiribati Family Violence project $^{9}$. To address the biased aspect of my sampling, given that many of my participants were from my own networks, during te maroro I put on my research hat to listen to the significant messages in their stories, as detailed in the following section.

\footnotetext{
${ }^{9}$ This project involved the inaugural national bowi (meeting) of Kiribati leaders (a mix of young and elders) from the South Island, Wellington, Auckland and Hamilton, at the Ministry of Social Development's old Central Office at Bowen Street in February 2015. As facilitator of the workshop, contracted by the Ministry of Social Development, I could reflect on these leaders' wealth of indigenous knowledge and power on the Kiribati culture that underpins Kiribati wellbeing, and which they shared and agreed to be documented for the benefits of future generations. The other significant part of the project was that it gave me the privilege to work closely with my former primary supervisor, the late $\mathrm{Dr}$ Teresia Teaiwa, who was assigned responsibility as writer of this framework. This work laid the foundation for subsequent related work on the design of the three-year Maneaba Strategic Plan (for preventing family violence), for which I was contracted by the Ministry of Social Development to lead the development and implementation of in 2016. The project opened doors for me to further extend my network with other leaders from Hastings, Te Puke, and across Auckland districts such as Warkworth, Otahuhu, Pukekoe, Manurewa and Waitakere. This was critical for the endorsement and delivery of the MSAP based on Kiribati core values documented in the Kiribati conceptual framework. Realising the critical importance to preserve Kiribati social identity to enhance family wellbeing, many of the leaders involved in these projects agreed to set up a non-profit organisation named the Kiribati Federation Aotearoa in June 2018 (www.kiribatifederationaotearoa.co.nz).
} 


\subsection{MARORO}

I developed trust with my participants, not only because we speak the same language, but we were of the same gender, thus creating a safe and open environment for te maroro. I have the advantage that I understand te maneaba system; being an insiderresearcher I could understand my participants' stories. However, it was important that I put on my hat as a researcher with different lenses to be able to take some analytical distance. For example, the governmentality conceptual framework helped me understand how and why power under the PAC scheme has disadvantaged these women. In anticipation that some Kiribati people would feel uncomfortable providing personal information to their own people, I ensured that I provided a good introduction of how future migrants would benefit from sharing their experiences which justified my research. In Porirua, I had three maroro sessions with three participants in each group; in Otaki, one maroro session with two participants; in Levin, one maroro session with two participants; in Pukekohe: two maroro sessions with three participants in each group; and in Hamilton, two maroro sessions with three participants in each group. In Porirua, there was only one participant who chose to have a one-on-one maroro. In Paraparaumu, I had a one-on-one maroro with the participant, who did not mind being in a group with other participants but I could not fit her in with the other participants in Otaki, a closer town to Paraparaumu, because they were available at different times. In Levin, I had three one-on-one maroro sessions as none of these participants were available at the same time to form a group. These maroro sessions provided strong empirical evidence and perspectives relevant to my research questions around whose responsibility it is to ensure that PAC immigrants receive good healthcare services; how the PAC immigration policy articulates, disarticulates and reactivates responsibility for good healthcare for PAC migrants; and what health conditions they have experienced since they arrived in New Zealand.

Conducting te maroro in the Kiribati language, made all my participants comfortable taking part in the discussion. At the outset of each maroro, I asked one of the participants to say an opening prayer. The majority of I-Kiribati are practising Christians, so at every important meeting or occasion, we began with an opening prayer. Following the prayer, I greeted them and thanked them for making time for te maroro. Before we started te maroro, we went through the following important 
supplementary documents: (copies in both English and Kiribati are presented in Appendix B).

- $\quad$ Ethics approval

- Information sheet

- Consent form

- Confidentiality agreement

- $\quad$ Topic guide.

\subsubsection{Ethics approval}

Before going through the documents, I showed them a copy of the ethics approval letter for this research from the Standing Committee of the Ethics Human Committee $^{10}$. I explained that before I could collect personal information from the community, the committee must ensure that my application aligned with the human ethics policy. For example, I was going to use the right process and methods that are culturally appropriate to the community to which my participants belong. They also wanted to ensure that the research methods that I was going to use respect the cultural practices of the community to which my participants belong. This further built the women's trust and confidence in my thesis. I managed to complete my data collection by 30 November 2016 .

\subsubsection{Information sheet}

At the beginning of te maroro, I provided an information sheet to each participant, which explained the purpose of my research. I also provided a brief introduction about myself, and what made me interested in choosing this thesis topic. As part of the research process, I also explained that I would not use their real names, but I would ask them to either give me a code name or pseudonym, or I would allocate one to them. This ensured that anything they said was kept confidential so that no harm could come to them because of what they said. The information gathered will be analysed to identify gaps in the PAC process and policy for improvements to benefit future immigrants. Some asked me to choose a pseudonym for them, others selected their

\footnotetext{
${ }^{10}$ Ethics approval was granted on 8 November 2015 and the application number is 22105 (see Section B.1.1).
} 
own pseudonym. Some participants prefered English pseudonyms as these did not identify them further as in Kiribati, names have connections to families, making it difficult or impossible to choose a Kiribati pseudonym that neither identifies one's own family nor inadvertently implicates another family.

\subsubsection{Consent form}

I explained the purpose of the consent form to the participants, ensuring that they understood the process of te maroro and why they had to sign it. The Kiribati translation helped the women understand that their personal information was important. It allowed me to use it for the purpose of the research project. It also helped them understand that the information that they provided will not be used for any purposes other than those specified on the information sheet. I also sought their consent to audio-record te maroro for transcribing and taking notes at the same time if required.

\subsubsection{Confidentiality}

In addition, I went through the confidentiality form with the participants in te maroro group between me and two or three participants. The form was developed for the participants engaged in a group maroro. I explained that the purpose of this was to keep the information discussed during te maroro confidential, meaning that a participant's personal information is important, so whatever was discussed during te maroro should not be discussed with any other people outside this group. Each group participant understood and signed the confidentiality form. Community trust is very important. My strong connection with the Kiribati community in New Zealand had a significant impact on my research. Participants were comfortable with the way I explained the formality of the research, the purpose of signing consent and confidentiality forms, and my process of how I would password protect their information so that I could access the information. They trusted what I told them, and were comfortable signing the forms. This is one of the benefits of having a small Kiribati community, as we tend to know each other's background and activities.

Articulating this robust process and using the culturally appropriate approach, built the women's trust and confidence in my research. We continue to have a strong relationship and talk to each other as usual, whenever we meet during any Kiribati community gatherings. I did not experience any ethical issues. 


\subsubsection{Topic guide}

The topic guide covered the topic areas for our maroro session. I explored each topic area by probing what participants know or have experienced (refer to Section B.1.5 in the Appendix). I originally prepared the questions in the topic guide relating to migration from 2002 to the present, resettlement, work-life and health status. Te maroro approach was not structured, but the women's stories covered most of these topics. None of these women were selected in 2002. They were successfully selected in the period between 2004 and 2015. The research questions formed the evaluation criteria for reviewing policy documents and shaping te maroro sessions for research participants.

\subsection{RECORDING AND TRANSCRIBING}

Halcomb and Davidson (2006) argue that as the benefits of using verbatim transcriptions are accepted in healthcare research interviews as a means of data collection these are increasingly used for a wide range of purposes. As these women maroroakina their issues, perceptions, feelings, lived health experiences, realities and aspirations in the Kiribati language, I audio-recorded them using a dictaphone while taking notes at the same time, when necessary. Each focus maroro group took about one to one and one-half hours. The one-on-one maroro took about one-half to one hour. I only recorded the main part of te maroro around my main research questions. As part of the norm of setting up the data collection sessions, I did not record the introductory part. This part mainly involved informal discussion to build the relationship, going over the information sheet, the consent form, and the confidentiality form for te maroro focus group.

In listening to and transcribing the women's stories, I had the impression that these maroro sessions were an empowering experience for these women by having their voices heard, and to contribute to future academic research and government policies. In transcribing the recordings, I had to replay some recordings a number of times as some participants had low voices, some talked at the same time as others, some were laughing, and others were emotional. I captured everything they said, including the laughter and emotional expressions such as stress, disappointment, dissatisfaction, and loneliness. In some cases, when it was impossible to hear some of the things they said, I put a dotted line. As Bailey (2008) states it can be difficult to understand the recording 
because of the low volume, overlap in speech, and interfering noise. Transcribing can also involve close review and understanding of data through repeated listening, which is an important first step in data analysis. I transcribed the audio-recording verbatim and then provided the women with an opportunity to have a copy of their anonymised verbatim transcription in the Kiribati language. After each maroro, I wrote my own reflection, capturing sensitive issues and points where the participants became very emotional and what other participants had to say in relation to a particular point, which had made the participant emotional.

\subsection{CODING}

I typed all the transcripts and saved them separately under each focus maroro group or one-on-one maroro in Microsoft Word. Then, I created two new projects in NVivo named as maroro (focus groups) and maroro (one-on-one). I imported the transcript files from the folder where I stored all my data to the relevant projects in NVivo. I went through each transcript of women's stories and coded the common messages across the participants' stories, which needed interpretation and unpacking. I highlighted significant parts of the women's stories that told me about this person's experience when they first left Kiribati, or first arrived in New Zealand, or how they navigated their way to settle in New Zealand. I created the nodes and gave them names relevant to the highlighted text. I dragged the highlighted text to the relevant node. This helped me identify the patterns and key themes and sub-themes, that collectively tell us the interesting lives and experiences of the research participants. It also made my analysis easy, by clicking on the relevant nodes, and quoting the relevant texts that require unpacking to support the analysis of the women's stories.

\subsection{STORY-TELLING}

"Story-telling and story usage is a socially embedded, historically guided mapping of the subjectively organised world; yet it is of this world and therefore is guided by a constant interaction and interrogation of the social and the collective" (BönischBrednich, 2016, p. 7). In other words, story telling is a powerful tool to gather participants' narratives of how they interpret the world they are in. For example, the women who participated in my research had the choice of offering me their stories of how they first left Kiribati, arrived in New Zealand, and settled in New Zealand. "What kinds of stories a migrant shares and performs also depends on whether or not one is a 
good story-teller, or what is triggered by questions in an interview" (BönischBrednich, 2016, p. 10). Conducting te maroro in these women's first language, using te maroro approach appropriate in the Kiribati cultural setting, and having a good size sample of 30 , resulted in consistent themes in their stories.

\subsection{TRANSLATION}

I translated the quotes from the women's stories to English and inserted them in the text to support themes and sub-themes. In the Kiribati language, there are expressions that are difficult to translate into English. The meaning in Kiribati will not be the same in English when translated. In such cases, first I had to translate the expression word for word and then provide another alternative close meaning in English to help the reader have a good understanding of the context and what these women were talking about.

\subsection{SAMPLE SIZE AND PROFILE}

I managed to maroro with 30 Kiribati women: 6 were from Pukekohe, 6 from Hamilton, 10 from Porirua, 2 from Otaki, 1 from Paraparaumu, and 5 from Levin. I have summarised in the tables presented below the participants' profiles including age, educational qualifications, religion, marital status, the Kiribati islands they come from, the year they were selected under the PAC, the year they received their permanent residency, and their international exposure. These women were of varying age groups ranging from 21 to over 45 years.

Table 3-1: Level of education achieved by age group.

\begin{tabular}{|l|r|r|r|}
\hline \multirow{2}{*}{ Age } & \multicolumn{2}{|c|}{ Education } & \multirow{2}{*}{ Total } \\
\cline { 2 - 3 } & Secondary & Tertiary & \\
\hline $21-25$ & 5 & & 5 \\
$26-30$ & 0 & & 0 \\
$31-35$ & 8 & 1 & 9 \\
$36-40$ & 4 & & 4 \\
$41-45$ & 4 & 1 & 5 \\
Over & 4 & 3 & 7 \\
45 & 25 & 5 & 30 \\
\hline Total & & & \\
\hline
\end{tabular}


The level of education attained by the research participants is presented in Table 3-1. Five of the 30 women had achieved a tertiary qualification and the rest had completed at least Form 3 of secondary schooling. The latter is a target of the PAC policy. The five tertiary qualified women did not experience many challenges compared to the other women. Their education and socio-economic background possibly leveraged their capability to challenge or work around the Immigration New Zealand process, or worked independently with minimum support from Immigration New Zealand in achieving permanent residency.

Seven of the 30 participants had some international exposure through their university studies, or living abroad (see Table 3-2). Their international exposure may have helped develop their capability and confidence to process their permanent residency with limited difficulties, compared with many other women.

Table 3-2: Overseas experience by age group.

\begin{tabular}{|l|r|r|r|}
\hline \multirow{2}{*}{ Age } & \multicolumn{2}{|c|}{ Lived abroad } & \multirow{2}{*}{ Total } \\
\cline { 2 - 3 } & \multicolumn{1}{|c|}{ Yes } & No & \\
\hline $21-25$ & & 5 & 5 \\
$26-30$ & & 0 & 0 \\
$31-35$ & 3 & 6 & 9 \\
$36-40$ & & 3 & 3 \\
$41-45$ & 1 & 3 & 4 \\
Over & 3 & 6 & 9 \\
45 & 7 & 23 & 30 \\
\hline Total & & & \\
\hline
\end{tabular}

Table 3-3: Marital status by age group.

\begin{tabular}{|l|r|r|r|}
\hline \multirow{2}{*}{ Age } & \multicolumn{2}{|c|}{ Married } & \multirow{2}{*}{ Total } \\
\cline { 2 - 3 } & \multicolumn{1}{|c|}{ Yes } & \multicolumn{1}{|c|}{ No } & \\
\hline $21-25$ & 3 & 2 & 5 \\
$26-30$ & & & 0 \\
$31-35$ & 7 & 2 & 9 \\
$36-40$ & 3 & & 3 \\
$41-45$ & 4 & & 4 \\
Over & 9 & & 9 \\
45 & 26 & & 30 \\
\hline Total & & & \\
\hline
\end{tabular}


Table 3-3 shows that four out of the 30 women were single and 2 were married but had no children at the time. The rest were married and had children ranging from 1 to 9. Three of the single women did not experience many difficulties. They found it easy to obtain a job offer that met the required income threshold. Two of them were assisted by their families whereas the other one used her case manager for assistance. One of the four single woman faced many difficulties as she did not receive any help from neither Immigration New Zealand nor from any of her families. One of the women who had a large family, struggled to find a suitable job offer that met the income threshold.

Table 3-4: Participants' island of origin.

\begin{tabular}{|l|r|}
\hline \multicolumn{1}{|c|}{ Islands } & \multicolumn{1}{|c|}{ Total } \\
\hline Butaritari & 1 \\
Marakei & 3 \\
Abaiang & 2 \\
Tarawa & 4 \\
Abemama & 1 \\
Nonouti & 3 \\
Tabiteuea & 6 \\
Beru & 3 \\
Nikunau & 1 \\
Onotoa & 1 \\
Not stated & 5 \\
\hline Total & 30 \\
\hline
\end{tabular}

Whilst Table 3-4 shows that most of these women initially came from different islands, most of them lived and worked on South Tarawa before coming to New Zealand. While there is only one language spoken, people from different islands have different cultures, ways of working and thinking. Generally, the people from the South Gilbert Islands are characterised as serious, hardworking and straightforward, whereas people from the North Gilbert Islands are thought to be flexible, approachable, not serious, easy going and enjoy having fun. However, the people who have been working and living longer in Tarawa have blended in and exchanged values and cultures from the different islands. For example, in the Southern Gilbert islands, such as in Tabiteuea, te tangobwai (borrowing) is not part of the norm. People who often tangobwai (borrow) are considered lazy, do not work hard to earn money and buy their own things, but 
rather depend on others. In the Northern Gilbert Islands, te tangobwai is considered to be a sharing, which is an important part of their culture.

The 30 participants were successfully selected under the PAC in different years ranging from 2004 through to 2015 (see Table 3-5). I wanted to explore whether the women who were successfully selected under the PAC in earlier years had more or fewer problems than those who were successfully selected recently. For example, have there been any policy changes for improvement throughout the period $2004-2015$.

Table 3-5: Year participants were selected under the PAC.

\begin{tabular}{|l|r|}
\hline \multicolumn{1}{|c|}{ Year } & Total \\
\hline 2004 & 3 \\
2005 & 4 \\
2006 & 3 \\
2007 & 3 \\
2008 & 1 \\
2009 & 6 \\
2010 & 1 \\
2011 & 1 \\
2012 & 2 \\
2013 & 0 \\
2014 & 3 \\
2015 & 2 \\
Not & 1 \\
stated & 30 \\
\hline Total & \\
\hline
\end{tabular}

Table 3-6: Participants' religion.

\begin{tabular}{|l|r|}
\hline \multicolumn{1}{|c|}{ Religion } & \multicolumn{2}{|c|}{ Total } \\
\hline Catholic & 24 \\
Kiribati Protestant & 5 \\
Seventh-Day & 1 \\
Adventist & \\
\hline Total & 30 \\
\hline
\end{tabular}

Whilst it was not my intention to maroro with mainly Catholics, Table 3-6 shows that the majority of the participants were Catholics. In the previous chapter, it was reported that more than half of the Kiribati people in New Zealand identified themselves as Catholics. 


\subsection{GENERAL PROFILE OF MIGRANT WOMEN}

This section presents the general characters of my research participants as they emerged from my maroro with them in groups or on one-on-one. I selected 14 research participants, and name them as composite Woman 1,2,3,..14 and group them in different categories, according to the general characters that are common across the thirty research participants. Depending on these general characters, some experienced minor issues, others experienced some issues, whilst others experienced many problems. Since the Kiribati community is small and almost everyone knows each other, I prefer to use the composite characters of these women to present their general profiles rather than being specific about the profile of each participant.

Below I present the general profile of women under different key common characters common across the 30 participants.

- $\quad$ Respect for young girls

Woman 1 came from Tarawa, was aged between 21 and 25, and achieved secondary schooling in Kiribati. She was single and stayed with her uncle and his wife who had settled in New Zealand. They assisted her in finding a job offer. Being single, in the Kiribati culture, it is important that a girl lives with a male relative. Whilst arriving in New Zealand on a visitor visa, she only waited for less than three months before her permanent residency was approved.

- Proactive

Woman 2 came from Beru, but she was brought up on Tarawa. She was aged between 21 and 25, and achieved secondary schooling in Kiribati. She was married, but had no children. She stayed with relatives who assisted her in finding a job offer. She was unemployed before coming to New Zealand so she could not afford to pay for her airfare and other immediate expenses. She was smart and managed to get a loan from a businessman who knew that she would pay the money back when she found work in New Zealand.

The following composite characters are based on participants who had used the services of Immigration New Zealand effectively. They approached Immigration New Zealand by explaining their situations and how they needed help. They were provided 
with assistance with finding a job offer, which resulted in the timely approval of their permanent residence application.

- Education and international experience

Woman 3 came from Nonouti, but lived most of her life on Tarawa. She was aged above 45, and educated in Kiribati and the University of the South Pacific. She was married and had children. She and her husband had worked both in Kiribati and Fiji. She had some international travelling experience attending regional and global workshops and conferences prior to migrating to New Zealand. Her education and international work experience had given her capability to communicate her needs to Immigration New Zealand for assistance in finding a job offer. As a result, she obtained a job offer and started work the week after she arrived in New Zealand. She was granted permanent residency in less than three months, and had found a house before the rest of her family joined her. After obtaining permanent residency, she undertook some courses in New Zealand to be qualified for skilled jobs. At the time of our maroro, she had completed a course, which helped her secure a skilled job with one of the airlines.

- Socio-economic background and cross-cultural experience

Woman 4 was single and had one child. She was brought up and educated in the Solomon Islands and Kiribati. Both her parents were educated in Kiribati and Fiji, and held good jobs. Her socio-economic background and cross-cultural experience gave her the confidence and the capability to communicate her needs to the PAC staff in Kiribati for assistance in finding a job offer before coming to New Zealand. When she arrived in New Zealand, her job interviews were already arranged. She started work not long after she arrived in New Zealand. Her permanent residency was approved in less than three months. At the time of our maroro, she was about to complete her degree programme at one of New Zealand's universities. 
Presented below are composite characters of two women who were successful in challenging the PAC gaps. As a result, they were granted permanent residency at the right time.

- $\quad$ Self-responsibility

Woman 5 was aged above 45, educated in Kiribati, Australia and New Zealand, and had a good job in Kiribati. Her husband was educated in Fiji and Kiribati, and had overseas work experience. Her overseas education, work experience and skills had given her the confidence and capability to work independently to apply to many employers for a job. While the job offer she received had allowed her to gain a two-year work permit, her hourly wage rate did not meet the required income threshold for permanent residency. However, the work permit allowed her sufficient time to undertake a course to obtain registration with a professional organisation. When she received her professional registration, she presented it to Immigration New Zealand who granted her permanent residency as she was considered a skilled migrant.

\section{- Perseverance}

Woman 6 was aged between 31 and 35, and worked as a secondary school teacher in Kiribati for four years. Her father and grandfather were successful Kiribati businessmen. Her mother was a full-time housewife who looked after her and her six siblings. She was young when her father passed away, so her grandfather sent her and her siblings to attend a secondary school in Fiji. Coming from a wealthy business family, she could finance herself and her husband while processing their application with Immigration New Zealand in Fiji. They travelled back and forth between Fiji and New Zealand looking for a job offer. She had the perseverance to keep following up with her case manager until they were granted permanent residency.

Presented below are the composite characters of three women who did not experience any stress about getting a job offer, nor waiting in New Zealand on a visitor visa until the issue of the work permit or permanent residency was granted. 
- Waiting offshore

Woman 7 was aged above 45 and educated in Kiribati, New Zealand and Fiji. She had a good job in the Kiribati government before migrating to New Zealand. Her husband, the principal applicant, was educated in Kiribati and England. He was already working in New Zealand when he was successfully selected under the PAC. He already met the income threshold as one of the criteria for permanent residency. She was able to wait in Kiribati until the approval of their residency application was granted before travelling to New Zealand with her children on a oneway ticket. At the time of our maroro, she had completed her nursing degree with one of the tertiary education providers in New Zealand.

Woman 8 came from Beru, was aged between 31 and 35, and educated in Kiribati and Fiji. Her husband was the principal applicant. He was the only child in his family and both his parents worked for the Kiribati government. He came first to New Zealand on a visitor visa to look for a job offer, which allowed him to gain a work permit. Her mother was a hardworking and successful business woman. She and the children came later on a two-year work permit, so had no problem in finding work and accessing healthcare.

Woman 9 came from Marakei, was aged between 35 and 40, and attended secondary schooling in Kiribati. She was married and had three children. Being the youngest in the family, her three siblings, who had already settled in New Zealand supported her. In the Kiribati culture, the youngest is often spoilt and the older siblings are responsible for providing everything this person wants or needs. Her husband also had good connections with other Kiribati friends who helped him find a job offer.

Woman 9 was able to relax and remain in Kiribati with the children, whilst her husband and siblings arranged the processing of their residency application. When their application was granted, she and the children travelled on a one-way ticket to New Zealand. 
Below are composite characteristics of five women who struggled in pursuing permanent residency under the PAC.

Woman 10 came from Tabiteuea, was aged over 45, and had a large family. She found it difficult to get a suitable job offer that met the income threshold for a large family. She experienced health problems whilst in New Zealand, which could be attributed to a number of factors including financial stress and isolation from her children who remained in Kiribati. She did not receive any support from Immigration New Zealand regarding advice on potential employers to contact, or access affordable health service providers.

Woman 11 came from Marakei, was aged over 45. Upon arrival, she did not have the New Zealand work experience to match any of the jobs listed by Immigration New Zealand upon arrival. She and her husband had no idea about life in New Zealand. English was their second language and they lacked the communication skills to liaise with potential employers.

Woman 12 came from Tarawa, was aged between 41 and 45, and had a large family. Her husband was the principal applicant. He could have received help from other relatives in finding a suitable job offer. However, Kiribati culture restricted him from staying with other married male relatives. When they were granted work permits,

Woman 12 and her husband had to work odd and long hours including night shifts. This was necessary to meet the required income threshold and the family's needs. Consequently, they spent limited time with their children and often found it difficult to take their children to see a doctor when they were unwell.

Woman 13 was aged between 31 and 35, was pregnant whilst on a oneyear work permit, and could not afford to access publicly funded healthcare services. There was nobody to accompany her during health check-ups and ensure that she understood what her midwife had to say 
about the health of either herself or her baby. Whilst she spoke a fair amount of English, this did not mean that she had the health literacy to ensure she fully understood her midwife's advice and explanations.

Woman 14 was aged between 36 and 40, was on a one-year work permit with a limited budget, and she had no access to free healthcare. She could not afford to take her children early to a GP when they were unwell, which would have prevented the serious complications that arose later.

\subsection{CONCLUSION}

In my research, I found te maroro feminist oral history method a very powerful and effective way of encouraging women to share their experiences openly. It is for this reason that in my maroro with 30 Kiribati migrant women, the questions were unstructured, so the women shared their experiences openly. A clear overview of the purpose of the research, the availability of resources in both English and Kiribati, and te maroro being conducted in the Kiribati language removed any language and cultural barriers between the researcher and the participants. The women were able to express themselves clearly and openly.

One exciting highlight was that some participants who attended one of my maroro initially thought I was an I-Matang (European descent) because of my surname. My key contact, who recruited them for te maroro, had not informed them that I am an IKiribati because she wanted to see their reactions when they met me. Excitedly, these participants felt relieved when they found out that I am an I-Kiribati. We had a good laugh in sharing this joke before te maroro commenced. This demonstrates the significance of Pacific researchers for Pacific people conducting research in their own language, which added value to the quality of information. As experienced in my maroro with these women, some of which were conducted in small groups of two to three participants and others on one-on-one, the women were very open when telling their own story of their health and other experiences since arriving in New Zealand. Some of the participants became emotional as they reflected on their past challenging experiences of settling in New Zealand. I told them it is normal to cry, so I let them cry and gave them enough time to reflect and relax before continuing with te maroro. I also gave them the option of arranging another time to continue te maroro. All of 
them just wanted to continue and complete te maroro. On the other hand, there were also exciting and humorous experiences that had implications on the research findings. These will be reflected in the following chapters analysing results.

Coding the information collected from the 30 participants helped me trace how the PAC articulated or disarticulated the right or will (or lack thereof) of an individual Kiribati migrant or family. The story-telling tool helped me understand how and why some women experienced more challenges than others. The extent of issues these women had faced has strong connections with education, socio-economic background, culture and language skills, and network/friendships. Women who had worked previously, had international exposure, had strong family/friendship networks, and were fluent in speaking English did not experience many issues compared to those with lower education, little work experience, and no family/friendship networks. This highlighted the lack of a PAC workforce plan to cater for successful PAC migrants who had no idea about life in New Zealand, no work experience that matched work on Immigration New Zealand's jobs list, no family/friendship networks, or other means of support. The Kiribati women's stories have highlighted key themes and gaps in the current PAC policy.

The following chapters analyse the women's stories according to four key themes: i) lack of government support, ii) family dependency, iii) cultural barriers, and iv) risks of self-care and responsibility. Under each theme, there are sub-themes that are also the result of the women's stories. The results also explain what a desired residency model would look like for future PAC migrants, and what can be concluded from the outcome of the PAC on the Pacific women's health, using these women's experiences since they left Kiribati, arrived in New Zealand, and settled in New Zealand.

At the beginning of each of the following chapters, I have picked and presented the most suitable Kiribati PAC migration stories that best reflect the theme of each chapter. For the next chapter, I picked the story of a member of a host family who was not amongst the 30 research participants of my maroro. This person shares the perspectives of both the neoliberal and te maneaba systems. The host family's support resulted in good healthcare and wellbeing of the successful PAC applicant and their family. Whilst the research focus is to explore the health and wellbeing experiences of Kiribati PAC migrant women, the host family's story provides valuable 
contextualisation to the context of Kiribati PAC migrant women's stories to add value to the discussion. 


\section{Chapter 4 Differing world views: neoliberal and te maneaba systems}

Kiribati/New Zealand family (Teiti) living in New Zealand and assisting a PAC family ${ }^{11}$.

Teiti was born and raised in Kiribati, but migrated and has lived in New Zealand for eighteen years. She understands neoliberalism and the Kiribati maneaba systems and their values and ideologies. She had been assisting a couple who were successfully selected under the PAC in July 2018. Teiti also understands Immigration New Zealand's systems and processes, and New Zealand's working culture.

Bou had completed Form 6 in one of the Catholic secondary schools in Kiribati. He also completed Seafarer Training at Kiribati's Marine Training Centre before working for almost five years on international cargo ships. His wife, Nang, had also completed Form 6 in one of the Catholic secondary schools, and worked as an accounts clerk, and executive assistant in one of the Kiribati Government's corporations. Teiti assisted Bou, the principal applicant (whilst offshore), to connect with potential employers. Bou was able to communicate with these employers directly by email. As a result, Bou was successful in being offered a suitable job in his specialised trade while he was still in Kiribati. Being pressured by some of their peers in Kiribati, Bou and Nang had wanted to come to New Zealand on a visitor visa to apply for their permanent residency. Flying to New Zealand first to find a job offer has become the practice of most successful PAC applicants as soon as they are invited to apply for a permanent residency application. As they had two young children aged eight and three, Teiti was worried about the health risks to the children if they came to New Zealand on a visitor visa without health insurance. She advised Bou and Nang to submit their documents to Immigration New Zealand in Fiji and to

\footnotetext{
${ }^{11}$ This story came from a Kiribati family not interviewed from the research.
} 
remain in Kiribati until their residency application was processed. They took Teiti's advice and waited in Kiribati for almost three months after they submitted their permanent residency application. Finally, they were granted permanent residency, and were all able to travel to New Zealand on a one-way ticket.

Bou came first as he was the main breadwinner and wanted to get settled into his new job and be able to support Nang and the children when they came later. Two days after his arrival, he sat an exam to become registered and recognised by Maritime New Zealand. Teiti also accompanied him as a support person at the exam. After Bou had completed his exam, the examiner said to Teiti, "you must be proud of this guy, he passed the test, and he is now qualified to work on any vessels in New Zealand". Teiti asked the examiner about his English. The examiner said that it was much better than other people she had examined. This is not a surprise as he had met the PAC's minimum English requirement, completed his Marine training and had considerable experience working on international ships.

After arriving in New Zealand with the children, Nang wanted to look for part-time work. Teiti took her to two rest homes and a supermarket, and advised her to go and ask for an application form. In the Kiribati culture, Teiti could have done everything for Nang, but instead wanted her to gain the confidence to engage with employers, so she could be responsible for her own life and adapt quickly to the new culture and environment. Teiti knew that Nang had the basic communication skills, as she had completed Form six (equivalent to Year 12), and had previous work experience. Her lack of practice in speaking in English made her nervous as she feared making mistakes. Nang had no choice but to complete all the forms and wait for a call for an interview from any of the employers. She was invited for an interview, so Teiti coached her, emphasising that if she showed any sign of shyness, the employer would feel that she was not fit and confident for the job. Following her interviews with the three employers, Nang was offered all of these jobs, demonstrating that her level of English was not an issue. She had three 
choices to select from that suited her and her husband's schedules, which also worked around the needs of their children.

Whilst Teiti assisted this couple to get into the workforce, she encouraged them to be independent and self-confident when doing things that are important for their day-to-day needs. These included completing an IRD form, registering with a service provider for housing assistance and a local GP, and arranging for a driving instructor to take Nang for driving lessons. Working full-time, and having a family of her own, Teiti did not have the time to do everything for this couple. She initially made contacts with the providers, and let Bou and Nang do the rest on their own. This helped them build their confidence, networking and understanding New Zealand's way of life. Initially, Bou and Nang found it very difficult to be left on their own to meet with a GP, potential employers or a service provider. They later realised that the experience built their confidence. Some Kiribati people were surprised to see Nang driving in a very short time after arriving in New Zealand. Some mothers, who had been living in New Zealand for many years, would ask Nang to drive them to a shop because they were too frightened to drive. Through the help of a service provider, Nang and Bou were able to find their own house, which they moved into four months after arriving in New Zealand. Bou worked full time, and Nang worked parttime in order to care for the children.

This story demonstrates that Teiti has integrated the ideologies and principles of the neoliberalism and te maneaba systems, which resulted in the successful migration of Bou and Nang. If Teiti did not weave in the neoliberal notions of self-care and responsibility, Teiti and Bou would be highly dependent, unable to access health and social services, and lack the confidence to carry out their day-to-day activities. Instead, it resulted in the good healthcare and wellbeing of the couple and their children. 


\subsection{INTRODUCTION}

This chapter uses the governmentality conceptual framework to analyse and understand the shift in the art and science of government, or forms of power and rules within the Kiribati and New Zealand societies, and what 'lack of government support' means to Kiribati PAC migrants. Drawing on the differences to how individuals are governed in New Zealand and Kiribati societies is important. They help explain how and why Kiribati PAC migrants were affected by their differing world views of the two different forms of governmentality: te maneaba system and neoliberalism. The first part this chapter talks about pre-colonisation, the role of the Church, colonisation and modern government in Kiribati, and the forms of power within Kiribati society that shape the behaviour, attitude and characteristics of Kiribati people, which make them unique from people of other cultures. The second part talks about the shift in power and governing in New Zealand from the 1840s during European migration to New Zealand until the shift from welfarism to neoliberalism in the 1980s, which marks the rolling back of the state. The third part of the chapter discusses the participants' stories that demonstrate the impact of the differing forms of governmentality (neoliberalism and te maneaba system) on the health and wellbeing of Kiribati PAC migrant women. The results also articulate PAC policy gaps that directly impact on these women and how such gaps could be addressed.

\subsection{KIRIBATI SOCIETY}

In order to understand the problems migrants are facing when migrating from Kiribati, it is necessary to understand the history of governance in their home country. There are three main historical phases of systems of government in Kiribati: a pre-colonial or indigenous system, the British colonial rule system, and an independent republic system.

\subsubsection{Pre-colonial or indigenous system}

Prior to colonisation by the British, Kiribati was governed by two main types of traditional rule: te uea (kingship) system and the unimane system. The southern Gilbert Islands village system was centred around te maneaba structure, a very large sociopolitical structure, which embodies the whole of society: te kainga, the kaawa, and the abwamwakoro. This type of traditional leadership model is similar to the European family model in the $16^{\text {th }}$ century that no longer worked in the $17^{\text {th }}$ to $18^{\text {th }}$ centuries 
because population became the unit of analysis (Foucault, 1991). In Kiribati, the extended family model remains useful. Its benefits are discussed in Section 4.2.8. Whilst women do not have a traditional role in decision making in te maneaba system and the home, their support role for their husband has a significant influence in the decision-making process. There is a Kiribati saying that when someone is in power, the wife is the one who makes decisions, so arguably women are passive decision makers. Given this, when someone wants to approach the man for help, they have to gain his wife's approval before seeking help from her husband. This culture remains practised to date, and women are considered the gatekeepers of men's decisions. Thus women play a key part in influencing decision making. Their culture travels with them, as Kiribati people continue to migrate to New Zealand under the PAC, other migration schemes and as a result of crosscultural marriage.

On the other hand, the northern Gilbert Islands from Makin to Abemama were governed by the uea (kingship) system (Tebano, Barako, Auatabu, Kakau, \& Kiata, 2008). The governing body was made up of the families of the uea (the king), who provided leadership within the village and island. Butaritari is one of the islands in the north, which has the most fertile soil and high rainfalls (Office of Te Beretitenti \& T'Makei Services, 2012). It used to be called Makin Atoll by US forces during World War II, and where the Battle of Makin took place. Makin is a small island north of Butaritari and it is the northernmost point in the Gilbert Islands (refer to Figure 1.11).

On Makin and Butaritari one chief was recognised as paramount. The chiefly dynasty of Makin and Butaritari was consolidated under one Uea, the latest being Nauraura Nakoriri, [both] before and after the arrival of the British rule. The heads of the kainga were always consulted on matters affecting the community and could initiate action, but always they were obliged to seek the approval of the chief, who provided overall leadership and regulated relationships amongst the kainga (Tebano et al., 2008).

While this type of traditional governance system was controlled by the Chief for the welfare of the people in the atoll islands, the role of women as the main provider of healthcare to the elderly and children is the same across all the islands. Women do light work such as collecting shellfish in the lagoon and doing domestic work. Men do physically demanding jobs such as fishing in the deep ocean, and cutting 'toddy' which involves climbing a coconut tree. 


\subsubsection{Role of the Church}

The introduction of Christianity to Kiribati in 1852 resulted in some changes to Kiribati culture and traditions. As a practicing member of the Catholic faith community, I must admit that my analysis of the role of the Church may be influenced by my Christian beliefs. Christianity has contributed to the enhancement of family wellbeing. New Zealand Kiribati leaders in a working group reported that the Church has played a significant role in the life of people. For example, "the introduction of clothing and care for the body; the introduction of new knowledge and the establishment of schools; breaking the traditions of darkness, and bringing understanding of a wider world; teaching how to love one another, even as strangers" (Ministry of Social Development, 2015, p. 13). The Church also supports family wellbeing by empowering men as leaders in the home as opposed to dictating what women and children must do. Whilst te maneaba-unimane model is supposed to maintain peace and wellbeing for everyone within the home and society, such power has been abused by some, thus leading to the disempowerment of women and children and violence (Ministry of Social Development, 2015). This is not considered an acceptable cultural value, but bad behaviour that is caused by a number of factors. Unfortunately, this behaviour has passed on from one generation to another. Children, observing this behaviour, think it is normal for women to have no say. It is expected that many young people will continue the cycle. The role of the Church in promoting love and peace in the home is significant. It is also expected that Kiribati migrants still have this mindset of male dominance, which arguably could have an influence on some Kiribati women in adapting to the neoliberal notion of self-responsibility and being independent (Ministry of Social Development, 2015). The role of the Church in addressing power inequality that disadvantages women is paramount. Gillard and Dyson reported that participants including Kiribati migrants have confidence in Church services and support. The Church provides an alternative safe space to mainstream service providers for people who are afraid to be misdiagnosed or have language and financial barriers (Allen, Davey, \& Davey, 2010).

\subsubsection{British colonial rule}

Since British colonial rule in 1892, te unimane leadership based on te maneaba system has been used throughout north and south Kiribati. The traditional role of the kingship system had been "undermined significantly since 1922 when the colonial 
administration completely reorganised the land tenure system, taking households that had been dispersed as hamlets in the bush and lining them up in villages along a central thoroughfare" (Brewis, 1996, p. 11). Te uea system was abolished in 1963 under British colonial rule (Brewis, 1996). Brewis added that control over village and families moved to the heads of families who were mainly men. For example, "[t]he Council of Elders (unimane), comprised of all the senior family heads, is now responsible for overseeing village and island affairs, with the administrative posts provided by the Island Council under the umbrella of the central government" (Brewis, 1996, p. 11). Today men remain the dominant decision makers in te maneaba and in the home.

The Gilbert and Ellice Islands (now known as Kiribati and Tuvalu respectively) became a British Crown Colony in 1916. Other islands included in the Crown Colony in same year were Banaba (Ocean), Tabuaeran (Fanning Island), Teraina (Washington Island) and the Union Tokelau Islands. In 1919, Kiritimati (Christmas Island) was incorporated into the Crown Colony as well as the Phoenix Islands in 1937 (Trease, 1993, p. 5). The colonisation of Kiribati by the British as well as the influence of other I-Matang (foreigners) including missionaries, whalers, and traders brought changes to the islands. One of the major changes was the introduction by the British government of the position of the Island Magistrate. Being the representative of the colonial power, he was responsible for administrating Native Laws, and became a powerful figure in island political affairs (Trease, 1993). However, his influence on unimane was not strong enough to undermine the persistence of the traditional culture of Kiribati. Tabokai (1993, p. 24) explains that "in the maneaba the culture is looked after by the elders who know the traditions, the social norms and the habits that must be maintained for survival". Te maneaba politics allows everyone equal status and does not allow a minority group of speakers in te maneaba to dominate decisions for everyone (Tabokai, 1993). This means that all unimane will collectively make decisions.

The scattered nature of the islands and lack of centralised authority slowed the development of political changes. The indigenous people of Kiribati did not take particular interest in national issues until the 1950s (Trease, 1993). Possibly, the strong influence of te maneaba system had slowed developmental changes. The interim government was introduced in 1974 to allow some time and provide opportunity to 
test self-governance (Trease, 1993). As a result of these national interests, there were a series of development changes leading to the independence of Kiribati in 1979.

\subsubsection{A sovereign independent republic}

Since independence in 1979, the government of Kiribati has faced social, economic and political challenges. In 1979, phosphate mining on the island of Banaba, which was a large part of government revenue, ceased. This put huge financial pressure on the new government. This was a time of rapid urbanisation and with the newly achieved independence there were high expectations by the people, but because the government had only just started, the expectations outweighed the reality and capability (Trease, 1993). Kiribati was under the British colonial administration for 87 years, this meant that in 1979 the new government was still somewhat dependent on the British system for knowledge of how to govern themselves as an independent sovereign nation-state.

Ieremia Tabai, the first Kiribati President, announced in his keynote speech in September 1986, at the University of Papua New Guinea's $17^{\text {th }}$ Waigani Seminar that:

The harsh economic environment is compounded by our historical legacy. I do not want to sound critical here, but there is no way I cannot mention that the British during their eighty-seven years of colonial administration did very little for economic development. They left us with a very poor infrastructure and not a single viable industry. Perhaps the only thing of any real economic importance that they established with their friends Australia and New Zealand, was the phosphate industry. As we all realise, unfortunately too late, this was only geared towards supplying their farmers with cheap fertilisers. That, I am sure, must definitely qualify as an unethical type of development. The more unfortunate thing about it for us is that the industry came to an end in 1979, the same time we achieved independence. And with it came the end of an assured income for our people (Trease, 1993, p. 49).

To address the impact of the colonial administration on the lives of the Kiribati people, the new government's top priority was to achieve self-reliance. Ieremia Tabai's government removed the traditional colonial government by getting rid of the recurrent budget support, promoting the development of its marine and other resources, encouraging foreign business investments and controlling government expenditure (Trease, 1993). While the independent republican government was committed to supporting self-reliance and modernisation, they also maintained and respected the significant value of te maneaba system, which made the government remain in control and responsible for the wellbeing of the populace. For example, the government would 
take full responsibility for servicing the needs of its citizens by being the main employer and supplier of healthcare, housing and other social services. This created high dependency on the public sector. Given increasing population growth, rising unemployment rates, limited housing for employees on South Tarawa and other social needs, the extended family or te kainga plays an important role in meeting such needs. For example, providing accommodation for members without a home. Te kainga operates like an informal non-profit organisation that serves the needs of vulnerable individuals including children, the elderly, single men or women, and fictive kin. This is discussed further in Section 4.2.6.

The House of Parliament, which is the supreme authority in the state, is also known as te maneaba ni Maungatabu [Maunga (Mountain) and tabu (sacred)]. In Kiribati, the family model, which is the centre of te maneaba system remains strong and is an integral part of the Kiribati government's economic, social and political policies. Uakeia (2017, p. 125) adds that the "enduring paternalistic customs also influence voting practices when people view election as a means to further family or island communal welfare. Consequently, people are often tempted to elect those who are closely related to them or who have contributed largely to the village or island, rather than choose a candidate based on their education, merit, work experience or leadership credibility". This shows the strong power of te maneaba system as governmentality, which is the conduct of conduct, influencing the mindset, behaviour and actions of people. It continues to have a strong influence on the political system in Kiribati. This asserts that te maneaba system is family and community centred, and has influenced the minds of individuals that they are born to work for other people not for themselves. As discussed in Chapter 3, Foucault (1991) argues that the pre-modern family model was not able to respond to the problems of the new science of government. In te maneaba system, the role of pre-modern extended families continues to be important, which is the same for other Pacific countries (Fairbairn-Dunlop, 2005; Southwick, Kenealy, \& Ryan, 2012; Su'a, 2017; Suaalii, 2006). Based on the principles of te maneaba system, family remains the centre of everything in the life of its people. Uakeia (2017, p. 120) also argues that "the importance of te maneaba system can never be underestimated in the current Western political system because it represents the entire life of the community. Te maneaba system can effectively facilitate order and stability in the society, as well as the dissemination and implementation of government 
policies by the community". It is therefore crucial for any new government initiatives to be well understood by unimane in kaawa and abwamwakoro so they can inspire everyone to support the implementation of such initiatives.

\subsubsection{Kiribati public health, social wellbeing, civil society and economic systems}

Kiribati's public health system, administered by the Ministry of Health and Medical Services, comprises four hospitals that are supported by a primary healthcare network of health centres. Hospitals provide free healthcare for both Kiribati citizens. This will be further discussed in Chapter 7. The Government is the only provider of health services in Kiribati (United States Department of Labour's Bureau of International Labour Affairs, 2012).

According to United States Department of Labour's Bureau of International Labour Affairs (2012, p. 2), in 2012 the Kiribati government approved the Children, Young People, and Families Wellbeing Policy, which protects children from sexual exploitation and unsafe labour. The government also runs social programmes to prevent hazardous forms of child labour. The Ministry of Internal and Social Affairs operates a 24-hour service for children to report cases, request information or access services. The Ministry also produces a weekly radio programme and conducts workshops for community leaders to increase awareness of services that are provided to enhance family wellbeing. From these examples, it is apparent that the social wellbeing policies and programmes remain the key responsibilities of the government (United States Department of Labour's Bureau of International Labour Affairs, 2012).

In 1982, Aia Mwaea Ainen Kiribati (AMAK) was set up as a non-government organisation (NGO) to serve as a parent organisation for various Church affiliated women's groups (Governnment of Kiribati, 2005). In 2011, AMAK became an NGO that coordinates programmes for women's groups across the country. It operates under the leadership of the National Council of Women consisting of representatives from member women's groups. Aside from its coordination role for women's groups, it conducts research and training, formulates development strategies, establishes and maintains networks, and seeks assistance from both local and abroad for the wellbeing of members and their families (Volunteer Service Abroad, 2019a).

Being the major provider of employment, the Kiribati Government is not able to meet the job market demand (United States Department of Labour's Bureau of International 
Labour Affairs, 2012). As reported in Section 1.4.8, about 54 percent of young people between the ages 15 to 24 were unemployed because of limited job opportunities in the private sector. As illustrated in the discussion on the contemporary maneaba system in Section 2.4.5, despite the government's limited resources, some government institutions have integrated te maneaba system principles of embracing and caring in providing temporary accommodation for people from the outer islands accompanying very sick families to the hospital or teams attending national events on South Tarawa. Mrs Kabuati, Nursing Lecturer (personal communication, September 26, 2019), told me that based on her conversation with a senior official of the Ministry of Health and Medical Services, the Kiribati government had been instrumental in financing the construction of a maneaba for each of the islands in the Gilbert group. The purpose of establishing these maneaba was to provide a space for people from each island to gather and socialise, and enhance the wellbeing of Kiribati people. The Ministry of Health and Medical Services has been using this economic and social infrastructure to accommodate families accompanying sick patients from the outer islands as its existing maneaba is insufficient to provide the growing demand of patients and their families. The Kiribati government also considered the extension of the project to cater for the health and wellbeing of Kiribati people living on Kiritimati Island. Each maneaba will be built for people from different islands within the Line Islands and Phoenix Islands (see the map of Kiribati in Figure 1.11).

\subsubsection{Moral economy}

The strong power of te maneaba system cemented the role of te unimane and family model, centred on the wellbeing of te kainga, has remained intact until now, especially in the outer islands. The role of te kainga in the context of a moral economy demonstrates the value of te maneaba system in the lives of I-Kiribati. Like other Pacific nations, Kiribati is predominantly described as a moral economy (Bennett, 2017; Edelman, 2005) where members of te utu, te kainga and fictive kin depend on each other to uphold their wellbeing through many things, including exchange of certain skills and knowledge, healthcare, child and elderly care, financial support, social capital, and so on. This type of moral economy is demonstrated through the roles of te utu, te kainga and fictive kin. Within te utu children are taught to love and respect each other by putting the needs of others at the centre. If someone asks for financial or any other help (this is called te bubuti [request] system), it is shameful to reject the 
request even though you may have almost nothing for your own family. When discussing women's stories in Sections 4.4 to 4.8, empirical data shows that all of my research participants have capitalised on this cultural system to address financial constraints in different areas. Some had bubuti financial support from members of te kainga so they were able to travel to New Zealand. Some of them were not working before coming to New Zealand and were not able to meet the cost of their airfare to come to New Zealand, as well as the cost of health check ups in New Zealand. All of the successful PAC migrants have depended on te bubuti cultural value to be able to access suitable housing from their first arrival in New Zealand until they had a secure job and could afford their own house. No one could afford to rent their own place when they first arrived, so they had to stay with someone. The examples are included in the discussion in this chapter and the following chapters. In Kiribati we say "I a taona tabon inaim (I am sitting at the end of your mat)", or "I a bon tautaua waem natim ke tibum ae [atonga arana] (I am holding the leg of your child or grandchild [say the name of their special child or grandchild])". It is therefore shameful to reject te bubuti in the Kiribati culture. Te bubuti is mainly applied between siblings as well as members of the extended family, mainly to support each other during occasions and commitments such as weddings, funerals, school fees and now to support other successful PAC migrants. In the women's stories discussed in Chapters 4 to 7 , practising this in the home in their early years, there is often pressure on the eldest child to learn to be responsible for the wellbeing of the younger siblings, e.g. financing school fees of the younger children. In Kiribati, there is a free education system from primary school to form 3 at secondary school. School fees from Forms 4 to 7 are compulsory. It is common that the eldest siblings do not complete their secondary schooling as they have to leave school early to find work and earn money to be able to support their younger siblings. This is a classic example of how Kiribati people have been taught to forego opportunities for the good of others or put the needs of others first and foremost.

Strengthening family ties within te kainga is very important in the Kiribati society. As this is an important aspect of the life of I-Kiribati, I provide more details on how it is applied in practice to support the health and wellbeing of Kiribati people. It is unusual to see a couple with no children or living on their own. If they have no children, they are most likely to adopt a family's son or daughter (Whincup, 2009). Te kainga, 
typically comprises a husband and wife, and their children, aunts, uncles, cousins, grandparents and other fictive kin (a relationship involving individuals not related by blood or marriage). This continues to be true in the modern Kiribati society on South Tarawa, which is over-populated and features a shortage of housing and accommodation. In the outer islands, which are less populated, generally, in each household the extended family comprises a husband and wife, children, daughters-inlaw and grandparents.

It is normal for unemployed members living in the outer islands to bubuti affluent members of their family, especially those working in South Tarawa (the Capital) for any kind of support. For example, when any of their children pass to form 4, they request financial support to cover school fees for certain terms or until the completion of the child's secondary education. The responsible member is not only catering for the immediate family members, but other distant relatives who are also facing hardship. In exchange, the recipients provide te baintangira (gifts) in the form of local cultural foods and items from the islands [e.g. salted pork, dried fish, bwabwai (giant taro), processed toddy (syrup), mats, and coconut oil] to show their appreciation. They are not compelled to provide these. However, this culture of moral economy is a means of sharing resources and keeping the extended family in unity. The benefit is that when the giver is hosting a cultural event such as a wedding, the members of their kainga especially on the outer islands will supply cultural and other valuable items for the ceremony. It is culturally considered that the larger te kainga you have, the more power, prestige and influence you have. For example, if you were a community leader, and you have innovative initiatives to implement for the good of the community, when you have a large kainga supporting you, you have the power and resources to fulfil your ideas. Having a crowded house is culturally considered normal, and a happy kainga, compared to a home with a very small family. So, in Kiribati, keeping the extended family in unity is paramount.

Some members of te kainga are fictive kin, which results from some forms of significant relationship, for example, someone unrelated who voluntarily offers to look after someone else's child while the mother is working. Consequently, the parents of the child develop the relationship with the baby-sitter and ultimately count her as a member of te kainga, in exchange for the kind support she has offered to them. 
While there is a culture of sharing and helping each other, when it comes to indigenous knowledge and skills, it is generally difficult for anyone to pass these on to anyone outside the immediate family. Some families have inherited certain indigenous skills from their ancestors. The skills include constructing canoes and local houses, traditional healing (e.g. birth delivery, healing bone fractures), deep bottom fishing, and navigation. Within the nuclear family, the father only passes on such skills to their sons, not the daughters because they will marry and would pass it to their husband. In exceptional cases such knowledge and skills could be passed to someone outside the immediate family if two unrelated people or families have a strong relationship that have benefited each other. As a result, these people or families belong to each other's nuclear family and kainga.

For such highly specialised traditional skills, it requires a well respected form of bubuti to the person possessing such skills, and the gift in kind of high value to pay for the knowledge and skill. For example, if you bubuti (ask) the local midwife to provide treatment during pregnancy until birth, as reciprocal respect you offer your mid-wife a valuable gift in the form of cash, food, or other in-kind gifts. Because such skills are special and inherited from ancestors, and are a source of wealth for certain kainga, people possessing such indigenous skills have a lot of pride in sharing these. There is an old saying "I a kawakinna ba kan kuakuakiu" (I am only passing this indigenous knowledge to someone who will provide me with healthcare when I grow old). Nowadays, people say it as a joke, but it has a deep meaning especially if one thinks of how much it costs to put an old person in a rest home in New Zealand. It is very costly. The cost is compatible with the value of the Kiribati indigenous knowledge, hence Kiribati people possessing such skills cannot share it with anyone without expecting something valuable in exchange. The only disadvantage of this is that many of our ancestors have passed away without passing on the knowledge to the current generation. During my childhood, my mother provided healthcare to an old lady, the grandmother to her step-daughter. Caring and supporting the elderly can be a very demanding job, so someone who could do the job with a good heart should be well compensated. Before the old lady died, she offered a piece of land to my mother, although she did not expect it.

For the purpose of this thesis, I have provided a high level of explanation of the form of power within te kainga that shapes our cultural identity and makes I-Kiribati 
uniquely different from other cultures. The roles and benefits of te kainga in Kiribati, as well as in other parts of the world to uphold the wellbeing of I-Kiribati is paramount. Internal and international migration of people bring with them this cultural identity of love and respect.

\subsubsection{Rural to urban migration}

According to Connell (2010, p. 120), “[m]igration responds to real and perceived inequalities in socioeconomic opportunities, within and between states: primarily access to incomes but also education and health services. Expectations have risen over what constitutes a satisfactory lifestyle, a desirable occupation and a suitable mix of accessible services and amenities". Connell (2010) adds that domestic migration in atoll island states such as Tuvalu, Marshall Islands and Kiribati with limited development opportunities involves the movement of people from remote islands and isolated rural areas to urban areas. In Kiribati, there is continuous migration from rural to urban areas (the outer Islands to South Tarawa, refer to Figure 1.12). Despite some forms of development in education, health, agriculture and fisheries, there is increasing population and limited job opportunities in rural areas. This has an influence on internal migration within Kiribati, which makes members of te kainga in the urban areas feel responsible for helping relatives from the outer islands in terms of accommodation and finding work. During the 1970s and 1980s, there were five main secondary schools: Elaine Bernacchi and King George Fifth (the only government school); St Joseph's College (Catholic) in Tabwiroa on Abaiang island taking Forms 1 to 3; Taborio Immaculate Heart College (Catholic) in Taborio on North Tarawa island taking Forms 4 and 5; Hiram Bingham High School (Protestant) in Rongorongo on Beru; and Kauma Adventist High School (Seventh-Day Adventist) on Abemama Island. Recently, privately owned secondary schools, have been emerging, most of them providing for day pupils.

Although there are both public and private secondary schools being established in some of the outer islands, they do not meet the growing demand of a young population, wanting to further its education. As a result, young people continue to migrate to South Tarawa for educational opportunities. Parents of these children urgently require accommodation for them to attend secondary schools. Many secondary school and university leavers also continue to require accommodation on South Tarawa whilst looking for work. The Kiribati government is the main supplier of state houses, which 
most government staff can afford because the rents are subsidised. The private sector is small, and renting a private house is expensive. Only foreign aid funded staff, for example, can afford to pay the rent. The government's housing issue on South Tarawa is currently addressed by the extended family whereby members owning a house or renting government houses provide accommodation for others.

\subsubsection{Benefits of te kainga}

Migration from rural to urban is perceived as a serious problem in the eyes of economists, environmentalists, scientists, and health professionals. It contributes to high population growth in urban centres and exerts social, economic and environmental stress pressure (Bedford \& Bedford, 2010; Borovnik, 2009; Cole \& Parry, 1986). However, from the perspective of te maneaba system based on te kainga wellbeing model, it is not seen as a bad thing. Whilst it is observed that it is not easy for families on South Tarawa to accommodate families from the outer islands, culturally it is difficult not to provide accommodation for others when requested. Arguably, it supports the needs of workers on South Tarawa. Unemployed members provide care for children, elderly and sick family members, and do other domestic work. There are no daycare centres and rest homes, thus the role of te kainga is of great value particularly for working mothers. In the absence of te kainga and the social capital they provide, the mothers, who remain culturally responsible for children and elderly people's care, would not be able to advance their careers.

Based on stories of women participating in this thesis research, as will be discussed below, it was a real shock to them coming to New Zealand as they expected to live the same way as they had in Kiribati. As most of these PAC migrants did not work when they first arrived, these women were appreciative of the support of host families in providing cultural capital in the form of free temporary accommodation, food, utilities, healthcare, transport and other means of support.

Kiribati migrants successfully selected under the PAC scheme brought with them this unique cultural identity shaped by the power of the state, te maneaba, the church and te kainga to New Zealand. One of the main themes in my maroro with Kiribati migrant women was that the New Zealand government is not supportive of their needs. In the following section, I will discuss the differences of the culture of New Zealand society to be able to understand what 'lack of government support' means in the PAC context. As mentioned in Chapter 2, utilising a Foucauldian concept of governmentality helps 
make sense of the tactics of government as employed by agents of the New Zealand nation-state in its design and implementation of the PAC, and how they disadvantage the Kiribati PAC migrant women. The employment of te maroro/feminist oral history approach was complementary in uncovering women's health/personal experiences.

\subsection{NEW ZEALAND'S SOCIETY}

\subsubsection{Māori society prior to European contact}

There have been debates as to whether Māori ancestors came from Rarotonga in the Cook Islands or Raiatea in the Society Islands. However, the similarity of the place names and language suggests the link with both these islands (Royal, 2005a). It is believed that by 1300AD Polynesians travelled by waka (canoes) and settled in what is now called New Zealand (Royal, 2005a). New Zealand is also known to some of them as "Aotearoa (the Long Bright World)" (Belich, 2001, p. 15). Māori traditional culture is oral, and their tribal histories are rich with stories of indigenous knowledge and skills in warfare. They believed humans to be part of nature and have a sacred relationship with forests, sea and river (Royal, 2005a).

\subsubsection{From Colonisation to the Welfare state}

Europeans were the first group of people migrating to New Zealand following the arrival of the Dutch explorer, Abel Tasman in 1642, and later the British explorer, James Cook in 1769 (Royal, 2005b). Settlement emerged from 1825 after the arrival of other groups including whalers, merchants, and missionaries. Between 1839 and 1852, the total number of immigrants increased from about 2,000 to 28,000 (Royal, 2005b). In 1840, representatives of the Queen of England and over 500 Māori chiefs signed the Treaty of Waitangi (Royal, 2005b). The English version gave the British government the sovereignty over the people of the land, and the rights to settle in New Zealand. However, the Māori version guaranteed tino rangatiratanga or chieftainship of New Zealand to Māori. The debate over the differing versions of the Treaty continues today. As a consequence of this misleading treaty process, in the mid 1840s, violence over land broke out between Māori and Pākehā in both north of the South Island and the far north of the North Island. Māori sought to hold on to ownership of their land as they did not want to sell. In the 1860s, the conflict became more severe as more settlers, mostly British, were determined to acquire land from Māori. Between 1840 s and 1860 s, the conflict over sovereignty and land led to battles between 
government armed forces and Māori tribes. Consequently, Māori lost millions of acres of land through confiscation (Royal, 2005a).

The Liberal Government introduced in 1891 wellbeing initiatives including the old age pension and rights of women in New Zealand to vote in parliamentary elections. The liberals also introduced the Lands for Settlement Acts enabling the purchase of land for the development of viable farms and the economy. This created further conflicts between Māori and the British (Belich, 2001).

In 1935, a Labour Party, aimed at abolishing poverty and bringing in a high minimum wage rate, formed the first Labour government of 1935-49. The new government was a reaction to the "Wall Street Crash" (Belich, 2001, p. 254) that affected primary products exporting countries such as New Zealand. The 1938 Social Security Act, the state's "cradle to grave" welfare policy allowed citizens to access free healthcare, and increased the family allowance for unemployed, aged, single mothers and people with disabilities (Holmes, 2004).

\subsubsection{Shift from a Welfare State to Neoliberalism}

A welfare state is "a system that allows the government of a country to provide social services such as healthcare and unemployment benefits, to people who need them, paid for by taxes" (Cambridge Business English Dictionary, 2019). "The welfare state exists to enhance the welfare of people who $(a)$ are weak and vulnerable, largely by providing social care, $(b)$ are poor, largely through redistributive income transfers, or (c) are neither vulnerable nor poor, by organizing cash benefits to provide insurance and consumption smoothing, and by providing medical insurance and school education" (Barr, 2012, p. 8). It is interesting to find how the shift from welfare state to neoliberalism impacted on the health and healthcare of the Kiribati PAC migrant women.

In New Zealand, the 1980s and 1990s were an era of neoliberal economic reform, rolling back of welfare state activities and a new emphasis on market for provision of public goods and services (Haggerty, Campbell, \& Morris, 2009; Larner \& Craig, 2005). Kelsey (1993, p. 15) stated that the Muldoon government elected in 1975 had faced a serious economic crisis, and to lessen the burden, his government engaged heavily in overseas borrowing. This lessened the short-term impact of the first oil shock in 1973, but other factors such as Britain's commitment to the European 
Economic Community, high inflation and balance of payment deficits continued to put severe internal and international pressure on the New Zealand economy (Kelsey, 1993). Records show that from less than 3,000 registered unemployed in 1975, the number went up to almost 21,000 by 1981 . Despite the state intervention through economic policies such as tax write offs and subsidies, these were not effective to reduce unemployment and inflation. By 1984, the number on unemployment benefits reached the 50,000 mark. Liberal economists blamed state intervention as the cause of the decline in global state profits (Kelsey, 1993). "The blueprint for change required less government, the privatisation of state assets and businesses, increased economic efficiency, reduced public expenditure, and rolling back the welfare state" (Kelsey, 1993, p. 16).

Welfarism or a social wellbeing policy was blamed for not providing proper incentives for workers to work hard. The provision of wellbeing benefits, the high level of dependency on the public sector, and government subsidies did not support moves towards privatisation in the labour market. Social policies, for example a welfare scheme, that protects the wellbeing of people had to be reconciled with capital market policies (Kelsey, 1993). In the 1990s, "the ideological climate was conducive to proposals for a deregulated labour market" (Scott, 1997, p. 7). The neoliberal project, which began in 1984, involves, for example, removal or reduction in government subsidies and other public goods and services. It was supported by economic theories that claimed that the economy should operate freely without government intervention. It was understood that rolling back the state or reducing government intervention would increase self-determination through individual freedom and choice, free "from authoritarianism, socialism and economic mismanagement” (Scott, 1994, p. 5).

Another major restructure during this neoliberalism phase, constituted the Minister of Health Simon Upton's 1991 'Youth Health and the Public Health' (Prince, Kearns, \& Craig, 2006) policy. This led to the elimination of the 14 Area Health Boards (AHBs) and the creation of four Regional Health Authorities (RHAs) on a geographical population basis across New Zealand. RHAs had the responsibility to purchase health services for the populace in its region (Prince et al., 2006). The government had delegated its responsibility to the RHAs to manage government funding for the delivery of health services and ensure accessibility for the population. This was reducing the state function, the rationale being "less government is good government". 
Under this system, the government encouraged private healthcare providers to enrol with the RHA and compete for funding. While rolling back the state looks good for ensuring services are accessible to individuals, neoliberalist ideology, which drove these changes, gave individuals the option of selecting their providers and financing their own healthcare services (Prince et al., 2006). This shows that neoliberalism in this context is not favourable for less fortunate people on low incomes.

Larner (2000b) points out that Māori and Pacific people are over- represented in statistics as disadvantaged groups most likely to be lacking the attributes of active citizenship in a neoliberal environment. PAC migrants would be included in this population. For example, Larner (2000b) reports that hearing loss at school entry affects $13 \%$ of Māori children, $16 \%$ of Pacific children and $7 \%$ of other children. Researchers indicate that childhood hearing impairment can result in poor literacy and social communication, thus leading to economic and educational disadvantage (LeClair \& Saunders, 2019; Stevens et al., 2013). "Hearing loss impairs the elders' performance of daily life activities, and it may increase the risk for functional decline" (Kopper, Teixeira, \& Dorneles, 2009, p. 39). In this chapter, I discuss the differing world views of governing individuals in Kiribati and New Zealand, and the women's stories demonstrating how the two different systems (maneaba and neoliberalism) have disadvantaged them in their attempts to settle in New Zealand. Drawing from their experiences demonstrates what they would like a New Zealand residency model to look like, and why government support is vital for their successful settlement in New Zealand. Critique of neoliberalism provides me with a lens to argue for the need for more state responsibility to enable an economic system that puts more emphasis on family wellbeing and equity. Based on the critiques of neoliberalism (Kingfisher \& Goldsmith, 2001; Larner, 2000a, 2000b; Lemke, 2002; Murray \& Overton, 2011; Suaalii, 2006; Trnka \& Trundle, 2014), it is evident that neoliberalism is making wealthy people even wealthier and making disadvantaged people more vulnerable.

\subsection{MISMATCH OF CULTURES}

Understanding the two contrasting types of cultures and governing systemsneoliberal society and te maneaba system - helps explain how the former has become a barrier to Kiribati migrant women in settling well in New Zealand. Being the sole provider of social and economic services, the Kiribati Government, which very much aligns with te maneaba system has not prepared its citizens to be self-determining, 
self-responsible, productive citizens when migrating to New Zealand. However, te maneaba system as a form of governmentality has cultivated Kiribati cultural values of love and respect amongst Kiribati families in New Zealand. These families take the responsibility and cost of acting as a wellbeing agency for the PAC migrants. They assist most of the PAC migrant families in notable ways. These include securing a job offer, registering with a GP, financing health costs, and providing transport and language support when visiting GPs or other authorities. Considering the huge health costs incurred by most PAC migrants as presented in this chapter and in the following chapters, it is surprising that Immigration New Zealand is not encouraging migrants to buy health insurance on entering New Zealand. On the other hand, being a neoliberal state government, Immigration New Zealand expects the migrants to conform to its policies and be self-responsible for all of these aspects when they arrive in New Zealand. This reflects the New Zealand government's lack of understanding of the cultural needs of PAC migrants in terms of assistance in finding a suitable job offer. These are spelled out in the women's stories throughout Chapters 4 to 7 . The impact of the differing forms of governmentality (neoliberalism and te maneaba system) on the lives of the Kiribati PAC migrant women is demonstrated in the women's stories below.

\subsection{LACK OF SUPPORT FROM STAFF WITHIN IMMIGRATION NEW ZEALAND}

Most of the PAC women were mainly concerned with the 'lack of support' from Immigration New Zealand in helping them find a job offer. On the other hand, based on the core tenet of neoliberalism that promotes self-responsibility, Immigration New Zealand does not consider it their responsibility to find a suitable job offer for the successful PAC migrants. This is where one of the huge gaps has occurred between the two systems. Obtaining a job offer is a top priority for these women. With a job, they would earn income, and be able to meet their healthcare needs and support the wellbeing of the family. Interestingly, these women did not feel that finding accommodation, and looking for healthcare and other support services were a major problem. The host family who were either the aunties, siblings or other members of te kainga, or friends took care of these needs. Below are some of the shared stories by women, which show the gaps in the current PAC services from their cultural lens. An invitation, from the Kiribati cultural lens point of view, means that the host will 
provide everything. This is part of cultural respect and hospitality. Some women actually thought that the New Zealand government would do everything for them when they arrived in New Zealand. From the Kiribati cultural lens, it made sense because being new in a foreign country, with no network with potential employers, limited practical experience in speaking English and being unfamiliar with the accent, meant finding a job offer without the support from the government or anyone else would pose a significant challenge. I analyse the women's stories below under sub-themes: selfresponsibility, richness of te maneaba system, the desirability of a hybrid of neoliberalism and te maneaba system, and the desired residency model for the PAC.

\subsection{SELF-RESPONSIBILITY}

Julia was the only one amongst my participants who had worked independently to look for a job offer, with minimum support from Immigration New Zealand and other sources. In the following extract, she shares her story about how she managed to find work.

\section{Julia [selected in PAC ballot in 2005 and came to New Zealand towards the expiry of the offer]}

Eng ma are au makuri ngai ngkanne I a bon tekateka naba i aon te computer

I a bon kanakoi naba au CV ni kabane nakoia...(Tia kakae says mass production)...I a bon kanakoa nae ma ngkanne are I marenan taai ti a buti...au maman ti a nako moa n nora te country side are te country side ai te buti ba te cruise ti a nako n cruise around I tara te maunga iaa I rang fascinated by looking $n$ tarakin te raa te maunga I taku ngai e rang kamaeu taratarakina kee ngkai naba e rereke naba irou are ngkana I stress ao au maan ti a nako moa $n$ drive au maman te cruise ma are bon te kabitaia ngke ngai $n$ drive ai te kakarekea naba temanna ngkanne anne aron... (Ngke e karaki Julia, ao e ngarengare man n oti ae e a tia n tebenako man te kanganga).

I tekeraoi ngai...ngke I a tara te form arei iaa e nang bane ara tai ai ti teuana riki ara namakaina I a bon kawaekoa naba n tarebonia...nee ko aki moa kona n taona moa am leave ba I a bon rang kaawa n nang nako moa $n$ tii kakaea moa angan te form aio $n$ na kanoaia.... e na reke am job offer ma am raa ao I a manga oki, neiko ao I oki ao ko a manga nako $n$ leave ma e na kanga n leave raou arei ba are I a nakomai ao I a bon stuck naba ikai ba...are ai kakaeakin te makuri...I a rang stress I taku ngkanne ngke e manga reke au makuri e a manga kanganga are nang bon kitanna nae. (Ngke e karakina aio ao I kona n namakina te nibara man aki rau are e a tia $n$ rotia $n$ te tai arei).

Yes, what I did. I sat in front of my computer. I sent my CVs to many employers at a time...I sent them all, and during my breaks, I liked to go and see the countryside. We went cruising around, looking at the 
mountains. I was fascinated by the views and beauty of the mountains, even now I still do. When I felt stressed again, we went driving and cruising around. At the time I did not know how to drive. I had often asked someone... (When Julia told her story, she laughed with relief).

I was lucky...when I looked at the form, I had one more month left. I quickly rang "can you please postpone your leave. I urgently need your help, I am going to seek advice on how to complete this form, find a job offer and other requirements, and then come back. When I come back, then you can take your leave." When I came here, I was stuck...I kept looking for my work, I was very stressed. When I finally got my job, I could not leave just like that. (There were visible signs of stress when she told this story).

In her story, Julia repeatedly said, "I a rang stressed". She meant that she was very stressed. Stress is one of the contributing factors to poor health outcomes. Julia's situation was similar to that of composite Woman 5. However, the lack of a work permit or other means of support from Immigration New Zealand made it stressful to look for a job offer. Whenever she applied to one employer, she was asked if she had a work permit. When she went to see Immigration New Zealand, she was informed that she needed a job offer before she could be granted a work permit. She treated the job search as her full-time work. She would sit in front of her computer, search for jobs, complete her CV and applications for different jobs, and then send them to many employers. Finding the first job is very difficult for many new migrants, however it is less challenging when they already have a work permit or residence visa. Julia often took breaks to manage her stress by going for a drive and watching the beauty of New Zealand's countryside, which is green and mountainous. Coming from a country made up of low-lying coral atolls, New Zealand is geographically very different and a beautiful country to explore. While she was sight-seeing, she stopped and said;

Julia

... iaa an bon tarai moa maan akekei a butibuti aikai a kibakiba aikai ao are raou arei e taku, ba e aera, ti aki ai bon akea aia stress a bon roko naba n akea aia work permit. Akea nae aia visa a bon roko naba n free a kiba ni kangai a kiba ni kangai ao ngaira akea ba ti a kainnano $n$ kakaea ara work permit. (Ngke e karakina ana namakin ibukia manikiba ao e ngarengare ma n tara ni kukurei ba e a tokanikai).

...have a look at those birds flying around and my friend said "what's happened?" Look they have no stress, they come here with no work permit and visa. They are free and can fly anywhere, whereas we are struggling to pursue a work permit in order to work. (She talked about these birds with laughter and relief knowing she had triumphed). 
In admiring the freedom of birds to fly in and out, Julia demonstrated the biggest constraint of the PAC policy on their ability to meet the requirements for permanent residency. This demonstrates that the PAC policy has characteristics of neoliberalism of being self-responsible. It created stress that could potentially lead to other health issues. Through her perseverance and hard work, she finally found a job offer from one of the employers she applied to, and whom she believed was the answer to all her prayers. Similarly in other Pacific countries, Christianity has a strong influence in the spiritual lives of I-Kiribati, especially having a positive impact on their wellness (Linscott, Randolph, \& Mayle, 2016). Julia also said "eng e koaua are a ibuobuoki ikekei kee ma ngke ti a roko ikai ai bon te struggle teuana ba e a bon depend are, ngaia I kangai ngke e aki reke te aine are e rang ibuobuoki ao ngai irou e na rang kanganga naba reken au job". She explained that she was better supported in Kiribati by PAC staff probably because she had good contacts, especially when working for the government as she could easily make connections with staff from other government agencies. However, she struggled to find good contacts when she arrived in New Zealand. Migrants are very fortunate when they have a case manager who is supportive. This was also the case for composite Woman 3 and Woman 4. In Julia's case, she did not just pray and expected a job offer to be simply given, but she also worked very hard to find work.

Whilst Julia was able to get a two-year work permit, her income rate was below the minimum requirement needed to qualify her for permanent residency. Although she was well educated, she still acted out the Kiribati culture of shyness (te mama) that prevented her from asking her employer for a wage increase to match the PAC policy income requirement. Instead, she worked hard to get her registration with her professional organisation so she could apply for a skilled job and earn a higher income that met Immigration New Zealand's requirements. Fortunately, when her registration with a professional association was approved, she took a copy of this to Immigration New Zealand. Her case manager issued her permanent resident visa straight away as she had met the skilled migrant category's criteria.

Nickie also experienced difficulties coping with the neoliberal influenced PAC policy. She had a young child to take care of. She only completed her secondary education in Kiribati, and it was her first time living abroad. 


\section{Nickie [selected in PAC ballot in 2009 and came to New Zealand in the same year]}

e rang kanganga ibukin baai ake e tangirii te immigration, a bon tuangira ba ti na bon kakaai. Nanona nakai e bebete naia tai ao ngaira man 2009 ao riki ngkana iai natim ae uarereke e rang kanganga reken am makuri. (Ngke e karaki Nickie, ao ko kona n namakina te un inanona ni manga ururing rikaki).

It was very difficult to provide information required by Immigration New Zealand. They told us we have to find it. It means that these other Kiribati PAC migrants found it easy, but during our time since 2009, and especially when you had children, it was difficult to obtain a job offer. (I could feel her anger when she shared her story).

\section{Researcher}

Ma bon anne ae ko namakinna, iai te discrimination mairoun te employer ibukin ae iai natim ae uarereke.

Did you feel being discriminated by the employer because you had a young child?

Nickie

Eng kanga I bon namakinna ba are ngke I kaotia ae iai natiu ao e aki reke au makuri...ma are ti bon rang struggle ibukin kakaeakin te job offer. Ngaia are I a kataia ni kawaekoa raou arei ba e bon tiku imwiu. I a kataia ni kawaekoa ao e a roko teuana tabun te namakaina imwina.

Yes, I felt it because when I told them that I had a young child I did not get the job...so I really struggled to find a job offer. So, I quickly told my husband to come over. He came about one and a half months later.

\section{Researcher}

E aera ngkanne ngke ko a kawaekoa tera te benefit.

Why did you want him to come over and what was the benefit?

\section{Nickie}

Te benefit ngkanne are I a taraia ba are iai ai natiu ae makuri $n$ te tabo arei ao ana boss e kukurei ba e kona n makuri buu irouna ngaia are I a kawaekoa $n$ karokoa raou arei ao e a reke ngkanne angan ana job offer iroun te boss arei.

The benefit is that my nephew's boss said that he is happy for my husband to work with them, so I quickly invited my husband to come over, and he got the job offer from that boss.

\section{Researcher}

Ngaia anne are ko taku ba iai te evidence ba iai discrimination ba ko aki anganaki te job offer ibukin ae iai natim ao ngke e a roko kain abam ao e anganaki ana job offer.

Is that why you said you felt discriminated because you were not offered the job because of your child, and when your husband came, he was offered the job? 
Nickie

Eng e a bon anganaki naba.

Yes, he was offered the job straight away.

Below are quotes from two other women who had similar experiences.

\section{Teresia [arrived in New Zealand in 2011]}

Ti taboo a bon karokoira nae kain te PAC ao bon tabeia kain te PAC ba a na struggle $n$ kakai $n$ nakoia te nan employer (E banaa $\boldsymbol{n}$ uringaba ngke e karaki).

It appears that the PAC brings people here, and makes them take responsibility for liaising with employers even if they struggle (You could hear the loneliness in her voice as she said this).

\section{Julia}

...nanona a ibuobuoki eng e koaua are a ibuobuoki ikekei kee ma ngke ti a roko ikai ai bon te struggle teuana ba e a bon depend are, ngaia I kangai ngke e aki reke te aine (e nanona te tia kamakuri) are e rang ibuobuoki ao ngai irou e na rang kanganga naba reken au

...they were helpful there, but when we came here, it was a real struggle, as I said earlier if I did not meet that lady (she is referring to the employer), who was helpful, I may have also found it hard to get a job offer.

When Nickie said "ngkana iai natim ae uarereke e rang kanganga reken am mwakuri (when you have children, it was difficult to find a job offer)", this demonstrates the gender gap in the PAC. It does not cater for the needs of mothers with young children, who have arrived on a visitor visa. The need for the New Zealand government support for these mothers to find work and obtain their permanent residency is paramount. While daycare centres are accessible in New Zealand, Nickie was not eligible to access social services because she was on a visitor visa. It is evident from the Kiribati PAC migrant women's stories that some women were not aware of the visitor visa's conditions. As consistently said by these women, if only the PAC offer would entail a work permit, this would make life easier for all successful PAC applicants. This story articulates an area where te maneaba system and the neoliberal model cross paths and create hardship for both the successful PAC applicants and the families in New Zealand supporting them. Nickie had just arrived in New Zealand for the first time, so she was new to the environment, and she had no idea about who and how to contact an employer for work. Not only that, she had a child to look after, which made it more difficult for her. Nickie was disappointed to find out that Immigration New Zealand did not provide any assistance at all in finding work for her, but left applicants to provide everything that was required according to the criteria spelled out in the 
invitation letter. This raises a question about who is responsible for informing migrants of their situation prior to travel to New Zealand. Nickie realised that Immigration New Zealand's PAC policy, process and system of managing the applicants to get their permanent residency did not work for her. She had no one to help care for her child, nor a job in order to afford to send her child to a daycare centre. The family she stayed with all worked, no one was available to look after her child while she was looking for work. She finally invited her husband to come over and look for work. The fact that her husband found work immediately after he arrived demonstrated that the PAC technologies (process and systems) were not only culturally inappropriate, but also gender biased, especially for mothers with young children and who were on a visitors visa.

Lily and her husband were both unemployed before they came to New Zealand. They left their first and only child with their parents, and came on a visitor visa to process their permanent residency. From a perspective shaped by te maneaba governmentality, Lily also felt that the support from the New Zealand government was limited. She expected staff from Immigration New Zealand to provide more guidance and support in securing work, and directing her to where she could access essential services for their day-to-day living.

\section{Lily [arrived in New Zealand in 2009]}

...iai natira te mane ma ti katikua moa ibukin are ti na nakomai moa ni kakaea ara makuri. Ibukin are ti na kakaea ara makuri ngaia are ti aki kairia ba ai tiba 10 ana namakaina. (Ngke e karaki Lily, ao e oti ae e rotaki $n$ te uringaba ibukin uringan natina). Ao e tiku irouia ana karo are raou. Ai bon tiba moan natira. Ngke ti roko ikai ao ti maeka moa irouia ara koraki.

...we left our little son behind because we wanted to come first to look for a job offer. He was 10 months old. (Lily showed signs of loneliness and the longing to see her child when she told this story). He stayed with my husband's parents. He was our first born child. When we came, we lived with our relatives.

Ao ngke ti roko ao ti anganaki moa are teniua te namakaina ibukin te visitors' visa, ngaia ti aki moa kona ni makuri ti a bon tiku naba ni maeka irouia ara koraki. Ao inanon tikura are teniua te namakaina arei ao ai manga karinan ara... (Ko namakina ae e rang tei ni kakawa ngke e karaki).

And when we came, we were given a three-month visitor visa. We were not allowed to work, so we stayed with our relatives. Within the first three months, we applied for our work permit. (When she talked, I could feel how vulnerable she was at the time). 
Researcher

Ao iai ae e buoki ngkami ibukin ami job offer?

Did anyone help you find a job offer?

Lily

Akea a bon anganira naba ba ti na kakaea ara makuri

No, they left us to look for our own work.

Researcher

Ao kam bon titiraki?

Did you ask?

Lily

Ti bon tuangia ibukin are a anganira naba te due date ae ti na roko iai $n$ te tai arei...ti na karekei naba inanon teniua te namakaina. Ao ti a tuangia nako ara koraki. Kain te immigration a aki katauraoia nakoira a bon tuangira ba bon tabera. Ngkana e aki reke ao bon ara kanganga ngkanne. A ti tuangira ba ti na tuangia ngkana ti na extend ke e kanga. Ngaia ti tekeraoi ba e reke ara job offer i main te due date. Teuana te rest home. Ngaia ti a karinna naba ara bai ao ngke ti karinna ngkekei ao ti bon aitara ma te na ni kanganga ba are boona ma rana ba are ti a manga aki makuri ikai, akea ara mane are ti aki kariakaki ni makuri ikai ngaia ti bon roko ao ti a manga bon bubuti nako Kiribati ibukin boon karinakin ara bai, ara work permit. Ti a manga aki makuri $i$ Kiribati akea naba ara mane ae ti uotia ibukin karinakin ara bai.

We told them that we only had three months to provide everything that was required. So, we asked our relatives to help. Immigration did not provide one for us. They told us it was our own responsibility. If we did not get it, it was our own problem. They only told us that if we needed to extend the period, they were happy for us to ask them. So, we were lucky to get a job offer before the due date. One of them was the rest home. When submitting the documentation, we faced financial problems including the fees for the work permit. We were not working yet so we were unable to meet these costs. We had to request financial assistance from our families in Kiribati. We were not working in Kiribati so we did not bring any money with us to meet such costs.

E rin ara bai ao e otinako teuana te ririki te work permit ti anganaki inanon teuana te ririki ngaia inanon ara tai, ao ngai I a manga bikoukou ao e tuai tia ara bai inanon te one year arei kanga ti a raraoma ba are ngke e tuai tia ara bai ao e kanga arora ma te oo $n$ aoraki ti aki ata arona ba ti na nakea, I aki roko $n$ te nako $n$ tutuo iroun au midwife ba are I aki ata arona ao mwina e na kaboaki ke kanga ngaia kanga I maaku ni mena ngaia I a bon tiku naba inanon are I bikoukou ao I a tiba tutuo n au kawaniua ke au kaitiua.

After submitting our papers, we were granted a one-year work permit. During this time, I got pregnant. I was worried that we had not yet received approval for our permanent residency, and we were unsure if we were eligible for hospital services, and we did not know where to go 
to get help. I never visited a midwife as I was unsure if I had to pay so I never went for check-ups. I had my first check up in my eighth or seventh month.

Lily and her husband were the right candidates of the PAC policy for both New Zealand and Kiribati. They were young and unemployed before they came to New Zealand. The Kiribati government aims to find employment opportunities for the young population. New Zealand also benefitted as the PAC had attracted immigrants especially the young and productive group between 18 and 45 years to meet labour shortages (see Section 1.4.2). However, Lily had been disadvantaged by the contrasting governmentalities of te maneaba system and neoliberalisn. It is evident from the stories by Lily and many other participants that they did not receive general information about life in New Zealand. This raises a question about who is responsible for providing such information to PAC migrants. By not being well-informed about the way of life in New Zealand, she was unprepared for life in New Zealand as no one made sure that they understood what to do when they arrived in New Zealand. For example, they were unaware that there are financial costs when submitting their residency application. Having not worked previously, they were dependent on the support of their family, which is normal under te maneaba governmentality. Under the neoliberal governmentality, individuals are expected to be self-responsible for their welfare. This is a new idea to them as most of them are used to living with their extended family who provide support. Lily was challenged by the transition from a dependency world shaped by te maneaba system that is primarily based on a moral economy to an independent world shaped by the neoliberal notions of self-care and individualisation. She experienced hardship, feeling isolated and upset from the time they arrived in New Zealand until they received their permanent residency.

Reka experienced problems with the PAC staff in Kiribati. Interestingly, these were Kiribati staff, but they have to work in compliance with Immigration New Zealand's policies and processes.

\footnotetext{
Reka [selected in the PAC ballot in 2015 and arrived in New Zealand in the same year]

...ba ngkana ti nakoia ba a na kabarabara ara beba ao kanga a aki kan kabarabara raoi nakoira are ara aomata kanga aki rang service raoi a ti kangai nae "nakekei eng ba tara kam na riai ni kanoa te visitor visa ba kam aonga ni waekoa n roko ikekei ba kam na kakaea ami bai ae kainnanoaki”. (Ngke e karaki ao e oti ae e aki kukurei).
} 
...when we asked them to explain how to complete the form, they were uncooperative, our own people did not provide a good service. They only said, "you have to complete the visitor visa form so you can go to New Zealand and look for the required documentation". (She looked frustrated when she told this story).

Being so dependent on the state and kainga members, Reka was disappointed to learn that the Immigration New Zealand PAC processing team in Kiribati were not helpful. They expected her to complete her forms with minimal support. From Reka's cultural perspective, this was lack of support, which indicated a lack of respect. On the other hand, Immigration New Zealand was giving the individuals the choice, the responsibility to complete the form and accountability for providing their personal information. Immigration New Zealand uses the information to assess if applicants are eligible to become permanent residents of New Zealand. Being responsible for the completion of their application forms is what an individual is expected to do under neoliberalism. The state delegates responsibility to individuals to make informed choices. Whilst the residence application forms are simple to complete, many of these successful PAC applicants need help to complete them, because they fear making mistakes and consequently fear being rejected. As discussed earlier, New Zealand had gone through the changes from welfarism to a neoliberal state stressing selfresponsibility and free choice. Kiribati still remains under te maneaba system which is collective and each individual has the support of the extended family. This is what is being implied in Foucault's theory of governmentality, which is useful for understanding how the neoliberal PAC of individual responsibility creates hardship for the Kiribati migrants.

Norma experienced the same problem as Reka.

\section{Norma [arrived in New Zealand in 2013]}

Ti aki ataia ba ti okiokira Abarao a taku kain Abarao ba e aera arei ba te immigration are i Abarao are a mena $n$ te PAC ao a taku bon mai Biti bon mai $i$ Biti te kanganga anne ti aia taetaeka nakoira ma are ngaira ti aki kan mena ma ti a kakaea buokara... (E taraa $\boldsymbol{n}$ nanokawaki ngke e kakaraki).

We repeatedly visited Immigration New Zealand PAC staff in Abarao and they kept telling us that the problem is with the staff in Fiji. Eventually, we had to go elsewhere for help. So, we did not find the people in Abarao helpful... (She looked so unhappy when she told this story). 
Norma sought help from other offices. Like most of the PAC migrants they were disappointed by the way they had been treated as 'individuals' and expected to be selfresponsible. These women's misunderstanding of self-responsibility made them think that the PAC staff were unhelpful. These women were very upset with how the PAC staff treated them, as this behaviour is not culturally acceptable, and contradictory to how they had been governed in a society based on te maneaba system that puts the needs of others at the centre, or people before process.

Nickie, Lily and Reka's frustration with the PAC system aligns with the literature's critique of neoliberalism (Ludwig \& Stefanie, 2009; Repo, 2016). That is, it demonstrates the negative consequences of the shift of the state's responsibility to individuals and vulnerable women who also share the reponsibility of caring for their children. Based on the empirical material, the neoliberal PAC policy does not work well for women of a lower socio-economic background. Julia's experience demonstrated the complexity of the PAC's process, but her skills and qualification helped her adapt to the neoliberal-influenced PAC policy of being self-responsible for meeting the PAC requirements. Whilst she had no previous New Zealand work experience, she was able to transfer her overseas experience to the job that she applied for. Foucault's theory of governmentality as the 'conduct of conduct' or regulation of behaviours (Gordon, 1991; Lemke, 2002) helps to explain why Julia, with her experience and socio-economic background, was capable of finding work and could therefore meet the PAC requirements. Combined with the power and knowledge of te maneaba system in the form of being 'well functioning/productive' (te toronibwai) and respect that Julia has acquired from her culture, Julia's ability to adapt to the expectations of neoliberal governmentality made her successful in achieving permanent residency.

\subsection{RICHNESS OF TE MANEABA SYSTEM}

Ruuti also had the same feeling as Norma and Reka, claiming that the PAC staff in Kiribati were unhelpful.

\section{Ruuti [arrived in New Zealand in 2016]}

... I a karina au visa ao ngaia are e aki roroko ao I a manga ririannaia nako Abarao neiko I kona ni bubuti ba e tuai man... e a koro teuana tabun te namakaina a taku ba teuana te namakaina ao e roko am visa ao e a koro ngkai ao e tuai, e a kaokiokai ao iraua okiokiu (naake $i$ 
Abarao) ni karokoa e a roko Ritemba ao e a otinako mwina ao e aki bwaati. (Ngke e karaki ao e kaota te mata n nanokawaki).

...I submitted my visa application and I never received any response, so I kept visiting Abarao. I asked if I could follow up my application. It was over a month. They said it would take one month before I would receive my visa. I asked if it is already a month or not. She made me come a number of times to follow up. In December, my application was declined. (When she told this, you could hear in her voice that she felt vulnerable at the time).

New Zealand High Commission (NZHC) a kanakoa aia meeri nako Biti, anga arau ao e a managa roko boona ao a kangai ti aki tabera anne ba bon mairoun ana case officer ni karokoa I a manga karinna te kateniua n tai...e aki bara nanou ao akea boon au visa ao I a nako ni butia tariu ba e a un ngke buu e a kabane tai...ti na aki babara n nano...I a nako ni karinna ao e a manga aki naba roroko ni karokoa e a roko are moan Maati ao I a okiokira te NZHC...e tikiraoi ma ko nang karini am bai, kai akea au mane ba e a bane $n$ te kakantoka...ko nang karini am bai nako Biti ao I a taninga naba rokon au passport are e a tia $n$ titambanaki, ko nang nako ni karini ao n na karini n te raa kai ti aki ata te bai anne are te bank cheque, ko na nako $n$ post are am mane are boon PR tenga tabun ao e nang reke iara te mane anne ao e nang aki reke kantokau? Ma tii buokam anne iroura ngaia I aoki ao I tataro ao I korona I tia ni korona ao e online naba are ai natiu ae buuna te IMatang I a kanakoa naba au bubuti nakoina ko aki buokai I a bon boboa rangan tibum ibukin boon au PR ibukin nakomaiu ba I a rimwi ao ngkai akea kantokau ngkana I roko ikanne ao I a bon kabara au tarau iroum n nang karini au bai ba I aki kona ni kiba e a rimwi au visa.

I approached the New Zealand High Commission staff who sent a follow up email to Fiji on my behalf. They sent my name. They responded saying it is not their responsibility, and that it is the responsibility of the case officer. I re-applied a third time. I never gave up even when we had no money to meet the cost of my application. So, I asked my sister because my husband was angry saying it was a waste of time. I put in our application, but I still did not receive a response, so I went to the NHC again. I was told to submit my papers in Fiji and wait there until approval is granted. I asked them how can I submit my residency application as I have no money. It costs over $\$ 1000$ to pay for the Permanent Residency. Where am I going to get money for my airfare? That is all we can suggest. I went back and prayed the rosary. Then my niece married to a Palangi was online. I sent her a request, can you please help me? I am holding your grandson's legs. Can you please send me money for my PR? It is nearly due, and I also have no money to meet the cost of my airfare to New Zealand. I will pay you back. I need to submit my papers before the due date.

Ruuti was frustrated for two main reasons, firstly the lack of support from the PAC staff in Abarao and the financial constraint in meeting the cost of the airfare to New Zealand and the application fees. She almost did not make it to New Zealand. 
However, her family living abroad supported her financially. Without their support, Ruuti would not have gained New Zealand permanent residency. Ruuti's story articulates the Kiribati value system, that is te bubuti, and the support of the extended family, which had been an enabler in supporting her in attaining her permanent residency. Fairbairn-Dunlop (2005, p. 67) provides examples where "Pacific women were using their family systems to encourage and enhance economic development options". As Fairbairn-Dunlop (2005, p. 68) stated, Aggie Grey’s Samoa, a well known hotel in the South Pacific, demonstrates that an indigenous business enterprise can work by capitalising on the values of an extended family model. Aggie used the indigenous cultural knowledge based on the family system in leading and growing the business. For example, Aggie treated her staff as members of her own extended family and when they had special needs, she was generous.

May had also used te bubuti system to finance her travel cost to get to New Zealand, without which, she would have missed out on the PAC opportunity to achieve residency.

\section{May [arrived in New Zealand in 2015] \\ I nako ni kakaea buokau iroun te business man e a reke iroun te business man buokakiu irouna I a bon aki mama ibukin ae n na manga bon kabara au tarau ngaia I a bon mananga nakon te business man e a butimaeai ibukina ba e bongana ibukiu e ataia ae bon akea au makuri e a support kantokau n nako ao $n$ oki in case ngkana iai au kanganga ba e aki tia au PR ke au raa au visa e aki rinanoaki.}

I went to seek help from a businessman. I was not shy because I knew I would pay him back. I went to see the businessman who was willing to help because he knew that I was not working. He financed my return airfare in case my permanent residence visa was not approved.

Both Ruuti and May's stories articulate the richness of te bubuti system as a form of power and knowledge of te maneaba governmentality in patching holes created by the neoliberal PAC policy. The phase 'I a boboa rangan natim' ('I am tapping your child's leg', meaning I humbly request) is very powerful. As soon as someone says it, it is shameful to refuse. The stories indictate that no matter where you live, or even when you are not related by blood, Kiribati people are still connected to their homeland and people. This is the whole meaning of te maneaba - connecting Kiribati people to their roots. In the next set of stories, the women articulate the constraints of neoliberalism which shows the need for a hybrid of neoliberal and te maneaba model. What and how this model could look like will be discussed below. 


\subsection{MORE STATE RESPONSILIBITY}

Most of my participants had consistently recommended more state responsibility to provide the necessary support to successful PAC migrants in settling well in New Zealand. Their recommendations were based on what they had experienced, and they would like to see that the new migrants do not go through the same challenges they went through.

\section{Nickie}

E raoiroi naba $n$ reke te agent mai I-Kiribati are taan karaoa te seasonal worker, e na riai naba ni karaoaki temanna mai I-Kiribati ae kanga e na tabe ibukia, kakaeakin te job offer ibukia kain te PAC.

It would be good if there was an agent in Kiribati to help PAC migrants, similar to the role of the agent responsible for needs of Kiribati seasonal workers.

\section{Tally [selected in the PAC ballot in 2006 and arrived in New} Zealand in the same year]

Ao ti a rang look forward ba ti na roko ao ti na kangai naba ke te aekaki are ti a roko naba $n$ have a life, ti a bon roko naba ba ti kona $n$ access $n$ aron aekakin arei without te knowledge are kee te awareness arei ao ti nang. (Ngke e karaki ao e oti ae mata ni mimi man aki kantaninga te bai are e a kaitara mangaia).

We were very excited to come to New Zealand, thinking that when we arrive we would have a good life, we could access any services. We had no knowledge of the reality, so it would have been ideal if someone had made us well aware in advance of what to expect. (There was a visible sign of disappointment as she told this story).

Te aekaki are kanga tao tabena e na kanakoi tenan job offer ao ko mananga ma te job offer...ke...kambana ke...it doesn't matter are terana ma as long as...

If there is an agent for PAC migrants, their most important job is to arrange job offers with existing companies.

\section{Josephine [arrived in New Zealand in 2006]}

Ngai irou ngkana e reke naba te job offer ao e less burden ae nakoia family aika ti a kakawaria ...ba are ngke a roko ao tabera ti na kakaea aia job offer ao ngkana a bon ti roko ni maeu ti teutana te tai ao a bon tii roko naba n straight nako ni makuri akea ara kanganga iai.

If we secure a job offer, there will be less burden on host families, as we are responsible for finding a job offer. If we only come to stay for a little while and find work straightaway, then there will be no problem.

\section{Julia}

Ngai irou bon ara responsibility ba are ti migrate ti nakomai $n$ migrate nakomai ma ngai irou...e na riai ni kamenaki riki e na easy access ... teuana ngai irou bon ti karekean te...Ao ngkana e reke ko bon 
tararuaiko ngkoe ba are ko bon ...e rawata naba aia kanganga am utu ba are ko mena irouia ao a bon tabeakiniko naba... a bon tabeakiniko naba...te burden ai auti ee e arawata kaina...te maiu...tao ko na kaboa tera ataiko ae...

For me personally, it is my responsibility as we want to migrate, but to make things easier for us, one thing that is important is the support.

In this case you can afford to look after yourself...the host family has their own commitments and on top of that they care for you. They have lots of burdens relating to an overcrowded house, food expenses, perhaps you like to help out but they know that.

\section{Sali [arrived in New Zealand in 2009]}

Te Immigration e na bon riai naba ni katauraoi naba taabo tao $n$ aron te naan Farmers a kona n... a na riai ni kangai kam roko te offer ami offer e na reke n taabo akekei. Aonga ni kiba n one way ngkana iai am job offer ao work permit te kakaewenako nakon te Immigration ba a na riai ni buobuoki $n$ te job offer.

Immigration must provide places for example with farmers so that when you come, you have a job available. They will be able to fly on a oneway ticket when you have a job offer and work permit. This is a humble request to Immigration. They must help out in providing job offers.

\section{Nickie}

Ngai irou e rang tikiraoi ba e aki naba bane aia mane te utu ake a roko... ao aki naba kamaebuakaia utu ake ikai ao a bon maeu buaka naba ngaia.

From my personal perspective, it is good, it helps the migrating family earn income and reduce the burden on the host family.

While appreciating the support of the extended family and friends in New Zealand, these women have clearly stated that it is unfair for the host family who themselves also have other social and economic obligations to address. These women suggested that more state responsibility will make things much easier for future successful PAC migrants, and reduce stress and the burden on host families. These women would have loved to stay on their own too, but had no choice as they could not afford to rent their own place whilst waiting on a visitor visa. Having experienced similar hardship while looking for work and waiting for the approval of their permanent residence, these women supported the idea for government support to be provided through the establishment of agents for the PAC, whose responsibility would be to liaise with employers and secure a job offer for PAC migrants before coming to New Zealand. This would ensure that the problems they went through do not happen to future migrants, and result in better healthcare for women and children. They also suggested that future successful Kiribati migrants need to be better informed when preparing to 
settle in a new culture and environment. Most of them acknowledged that having a job offer is key to successful migration so that they can afford to rent their own place without living with a host family, meet the cost of healthcare, school fees and other basic needs. If they do not have a job offer, they create a burden on the host family who has to take the responsibility for searching for a job offer and taking on additional responsibilities. They also recommended that a job or work permit be included as part of the PAC offer to successful migrants. Gaining employment for most migrants is a top priority as a source of income to support family wellbeing (Hewagodage \& O’Neill, 2010).

\subsection{DESIRED RESIDENCY MODEL OF THE PAC}

Two of the research participants settled in New Zealand without having gone through many difficulties because they waited in Kiribati until the approval of their permanent residency. Their shared stories were valuable as I was interested to hear from women who waited abroad while waiting for their applications to be processed. Their stories aligned with the recommendations of other participants. That is, there is a need to have an agent responsible for liaising between successful PAC migrants, and employers and Immigration New Zealand. This would make the process of finding a suitable job offer maybe much easier. Sally had studied in New Zealand for one year so she had experienced life in New Zealand. Despite the good life for the migrating family, there are costs to be prepared for. She shared her experience, which provided good lessons for future successful PAC migrants.

\section{Sally [arrived in New Zealand in 2006]}

Ao ngai...kanga I bon rang kukurei ngke ti reke $n$ te PAC ma kanga e mix au mena ba are I kukurei ao I bon raraoma iaan are I bon aki naba koaua, ba e bon koaua ae e na bon reke tikuu ao ko naaki manga kanakoaki? Ao iaan are e a bure torona aio are bon au namakin I kukurei ma ngke I a manga iangoa are n nang aki oki rikaki ao bon roko arei I bon roko ni karaoa au study ikai ao e manga bon roko irou te raraoma ngaia are I a manga bon nako ngaia anne are I bon aki koaua raoi ba bon te koaua ae bon te PAC e na karekea tikuu ikai ngaia are I a manga bon nako iaan au koaua arei ba kanga I a rawa ni kabua are bon au makuri ao ngaia tao te kewe te PAC ao n ang aera, ngaia are I bon nako n oki I bon nako ni wakina are kanga bon arou ikekei $i$ abau ma au kantaninga are I a tataninga mwina ba ngkana e bon koaua ba I a bon noria imatau te titamba ba I a bon PR $n$ aron are e taekinaki ngaia are I a oki ao I bon nako ao ngke I a bon noria are e a titamba raoi te PR ke ngaia are I a tiba oki ni kairiia natiu. (Ngke e karaki, ao e rang tara ni kukurei $n$ aron ae akea ana kanganga). 
I was very happy to hear that we were successfully selected under the PAC. However, I had mixed feelings of being happy and worried as I was not sure if it was true that we could become residents and not get sent back. Even though I was happy about it, I was mindful in case anything went wrong with our applications and the fact that I came here to study in the first place. I could not believe that we could become residents through the PAC so we decided to return so I did not lose my job that was waiting for me. I carried on with life as normal in my home country while waiting for the outcome of our application, and seeing the PR (permanent resident) stamp with my own eyes like I have heard. When I saw the PR labels on our passports, I travelled back to New Zealand with my children. (When she said this, she looked very happy without any stress).

Understanding the cost of living in New Zealand, and not yet believing that the PAC could give them the opportunity to gain permanent residency, Sally did the right thing to wait with the children in Kiribati for the outcome of their residency application. She travelled back to New Zealand with the children as New Zealand permanent residents. Compared with most of the other women, Sally had the advantage of studying in New Zealand, and had a good understanding of the life and culture in New Zealand, where nothing comes for free. This is a new concept for many Kiribati migrants especially when it was their first time away from Kiribati, where the cost of living is low, social services are mainly provided for free by Government, and there is strong family support. These women were not well informed about life in New Zealand before leaving their home country. Based on the empirical material, the PAC system has been influenced by neoliberalism. It clearly shows that it is the responsibility of individuals to provide all the required information, most PAC migrants have struggled with this responsibility whilst adapting to the new way of life and environment. It appears that the only people who could work around the rigidity of the process independently are those with tertiary qualifications, and who have previous work and international/regional experiences. Without the support from New Zealand's government, as these women have argued, it means that the PAC policy had made things very difficult for the people with lower qualifications, limited previous work experience, or having no family support.

Jessica waited in Kiribati while her husband, the principal applicant, processed their papers in New Zealand. Jessica did not go through the challenges like many of the other women, as she waited in Kiribati until her family's residency was approved. 


\section{Jessica [arrived in New Zealand in 2009]}

E a karaoa naba, e a otinako naba ana PR n te tai arei, nanona ngke ti a mananga ao ti a mananga $i$ aon te one way (Ngke e karaki, ao e tara ni kukurei $n$ aron e aki rinanon te kanganga).

He did it too. The PR was approved at the same time, so when we came, we travelled on a one-way ticket (When she shared her experience, she looked happy as she did not go through any challenges).

She still relied on families in New Zealand, who helped her husband find a job offer. She is still the beneficiary of the cultural capital. She and her children were able to travel as New Zealanders on a one-way ticket. The desired future state of the PAC under the hybrid of neoliberal and te maneaba systems is demonstrated by the experiences of both Jessica and Sally. They waited in Kiribati while their residency was being processed. The two women were only affected by the waiting time and separation from their husbands. They were not stressed about looking for accommodation, or staying with other families, impatiently looking for work, and not accessing free healthcare services.

The story by Teiti in supporting a couple who also came under the PAC affirms the experiences of Sally and Jessica and the recommendations by other women for the need for better support services from the New Zealand government. Teiti's experience also shows two world views, the neoliberal notion of self-responsibility and te maneaba system based on a moral economy. It is a classic example of how te maneaba system and neoliberalism could be integrated to support future successful PAC families, whilst making life easier for these applicants. The experiences of host families as well as lessons shared by these women would inform the desired residency model to reduce hardship for future successful PAC migrants. The desired residency model is a concept that emerged from my participants' stories. It refers to the requirement to improve the current conditions and support systems of the PAC scheme. These would enhance the health and wellbeing of future PAC migrants as well as their host families in New Zealand. As Teiti explained, she had no time to talk to each employer on behalf of Nang, so she challenged Nang to talk directly to potential employers. Being nervous and unsure of what to say, Nang was relieved to discover that the employer was supportive and provided all the information that she needed. After successfully being offered all three jobs that she applied for, Nang expressed her excitement that finding a job was not as challenging as she initially expected. It was a matter of being confident and not being afraid to talk with employers. She also learnt 
that making contact with an employer in person added value as it demonstrated her determination to work. Nang had also taken a course in aged care in Kiribati as part of her planning for migration to New Zealand. Although she did not have the relevant New Zealand work experience, having successfully completed the course in aged care helped her get a job with a New Zealand rest home.

\subsection{CONCLUSION}

Foucault's governmentality conceptual framework was applied equally to understand both the changes from pre-European contact to modern societies in New Zealand and Kiribati. In New Zealand, there has been a shift from welfarism to neoliberalism, which largely shows that the PAC system has a strong neoliberal attribute of selfresponsibility with minimum state support. For example, successful applicants were given the responsibility for providing required information such as an acceptable job offer. From the Kiribati PAC migrant women's world view influenced by te maneaba governmentality, 'self-responsibility' was interpreted as 'lack of government support' or 'PAC agents staff are not being helpful'. The empirical materials demonstrate that the mismatch in the two governmentalities (te maneaba system and neoliberalism) has created social struggles for Kiribati PAC migrants. From the feminist oral history approach, it is evident from these women's shared experiences that the neoliberal PAC policy has disadvantaged women, especially those who have children and come from a lower socio-economic background. Repo (2016, p. 314) argued that "[g]ender equality policy was the means by which women could be mobilized to boost the capitalist economy through their self-transformation into entrepreneurs and job seekers." The PAC has provided opportunities for these women to look for jobs, but with limited support for the care of their children. In telling their stories, these women have naturally expressed feelings of stress, dissatisfaction, disappointment, being unwelcome with no sense of belonging, as well as happiness with triumph for the hard work in achieving permanent residency. These are the consequences of neoliberalism as argued by various researchers discussed in Section 2.3. The women's experiences and emotions demonstrate how the differing views of the two societies have created barriers for many of these women. Based on their experiences, they know what policy improvements they want to see that would make life easier for future PAC migrants. Whilst the two societies, Kiribati and New Zealand, are shaped by different sources of power and knowledge, these women were confused by being left on their own to meet 
their day-to-day needs. Without the Kiribati and Pacific Island's cultural lenses, Immigration New Zealand would not understand the issues that PAC migrants have gone through. Immigration New Zealand would also add that New Zealand is playing its part by contributing hugely to the economies of eligible Pacific countries including Kiribati, by providing opportunities for their citizens to work and reside in New Zealand.

Based on the women's stories, I argue that if the PAC was designed appropriately using te maneaba wellbeing model, the government representatives would consult unimane in each maneaba to clearly present a new initiative and its benefits to te kainga. This would give unimane the opportunity to ask questions, and if they think that it would benefit members of te kainga, te kaawa and te abwamwakoro, they would endorse it and encourage members to apply. Unimane would make sure that there is somebody who would be available to provide assistance to selected people to ensure they understand and follow the process correctly. As illustrated also by research on the experiences of Tuvaluan and Tongan migrants, the PAC has extensively depended on members of the extended families to ensure the successful migration of family members who were successfully selected under the PAC (Gibson \& McKenzie, 2006; Simati, 2009). In its current form, the PAC is an Immigration New Zealand initiative that gives eligible citizens of Pacific Island countries the opportunity to apply to become permanent residents, without integrating the Pacific indigenous culture and approach. Using a governmentality lens, the PAC had been installed without considering how eligible migrants would behave and act because of the way they had been governed within their state, the influence of te utu, te kainga, te kaawa, te abwamwakoro, and their religion, and what information they would require to be governed in a neoliberal society of self-responsibility. The PAC has required individuals to be self-responsible for their own documentation. While it sounds like an excellent initiative as it gives individuals the freedom and choice to apply provided they comply with the policy and criteria, New Zealand does not take any responsibility for any risks or failure. Individual applicants only have themselves to blame if they are unsuccessful. As Lemke (2002) argued, this is what is understood as the negative impact of neoliberalism on vulnerable families whereby the responsibility and risks are transferred to families and individuals to take care of their own health, find work, and be responsible for any social risks including illness, unemployment and poverty. 
The women's stories articulate a consistent requirement that there is a need for a hybrid of neoliberal and te maneaba system. It is a desired future state residency model that these women long to have, to support successful PAC applicants settle in New Zealand without repeating the stress and pain that most of them endured. The desired future state residency model entails having an independent PAC agent, or some kind of support for successful PAC applicants. That person must understand both New Zealand's neoliberal environment based on expectations of self-care and responsibility, and the Kiribati maneaba system of collectivism and family centricity. This person would be a middle person between Immigration New Zealand and the successful PAC applicants, providing culturally appropriate advice as required. As these women argued, to reduce the burden on Kiribati families in New Zealand, successful applicants should be provided with a work permit on arrival. As illustrated also by research on the experiences of Tongan PAC migrants, a job offer is required to ensure that new migrants are able to quickly begin work in their new country, and to avoid associated issues with prolonged unemployment (Gibson \& McKenzie, 2006, p. 27). Similarly from my participants' experience, a work permit would allow them to find work easily, and be responsible for their own accommodation, healthcare, food, and basic needs, without having to depend on, and impoverish, the Kiribati families already in New Zealand. It is not the intention to abolish the Kiribati maneaba system where families always support each other. It is a hybrid neoliberal-maneaba system (residency model) that would accommodate the cultural needs of PAC migrants in a new (to them) culture of self-care and responsibility. This would benefit the sending country, receiving country, individuals and their families, and Kiribati families in New Zealand. Each of these parties should benefit.

As Teiti also demonstrated, the host family's experience in assisting Nang and Bou, PAC migrants, the Kiribati Government and New Zealand Government all have an important role to play in order to make the PAC policy a triple win for all parties: the successful applicants, and the New Zealand and Kiribati governments. The successful applicants should also be strategic by proactively taking on courses locally prior coming to New Zealand to build their confidence when applying for jobs overseas. One of the common issues that most of the research participants faced was the lack of New Zealand work experience. From Nang's experience, one of the recommendations is that successful PAC migrants be proactive in doing courses that would help them 
find work in New Zealand. Immigration New Zealand should make it easier for PAC migrants to process their applications by providing the support services needed when they arrive in New Zealand. For example, Immigration New Zealand could develop a better way to help future migrants find work, better inform successful PAC migrants on how to prepare for life in New Zealand, and become independent like Julia in order to proactively look for work, make regular and appropriate enquiries with Immigration New Zealand, and be confident enough to ask authorities questions. The Kiribati Government should provide training opportunities for PAC migrants such as driving lessons, industry-specific courses (e.g. aged care), English language and culture courses. 


\section{Chapter 5 New responsibility for Kiribati families in New Zealand in bridging the PAC gaps}

Jessica (aged between 35 and 40, came to New Zealand in 2009)

Before coming to New Zealand, I applied for the PAC many times, but I was not successful. I told my husband to fill in the PAC form. He applied once in 2008, and was successful. I felt excited by the fact that we were going to a new country. At the same time, I felt sad that I was going to miss my home country and people.

Seeking the advice of the PAC staff in Kiribati, they stressed that the important thing for us was to get a job offer, as it was the only way for us to come to New Zealand. When we heard that, we were not stressed because we have family members there. My sisters and brother have already settled in New Zealand. We did not expect it to be a challenge. Being the principal applicant, my husband arrived first in New Zealand to find a job offer. He was offered a job at a glasshouse through the support of our family and Kiribati friends. He processed our permanent residency, which did not take long before we received approval.

As soon as our permanent residency was granted, I travelled with the children to New Zealand early in 2009 on a one-way ticket.

\section{Researcher}

It seems that you never experienced any difficulties before you were granted permanent residency. Why is that?

Jessica

If you do not provide Immigration New Zealand with what was required, the processing of documents will take a long time.

\section{Researcher}

Did you do your medical checks and clearance in Kiribati?

Jessica

Yes, that is why we did not have to pay anything for our medical examinations.

\section{Researcher}

When you arrived in New Zealand, did anyone explain everything such as where to register with a health service provider?

\section{Jessica}

Yes, the family we stayed with explained everything to us and they got us registered with the health clinic they were with. 


\section{Researcher}

Was it easy to find a house?

Jessica

It was quite difficult, but when we first arrived, we stayed with my sister in Auckland. Later when we decided to move to Wellington, where two of my siblings lived, one of the social workers helped us find a house. One of my friends recommended this social worker to me. We were able to get a house to rent, and the housing supplement as well from the New Zealand government.

\section{Personal reflection:}

Jessica is the spouse of the principal applicant under the PAC. Neither of them or their children experienced any health problems and other issues mainly because they were able to provide all the required documents at the right time. It is obvious that the cultural capital and asset of members of their utu and friends in New Zealand, had facilitated the smooth processing of their residency application. The cultural respect, reciprocity and love rooted in te maneaba system had made the family feel welcome and gave a sense of belonging into the new transformed maneaba system in New Zealand. They did not experience financial stress, as Jessica and the children travelled on a one-way ticket to their new country. The responsibility of the PAC in ensuring the success of this family in becoming New Zealand residents was shouldered by Kiribati host families who practiced Kiribati's cultural values, which each and every I-Kiribati have inherited from their parents since childhood. These cultural values add value to New Zealand's society and the development of its economy.

\subsection{INTRODUCTION}

In the previous chapter, I discussed how women have struggled by having to conform with the requirements of the PAC policy, which has the attributes of neoliberalism. This struggle is exacerbated by the mismatch between the emphasis on te maneaba governmentality on family and group responsibility and the contrasting emphasis of neoliberal governmentality on self-responsibility or individual responsibility and minimal state responsiblity. The first part of this chapter discusses the role of families in the lives of Kiribati people, as well as other Pacific and Māori cultures. The second 
part discusses the experiences of participants who have graciously acknowledged the support of Kiribati families living in New Zealand for accommodation, securing jobs, healthcare, language support and other assistance. Thus, the PAC policy has created a new responsibility for these host families in supporting the health and wellbeing of migrating women and their families. This discussion is structured as a conversation between the traditional Kiribati culture of family care and the New Zealand government's expectation of a self-directed and independent individual based on the ideology of neoliberalism. The women's stories will demonstrate how the PAC policy has impacted on the health and wellbeing of Kiribati PAC migrants and the assisting families, and how PAC gaps could be addressed.

\subsection{FAMILY RESPONSIBILITY}

As discussed in Sections 4.2.6 and 4.2.8, the role of te kainga is significant in the lives of Kiribati people. Similarly, Schmidt-Busby, Wiles, Exeter, and Kenealy (2019, p. 3) asserted that " $[t]$ he most important group in the lives of many Pacific peoples is family, where family refers not only to the immediate or nuclear unit, but also to extended and wider family, where linkages may or may not be blood related. Along with Māori, Pacific families in New Zealand are significantly more likely to give support to extended family when compared to other New Zealand families". Robinson and Williams (2001, p. 55) stated that "the Māori concept of family (whānau) moves seamlessly from the immediate family to the wider family network (hapū) and the tribe (iwi), where the (extended) family becomes the community and the community is made up of the (extended) family. Social capital is created through networks and relationships that are within all of these expressions of 'family' (or community). In the Kiribati culture as well other Pacific and Māori cultures, the kind of support one provides to other members of te kainga is a cultural obligation. It is not a free service nor based on the Western concept of volunteering (Robinson \& Williams, 2001, p. 66). Robinson and Williams (2001, p. 56) asserted that the "[k]ey concepts of Māori society that relate to social capital include manaaki (cultural obligation to welcome and care for visitors) and hāpai (the requirement to apply the concept of uplifting/enhancement) and tautoko (providing support within the community)". Writing about their work in a Samoan community context, Tamasese, Parsons, Sullivan, and Waldegrave (2010, p. 26) argued that "cultural obligation by implication involves relationship, and the expression of cultural values within a specific 
social/community network". The following women's stories show how the cultural obligation for families has supported PAC successful applicants with their migration process.

\subsection{WOMEN STORIES}

The narratives of my participants articulate the devastating experience they went through in completing the transition from the Kiribati welfare state policy entailing the principles of te maneaba to New Zealand's neoliberal policy of self-responsibility. A clear communication with PAC applicants is required to make them aware of this transition before they decide to emigrate. While the PAC is very much driven from neoliberalism as a policy, ideology and governmentality that stresses selfresponsibility (Larner, 2000a; Suaalii, 2006), in actual practice, the gaps in service provision in existing PAC policy has necessitated the collective effort and assumption of responsibility by Kiribati families in New Zealand to support migrants. Kiribati families within New Zealand have acted as a surrogate welfare state agency in providing housing, seeking job offers, providing healthcare, and other services. They simply provide a proxy maneaba system for bewildered Kiribati PAC migrants.

\subsection{BUILDING A NEW LIFE}

\section{Tete [selected in the PAC ballot in 2014 and came to New Zealand} in 2015]

Ngai ngkanne ngke I moan reke I ataia ba I reke $n$ te PAC inanon te ririki ae nako tao inanon June ke July. Ngke I moan reke n te PAC ao I rang kukurei ba I ataia ba n nang manga build a new life $n$ te country aio New Zealand, ao I ataia naba a na rang maiti naba kanganga n na rinanoi. Teuana mai $i$ buakona bon tena $n$ expenses $n$ aekakin te kantoka ao tao bai riki tabeua ake $n$ na kabane mane iai $n$ aron te tutuo ma te bae ae riki I bon kakaitau ba e aera ngkai are I bon makuri teutana tiaki te bai ae rang bubura au makuri (Ngke e karaki ao e rang tara $n$ kukurei).

I was selected under the PAC last year in June or July. At first, I was very excited because I knew that I was going to build a new life in this country, New Zealand, but I also knew that I would face many challenges. One of them is meeting expenses such as travel and medical costs, but I was grateful that I had a job in Tarawa to help meets these costs. (When she told this story, she did not look worried. She looked happy).

... ma e bon reke naba ae e aera arei teutana buokana ao moarara riki bon au utu ake a buokai ngaia riki ae rang bubura aia ibuobuoki $i$ 
Tarawa. Ao I bon kaman kakaraoa au tutuo ikekei $n$ te aro are I kona $n$ save.

But above all, I am so grateful for my family who had contributed so much when I was in Tarawa. I did my medical check-up there so I could save on costs.

Researcher

Ko uringa tao ko a bon tia $n$ titikiraki buokam ibukin karekean te job offer?

Can you remember if you asked anyone for help in seeking a job offer?

Tete

Kanga bon akea te tai ae I a tia n titiraki aekan titiraki akanne ibukina ba ngai irou I bon rang depend iaoia au utu. N rokou ikai ao I a bon titirakinia naba au utu ibukin te job offer, bai akanne a bon bane naba $n$ reke mairouia au utu.

I never asked around for help, because I depended a lot on my family. When I arrived in New Zealand, I asked my family to help me look for a job offer. I got everything from my family.

Being young and single, Tete was very excited to be going on a new venture and to migrate permanently to New Zealand where she would build a new life for herself. When she mentioned 'new life', it struck me that young Kiribati women are starting to look beyond the horizon, i.e. looking for opportunities elsewhere because they do not see themselves reaching their potential in Kiribati. This means that the PAC provides opportunities not only to mothers, but for young single women to fulfil their dreams as well. Being in her early twenties, Tete has many years ahead of her to pursue a New Zealand education and a career. One of the things she said was:

\section{Tete}

Ngke I a roko ikai ao te kabane ni bubura ni kabane mane te tutuo, tao bon aio au kanganga ba are I a maninga ae e a bane tain au tutuo mai Tarawa ma tao buokau ai manga au utu naba ikai i aon New Zealand ngaia a manga cover naba.

When I arrived here, the most expensive thing that I found was the medical examination. This was my fault because I forgot to renew my medical results in Tarawa. It was my family in New Zealand that helped cover these expenses.

Kiribati cultural values of te karinerine and te tangira have bonded Tete's utu and kainga together, thus providing a vehicle for supporting Tete to pursue her residency application. As I-Kiribati, when we are asked to help each other, we help until we exhaust all possible resources, without any expectation to be repaid. Tete did not see the need to ask Immigration New Zealand for help in seeking a job offer or other 
assistance because, from her cultural perspective, it was the responsibility of her family to assist. She felt indebted and grateful to her family in New Zealand, who have generously provided financial support including the cost of renewing her medical report as she forgot to renew it before leaving Kiribati. Being on a visitor visa, and having no access to healthcare and other services, family support was paramount. She was able to overcome financial and cultural barriers and pursue her dreams of building a new life. It is understandable that rather than waiting in Kiribati for her permanent residency application to be processed, Tete had the confidence to travel on a visitor visa to New Zealand without thinking of any of the risks that may have occurred whilst in New Zealand.

Tete's family support had bridged the PAC gaps around healthcare and financial constraint. To affirm this, when she said that she never asked Immigration New Zealand for help in looking for a job, it shows that Tete did not think that it was the responsibility of the New Zealand government to provide information and guidance to her in looking for work. As Tete was on a visitor visa and could not access free healthcare services, it was critical for her to have a job so she could earn money and be able to afford the cost of healthcare. But it appears that this was not a concern for her, mainly because the family is bridging such service gaps. The strong bond between her and her family in New Zealand and Kiribati meant that it brought great joy and pleasure for Tete's $u t u$ and kainga to see her succeed in building a new life in New Zealand. She could also support the rest of the family migrating from Kiribati in the future, or possibly remit money back to her parents, and take pressure off her siblings remaining in the islands. The development of other members of the family, especially the young ones, is vital because once they have established themselves, there is an expectation that they will help other less fortunate family members.

Consistent with this mentality, Connell (2014) argues in his paper on migration culture based on Fiji, Tonga, Niue and Samoa that a longstanding culture of migration is centred on the households. People make the decision to migrate to seek better living and improved welfare for both individual migrants and families remaining in the sending country. They migrate because they see limited opportunities for economic advancement in these countries, and they see migration as the solution. However, compared to other Pacific islands, Kiribati is relatively late in the practice of migrating to live permanently abroad, except for those who married foreigners from other parts 
of the world, and a few people who migrated to New Zealand or other developed countries under the skilled migrant category. It was not until after the implementation of the PAC that permanent migration from Kiribati became more prominent.

\subsection{HOUSING}

\section{Runga [selected the PAC ballot in 2005]}

I tekeraoi ba I aki tatara au auti ba I a bon memena naba irouia au koraki ba are ti rabatau. Te tabo are I makuri iai. Ao natiu a bon tiku $i$ Kiribati, ti uoman. A ikawai ti temanna e irai ngkoa. Are e a tia n kaman iein are e a nako I bon ikai. Ngai ngkanne te tabo are I makuri iai. Te tabo are e reke iai au job offer I a tiku naba irouia au koraki ni kania au makuri. Ngkana I a manga aki makuri I a manga mena ngkanne irouia...Akea raoi oin au auti ba I a bon tiku naba irouia au koraki ma raraou. I tii kangaraoa te tabo are I makuri iai ba are I kabi $n$ drive. (Ngke e karaki ao e tara $n$ kukurei man akea tabetabena).

I am lucky because I am a single mother, I don't have to worry about looking for a house as I always stay with my relatives. My children are in Kiribati. They are grown up. Only one of them came with me. He/she was married, and had gone somewhere here. Wherever I got a job offer, I stayed with my relatives who lived close to my work place. When I didn't work, I stayed with them...I don't have my own house, but I rely on my relatives and friends for accommodation. I make sure I stay close to my work place because I can't drive. (She looked free from any stress as she told her story).

Runga lived a simple life with little stress about house hunting. In addition, because of her age, her inability to communicate well in English, the high cost of housing in New Zealand, and having only one source of income, it is understandable that Runga could not afford to rent a flat on her own. Whilst she is still strong and healthy, she enjoys being independent by working and earning her own income, rather than depending on her children to provide for her. Given the high cost of housing in Auckland, Runga's friends and families would not be able to afford to buy or rent a larger house to provide Runga with her own room. Being used to living in a household comprising the extended family, it is assumed that Runga was not worried about having her own space. The family she stayed with may not have been bothered too that their house was overcrowded. Even if they had, it would be difficult not to invite Runga to their home under the Kiribati maneaba and bubuti systems, which are based on te karinerine and te tangira values. The family would have felt responsible for providing temporary accommodation. In Kiribati where the cost of living is low, the host family can benefit in many ways from the extended family who can help with child and care for the 
elderly, and producing food by going fishing, and cutting toddy, which are the essential tasks and sources of making a living.

Arguably, from the New Zealand culture advocating a neoliberal policy of selfresponsibility, this means that Runga is deemed responsible for finding her own house. Her limited awareness of the New Zealand system, language and other cultural barriers limiting her from contacting landlords or agents, meant that it was much easier for her to depend on other Kiribati relatives and friends to seek accommodation.

\subsection{SURVIVAL FROM UNEMPLOYMENT}

\section{Sandy [The years in which she was selected in the PAC ballot and arrived in New Zealand were not stated]}

Ngaia ti a nakomai ao ai manga tikura ikai irouia ara koraki, manga te kanganga are ti aki makuri ba ti roko iaan te visa. I ti roko ma buu ma natira ti katikuia a tuangiira kain Tarawa (te aobiti) ti na katikuia natira ibukin are ti na kakaea moa ara jobs ao ara auti, ngaia ngke ti roko ao ti a nakon te aobiti kanga ti tekeraoi mai maina ba kanga iai te job offer ae a katauraoaki irouia kain te immigration kain aobitin te PAC are i Auckland. Ngkana ko roko ikekei ao neierei e butimaiko e anganiko aran taabo ake ko kona $n$ tarebooni ngaia are e reke te care giver. Ngkanne ai manga tataningakin ara permanent visa ngkanne a manga kaawa ara utu ake ti mena irouia. Tao iai ara tianti teutana ibukin boon ara bai $n$ te immigration, ti na manga bon ibuobuoki $n$ aron te maeu. Am mane are ko kawakinna ibukin boon am PR e a manga bane ibukin boon te maeu bon 8 ara namakaina n tataninga. E kan ririki raoi ao e a tiba tia te $P R$ ngaia a tiba roko natira. E reke ara auti imain rokoia natira ba are manga tuan Niutiran e tabuaki te maiti n aomata $n$ teuana te auti. I nanon te maan are a tuai roko natira ti bon rang miss nia, ti kabane mane $i$ aon te tareboon. (Ngke e karaki ao ko namakina te rawawata are $e$ a tia $n$ rinanona $n$ aron uringakin te tai are $e$ maenako ma natina).

When we came here we stayed with our relatives and faced the challenge of not working as we came on a visitor visa. I only came with my husband and we left our children behind as advised by the officer in Tarawa as we needed to find work and a house first. When we came we were lucky because the immigration officer in Auckland had prearranged a job offer. When we arrived, the person meeting us gave me the contact number of the prospective employer. This was how I got the caregiver job. I rang the employer from there and arranged an interview. The next challenge was the waiting period for residency. We felt sorry for the family we stayed with. We used the money that we saved to cover the costs of our documentation for immigration to contribute towards food expenses. We waited for 8 months. It was nearly a year before our PR was approved, then our children arrived. We found a house to rent before the arrival of our children. The law in New Zealand controls the number of people per house. During this long period, we 
missed our children, and spent a lot of money on making international calls. (In telling her story, she did not look happy as she reflected on the time when she was separated from her children).

When Sandy said that "when we came we were lucky because the immigration officer in Auckland had pre-arranged a job offer", it raised a question around inconsistency. Sandy and three other participants (Cookie, Ann, and Twenty-Five discussed in the earlier chapters) received contact details of possible employers from Immigration New Zealand. Others declared that they were responsible for looking for job offers, and the rest never asked as they depended on their Kiribati relatives and friends' networks to find a job offer. As discussed in the previous chapters, finding a job offer was challenging for most of the participants because they did not have New Zealand experience, were constrained by the language barrier, were scared to contact authorities, did not receive any support training on how to apply for a job and be interviewed, and many other factors. Recently, I was involved in helping a couple from Kiribati who were also selected under the PAC, and I was able to confirm that the responsibility lies with the PAC migrants and their families to find a job offer. This is understandable as being a small team, Immigration New Zealand would not be able to service the needs of the PAC selected applicants, covering Tonga, Solomon Islands, Fiji, Tuvalu and Kiribati. However, Immigration New Zealand helps by preparing the profile of each successful PAC applicant and submitting their profiles to the employers to select their own people. At the same time, applicants are encouraged to contact their families and friends in New Zealand to look for a job offer. This shows that some staff of Immigration New Zealand are partly aware of the Pacific culture of sharing and supporting family wellbeing, thus they have transferred responsibility to the Kiribati community and families to find work for successful PAC migrants.

By not being responsible for an applicant's job offer, it means that Immigration New Zealand would not be accountable for any of the applicant's possible misbehaviour to employers. Through my engagement with employers, there was resistance expressed by some employers who have experienced issues with some PAC migrants whom they helped by providing a job offer. These PAC migrants would work for a short period of time before leaving without any notice to take on jobs that were more relevant to their skills and experience. Sometimes, they would get their permanent residency, and as soon as they had landed in New Zealand, they did not even show up to express their gratitude to the employers who had provided them with a job offer. The cultural barrier 
and lack of confidence to confront authorities have hindered the communication skills of some Kiribati migrants. This is discussed further in the next chapter. Arguably, New Zealand's neoliberal policy of self-responsibility could help PAC migrants become more responsible. However, the PAC self-responsibility should have entailed some help on how to apply for a job, or attend an interview. Coming to New Zealand for the first time, they need training on how to look for a job, they need to become aware of the cost of housing, and to understand New Zealand laws that will have an impact on their day-to-day life. Condron (2007, p. 371) stated that self-responsibility allows adults in any work place to own and manage their own work-life resulting, overall, in a higher quality of performance and satisfaction. However, as is usual with new or inexperienced staff, close monitoring and support by their managers is needed before they take responsibility for their own performance. Consistent with this argument, Galloway and New Zealand Foundation for Character Education (2008) argues that self-responsibility can improve the behaviour of students in school, but they also need the support from teachers to teach responsibility to improve their learning and behaviour in school. This shows that while self-responsibility can make a person independent, the PAC has gaps around supporting and informing the applicants on all aspects of work-life in New Zealand to assist them to take responsibility.

Aside from self-responsibility for obtaining a job offer, which Sandy did not find an issue compared to the rest of the participants, she reflected on a heart-felt experience with a Kiribati family who she stayed with in New Zealand while waiting for her work visa and permanent residency. When she said "we felt sorry for the family we stayed with", she is articulating the limitation of te maneaba governmentality. Although she was unemployed for almost eight months and was on a tight budget, she had to contribute some money towards the cost of food and other day-to-day expenses. Coming from Kiribati, a poor country, one can understand that most of these PAC migrants travel with a limited budget. Sandy and her family struggled during the eight months with no job and faced with the challenge of seeking suitable accommodation for her family.

In addition, the lack of government advice to Sandy had affected her relationship with her children. Her family remaining in Kiribati provided parental and healthcare for Sandy's children until their permanent residency was processed and the children could reunite with their parents in New Zealand. Sandy and her husband's decision to leave 
their children in the care of family in Kiribati was the right decision, but it meant a lengthy period of separation. Sandy had no choice but to leave her children behind until her family obtained permanent residency. This demonstrates the challenges with self-responsibility under neoliberalism. However, the cultural values under te maneaba system played an important part in their successful settlement in New Zealand, by bridging health information gaps and providing accommodation and healthcare for the children.

\title{
5.7 CANNOT AFFORD TO LOSE OPPORTUNITY
}

\begin{abstract}
Josephine
E mena iroun ai manena ae mena i Auckland. E a tuangai, neiko ko taku ba e bebete aron kakaean te makuri ikai, e a bon aki kona n reke au makuri ko ataia ngkana I nako ao a kangai ba ko a tia n makuri mai mwaina, ba I tuai ao iai...are te permanent residence, ao kai tiaki naba kain te aba, kai are akea taan ibuobuoki ba a bon kangai naba ko na bon nako n kakaea am makuri ba a na bon offer niko te job ao ngkoe ngkanne ko na oki $n$ raa, ... anganiko te job offer arei ba e na issue naki am work permit. Ma ngaia are I taku ba every job are e nako iai, ti tabo ba e na riai ni kaaina te aba, e na iai ana experience kee, ao ngaia are ti tabo ba kanga e a rang nako buaka irouna, I aki kona moan are e nang manga oki ao e a manga aki bongana ti tabo ba ti nang cancel, a ngaia tao $n$ nang nakoati ba tao ngkana ngaira uoman tao e a reke riki angana, ao ngaia I taku ba e bon raoiroi riki ngke I roko.
\end{abstract}

He stayed with his cousin in Auckland. He told me, you think it is easy to find work here, it is very difficult to find work. When I saw them, they asked, "have you worked before?" I haven't. "Have you got... a permanent residence?" I am not from here. No-one is able to help. They told me to find a job offer so they can issue a work permit. That is what I said. For every job he applied for, he is required to be a local, he must have relevant experience, so things did not go well for him. I can't stand the fact that he was wanting to return, and we did not want to miss the opportunity, and we were going to cancel it, so I am going over. Maybe it would be much easier if the two of us are there.

Ba ko a bon managa n te hope ae ko na nako ni kakaia kain Kiribati...ao bon ngai naba anne are e a bon ngae ni kangai... nee I a bon aki kinaia kain ikai ma nang oki, ao ngai, "ko kinaia ma bon kakaia” e aki akaka ara aomata are ti nang kakaia.

You came with the hope that you will look for I-Kiribati...that was me, my husband told me. I don't even know these Kiribati people so I am returning home. I told him, you know them, look for them, we needed to contact any I-Kiribati people.

When saying “...I aki kona moan are e nang manga oki ao e a manga aki bongana, ti tabo ba ti nang cancel (I can't stand the fact that he was wanting to return)", Josephine 
did not want to lose the opportunity for her family to live a better life in New Zealand. Her husband (the principal applicant) came to New Zealand first and stayed in Auckland with a family where he was related to the wife, while looking for work. In the Kiribati culture, it is culturally appropriate for a male to live with a couple if he is related to the wife. This, however, limited his opportunity to stay with other male relatives, who might have been more connected with other employers. This shows that the Kiribati culture had certain limitations for Josephine's husband to explore opportunities such as looking for a job offer. When the husband had exhausted all possible resources, and decided to return home, Josephine was very persistent in encouraging him to seek help from any Kiribati people in New Zealand, despite the fact that he knew very few people. Interestingly, Josephine never thought of encouraging her husband to ask Immigration New Zealand for help. One of the things she said, when the husband told her that he did not know many Kiribati people, she said "yes, you do." As mentioned earlier, the language barrier and the confidence to approach authorities, are significant factors in the successful settlement of PAC migrant families. When Josephine arrived, there were other relatives from her husband's kinship group, who kindly offered accommodation and also helped liaise with other employers for a job offer. Not long after they stayed with this family, both Josephine and her husband obtained job offers, which immediately supported their application for permanent residency.

This clearly shows that the successful settlement of some PAC migrants depends on the support provided by the host families in New Zealand. Good relationships and communication skills that most of these participants lacked are critical for successful migration, hence the important role of Kiribati families in New Zealand in this area. Language and shyness have been barriers for some PAC migrants. These could be why Josephine and other participants opted to seek help from other Kiribati families. Immigration New Zealand has an expectation that Josephine's husband as the principal applicant and all other PAC principal applicants have good basic English communication skills, so they can take control of their own lives when migrating. Although English is the official language in Kiribati schools and workplaces, most PAC migrants lacked the knowledge of New Zealand's systems, and the confidence to approach employers, and other authorities - this is explored further in the next chapter. These are some of the significant gaps under the PAC, which Kiribati families in New 
Zealand have stepped in to address in order to ensure that PAC migrants gain permanent residency.

\subsection{DISCUSSION AND CONCLUSION}

In this chapter, it is argued that without the support of Kiribati families in New Zealand, the PAC policy would not have been viable. The empirical data based on women's stories in Sections 5.3, 5.4 and 5.5 as well as Sections 4.5 4.6, 4.7 and 4.8 provides strong evidence for this. This is consistent with empirical evidence from other reports based on the experiences of Tongan and Tuvaluan PAC migrants, that indicated that extended family played a key role in supporting the process of migration (Gibson \& McKenzie, 2006; Simati, 2009). Foucault's governmentality framework was useful in analysing how the neoliberal PAC policy presumes self-responsibility but has in actuality transferred responsibility to Kiribati families in New Zealand and Kiribati to assist the Kiribati PAC migrants settle in New Zealand. The women's stories in this chapter bear witness to the emergence of a new responsibility for Kiribati families in New Zealand in bridging the PAC gaps, to support the needs of Kiribati PAC migrant women and their families. Whilst te maneaba governmentality is beneficial to Kiribati PAC migrant women in securing residency, this has contributed to the burden on members of te kainga in meeting their cultural obligations of providing hospitality to new migrants (Robinson \& Williams, 2001; Schmidt-Busby et al., 2019; Tamasese et al., 2010). These translated quotes articulate the dependency of Kiribati PAC migrants on family members.

\section{Tete}

I am so grateful for my family who had contributed so much when I was in Tarawa.

\section{Josephine}

You came with the hope that you will look for I-Kiribati.

\section{Rung}

I don't have to worry about looking for a house as I always stay with my relatives.

These are additional drawbacks and associated risks within a neoliberal system of transfering state responsibility and burdens to migrants and their families. Such issues have been debated by various researchers as discussed in Chapter 2 (Kingfisher \& Goldsmith, 2001; Larner, 2000a). 
As demonstrated in their stories, Jessica, Runga and Tete were happy and did not appear to have any visible sign of stress because their families in New Zealand provided a proxy for a social welfare agency. Although Sandy was affected by the lengthy separation from her children, she still enjoyed the benefits of having the support of her families both in New Zealand and Kiribati who provided accommodation and healthcare for the children. As Trnka and Trundle (2014, p. 140) argued

Neoliberal ideals of accountability, risk, and responsibility can thus curtail certain freedoms and choices in order to enable other, more valued forms of autonomy and empowerment.

The same neoliberal processes that highlight the importance of granting individual freedom, choice, and autonomy thus simultaneously constitute new relations and dependencies. They can also create the potential for new forms of social action. Indeed, when responsibilities are divested from the state, they do not always fall upon individual actors; rather in some cases, new collectivities emerge. What has been called 'the death of the social' thus simultaneously created new notions of 'community' and spaces for collective action and responsibility...

The women's stories show that the PAC scheme is a private arrangement between Immigration New Zealand and individual applicants. The key challenges that they face are related to difficulty in finding a job, meeting healthcare costs, and meeting the high cost of housing. Kiribati cultural values of te karinerine and te tangira that shape the connectedness amongst te utu, and te kainga, have compelled Kiribati families in New Zealand to be responsible for helping new Kiribati migrants to settle permanently in New Zealand. Having lived in New Zealand long enough, they have gained the knowledge of the New Zealand system, have strong networks with potential employers and other key contacts, and the experience needed to look for work. They act as elders or unimane within te maneaba, with the responsibility for looking after the wellbeing of the new migrants, who are young in knowledge, skills and experience in the New Zealand system and environment. As discussed in Section 2.4, te maneaba governmentality is applied within the home and other parts of society and with the use of this analogy, older migrants (men and women) act as elders or unimane to support the wellbeing of new migrants.

Kiribati families in New Zealand act as a social welfare scheme in meeting the housing needs of most PAC migrants. They do this as part of their cultural obligations, with no expectation of being compensated for hosting new Kiribati migrant families. Coming 
from Kiribati with a moral economy but with rich culture, none of these migrants could afford to rent their own place when they first arrived in New Zealand. They had no other choices, but to stay with families or friends until they secured a job, and could afford their own accommodation. Some took more than a year before they could afford to rent their own house. Welcoming people into your home is one way of showing respect and providing hospitality as part of te maneaba governmentality. It is also a way for Kiribati families in New Zealand to portray their connectedness and support to their families in their homeland. This is similar to the traditional gift giving to family in the Pacific Islands as pointed out by Cowley, Paterson, and Williams (2004, p. 440). This reflects strong alignment with Pacific culture and the importance of strong cultural beliefs and values of committing resources to help family members. Positioning te maneaba system in its current state in New Zealand society has social and economic risks. It is reported in Cowley et al. (2004, p. 431) that 59 percent of mothers who participated in the traditional gift giving study, which involved gifting to families in New Zealand, families in the Pacific and their Church, reported that they had consequently experienced a financial burden.

The strong empirical materials indicating that extended families are taking responsibility in providing housing and other support services for new migrants under the PAC scheme indicate consequences of neoliberalism. Housing shortages and affordability is a critical problem experienced by Kiribati PAC migrants. When Sandy said, "we felt sorry for the family we stayed with", it demonstrates that the cultural obligations in supporting the wellbeing of new migrants is impacting on the wellbeing of existing families. This shows the limitation of te maneaba governmentality within the new society. Silvius (2016, p. 35) argues that "[e]xtended kinship and ethnocultural community ties do retain the potential to serve as sources of 'social capital' that contribute to refugee wellbeing. However, they are increasingly being relied upon to provide 'private' services, support and care that may be conceived as being broadly public in nature and should therefore be supported through government finances". Future research is required to determine the size of the problem resulting from the cultural obligation for Kiribati families to provide support and care to successful PAC migrants. 
The neoliberal Immigration New Zealand policy has left the full responsibility to the PAC migrants to work independently to meet necessary criteria as a stepping stone to permanent residency but without sufficient training and support. As discussed in Chapter 4, the era of neoliberalism in the 1980s and 1990s in the New Zealand society (Larner \& Craig, 2005, p. 13), as an attempt to improve the economy, has impacted on immigration policies. Other researchers and the New Zealand government media release indicates that the PAC policy has an economic incentive to address labour shortages. There is strong empirical evidence that social and health needs of migrants are overlooked. New Zealand formally acknowledges Māori culture in policy, which shares similar cultural values with the Kiribati culture, e.g. welcoming visitors and hospitality (Robinson \& Williams, 2001). The PAC policy, by contrast, is built on the self-responsibility concept. If this neoliberal self-responsibility policy is maintained, the scheme should include a component involving pre-departure training on how to look for work, and cope with the new environment. This is critical so the migrants can afford to meet their healthcare costs, housing, transport, and education for their children. Such training would benefit both PAC migrants and Kiribati families in New Zealand. Helping Kiribati migrants learn to be independent and self-reliant will take the pressure off Kiribati families in New Zealand who have supported these migrants to get through their documentation for permanent residency, or who have provided accommodation for as long as it has taken for PAC migrants to receive their permanent residency.

One of the participants (Tally) stated "ti taraia ngkai ba ti are ngkoa au iango ngkoa are ngkana iai aika a roko kam aki bane n nakomai ao ti tabo ngkai kanga ko aki kan...te aekaki are I aki kan encourage are te roko (Previously, I encouraged Kiribati people to migrate, but recently I am not encouraging them to come).” Based on her experience, Tally did not want future migrants to go through the hardship she endured. Clearly, many PAC migrants, especially those who had not travelled overseas previously, would not be able to successfully process their permanent residency on their own without someone taking the responsibility for helping them. The amount of time, costs and other hidden risks to both the immigrants and the host families, could discourage others from assisting future migrants. Tally's story demonstrates evidence of neoliberal governmentality, which disadvantages people with a lower socioeconomic status. 
The next chapter discusses how Kiribati PAC migrants survive cultural barriers, one of the main themes of the women's stories. I identify the challenges they faced and who helped them, and also examine how the state or individuals should take responsibility to make a residency model appropriate for the sending country, receiving country and PAC successful applicants. 



\title{
Chapter 6 Cultural barriers: language, te mama (shyness), and te aki kakarongoa (silence)
}

\author{
Riri [aged between 35 and 40, selected in the PAC ballot in 2009 \\ and came to New Zealand in the same year]
}

Prior to coming to New Zealand

I was delighted to hear that I was selected under the PAC and that I was coming to New Zealand, where I could work and be able to support my family financially. My father was about to retire soon from his position as a school teacher, so this opportunity was timely. I went to seek help from the PAC staff in Tarawa, and was advised that I had to look for a sponsor and a job offer before coming to New Zealand. Having not been abroad in my life, it was going to be my first time to travel to New Zealand. I did not know anyone there and I did not know where to go. I felt that the explanation and information that I received from the PAC official was inadequate. So, I sought support from other friends who had previously been successfully selected under the PAC.

\section{After arriving in New Zealand}

I did not know anything about Immigration New Zealand's systems and processes. I did not know how to look for a job offer. Being in New Zealand for the first time, I did not know any I-Kiribati people other than the family I stayed with upon arrival. I did not know what to do. I did not know where Immigration New Zealand was physically located, and I did not know where I was. I was helpless and remained silent. I could not do anything about my immigration documentation. The family that I stayed with had no idea about finding a job offer or Immigration New Zealand's processes. Finally, they were worried about my papers, so they decided to take me to Immigration New Zealand's office. The immigration officer that we saw advised me that my application could not be accepted because it was late. I was upset and frustrated. If only I spoke English well, I would have communicated earlier and asked authorities for their assistance. This would also not have happened to me if I had known a local agent, a family member or a friend who could have connected me with potential employers and advised me about New Zealand's immigration process.

A Kiribati woman came to see me and tried to understand my situation so she could help. She contacted one of her contacts in Hastings to see if they could help me lodge my application with Immigration New Zealand for an extension. My visa was extended for another three months so I could look for a job offer. I still could not find a job offer so my application was declined. I did not give up as I knew it was not my intention to break the law, so I was persistent in seeking help to regain my PAC status so I could reapply for permanent residency and 
achieve my goal of settling in New Zealand. Finally, through my networks with the Kiribati people that I later developed, I found a very good New Zealand immigration lawyer in 2014 who helped me obtain permanent residency.

\section{Researcher}

What was your aim for seeking legal help?

Riri

I wanted to fight for my rights. I did not intend to break the law when I overstayed my visa as I did not understand everything in the first place. I wanted the lawyer to help me regain my PAC status and to become a New Zealand resident. This was my objective and I needed the lawyer to help me. So, when I saw the lawyer, he wanted every document related to my PAC application and invitation, and other documents that would support my application. The lawyer helped me get a work permit so I was able to work and earn an income so I could meet my legal and living expenses. Whilst my papers were being processed by the lawyer, I went through many ups and downs. I am indebted to my employer who is the most generous boss I ever had. He provided me with a job offer and often lent me money so I could pay my legal bill on time. While processing my papers, my lawyer often asked me if I wanted to stay in New Zealand. I told him that I wanted to live in New Zealand and that was the reason I came here in the first place. I also wanted to work here so I can support my family in Kiribati. Finally, my permanent residency was approved in 2016. I was overwhelmed with joy. Currently, I am still working for the same employer whom I am indebted to and I will endeavour to offer my very best to support his company.

\section{Researcher}

You are very brave. Whilst on the work permit, did you experience any health problems? Could you access any health services whenever you felt sick?

Riri

There were times when I really needed to see a doctor when I felt sick, but it was difficult because of the costs.

\section{Personal reflection:}

Riri is a very strong woman to challenge Immigration New Zealand's initial decision to decline her application for residency under the PAC. Initially, she was mostly disadvantaged by her unfamiliarity with the new environment, lack of practice in speaking the English, te mama (shyness) which prevented her seeking help, and therefore also te aki kakarongoana (silence). She also suffered from a lack of understanding 
of immigration systems and processes, and lack of support networks with the Kiribati people in New Zealand. Unfortunately, Riri was initially staying with a Kiribati family in Auckland, who were unfamiliar with the PAC process for permanent residency. They also did not have connections with employers who could help with a job offer. It took her seven years of fighting to regain her PAC status and obtain permanent residency. Unfortunately, this came at great costs to her physically, emotionally and financially. She would not have gone through this hardship had she received sufficient information about New Zealand's way of life and immigration processes prior to leaving Kiribati, and support with obtaining a suitable job offer when she arrived in New Zealand. It was her desire to live in a better place, get a good job and earn an income for herself and her family back in the islands that drove her to overcome this adversity. Even if it meant being in denial of her health needs because she could not afford the cost of accessing healthcare services.

\subsection{INTRODUCTION}

In previous chapters, I argued that there is a missing link between the PAC being governed by the power of the neoliberal notion of self-responsibility and self-care, and the Kiribati migrants being governed by the power of te maneaba system. In effect, this has led to an emerging responsibility for Kiribati families in New Zealand to help successful PAC migrants achieve permanent residency. The first part of this chapter discusses cultural barriers of language, i.e. te mama (shyness) and te aki kakarongoa (silence), which have contributed to the burden of other families in providing support

services. The second part of this chapter reviews the education system in Kiribati to identify gaps in the Kiribati education system that contribute to challenges for Kiribati PAC migrant women. The third part of this chapter discusses women's stories to demonstrate how such cultural barriers have created more challenges for these migrants in terms of complying with the PAC requirements, and how the education system in Kiribati could help future Kiribati PAC migrants. 


\subsection{CULTURAL BARRIERS}

Analysing issues through the lenses of governmentality and Kiribati culture rooted in te maneaba system, helped me uncover the women's issues. These approaches also help make sense of why and how New Zealand state agencies and Kiribati PAC migrants have talked past each other, or have problems of cross-cultural communication (Blauner, 1992; Metge \& Kinloch, 1984; Tone, 2005). Metge and Kinloch (1984) articulated the cross-cultural differences between Pākehās, Māori and Samoans. Pākehā children are taught to make eye contact when talking to someone. This demonstrates respect and interest. However, looking at someone in the eye when talking to them is considered rude and disrespectful for Māori and Samoans. As Blauner (1992) argued, blacks and whites who have differences in language and world views often talk past one another. This means that the different cultural groups have their own ways of interpreting things based on how they view the world. Tone (2005) argued that at an early age, we learn the language and rules of our culture, without being aware that it influences the way we behave and communicate. During my maroro with 30 Kiribati women who came to New Zealand under the Pacific Access Category between 2001 and 2016, it is evident that the cultural barriers of language, te mama (shyness) and te aki kakarongoa (silence) were among the key themes identified from the women's stories. This chapter explores how the cultural barriers make life challenging for these women and how the PAC policy could have empowered them. Given the limitations of literature on the Kiribati language, te mama and te aki kakarongoa, this chapter draws from literature that analyses cognate issues in similar migrant populations as well as exploring the stories from my research participants.

\subsection{MAMA (SHYNESS)}

Aizawa and Whatley (2006), who investigated shyness in three different countries (Japan, Chile and United State of America), argue that shyness differs from culture to culture. For example, shyness in a collectivistic society is considered positive and acceptable when compared to an individualistic culture. In most collectivist Pacific cultures generally, shyness is complex and has strong linkages with the culture of respect and upbringing (Hang, 2011; Singh, 2001; Thompson, 2016). As Campbell (2003) states, children form a self-image from what they learn from their parents. In Kiribati, shyness, or what I-Kiribati call, te mama, could be considered positive as it 
could be interpreted as a sign of respect or obedience. Children are taught from an early age to obey their parents, older brothers and sisters, teachers or people in authority without question. In the Kiribati tradition, when children are mama, which is also interpreted as quiet, they are expected to behave well during social gatherings, which reflects well on their parents. In the Pacific Islands, children are brought up to be respectful and good people so that they can be good ambassadors for their parents. "It is the family name and reputation that is valued the most" (Tone, 2005, p. 21). In Kiribati, when someone causes trouble in the village, workplace, or anywhere else, the first thing that people would ask is, whose son or daughter is it? No one would say, who is causing trouble? No one would be judged as an individual, but would be judged based on their parent or family. Bad behaviour is considered a reflection of the way their parents brought them up. That is why, raising children in a respectful way and not to challenge people with authority is the norm in Kiribati. Girls who are mama are generally regarded to be more pleasant compared to girls who are not mama. Parents are proud when their daughters have pride in themselves and wait until a boy approaches them. Girls who are mama are valued more because when they get married and undertake the role of a housewife, they are expected to be loyal to their husband who acts as the head of the family and as the main decision-maker for the family's welfare. As PAC migrants, women conducting themselves according to these expectations of te maneaba governmentality face challenges as compared to women who are more familiar with the differing gendered expectations in New Zealand society. The strong influence of te maneaba system recognises and respects the role of unimane as key decision-makers, and men are still respected as heads of their families, while women play a complementary role as the main caregiver of the family. This culture and identity are integrated in the principles of the Kiribati Catholic Church, which remains the main faith community for Kiribati people. Men are the leaders of the Church and within the family, where they are expected to love their wives who in return should love and respect their husbands. In the outer islands, which are predominantly based on a subsistence economy, women mainly stay home and perform domestic roles. Dora and Faustina came from the outer islands with no previous work experience, so they found it challenging to work in New Zealand for the first time. Josephine and Lily were full-time mothers before they came to New Zealand. It involved a big cultural shift from a developing economy to a developed one. These women needed to be coached on how to look for work in a new 
environment. These issues are demonstrated in the women's stories discussed throughout this chapter.

\subsection{TE AKI KAKARONGOA (SILENCE)}

Te aki kakaronga (silence) is part and parcel of te mama. It is imperative for nonKiribati people, especially New Zealand government departments, employers and teachers, to understand the significance of this cultural communication practice. Hang (2011) found that in the Samoan culture, children are raised to respect people with authority such as parents and teachers, by being expected to be le tautala (silent) at home where there are elders and visitors at home or during extended family meetings. Le tautala can be misleading for teachers, who have no awareness of this cultural communication practice, and need to understand it to be able to find culturally appropriate ways to elicit information from silent children to assist with their performance at school. Hang (2011) adds that in the Samoan culture, it is common for parents to tell their children to be good to their teachers. This is the same for other Pacific cultures, including Kiribati. Singh (2001) uses an example of Samoan children being raised to obey and respect people with authority in the classroom. The discipline that is currently given to these children with all good intentions which restricts the freedom to question anything, is for the whole wellbeing of the child and not just for their intellect. In my upbringing, my parents never told me to ask my teachers questions if I did not understand the subject. But when I went to secondary school and spent the school term break with my sister and her husband, a Palangi, on South Tarawa, my brother-in-law often advised me not to be mama and to ask my teachers if I have any questions.

It has been observed that most Kiribati people are humble and quiet, but also have pride in themselves. Generally, they avoid asking questions in public in case they ask the wrong questions and others would mock them. Some prefer not to speak English to an I-Matang (foreigner) in public in case they are either perceived as kantiroaki (a show off) or make mistakes, and attract unwanted laughter or judgement by others. Similarly, if they have skills in certain areas, they would not showcase these skills in public because they are conscious that others may think that they are kainikatonga (proud). There are different underlying reasons for not showcasing your skills in the Kiribati cultural context. When you do not showcase your skill, you are respected for being humble, and more people have trust and confidence in you. There is a cultural 
belief that the people who do not boast about themselves have a lot of wisdom. When someone boasts about their own skills, people do not tend to believe in them. Kiribati people prefer to hear good things about a person from someone else. This makes sense, for example, if you are looking for a good builder, you prefer to hire someone who is being recommended by someone else after having demonstrated their great work. There is a cultural belief that if you tell everyone that you are good at something, e.g. treating a particular sickness, by the time you use the traditional medicine to treat someone, it is no longer effective. There must be an underlying reason related to this tradition, but it is outside the scope of this present research. Based on my conversation with one of the Kiribati leaders in Wellington (S. Iotia, personal communication, May 12, 2019), there is also a cultural reason for not sharing certain skills and knowledge with others, as they may use it against you. If they do not use it against you, one of their descendants may use it against one of your descendants. The practices and cultural reasoning have impacted on the way Kiribati people think and act as explained in the governmentality theory relating to power and knowledge (Bevir, 2010). Generally, a combination of te mama and respect for authorities, and the upbringing of children not being allowed to question adults when they are talking would affect the children when they grow up. It creates unnecessary fear that impacts on their ability to communicate and is reflected by te aki kakarongoa (silence). This culture of te aki kakarongoa may have significant impact on children at school, because it means that they may find it difficult to ask questions or even challenge their teaching.

Whilst such attributes of te mama and te aki kakarongoa are considered normal in the Kiribati society, they pose barriers to Kiribati people when migrating to developed countries such as New Zealand. From the researcher's experience as a Kiribati RSE Liaison Officer, they affect many of these workers. For instance, some workers have lost control over their emotions because they have been mama or aki kakarongoa to share their issues and seek help. These issues are addressed in the Kiribati Institute Technology training programme by building their confidence to not be mama or too proud to ask for help. It is made clear in this training that their work performance can be affected if they are mama, or refuse to ask questions or seek help. These cultural barriers of te mama and te aki kakaronga are also evident in my research participants' stories. 
Whilst these women have the ability to communicate in English, these cultural barriers impact on their ability to contact employers, look for a house, approach a health or social service provider, or in their day to day lives. In the following section, I examine te mama (shyness) in the Kiribati cultural perspective, what it means in the Kiribati culture, and how it has affected the ability of the research participants to pursue permanent residency.

The underlying cultural reasonings could explain why most of these women were $a k i$ kakarongoa and mama to ask questions when they needed help. One concept, which I have been sharing with my Kiribati friends and even my children, is "you have nothing to lose". If you ask questions, or apply for a job or anything else, and the answer is no, you have nothing to lose. This culture of te aki kakarongoa can be misleading to nonKiribati people, and disadvantages many Kiribati PAC migrant women when they arrive in New Zealand, which is an individualistic society. Moreover, this creates more work for families and friends in New Zealand by having to assist Kiribati PAC migrants seeking a job offer, accompanying them to a health or service provider, and bridging cultural barriers. The job offer that is acceptable to Immigration New Zealand qualifies them for permanent residency. Whilst the PAC should have benefits for the sending country, the receiving country, and successful applicants and their families, the question is, who bears the cost of this triple win and why?

\subsection{KIRIBATI EDUCATION SYSTEM}

This section outlines the education system in Kiribati. It explains how young people are supported so that they are able to find work locally and abroad. To understand the linguistic challenges that most Kiribati migrants face on arrival in New Zealand, the following section provides some context. English is the official language for the education system in Kiribati starting at pre-school right through to tertiary. The Kiribati Ministry of Education sets the strategic direction and administers the education sector, while the Ministry of Curriculum Development and Research Centre manages curriculum development. In 2015, the adult literacy rate (15 years and over) in Kiribati was estimated at $79.6 \%$ (refer to Table A-5 in the Appendix), which was below the global adult literacy rate of $86 \%$ in 2016 (United Nations, 2019). It has been argued that literacy supports sustainable development by enabling

greater participation in the labour market; improved child and family health and nutrition; reduces poverty and expands life 
opportunities....[Literacy is also understood] as a means of identification, understanding, interpretation, creation, and communication in an increasingly digital, text-mediated, informationrich and fast-changing world (UNESCO, 2019).

Whilst the above statement is correct, there are other barriers related to culture that could affect the ability to communicate and participate effectively in the labour market. Examples of situations where literacy can be undervalued are evident amongst successful PAC migrants' stories, and are discussed later in this chapter. This affects people from different cultures moving from one country to any other which has a different culture and environment.

To some extent, it is important to show neoliberal influence in the Kiribati economy. Pre-schools in Kiribati are privately owned and mostly run by retired teachers who are self-employed. Primary schools were formerly owned by Churches until early 1980s when ownership was transferred to the government. Given the limited number of secondary schools, many young people did not get the opportunity to enter Form 1 at secondary school. They remained in the upper primary school to complete Classes 7 to 9. Churches, other non-government schools and the Peace Corps delivered voluntary courses in the outer islands to give young people living there the opportunities to learn English and other courses that gave them the capability to find employment or become self-employed. Some children who were serious about these courses were able to further their education by entering the Kauma Adventist High School in Abemama, and the Kiribati Catholic Post School Training (PST) at Teaoraereke. After successfully completing courses at these schools, students continued to be educated at the Kiribati Marine Training Centre (MTC), Kiribati Institute of Technology (formerly known as Tarawa Technical Institute), Kiribati Teachers College (formerly known as Tarawa Teachers College) or Nursing School. Students attending Kauma School have the opportunity to re-sit exams to continue to its senior secondary school in Suva, Fiji, or King George V and Elaine Bernachi (KGV/EBS), which is the Kiribati main government high school. The quality of English teaching from Forms 1 to 6 provides students with basic communication skills in English. However, an issue is that there is limited opportunity to speak English on a regular basis because everyone speaks Kiribati. In Tabwiroa St Joseph College and Taboria Sacred Heart College, where I was schooled, speaking English was compulsory. The teachers who were mainly from Australia, Ireland and America created an English speaking environment for students. 
As most teachers had international experience, I believe that this was a strategy to prepare students for further studies or work abroad. Listening to the experience of my research participants, this policy makes a lot of sense, and should be introduced in all other schools to prepare students if they should choose to go abroad.

The Kiribati Marine Training Centre (MTC, see Section 6.5.1) is the only education provider established to prepare graduates to secure employment on international seagoing vessels (Bell \& McDonald, 2013). MTC's education system is different from other education providers as it prepares students to be able to work abroad as seafarers. Most of the instructors and officers are German, New Zealanders or other Europeans, so the quality of teaching English helps students to be able to communicate with people from other cultures in English. By contrast, other education providers such as Kiribati Teachers College and the Nursing School are designed to prepare the Kiribati populace for the domestic labour market. However, there is an emerging trend to migrate for work or to live abroad. This has largely been driven by the availability of new opportunities (e.g. RSE and PAC), but also by the shortage of jobs in Kiribati as evidenced by high unemployment rates presented in Section 1.4.8. It is about time that the Kiribati education strategy is revisited and fine-tuned to the demands of the global labour market to make Kiribati workers more competitive internationally. Consistent with this argument, as stated in the Kiribati Development Plan 2016-2019, it is a government priority to support "developing a contemporary workforce with the ability to compete internationally and ultimately be in a position to capably mobilise to meet the demand for skills in neighbouring developed countries such as New Zealand and Australia" (Government of Kiribati, 2016b, p. 26). Teaching English as a requirement must be part of the Education national strategy as there are recent advertisements for roles of English Teachers and Trainers in Kiribati. The Volunteer Service Abroad (VSA) advertised a job for an English Teaching Trainer ${ }^{12}$ to work closely with the Kiribati Ministry of Education to assess and improve the teaching skills of English Teachers and Trainers to identify professional development pathways. The trainer will also focus on mentoring and skills transfer by teaching local teachers how to develop resources in line with the national curriculum (Volunteer Service Abroad, 2019b). While the aim of the programme is to equip Kiribati citizens to compete and work

\footnotetext{
12 The job number is 41041 and closed on 26 May 2019.
} 
internationally, the programme should also consider aligning their teaching strategy with other international education frameworks from countries, where most of its people are emigrating to, such as New Zealand.

Another job ${ }^{13}$ was advertised on the VSA's website for an English Teaching Trainer for the Kiribati Marine Training Centre. Among the requirements, the trainer must have "experience in teaching English as a second language" and have the responsibility to assess the current competency of the existing teaching workforce using the Common European Framework of Reference. The trainer is also expected to work with the Head of Deck Department, where most of the Seafarers work on foreign merchant ships and fishing vessels. This programme is aimed at providing long-term employment opportunities for young Kiribati people (Volunteer Service Abroad, 2019b). This is a more suitable type of training that successful PAC migrants would find helpful before coming to New Zealand, or upon arrival in New Zealand.

During Teburoro Tito's presidency, from 1994 to 2003 (Johnstone \& Powles, 2012), the universal junior secondary schooling programme was initiated in 1998 with four schools established on different islands (Government of Kiribati, 2006, p. 4). By 2002, all islands had their own government-funded and run junior secondary school, which starts from Form One (Year 7) and finishes at Form Three (Year 9). Primary schooling through to junior secondary schooling is free. The benefit of this system was that children who did not reach Form Four (Year 10) in secondary schools left with some basic level of English, helping their communication with non-Kiribati people. At the end of Form Three (Year 9), students have to sit an exam in order to continue to senior secondary school (Years 10 to 13) (Government of Kiribati, 2006, p. 4). In 2006, there were 16,239 students enrolled in primary schools (Years 1 to 6), 7,163 students enrolled in junior secondary schools (Years 7 to 9) and 4,296 students reached senior secondary schools (Years 10 to 13). There were 91 primary schools, 24 junior secondary schools and 13 senior secondary schools (Government of Kiribati, 2006, p. 5). According to Government of Kiribati (2016a, p. 12), there were 16,880 students enrolled in primary schools (Years 1 to 6), 6,423 students enrolled in junior secondary schools (Years 7 to 9), and 5,362 students enrolled in senior secondary schools (Years 10 to 13). Primary schools are still owned by the government. About 89 percent of

\footnotetext{
13 The job number is 41180 and closed on 26 May 2019.
} 
junior secondary students attend schools operated by the government (Government of Kiribati, 2016a, p. 17). About 45 percent of senior secondary students are enrolled at Catholic operated senior secondary schools, whereas 48 percent of student enrolments are at schools that are run by the government (Government of Kiribati, 2016a, p. 21). All private secondary schools charge school fees, while government secondary schools are subsidised. In addition, it was estimated that about 5 percent of students completing their secondary education gain university entrance. The majority of these obtained a scholarship to the University of the South Pacific (USP) in Fiji, with funds coming from the governments of Australia, New Zealand and Kiribati (Moy, 2008, p. 11). Students who do not meet the sponsor's criteria to enter an overseas university could do in-country training through the USP extension centre at Teaoraereke, Tarawa. This provides students with the opportunity to re-apply and get a scholarship to USP in Fiji or universities in other countries. The centre was established in 1973 and communicates with the main campus in Suva via satellite and radio telephone (Moy, 2008).

Improvements in the education system increased the supply of young people with qualifications from both secondary schools and tertiary institutes in Kiribati and abroad. As the government is the main employer, and the private sector is relatively small, the current labour market is not able to provide enough jobs, resulting in high unemployment amongst young people as discussed earlier in Section 1.4.8.

The PAC provides an opportunity for young people to reside permanently in New Zealand where they can pursue further education and find work. One of the requirements for permanent residency under the PAC is that the principal applicant must meet the minimum standard of English outlined in the Immigration New Zealand (2018b) Operational Manual. This is important because if applicants can speak and understand English, they will find it easier to secure employment and become a contributing member to New Zealand's society, whilst supporting the welfare of their family. Immigration New Zealand (2018a, p. 3) states that the minimum standard of English refers to showing evidence of an English-speaking background which includes:

- Certificates showing the applicant was taught in English for all the years they were at primary school and for at least 3 years of secondary school, or 
- Certificates showing the applicant was taught in English for 5 years at secondary school.

As explained earlier in this chapter, the Kiribati education system teaches in English from pre-school through to tertiary education. Most of the Kiribati migrant women who were principal applicants and their family including children aged above 16 years met the minimum standard of English. As explained above, the universal junior secondary schooling programme gives young people the opportunity to complete at least three years of secondary education. Thus, successful applicants must have met the PAC requirement of at least three years of secondary education. All of the Kiribati migrant women who participated in my research satisfied the minimum English standard, which enables them to meet the functional requirements for daily life. Their qualifications range from secondary to tertiary education level. They have the capability to work in places ranging from aged-care facilities to agriculture/horticulture industries, to professional/technical jobs in maritime, nursing school, and public sector offices. However, many of them have limited previous experience using the English language in the workplace or any other English speaking environment. Arguably, cultural barriers of te mama and te aki kakarongoa, the lack of English courses in Kiribati that prepare PAC migrants for work and life in New Zealand, and the lack of knowledge and understanding of these cultural barriers by Immigration New Zealand have contributed to burdens on PAC migrants. In this thesis, I use the term 'English culture', which I interpret as the core work and life skills required by PAC migrants in order to be competitive and thrive in the global labour market. These migrants should have the confidence to talk with employers, ask questions of authorities with confidence, and settle successfully in New Zealand. This English culture should be embedded in the Kiribati education system so that school leavers are well prepared and empowered to work anywhere in the world or run their own business that is competitive in the global market. This reflects the Kiribati government's 'migration with dignity' policy, aimed at preparing Kiribati people for emigration. In Nic Maclellan's interview with Kiribati's (former) Foreign Affairs Secretary, Tesse Labourne stated that,

[t]he government's migration strategy aims to improve language, workplace skills and qualifications, in order to make i-Kiribati Kiribati citizens - "competitive and marketable at international labour markets," with options for labour mobility developed over time. "The 
key element of our policy is the up-skilling of our nationals at all levels, though we are focussing on the vocational and technical levels at the moment," Lambourne says. "We are improving our primary and secondary education system, starting from the basic foundations of education, but the focus of the policy is strengthening our local and national training institutions." (Maclellan, 2011, p. 2).

The 'Migration with dignity policy' aligns well with these women's stories in this research, which strongly indicates the need for the Kiribati government to prepare its citizens for emigration, and to find work and settle well in a new society without much difficulty. In this way, when I-Kiribati people migrate to New Zealand under the PAC or other immigration policies, they would be able to easily find an acceptable job offer and not become a burden on New Zealand tax-payers, including both extended and host families who have already settled in New Zealand.

Whilst climate change and associated issues around relocation are not the focus of this thesis, the English culture concept will provide a long-term solution not only for future PAC migrants but other I-Kiribati immigrants seeking overseas employment on a competitive level. Given high unemployment rates in Kiribati, advocating for teaching English culture in school from pre-school through to tertiary education including the University of the South Pacific centre in Kiribati as well as local education institutions is critical. In the following section, I discuss the role of the Kiribati Marine Training Centre that delivers English programmes aimed at building the capability of Kiribati seafarers to overcome the language barrier and prepare them for work in a new environment where English is the main means of communication. Although this research focusses on women, I include information about this training centre because it is a good model for preparing these women for finding work and integrating into a new society. The Kiribati government should take more responsibility to provide similar training to prepare citizens planning to apply under the PAC as well as successful PAC applicants before migration.

\subsubsection{Marine Training Centre}

Kiribati's Marine Training Centre (MTC) was established in 1967. It provides a valuable source of employment for I-Kiribati. Since 1984 about 3,500 male students were recruited to enter the courses, with 2,100 graduating. This represents a pass rate of $60 \%$. Over 27,000 jobs with an average of 936 jobs per year were created with the German shipping line called South Pacific Marine Service (SPMS) (Bell \& McDonald, 2013). New Zealand has been a significant supporter since 1984, contributing about 
25 percent of the total cost of running the MTC. "The Kiribati government and people can be justly proud of the Centre as it has the distinction of being the only institution in the Pacific to achieve White List status under the Maritime Labour Convention 2006, thus facilitating future employment opportunities for seafarers" (Bell \& McDonald, 2013, p. 4). Learning English is an important requirement as students need to be able to communicate with other crews and officers after they graduate, and other people they meet when travelling overseas. Overall, the training programme at MTC was designed to build the capability of students for work abroad. This was highlighted in the story by Teiti. Bou (a PAC principal applicant) whom she assisted was trained at MTC and had previous work experience abroad. After he sat the examination to be certified to work on New Zealand maritime vessels, the examiner was impressed with his results, and his good English. Clearly, the type of training that he underwent at MTC built his capability and confidence in the English language. It is assumed that MTC provides the level of English that is needed to be taught in the Kiribati education system. This then meets the needs of both the domestic and international job markets.

\subsubsection{Kiribati Institute of Technology}

Kiribati Institute of Technology (KIT), formerly known as Tarawa Technical Institute, was established with the aim of catering mainly for jobs in the area of trades such as carpenters, mechanics, and clerical work such as typists, accounts clerks, office managers and personal assistants. Recently, due to the growing youth unemployment rates locally, it makes a lot of sense for KIT to run programmes to prepare young people for work overseas in the areas of hospitality, aged care, construction, farming and other industries. KIT works in partnership with the Australia Pacific Training Coalition so that the certificates it awards are recognised in Australia and across the Pacific. This will help a KIT graduate to find work in relevant jobs in Australia and other Pacific countries. KIT also runs pre-departure training for the people of Kiribati who have been successfully recruited to work in New Zealand and Australia as part of the Recognised Seasonal Employers (RSE) and Seasonal Worker Programme, respectively. The training covers a number of areas. One of which is to help new workers understand the way of life, culture and environment in these countries (Ministry of Labour and Human Resources Development, n.d, p. 2). For example, it is important that these workers know how to manage their self-care, what to do if they are sick, who they should report to, types of offences (drink and drive, drugs), how to 
save their money, and how to identify and achieve their personal goals that support their wellbeing. This type of training programme would be useful for successful PAC migrants to undertake before coming to New Zealand.

In the following sections, I examine the women's stories to understand how the language barrier, te mama and te aki kakarongoa constitutes a barrier to PAC migrants' successful migration experience. Whilst culture should be an asset that these migrants bring with them and contribute to their new society, it is important to uncover how cultural barriers could be a problem for many of these women, especially when the receiving country has no cultural understanding and knowledge of the Kiribati culture.

\subsection{CULTURAL COMPETENCY}

This section further discusses the women's stories. It examines how English as a second language and the cultural barrier of te mama and te aki kakarongoa have a significant impact on their successful migration under the PAC. The women who were not mama had the confidence to approach Immigration New Zealand and employers, had lived abroad, spoke fluent English, or had previous work experience, or had families and friends in New Zealand helping them. They did not experience as many problems as other participants. These women, reflected by composite Woman 3 and Woman 4, did not have any barriers when communicating with Immigration New Zealand, New Zealand employers or the New Zealand High Commission in Kiribati.

The women as reflected by composite Woman 11, faced language and cultural barriers. Whilst most of them had completed at least Form 3 secondary schooling, which should have provided them with enough basic English to communicate, this did not prepare them to work independently and settle in a new culture and environment.

Mary shared the same experience as composite Woman 11. She was in tears as she shared her story about her son. She said that when she submitted her application for permanent residency, she included her son as he was within the required age group of less than 18 years of age. By the time her application for permanent residency was nearly approved, her son was over the age limit, so the Immigration officer advised her to remove her son from the application. 


\section{Mary [came to New Zealand in 2001, but was selected in the PAC ballot in 2004]}

...te kananokawaki ba e aera arei are ngke e a tia au bai ao ngkanne immigration a manga raa, a manga kanakoia natiu ni kabane mai iaan au application kee

...it was sad that when my application was completed Immigration New Zealand removed one of my children from my application.

Researcher

Ibukin ae aonga $n$ raa?

Why is that?

Mary

... a tuangai are a kangai ee e a baenikai ngkai am bai ibukia natim ba are natim are temanna e a over age ma ngai are akea au taeka ni kan mena nakoia iaan are e aera kanga ko kabi raoi ba are ko aki naba ata raoi tein am taetae ni matang ba are ngke tao e a manga bure ao ngaia are a bon roianiko...Eng ao a bon ataia ba (ngke e karaki ao $\boldsymbol{e}$ tang)...kanga bon iai riki au iango ni kan tiku ao a bon kangai naba e aki kona $n$ approve am bai ngkana arona ba a mena natim iaam ba e a over age natim ngkanne nanona ko na manga bon apply te bai teuana ibukia ao ko na manga bon kaoia.

...they told me, your residence application was delayed because one of your children was over age. I could not ask any questions to seek clarification, because I could not speak English well and I did not want to say anything wrong... Yes, they know that (she cried when she told her story) ...I wanted to stay but they told me that because one of my children was over age, they could not approve my application. They told me that I will have to apply under a different category in order to bring them over.

Researcher

Anne ana advice te immigration?

Is that the advice from Immigration New Zealand?

Mary

Nanona bon ti temanna natiu ae e aera arei te mane ma are te aine kanga bon akea menana iai ba e na bon roko ma are tamana e bon taua ma ngai ngkanne I kan titiraki iaan are a ataia ae iai natiu ae I kamena au bai iaana ao a ataia ae e a bane ana tai kanga akea aia ibuobuoki

I only had a problem with my son. I did not have a problem in including my daughter, but it was her father, who did not give his consent. They knew that I included my son in my application when he was within the age limit and while waiting for the approval of my residency, he turned above the age limit. I am questioning 'why didn't I have any help in this regard?'

Researcher

Ba a taku ba e a over age?

Did they say he was over age? 
Mary

Eng ao e rang maan au bai irouia n apply n tiku ni process naki.

Yes, it took a long time to process my application.

Sally (another participant in the group)

Nanona e bon tuai koro 18 te moantai?

This means that when you first included him, he had not turned 18 ?

Mary

E aki ba te aekaki ae tao 14 ke 13

No, he was perhaps 14 or 13

Researcher

Akae

Really!

Sally

I aa, kanga e a rang unfair kee?

It is unfair, isn't it?

Mary

Ma are ibukin e rang karako tera...te taetae ni matang $n$ aron are...ti a bon say yes naba ba ngai irou, I a tii say yes naba iaan are e aera a withdraw aran natiu ba ngai irou e a useless ma I a tangiria riki are ba tao iai riki aia chance $n$ taai aika a na roko ke, kanga te aekaki anne.

As I had limited ability to speak English at the time, I just said yes agreeing with their decision, thinking that there may be other opportunities to bring them in the future.

\section{Researcher}

Ma e rang kananokawaki ngke ko bon moan apply ao natim bon 14

It is sad to hear that when you first applied your son was 14 .

Mary's respect for people with authority, te mama to make mistakes when speaking English, and inability to use the English language to talk with people in authority disadvantaged her. When someone with authority says something, Kiribati people generally would not challenge it, but they would agree to show respect even though they were not happy, or would not agree. This is an element of te aki kakarongoa culture. This is demonstrated in Mary's statement, "Ma are ibukin e rang karako tera... te taetae ni matang $n$ aron are...ti a bon say yes ba ngai irou, I a tii say yes naba iaan are e aera a withdraw aran natiu (As I had limited ability to speak English at the time, I just said yes, agreeing with their decision)". Whilst she had functional English or basic communication, she did not have the ability to talk with staff at Immigration New Zealand. To the Kiribati people, those people within Immigration New Zealand have the power, and you cannot go against them. The easiest thing for 
her was to say 'yes' agreeing to the withdrawal of one of her children from her application. In this situation, it would have been beneficial for Mary to have had an agent providing language support. As a mother, it must have been very painful to agree to the removal of her child from her application. During te maroro, Mary cried as she reflected on this painful experience, but she had no choice as there was no one who could advocate on her behalf. She added, "iaan are e aera kanga ko kabi raoi ba are ko aki naba ata raoi tein am taetae ni matang ba are ngke tao e a manga bure ao ngaia are a bon roianiko (I could not ask any questions to seek clarification, because I could not speak English well and I did not want to say anything wrong)". She felt disabled or paralysed as she could not express her opinion. Mary had a secondary school qualification, but was without prior exposure to an English speaking environment. Whilst all of the research participants, who were principal applicants met the English requirement under the PAC, most of them experienced difficulty in understanding the New Zealand accent, terminologies and the culture of speaking English when they first arrived. This would likely apply to other migrants from countries where English is their second language. Although English was taught in the Kiribati school system, it did not prepare them to live in an English-speaking culture and environment. Arguably, whilst the rich Kiribati culture of respect would be an asset to New Zealand's society, Mary and other PAC migrants need to be well informed that asking and clarifying questions with someone with authority does not signal disrespect.

Some form of culturally appropriate training is needed to support Kiribati PAC migrant women to be empowered to ask questions and seek help, and not be mama for fear of making mistakes as English is their second language. This would help relieve their stress, attain a better quality of life and enjoy being a new settler in their new homeland. Researchers (e.g. Brach \& Fraserirector, 2000; Ortactepe, 2013) argue that cultural competency training increases cultural knowledge and skills, and addresses problems stemming from the cultural mismatches that result in the misunderstanding of each other's behaviours.

Based on the experience of my research participants, there is a need for the Kiribati government to provide more support through its education system that could focus on the English culture and prepare its citizens who choose to emigrate. A similar programme to KIT's pre-departure training for the seasonal workers in New Zealand 
and Australia is needed by successful PAC migrants in order to prepare them for emigration and be able to adapt to the new culture and environment.

In the following story, Reka shared her experience when she attended an in-country workshop in Kiribati before coming to New Zealand. At the time of my maroro, Reka had recently arrived in New Zealand after being selected under the PAC. She reported that Immigration New Zealand organised a workshop in Kiribati for successful participants, so they knew what to do when they got to New Zealand.

\section{Reka \\ ...e a manga taetae ni matang ti aki naba rang $n$ ota ba are akea ana tia rairiri...ti aki naba rang ota $n$ ana taeka (E nanonna ae e aki ota $n$ te ee ni matang). \\ ...they spoke to us in English so we didn't understand anything and there was no translator... we didn't understand what he was saying (She meant that she did not understand the Kiwi accent).}

Although all PAC applicants had basic communication skills in English as they met the English requirement under the PAC, it was evident from my participants' stories that they need translation support. In view of this, it is necessary that a good Kiribati translator, who understands both the New Zealand and Kiribati culture, participates in this type of workshop. It was significant for all participants to understand what to do when they got to New Zealand. Migrating from one country to another involves making big decisions and significant transformation in people's lives. Connell (2014, p. 74) argued that "[m] igration decisions are usually shaped within a family context, as migrants leave to meet both family and personal expectations, the key one usually being material support for kin". Coming into a new culture, arguably they need to be well supported in order to be successful. When Reka said, "e a manga taetae ni matang ti aki naba rang ota (spoke to us in English so we didn't understand anything)", it appears that the workshop lacked cultural competency to ensure that the target audience understood the purpose of the workshop. Cultural competency training will improve communication, cultural awareness, knowledge and skills (Brach \& Fraserirector, 2000, p. 185). Cultural competency is about respecting differences and making sure that they are bridgeable in order to improve clear communication (Schouler-Ocak et al., 2015, p. 432). Arguably, it is important that facilitators of PAC migrant workshops are aware of Kiribati cultural factors before running such workshops to elicit information from successful PAC applicants. This would ensure that they understood everything discussed in the workshop. As Reka explained, even 
though the participants did not understand anything, they were mama to ask questions. It is expected that if the workshop facilitator understood the Kiribati culture of te mama and te aki kakarongoa, they would have used culturally appropriate methods during the workshop, to make them actively engage in the workshop. The quality of teaching English in the Kiribati education system must build the confidence of students, so when they leave school they are able to communicate effectively with I-Matang and teachers. Two of my participants (Twenty Five and Cookie) said that in New Zealand, if someone does not ask questions, no one would know that help is needed, so it is likely that no one would provide any help.

Mary and Reka's stories, as well as the experiences of other PAC applicants who did not formally participate in my research but spoke with me anecdotally, articulated the need for PAC decision-makers to take into consideration the cultural lens. This would help them understand the Kiribati PAC migrant women's needs and to design support service for them. Kiribati culture contributes to the richness and diversity of New Zealand's multi-cultural society. In addition, the PAC will also benefit the New Zealand labour market given the original intent of the scheme as described in Chapter 1. The New Zealand government announced that the quota system (PAC and Samoan quotas) would not only benefit Pacific nations, but would also support New Zealand's economy at a time of low unemployment (New Zealand Government, 2001, 2004a). Therefore, it is important that New Zealand Immigration should 'understand the Kiribati culture' when selecting PAC applicants in order to create a more successful and positive experience.

While the successful PAC applicants meet the English language requirement, they need to be empowered to make meaningful communication in order to thrive in a foreign society and culture. Assistance by Immigration New Zealand and the Kiribati Government is paramount and needs to be provided from the moment they are invited to apply for permanent residency. Although Kiribati families will always help other new Kiribati migrants, there is a need for the state to take more responsibility to help these migrants. New Zealand is not the same as Kiribati where the cost of living is relatively low. As consistently mentioned by the research participants, they needed support from Immigration New Zealand in order to find work earlier so they could find their own house. Identifying language support agents in Kiribati and New Zealand to help successful PAC migrants during the first six months would be sufficient. Helping 
with development of their curriculum vitae and interview skills would also be useful. In this way, it would help new migrants become independent and adapt to the New Zealand culture and environment, without losing their Kiribati cultural identity. Alzayed (2015) argued that it is important to preserve one's culture not only for one generation but through generations. It is important that our children experience our culture so that they develop a connection to the home that we have left behind. Being new to the country, these women's stories articulate the need for a Kiribati translator or agent with good knowledge of both New Zealand and Kiribati culture to work with Immigration New Zealand throughout the entire process starting when applicants are invited to apply for permanent residence until they are settled. Disseminating these messages using culturally appropriate methods (e.g. video clips in the Kiribati language) is crucial to help these migrants understand the process. In the next story, Molly articulates the need for a training programme to build PAC migrants' confidence to cope with the new culture.

\subsection{SELF-ESTEEM}

Molly claimed that the language barrier is a real issue for many migrants coming under the PAC, particularly with finding work. Fortunately, she did not experience many difficulties compared to others because she received language support from family, and members of the Kiribati community and other non-Kiribati people from another Church in New Zealand. English being her second language, and being new in New Zealand, she acknowledged that without their support, she would have faced a lot of difficulties in contacting potential employers to secure a job offer, registering with a local GP, and looking for a house.

\section{Molly [selected in the PAC ballot in 2011 and came to New Zealand in the same year] \\ ...ti mananga man te aba ae te kauoua te English tiaki are first language $n$ aekakin anne tao ti bon tuangaki kawai ae ti na...ibukin buokara $n$ kareke makuri ke tao ibukin te taetae ni matang ke tera. \\ ...we come from a country where English is our second language, so we need help to look for work, or in learning English to be able to communicate clearly.}

As English is the official language in education and work in Kiribati, it is expected that applicants coming to New Zealand were selected because they met the English literacy requirement. Most of these participants including Molly gained a Form 6 
qualification and had previous work experience, hence they were expected to be capable of communicating in English. While Molly said that "ti mananga man te aba ae te kauoua te English tiaki are first language (we come from a country where English is our second language)", arguably these migrants need training to help build their confidence and capability to cope with the new culture, be able to apply for jobs, integrate with people from other cultures, and use English in their day-to-day activities. Learning English as a second language entails the need to establish a social network to practise the language and understand the culture and politics of the host culture in order to make meaningful communication (Ortactepe, 2013). Ortactepe shares an example where two international students got on well even though they did not understand each other's language, but felt they shared the cultural similarities and status as international students and could communicate meaningfully with each other. The Kiribati PAC migrants need to learn the language to make meaningful communication when they look for work, access good healthcare and carry out their daily activities.

Cookie shared her experience when she and her husband were assisting many PAC migrants' families. This is how she understood the challenges they faced.

\section{Cookie [selected in the PAC ballot in 2007 and came to New Zealand in 2008]}

I bon ataia ba iai naba ake a reke n te PAC ko rang kan angania naba te life ma a bon disadvantage are aki taetae ni matang.

I know there were people who came under the PAC and you wanted to help them so they can have a good life. Their inability to speak the language had disadvantaged them.

When Cookie said "ko kan angania naba te life (you wanted to help them so they can have a good life)". This shows that many PAC migrants had been disadvantaged not only by the language and cultural barriers, but other factors such as their socioeconomic background. Cookie was highly educated and had previously worked in Kiribati and overseas. Her level of communication was much better compared to some of these women, who mainly have only functional English. Cookie did not experience these cultural barriers because of her socio-economic background. She had worked previously, attended international conferences/workshops in her previous job in Kiribati and lived overseas (not New Zealand) for more than 10 years. She had good communication skills to liaise with Immigration New Zealand authorities for assistance. She did not have as many problems as the others. Cookie's personal 
experience indicates that the PAC works for people of higher socio-economic status. It also highlights the PAC policy gaps in areas of training and support for PAC migrants from a lower socio-economic status. Another important area of training and awareness before coming to New Zealand, concerns their human rights relating to employment and other rights.

\title{
6.8 GENDER AND HUMAN RIGHTS
}

Reka's story shows the needs of Kiribati PAC migrant women to understand their human rights. She shared her story when she was interviewed by an employer with a Kiribati wife who helped with translation.

\begin{abstract}
Reka
...e a manga bon titirakinira "ngkami tanga" ao ngaira eng ao ngkai kam babairea ami utu ke kam aki ao ngaira ba ti a bon maan ni iein ao ti tuai kariki ao are e manga tuangira buuna ba kanga te I-Matang arei e aki tangira...kanga e ti rang kaungaia riki single ibukina are mwina aine a bikoukou ao a kabuanibai n te farm kanga te aekaki anne ngaia ngaira ti nai $n$ iangoa are e na reke ara... E kangai "iai naba te aine ae roko n butia ibukin job offer" ma e interview nna naba "ko aoraki ko iein naba ngkai" ao neierei e a bon kakangai naba, "I aki bikoukou" ao ngaia e aki makuri neierei irouna ba e bikoukou ngaia are e rang un ngaia are e rang interview nira ao e aki kan butimaira ngke e tuangira are ngkai "I rang raraoma iroumi kam rang uarereke ao ngkana e bikoukou”.
\end{abstract}

...he asked if we were a couple and if we use forms of family planning. We told him, we are married and have been living together for a long time and we have no child yet. The wife told us that her husband preferred single women because he fears that when he employs married women, they will get pregnant or get injured on the farm. She also said that there was another woman who also came to look for work and he asked her if she was married and pregnant, but the lady kept saying, "no I am not pregnant". He discovered later the lady was pregnant, so she no longer worked there and the owner was very angry. That is why he interviewed us thoroughly and he was not willing to employ us, and told us "I am worried you are very young and you might get pregnant".

Because of her gender and marital status, the employer nearly declined Reka's request for a job offer, but the employer's wife persuaded him to reconsider their application. It was clear from Reka's story that the employer was going to decline her request because he did not want to take the risk of her becoming pregnant after employing her. While Reka felt that her gender and marital status had disadvantaged her, she was 
constrained by cultural barriers from reporting such issues to Immigration New Zealand for future service improvement.

As discussed in Chapter 3, Nickie also felt that her gender had disadvantaged her. The employer that she approached did not offer her a job when he heard that she had a small child to look after. Fozdar and Torezani (2008) found that discrimination is a barrier to employment based on a number of factors including gender. It is expected that there were other Kiribati migrant women who might have experienced the same issues as Reka and Nickie, but their inability to make meaningful communication and cultural constraints prevented them from reporting such issues to Immigration New Zealand. Arguably, whilst it is in the best interest of New Zealand companies to sustain their operation, they need to have the confidence in their workers to do the work. This is where the women with children could be disadvantaged as there are times when children may get sick so mothers would miss work. Future in-depth research to identify evidence of discrimination based on gender and marital status is required. According to the New Zealand's Human Rights Act (1993), the prohibited grounds of discrimination include areas such as

- $\quad$ sex, which includes pregnancy and childbirth;

- marital status, which means being (i) single, or (ii) married, in a civil union, or in a de facto relationship.

Fairly, the employers must consider the merits of employing applicants based on their skills and experience and other qualities, and women must not be discounted because of their gender and marital status. Essentially, this may be a case where the employer is unaware of the law or where they deliberately violate the law because they know they could get away with it because of the desperation of migrants to find work and lack of knowledge of their rights in New Zealand. In the following story from Taaro, there was a breach of employment legislation by an employer who had offered a job offer in return for a payment.

Like most of the applicants, Taaro was desperate to get a job offer within the required timeframe for submitting the necessary documentation.

\section{Taaro [selected in the PAC ballot in 2009 and came to New Zealand} in 2010]

ao teuana e kaboaki i Auckland. $\$ 400$ tabun $\$ 485$, kanga teuana te rest home ae offer e aki kamakuriko ikekei ma e ti anganiko te job offer ao 
ngaia ngkanne ti a tara ngkanne e nga ba are te criteria e na riai $n \$ 14$ $n$ te aoa te rate kanga $n$ taai akanne e taraki ngai ma buu ao ti temanna natira $n$ te tai anne ti anganaki $\$ 14$ te rate ae tina riai ni makuri temanna $i$ aona ngaia are ti tara are ti kaboa arei $\$ 14.50$ are ti anganaki ao are kanga ikekei kanga te rate $\$ 12.50$ kanga e rang uarereke ngaia are ti aki anaa are $i$ Wellington ao ti anaa are ti kaboa ti a kaboa ngkanne ao e bane naba ara mane.

One job offer was bought in Auckland, at the cost of around $\$ 400$ or $\$ 485$. It was a rest home that offered the job offer, but did not employ you. To meet the income threshold, my family needs at least a $\$ 14$ hourly rate. So, we were happy to buy the job offer that offers $\$ 14.5$ and declined the offer at $\$ 12.50$ in Wellington. We bought the job offer, and then ran out of money.

Purchasing a job offer raises a potential risk relating to trafficking. Researchers (e.g. Askola, 2010; Fozdar \& Torezani, 2008) found that many migrant women face challenges finding their experiences and skills are not suited to available jobs in the receiving countries. This means that they are likely to do the jobs that are most unwanted by the locals and are prone to different forms of trafficking.

In attending the Recognised Seasonal Employer scheme annual conferences between 2017 and 2019, I understood the Minister of Immigration New Zealand and his officials delivered a clear and strong message to employers to follow best practice and comply with employment legislation. The message was very clear that breaching such employment laws can lead to serious offending. This information also applies to Kiribati PAC migrants. Reka and Taaro's story as well as other women's stories demonstrate the need for the PAC to ensure that successful applicants understand their rights, and what processes they need to follow and how to report any incidents. A culturally appropriate workshop would be critical so that PAC migrants understand their rights when they come to New Zealand. This can be challenging as some of them would be desperate to get a job offer to meet the elibility criteria for residency. Whilst educating PAC migrants to help them understand their human rights, this could be challenging for those who are on a visitors' visa and are desperate for a job offer. Arguably, urgent policy changes around the PAC are needed to protect the welfare of PAC migrants from any form of trafficking.

The next stories demonstrate how three women were satisfied with Immigration New Zealand services while the other two were upset with how their case managers had been serving them. This shows the importance of meaningful communication, and how 
the PAC policy setting ensures that information can be clearly communicated to immigrants.

\subsection{MEANINGFUL COMMUNICATION}

Cookie communicated directly with Immigration New Zealand from overseas to seek assistance with a job offer prior to coming to New Zealand for a job interview. She and her husband are both qualified and had been working abroad (not in New Zealand). She did not want to live with her relatives for long without any work. She shared her success.

\section{Cookie}

Ba ngkekei e rang tikiraoi ba a kakaia tenan employers ake a kona $n$ offer te job nakoia nake a reke n te PAC. A kakae beforehand, are bon tuangaia kain te PAC ke ngkam ngkana ko bon titiraki ao ko bon anganaki ao ngkana tao ko bon aki. Ao ngai ngkanne inanon Maati are a nang roko au koraki I a plan imain are e nang otinako au PR ao I a kakaea naba te auti imaia ao e a reke nae ngaia are ti a move in nakon ara auti ao a roko raoi $n$ te week anne.

During our time, Immigration New Zealand was helpful in identifying employers who can provide a job offer to people who have been selected under the PAC, before coming to New Zealand. I asked the PAC team for help. I think they only help you if you ask and if you don't ask perhaps you don't get assistance. In March before my family arrived, I started looking for a house so when my family came, we all moved to our new home during the same week they came to New Zealand.

Compared to some of the other participants, Cookie was confident and communicated from overseas with her case manager in New Zealand and bubuti (request) for assistance in obtaining a job offer. In her communication to her case manager, she explained that she had children that she wanted to bring, and needed to work in order to support them. If she did not work, she would become a burden on the host family.

The case manager arranged two potential employers (as a mobile caregiver and at a $\mathrm{Z}$ petrol station). She came on the Monday, she was interviewed on the Wednesday and offered the job at the same time, and she submitted it to Immigration the next day. This happened all in the same week. The following week, her work permit was approved, so she commenced work straight away. Her permanent residency was approved three months later. She arranged a house to rent before her family arrived in New Zealand.

As mentioned earlier, there are gaps in the PAC policy. For example, the lack of clear and culturally appropriate workshops and information about migrants' rights, lack of 
housing support, how to find work, and how and where to access healthcare services. These need to be addressed when delivering a workshop to applicants before leaving Kiribati and when arriving in New Zealand. In this statement, "A kakae beforehand, are I bon tuangaia kain te PAC ke ngkam ngkana ko bon titiraki ao ko bon anganaki ao ngkana tao ko bon aki (They identified an employer before I came to New Zealand because I asked the PAC team for help. I think they only help you if you ask and if you don't ask perhaps you don't get assistance)". Cookie demonstrates the gap in the PAC not supporting most PAC migrants who have language and cultural barriers. Cookie was not mama and had the confidence to approach her case manager for help. Her education, previous work experience and international exposure made her capable of communicating her needs to her case manager about the healthcare of her children. While she could stay with relatives and look for work at the same time, Cookie was concerned about who would be responsible for feeding her children if she had no work. Cookie was smart to voice this to her case manager. It is New Zealand's priority to ensure the healthcare of all New Zealanders, and reduce health inequality (Ministry of Health, 2016). This will be discussed further in Chapter 6. Having lived abroad made her more integrated and easily adaptable to the new culture. She did not require as much extended family support as other participants because she worked shortly after she arrived in New Zealand.

Another research participant, named Twenty-Five, shared a similar experience to Cookie. Twenty-Five did not experience many difficulties because she asked staff at the New Zealand High Commission in Tarawa for help before coming to New Zealand. Similar to composite Woman 8 , Twenty-Five had the socio-economic advantage and the confidence to seek help from the New Zealand High Commission in Kiribati. Even if she did not know anyone in the office, she did not have either of the cultural barriers of te mama and te aki kakarongoa to impede her communication.

\section{Twenty-Five [selected in the PAC ballot in 2006 and arrived in New Zealand in the same year] \\ Ti kona n buokiko kai ko tuangira ae ko maaku n mananga $n$ tii ngkoe ao ko aki sure ba e na reke iaa am makuri so before are I take off $n$ nakomai ao e kaman reke a kaman tauraoi au CV a kaman copy a kaman send nakomai a kaman send kain te New Zealand High Commission.}

We (the New Zealand High Commission staff) can help you since you told us that you are scared to travel on your own and you are not sure 
whether or not you will find work. So, before I took off to come to New Zealand I had already prepared my CV, and the New Zealand High Commission in Tarawa sent a copy of it to Immigration New Zealand in New Zealand.

She had lived in another Pacific Island before living in Kiribati, and spoke good English. Being young and single, she was nervous about coming on her own to New Zealand. From Twenty-Five's success story, it is evident that she was not mama to ask staff from the New Zealand High Commission in Tarawa for help, and maintain a strong relationship with her case manager on arrival in New Zealand until she received her permanent residency. The New Zealand High Commission did not organise workshops to prepare successful PAC migrants before coming to New Zealand. However, what the staff had done for Twenty-Five was something that other successful PAC migrants really require. As described earlier, when Kiribati PAC migrants meet the English criteria, they still require language support to be able to be integrated well into the new culture, and have the ability to approach authorities, take responsibility for their healthcare and day-to-day activities. As discussed in Chapter 4, most of the participants relied on their Kiribati families and friends in New Zealand to liaise with employers and authorities. Arguably, this may not only to have to do with te mama, but a combination of a range of factors including social capital and unfamiliarity with the New Zealand system and culture of the host country. The Kiribati cultural expectation to respect and not to question parents, teachers and seniors and family means that they lack the ability to take responsibility for individual problems which disadvantage many PAC migrants when they come to New Zealand. It might have affected the Kiribati people's confidence to approach authorities to ask questions or seek help. There is a Kiribati joke that when you talk with strangers, others would laugh saying that you are "kakan rena (wanting to make friends)". This phase reflects the Kiribati reluctance to ask questions and the fear to make mistakes or be rejected.

In the following story, Florence had a child to care for, coupled with other factors such as being new in the country and having no transport and she found it very difficult to look for work.

Florence [selected in the PAC ballot in 2005 and came to New Zealand in the same year]

.... ba ngaia kam kona $n$ ibuobuoki ni karekea te job offer ao e aera kam bon... ao a taku ba a bon kona naba ni buokia ake a taku ba a kainnanoa buokaia $n$ aron ngkoe ko a tuangira ibukin natim (Ngke e karaki ao e rang tara $n$ un). 
....so, you can help with providing a job offer now and why could you not....and they said they can help those who needed help for example in your case you told us you have issues looking for work as you have a child to look after (She showed signs of anger when she recounted this experience).

Florence is well educated and was confident in explaining her difficult situation to Immigration New Zealand and eventually they agreed to help her find a job offer. When she said, "ba ngaia kam kona $n$ ibuobuoki (so, you can help)" this shows that Immigration New Zealand can help when people ask and justify their needs.

While many other migrant women do not have the same level of confidence as Florence, Cookie and Twenty-Five, and other participants do ask for help, how else can Immigration New Zealand be made aware of the gap in cultural understanding to overcome language and cultural barriers? Asking Immigration New Zealand or other authorities, does not require someone with a high qualification, or level of exposure to other countries to be able to do that. What these women require is for the PAC policy to recognise that the participants have different needs, to better understand the Kiribati culture of te mama and te aki kakarongoa and weave the PAC strategy around these social identities.

The experiences of Cookie, Twenty-Five and Florence demonstrate a benchmark of what other migrants need to achieve so they find it easier to process their permanent residency. To bridge the PAC gap and stop perpetuating social disadvantages in the new environment, it requires a good understanding of the underlying reasons for the Kiribati culture of te mama and te aki kakarongoa and how to address them. As discussed earlier in this chapter, other researchers (e.g. Brach \& Fraserirector, 2000; Schouler-Ocak et al., 2015) support this argument by emphasing the need for cultural competence training. As mentioned earlier, it could be related to upbringing so it cannot be changed overnight. Including teaching English culture in the Kiribati education system would make a change, but the impact may not be realised until the next generation. Improved changes to the PAC policy, using cultural and feminist lenses, are needed now to help successful PAC migrants in the future. This would prepare them for confident meaningful communication with authorities when they come to New Zealand, and to access childcare and other essential services.

In the next story, Maria shared her story about how she had been travelling between Fiji and New Zealand and visiting Immigration New Zealand's office in Fiji to provide 
the required job offer. When two or three different job offers were rejected, she finally broke down.

\section{Maria [selected in the PAC ballot in 2004 and came to New Zealand in 2005]}

... a taraia kanga a kabara bae, kam a tarebonia ami lawyer anne ba e aera arei, kam a manga tarebonia am lawyer anne ba e aki tau boon bum anne kam aki kona ni maeu ni boona aei ma ti tangira riki te job offer ae bubura riki tera maitin boona $n$ te ririki are e na kona ni kamaeui ngkami are maitin natimi ni kaaman ngaia are ngai ngke e tuangai arei ao I a bon broke down nae ikekei are I a bon roko naba ae I a rang upset ao I a bon tang nae. (Ko kona n nora teina ngke e un, ngke e taekina ae 'I a bon broke down').

...they only looked with no interest, and they said, you ring your lawyer to tell him that your husband's salary is insufficient. We want a job offer with a higher salary per annum that will support you and your children. When they told me that, I broke down, got really upset and burst out crying. (There was a visible sign of anger when she said 'I broke down').

One can understand Maria's frustration when her job offer was rejected multiple times and that she thought the staff were hostile. Maria and her husband travelled from Fiji to New Zealand to look for a suitable job offer, and they almost ran out of money. When Maria said "ti tangira riki te job offer ae bubura riki tera maitin boona n te rirkii (we want a job offer with a higher salary per annum that will support you and your children)", she was referring to an Immigration New Zealand official asking for a job offer with a higher hourly rate that matches the minimum income requirement. Many other participants consistently experienced the same issue. This shows that many participants had not fully understood this requirement before submitting their application forms, thus creating misunderstanding and frustration amongst these PAC migrants. Given the high number of applications Immigration New Zealand staff have to deal with, one can understand that they probably do not have much time to explain the requirements. This should be emphasised during a pre-workshop for the PAC successful applicants in Tarawa, and on arrival in New Zealand.

\subsection{COST OF NEOLIBERAL GOVERNANCE}

Further to Riri's story reflecting the theme of Chapter 5, it is obvious that she had been disadvantaged by the lack of knowledge about the Immigration New Zealand systems and processes, language and the effect of the cultural barriers of te mama and te aki kakarongoa when seeking help. 


\section{Riri}

Eng ao ngai are I bon aki ata arou I aki ata te immigration,I aki ata ae $n$ na karekea iaa au job offer ao e bon rang karako naba ae I nang kinaia ba are I aki ata raoi aon ikai, I aki ataia ba I mena iaa ao I a bon titiku naba $n$ arou arei ni karokoa $n$ te kabane $n$ tai a tiba kan buokai nakekei ngaia are ti a nakon te immigration ao are e a rimwi au bai ba are akea otau $n$ aron arei ngaia are I a oki ao I bon rang nanokawaki ba are bon tiaki nanou n kan urua te tua ma are bon akea au atatai $n$ raa ni karinan au beba ma aron kakaeakin au job offer I a bon tiku naba $n$ arou arei.

I had no idea about Immigration New Zealand. I didn't know whether or not I will get my job offer and I didn't know many Kiribati people because I was new in this place. I didn't even know which part of New Zealand I stayed. I remained doing nothing about my immigration papers until the last minute when the people I stayed with just thought of helping me. So, when we came to Immigration, it was sad to find out that I had missed the deadline for submitting my documents. I was very sad as it was not my intention to break the law, but it was my lack of knowledge about Immigration New Zealand's systems and processes.

In 2016, she gained PAC status and eventually she was granted permanent residency. During the period of almost seven years, Riri, had suffered emotionally for being undocumented and not able to access any of the social, economic and political services accessible by other residents and citizens.

\subsection{DISCUSSION AND CONCLUSION}

The adult literacy rate in Kiribati has been assessed at 79.6\% (Ministry of Finance and Economic Development, 2018), which is below the global literacy rate of $86 \%$ (United Nations, 2019). English is the official language used in the education system in Kiribati right from pre-school until tertiary education. Most of the other participants spent at least three to five years in secondary school, so they met the minimum English requirements for permanent residency but did not have the ability to use spoken English in day-to-day activities. They had also not been exposed to other cultures. They were constrained by their social identity of being mama and aki kakaronga when approaching employers or Immigration New Zealand for help. In addition, they lacked a social network and understanding of the New Zealand system and culture. A combination of these factors has disadvantaged these women in pursuing their permanent residency. As Awumbila (2015, p. 134) stated, the literature indicates that 
women as well as those they leave behind can benefit from migration. It can change gender relations, status and responsibilities to women's advantage. Llácer, Zunzunegui, del Amo, Mazarrasa, and Bolůmar (2007) argue that other women gain status from changing their career from homemaking in their country of origin to a labour market in their country of destination. However, migration may also expose women to risks, new vulnerabilities and entrenched inequalities around gender (Awumbila, 2015). "A gender analysis of migration therefore needs to look beyond simple differences in migration behaviour between men and women, and examine the inequalities underlying those differences" (Awumbila, 2015, p. 134). Llácer et al. (2007) argue that the role of gender in developing countries disadvantages women far greater than men compared with their counterparts in industrialised countries. "Women have less access to basic rights, lower rates of education and employment, lower salaries and less access to healthcare services. Childcare and domestic duties fall almost exclusively on women" (Llácer et al., 2007, p. ii6). Most of my participants experienced similar issues given their social status under te maneaba governmentality; this places more challenges on migrant women, and they therefore require a stronger bridge of support than men.

As Lamb and Officer (1996, p. 4) reported, women who would never have dreamed of working in their home country have forced themselves to work in a new country if their husband is unemployed. Some women who do not wish to work are forced to work by their husband who is not earning enough income. These women who have not been in paid employment may have no idea about what they want to do, what they are capable of, or how to look for a job. Reka's vulnerability based on gender and marital status coupled with the language and cultural barriers and insecurity about their residence status also created stress and affected her wellbeing. The feeling that Mary demonstrated when she cried whilst telling a story about her interaction with Immigration New Zealand's staff was very disruptive to her wellbeing. She was constrainted by similar social and cultural barriers. The Kiribati women's shared stories demonstrate the strong characteristic of neoliberalism of minimum state support, which create risks and make women more vulnerable. Repo (2016, p. 308) argued that a "[g]ender equality policy...is deeply biopolitical and gender is deployed therein as an apparatus of power for modifying human behavior in accordance with neoliberal governmentality". Gender equality policy was the means by which women could be mobilised to boost the capitalist economy through their self-transformation into entrepreneurs and job seekers (Repo, 2016, p. 314). Ludwig and Stefanie (2009, 
p. 12) explained that "[n]eoliberal governmentality implies that it is the economy that now becomes the regulating and main principle of the state and its form of government". The contrasting neoliberal and maneaba governmentalities have made it very difficult for the PAC migrant women to integrate smoothly into the New Zealand culture. The empirical material shows that Kiribati PAC migrant women who experienced many problems were those who had to work in New Zealand for the first time in their life or relied on their mother, grandmother or other members of their kainga to assist with domestic responsibilities in Kiribati before migrating to New Zealand.

Integrating the two governmentalities well is significant to inform an appropriate social service for Kiribati PAC migrant women and their families. "It is how we grew up in our individual environment that gives us the understanding of this world. It is how we understand the world around us that influences our actions. It is our action and reactions that bring outcome" (Su'a-Tavila, 2019, p. 11). Kiribati people are brought up to be respectful and humble, so te mama and te aki kakarongoa are another way of demonstrating respect and could be misinterpreted as a negative behaviour in New Zealand's culture. Understanding what these customs mean for migrant women, and how they could be empowered to integrate well within New Zealand society and embrace New Zealand culture are paramount. Understanding the PAC migrants' cultures would result in improved services under the PAC scheme to better meet the needs of new migrant families.

The development of cultural competence means our willingness to engage in a series of activities such as examining the institutional biases of traditional practices and services of the agencies we work for; being open and willing to accept individuals from other cultures; trying nontraditional interventions or changing standard procedures to better address individual needs; and challenging racist practices, discrimination and oppression when observed (Balcazar, SuarezBalcazar, \& Taylor-Ritzler, 2009, p. 1158).

Their families and friends have been the main source of support to overcome PAC migrants' cultural barriers. Some families and friends have weak ties to authorities and consequently have not been helpful to PAC migrants. Riri did not receive any help from her families. Mary experienced challenges to communicate with Immigration New Zealand. Reka experienced cultural barriers when being interviewed by an employer. Ryan (2011) argues that within the migration studies literature, there is a 
tendency to assume that migrants have families and friends who will facilitate the migration and settlement process. The paper argues that more attention is needed for ways in which migrants might access, maintain and construct different types of networks in different situations, in varied social locations, with diverse people. Migrants also need other forms of support to get them prepared before coming to New Zealand, and extend their network with other ethnic groups.

In my maroro with the Kiribati participants, I found that all of them were not mama to share their experiences with me because I conducted te maroro in the Kiribati language, and we all shared the same culture. Cookie and Twenty Five were not constrained by te mama and te aki kakarongoa, and they had the confidence and perseverance to work closely with Immigration New Zealand until their permanent residency was approved within a shorter than expected period of time. Compared with other participants, they had been exposed to other cultures during overseas travels, had higher tertiary education and employment outside Kiribati before they were selected under the PAC. They were confident when approaching Immigration New Zealand for help. The stories of these two women provide a bench-mark for PAC migrants as to what they are expected to do when they come to New Zealand if both the sending and receiving countries provide the necessary support to overcome language and cultural barriers. The stories also articulate what is expected of both the Kiribati and New Zealand governments to support future PAC successful applicants. It also clearly shows the critical need for improvements in the Kiribati education system for preparing future Kiribati people to emigrate and be competitive internationally in the job market. The empirical materials demonstrate that neoliberal governmentality works well for women with a higher socio-economic status or those who have powerful families who helped them successfully achieved their residency. Molly experienced language and cultural barriers, but fortunately her powerful families provided a bridge to overcome barriers and helped her family gain permanent residency without difficulty. The neoliberal PAC scheme of self-responsibility and minimum state support, has resulted in transferring the responsibility to existing Kiribati families and friends to assist these women in overcoming language and cultural barriers to find employment, meet health requirements and other Immigration New Zealand policy's requirements. This was discussed in Chapter 4. 
One of the 30 participants who experienced language and other cultural barriers but had no family to assist, unfortunately had her application declined. She believed that it was not her fault, but blamed Immigration New Zealand for not explaining everything to her. Riri did not know what to do, and remained mama and aki kakarongoa to ask for help. Unfortunately, she stayed with a family who did not understand the Immigration New Zealand system and processes either and she did not have a social network to help her. Many other women experienced the same issues as Riri, but they had family members in New Zealand to support them, and were able to obtain their permanent residency. Through her determination and the help of a lawyer, Riri regained her legal status and permanent residency. Using the governmentality framework, Riri's shared experience demonstrates the effects of neoliberalism, which encourages people to see themselves as being self-responsible and active subjects responsible for enhancing their own wellbeing (Larner, 2000a, p. 13). The story also shows the limitation of te maneaba governmentality, where women's social position in the maneaba, home and communities does not give them the confidence to easily integrate in the host country and ask other friends from their own culture as well as from other cultures for appropriate help. Balcazar et al. (2009, p. 1158) argued that "organisational support seems to be a very important factor in determining the capacity of individual practitioners to deliver culturally competent services." Case managers or anyone providing relevant support services to PAC migrants need to be well supported with cultural competent policies.

Empirical data provides evidence for the need for English as a second language (ESOL) courses to support them when they first arrive in New Zealand. Some researchers (e.g. Askola, 2010; Fozdar \& Torezani, 2008) discovered that an ESOL course is paramount for migrants. According to Hewagodage and O’Neill (2010) an English course contributed to the confidence of migrant women who participated, as a socio-cultural approach was used to focus on practical topics relevant to their daily lives. Hewagodage and O’Neill (2010) argue that immigrants become marginalised when they do not have enough functional English to interact with English speakers. Cervatiuc (2009) studied adult immigrants in Canada and observed that during the first year of their lives in a new country, they had limited external power, meaning that they had limited access to a social network, limited understanding of the environment and no meaningful jobs. However, they continued to learn the target language under 
conditions of marginalisation, which eventually made them academically and professionally successful. In the case of my research participants, who should represent the characters of successful PAC migrant women, they have basic English or functional English, but lack the practice in speaking the language.

Culturally appropriate training is required to inform Kiribati PAC migrant women how to improve their self-esteem, undertake meaningful communication with authorities for help when seeking job offers and understanding their rights. They also need free English courses to help them use the language for day-to-day work, integrate with the new culture and environment, and overcome cultural barriers. As most of the PAC migrants have limited income, it is suggested that Immigration New Zealand in collaboration with the Ministry of Education or Education Service Providers meet the cost of training. There is also a need for someone who understands both the New Zealand and Kiribati cultures, to assist future successful migrants during the first six months of settlement. This includes looking for a job offer, enrolling with a health provider, finding a house, enrolling children at school, and registering adult applicants in a driver's licence course.

They also need information about New Zealand's Human Rights Policy that is in line with CEDAW that protects women's rights, to avoid gender discrimination in employment, avoid pay disparities and inappropriate behaviour of employers. Given the importance for women to understand their rights as immigrants, the training provided for free for successful PAC migrants also needs to be integrated with Labour Inspectors and other support services to ensure that the migrants have a basic understanding of employment contracts, their rights as employees, features of trafficking and important aspects covering gender discrimination, pay gap, and other behaviours of employers that are unacceptable and unlawful.

New Zealand has commited to international laws relating to the protection and promotion of human rights. Below are some examples that are of interest to this thesis.

The international bill of rights is supplemented by more specific treaties that protect the human rights of particular vulnerable groups or that explore in more detail the state's obligations with respect to a particular category of human rights. Notable among these are the Convention relating to the Status of Refugees (the Refugee Convention), the Convention on the Elimination of All Forms of Racial Discrimination (the Race Convention), the Convention Against Torture and Other Cruel, Inhuman or Degrading Treatment or Punishment (the Torture 
Convention), the Convention on the Elimination of All Forms of Discrimination Against Women (the Women's Convention) and the Convention on the Rights of the Child (the Children's Convention) (Geiringer \& Palmer, 2007, p. 17).

Despite New Zealand's commitment to protect the human rights of individuals and achieve gender equity in compliance with the Convention on the Elimination of All Forms of Discrimination Against Women CEDAW, it has not yet been successful in closing the gender pay gap.

...fundamental human right of gender equality internationally, despite the lack of progress in the implementation of equal pay and pay equity for low paid female workers domestically... It is also argued too, that there is currently a revival of advocacy by non-government actors using a human rights framework to apply pressure for change on pay equity breaches (McGregor, 2014, p. 4).

McGregor (2014, p. 6) also reported that "[f]eminist academic, Prue Hyman (2008; 2010), has usefully chronicled the painful and slow history of equal pay implementation in New Zealand". Work of strong advocates pressuring government must be acknowledged as recently there has been an increase in the pay for workers in the aged care sector. The slow progress in closing the gender pay gap may indicate the complexity to operationalise laws, and the need for a good monitoring and evaluation system to be put in place. The wellbeing of PAC migrant women is another area to be closely monitored to ensure that their human rights are respected and there is no discrimination by their employers.

International Convention on the Elimination of All Forms of Discrimination Against Women (CEDAW). Article 11 reads: State Parties shall take all appropriate measures to eliminate discrimination against women in the field of employment in order to ensure, on a basis of equality of men and women, the same rights, in particular: (d)...the right to equal remuneration, including benefits, and to equal treatment in respect of work of equal value, as well as equality of treatment in the evaluation of the quality of work (McGregor, 2014, p. 5).

United Nations $(2018$, p. 2) reported that some progress has been made toward gender equality and women's empowerment through various strategic programmes and policies. However, discrimination towards women and girls in the Pacific remains a key development challenge. Nearly all Pacific Island countries and territories, including Kiribati but with the exception of Palau and Tonga, have ratified CEDAW, but reporting has been delayed by up to 10 years. The rate of family violence in Pacific countries is amongst the highest in the world. The Kiribati government has ratified 
human right conventions, including CEDAW. Kiribati has committed to its implementation by also signing the United Nations Pacific Strategy, which supports the implementation and reporting of human rights conventions (United Nations, 2018, p. 101).

The next chapter examines stories by research participants who have experienced health problems due to a number of factors. These factors include the lack of access to free healthcare services, health illiteracy, prohibitive healthcare costs, and inadequate time to attend to the healthcare of their children because of the nature of the work that they do. The women's stories also show how this notion of self-responsibility makes life difficult for them on the one hand, but also empowers them as well. Their stories also demonstrate the power of te maneaba in governing the way they think, their beliefs and actions, and how these impact on their self-healthcare. This is reflected in the description of 'power' and 'knowledge' relating to Foucault's governmentality theory. This is not going to change overnight, and therefore, a strong support system to assist the new PAC migrants is needed. 



\section{Chapter 7 Risk of self-responsibility for healthcare and wellbeing}

The following story shared by one of the research participants reflects the main theme and sub-themes of the present chapter. They relate to a combination of factors including the lack of access to free healthcare services, health illiteracy, finances, language and cultural barriers.

Ann [aged between 31 and 35, married, has two adopted children, and came to New Zealand in 2009]

As principal applicant, I organised everything in Tarawa prior to coming to New Zealand. When I came, the only thing we needed to do was to obtain a job offer.

When we first arrived, we went to see Immigration to seek help in finding a job offer. My cousin helped us with translation. At the time, it was quite easy to find a job offer because there was a division for the Pacific based in Manukau, which was responsible for the PAC. They were helpful in contacting employers and arranging our interview with the appropriate employer. The following week, we went for an interview with an employer. Not long after our interview our work permit was approved. My husband and I started working. We were on probation for three months. Within the three months, I did not know that (Ann started to become emotional), I hate this part (Ann could not speak well).

\section{Researcher}

What type of work was involved?

Ann

You planted vegetables such as tomatoes and capsicum. I did not know that I was pregnant. I am sorry, but I can feel the pain again.

Researcher

Are you alright? We can continue our maroro another time when you feel comfortable.

Ann

I felt the wound... (Ann paused for a long time, then she was in tears and pain) ...I am sorry. I felt the pain, which affected me at the time...I was in pain because my child did not survive. We worked so hard, leaving our other two children (adopted) behind in Kiribati with the aim of bringing them over when we had settled, and had our own house. You could not work properly, as your mind was on your children, thinking about how they were doing, while you were away from them. 
We had sufficient money to keep us going and it was even more helpful that we did not wait long before we started working. I did not know that I was pregnant. I did not experience any sign of morning sickness. My cousin helped me look for a family doctor, but I was afraid of the cost because we were not yet New Zealand residents at the time. I continued to work in my third and fourth months. I was very pregnant. I felt unwell, but I continued to work in order to earn enough money to meet our expenses and save before my birth delivery. I worked until I was seven months pregnant. I was advised to go on maternity leave to avoid any health risks that could be caused by chemicals used where I worked. I stopped working. My husband continued working. Whilst on maternity leave, some of my relatives helped by taking me for health check-ups. During my first interview with my midwife, she warned me that because I was in my late thirties, I could potentially have complications with my birth delivery. She knew that it was my first pregnancy. I was surprised that in my ninth month, she told me my child was alright and allowed me to wait for another week. I felt that she was not quite helpful. I learnt from my family members that my midwife should be regularly monitoring my health because it was my first pregnancy and that she had warned me of complications during the delivery.

When I arrived for my next appointment, one health staff examined me. I was surprised when all of a sudden she stepped out and not long after she came back with three or four doctors. They were in their surgery gowns. They examined me and then they told me that my baby had died.

Researcher

Your baby died in your womb?

Ann

Yes... (Ann burst into tears) ... They told me my child had died. I told them, my child is not dead, it is floating in my womb, no my child is alive.

\section{Researcher}

I am very sorry to hear that you went through this ordeal.

Ann

I was moved to another place for scanning. I told them, look it is alive. It is floating from one side to the other. They asked me, who is your midwife, so we can ring. Then my midwife came and tried to comfort me, but I was very furious. I still refused to accept that my child had gone and I told them my child was alive. Finally, an Asian doctor came and explained everything and tried to calm me down.

I was then given two options, either undergo surgery or natural birth. The surgery was more expensive than the natural birth. If I could access free healthcare services, I would have preferred surgery because it was painless. I decided to have the natural birth because I could afford it even though it was painful. At the completion of my labour and birth delivery, I could not stop crying. All my family members came and were very upset. They claimed that this was a result of poor healthcare 
provided by my midwife. We arranged for automatic payments towards the cost ( $\$ 4000$ plus) for my hospitalisation.

\section{Personal reflection}

Ann's tragedy resulted not only from the poor healthcare provided by her midwife as Ann's family have claimed, but from many other factors. (1) First and foremost, Ann experienced issues of not accessing free healthcare services because of her non-residence status as she was on a short-term work visa; (2) Ann did not have a good language translator with adequate health literacy to ensure that Ann understood her midwife and the midwife was aware of Ann's needs; (3) The nature of her work could also have been a contributing factor as she worked right through towards to the end of her second trimester; (4) Financial constraint had forced Ann to work right through even though she was very pregnant; (5) There was a missing link between PAC officials and Health officials to ensure that successful PAC migrants have language support when they see a GP or any health professional. If the midwife had understood the Kiribati language and culture, she would have been able to provide a cultural competent service to Ann during her pregnancy.

\subsection{INTRODUCTION}

The previous chapters examined three key themes of my research. Chapter 4 discusses the lack of government support; Chapter 5 discusses family dependency; and Chapter 6 discusses cultural barriers: language, te mama (shyness) and te aki kakarongoa (silence). This chapter examines the fourth theme regarding challenges faced by Kiribati PAC migrant women when accessing healthcare in New Zealand. I also examine the Kiribati health system and the traditional healing methods currently being used in Kiribati using three of my participants' experiences to provide cultural context to the analysis. As there is limited literature on traditional healing in Kiribati, I reviewed research in other cultures to elicit whether or not there are similar experiences to that in Kiribati. I focus on the health experiences of these Kiribati migrant families during the period from when they received a temporary visa until they were granted permanent residency. I examine these women's powerful stories about their health experiences by addressing: i) what these stories tell us with regard to who is responsible for the healthcare of these women and their children, and (ii) how New 
Zealand's Immigration Policy articulates the Ministry of Health's policy for the healthcare needs of these women and their children. In discussing the results, I also look at what feminists and other researchers have to say about women's similar and related experiences in other countries.

\subsection{KIRIBATI GOVERNMENT HEALTH SYSTEM}

Kiribati's public health system, administered by the Ministry of Health and Medical Services, comprises four hospitals that are supported by a primary healthcare network of health centres. The four hospitals are Tungaru Central Hospital located on the capital island of Tarawa, Southern Kiribati Hospital servicing the southern islands of Kiribati, Betio Hospital located on Betio islet, and Kiritimati Hospital servicing the Line and Phoenix island group (WHO \& Ministry of Health and Medical Services, 2012). The establishment of the four hospitals in different parts of Kiribati provides better distribution of health services to the wider population given the scattered nature of the geographical locations of the Kiribati islands. There are no private health service providers. The government is the only provider of health services in Kiribati (United States Department of Labour's Bureau of International Labour Affairs, 2012). Healthcare is free to Kiribati citizens. Non-Kiribati tourists, travellers and foreign seaman are charged for any medical services (WHO \& Ministry of Health and Medical Services, 2012). In a Messenger conversation (T. O. Kabuati, personal communication, September 26, 2019), Mrs Kabuati, Nursing Lecturer, told me that after consulting the Deputy Secretary and the Director of Nursing within the Kiribati Ministry of Health and Medical Services, healthcare services are also free to foreigners who work for the Kiribati government. This is based on current practice as there is no clear policy on this to substantiate this statement. This should also apply to foreigners marrying Kiribati citizens and living in Kiribati. The high population density in South Tarawa, the urban area, has put pressure on the environment and water resources, leading to many health problems. The strong ties of Kiribati people to their culture and heritage, which involves reliance on the use of traditional healing practices for certain diseases/sicknesses, is an important area that has not been documented. While medical care is free to Kiribati citizens, supplies and services are limited. Thus, the preservation and use of traditional medicines and local massage treatments are important. Such specialised skills are passed on within families. In the next section, I discuss similar 
traditional healing practices in other cultures, and my observations of Kiribati traditional healings practices.

\subsection{KIRIBATI TRADITIONAL HEALING}

Traditional medicine (TM) is defined by World Health Organisation (WHO) as includ[ing] diverse health practices, approaches, knowledge and beliefs incorporating plants, animals and/or mineral based medicines, spiritual therapies manual techniques and exercises, applied singularly or in combination to maintain wellbeing, as well as to treat, diagnose or prevent illness (Bassett, Tsosie, \& Nannauck, 2012, p. 19).

Some researchers (e.g. Fiedeldey-Van Dijk et al., 2017; Ghiasuddin, Wong, \& Siu, 2015; Hurdle, 2002; Serbulea \& Payyappallimana, 2012; Su'a, 2017) have stated that the use of traditional healers remains a significant part of the lives of people in certain cultures. It reflects the acknowledgement and appreciation of the values of their respective culture and heritage. In a study involving different ethnic groups, i.e. Samoans, Marshallese, Filipino and other ethnicities living in Hawaii, Ghiasuddin et al. (2015) found that participants had their beliefs around their healthcare rooted in their traditional culture, which helped improve the cultural competencies of health providers. Other researchers (e.g. Bassett et al., 2012; Ghiasuddin et al., 2015; Su'a, 2017) argued that cultural competency in healthcare involves considering the diverse cultural values, beliefs and behaviours of patients in the system.

Hurdle (2002) noted the importance of more research and development on the integration of cultural healing practices with healthcare and social work practice. The lack of cultural competency in healthcare has been linked with poor health outcomes of 'migrants and ethnic minorities' (Ghiasuddin et al., 2015). However, there are young Pacific people, children of Pacific migrants, especially New Zealand born, who do not believe in traditional healing methods (Churchward, 2011). Alternatively, Su'a (2017) argued that the lack of traditional cultural knowledge and language amongst the young people disconnects them from their roots and heritage. Su'a also stated that Samoans, who migrated to New Zealand and those who were born in New Zealand, who speak the language and understand their culture are still very much connected to their roots. It is possible that there are, amongst Kiribati PAC migrants living in New Zealand, families who may seek traditional healing methods rooted in their culture and heritage before seeking help from a doctor. It would make sense for those who experience a language barrier, do not have free access to health services, and have 
limited knowledge about the New Zealand health system, to prefer to seek help from traditional healers within their own cultural group.

While there is virtually no specific literature on Kiribati traditional healing methods, they share the same experiences as other cultures (Fiedeldey-Van Dijk et al., 2017; Ghiasuddin et al., 2015; Hurdle, 2002; Serbulea \& Payyappallimana, 2012; Su'a, 2017). As part of their culture and heritage, many Kiribati people still maintain their traditional healing knowledge and skills in various areas including tuoakin te tina ae ae bikoukou (antenatal care), te kabung (child birth), karawataan te ran ni mama (helping breast feeding mothers with no breast milk), te riring (massage), tarou (muscle sprains), and te bakabua (sore throats). According to WHO and Ministry of Health and Medical Services (2012), most people use the public health system and a traditional health system; however, the two systems have not yet been formally integrated. In a conversation (T. Tebouaki, personal communication. September 1, 2018) with a member of the Kiribati Community in Wellington, Mrs Tebouaki told me that many Kiribati people are still using traditional healing methods to help meet their health needs. It is expected that Kiribati PAC migrants practise this traditional knowledge and skills as part of maintaining their culture and identity, and supporting their wellbeing.

The strong Kiribati culture rooted in te maneaba system expects te utu (the family unit), te kainga (the extended family) and te kaawa (the village) to be responsible for the health of individual members. Traditional healers are not only responsible for their own $u t u$, but are compelled to provide healthcare and treatment to members of their kainga or kaawa without expecting to be paid. As discussed in Chapter 3, this is part of the Kiribati moral economy where members of te utu, te kainga, te kaawa and te abwamwakoro help each other, and provide gifts in different forms to show appreciation. Local healers are expected to attend to local people needing help at any time of the day and night when needed, just like medical doctors being on call and available at any time when needed by patients as part of their responsibility. It is also part of the Kiribati bubuti system connected to te maneaba system's core cultural values of te karinerine, te tangira, kakawakin te aomata. This system expects local healers to be responsible for ensuring that the sick people in their kainga or kaawa receive the necessary treatment. For example, my parents inherited the traditional healing knowledge of how to treat mothers who do not produce much breast milk. The 
medicine contributes to mothers' and children's wellbeing. Mothers are able to produce sufficient breast milk, so their babies have sufficient nutrients, stop crying, sleep throughout the night, and the mothers have a good rest. My older sisters were made responsible for the collection of the leaves and roots of selected native plants, and prepared the herbal juice for a mother to drink. I recalled, the look and feel of the herbal juice. It looks like a milky, smooth, chocolate and caramel juice. In our conversation (T. Tebouaki, personal communication, September 1, 2018), Tebouaki said that when she was pregnant with both her children before migrating to New Zealand, she relied on her traditional midwife for regular monitoring to ensure that her baby was healthy. She used the hospital for delivery as it had available technologies in case of any emergency. This is a good model of integrating both the western and traditional delivery for the healthcare of mothers and their children. There are other women, who still prefer to privately give birth in the care of their traditional midwives. Most of my participants were not eligible for healthcare services in New Zealand because they were either on a visitor visa or one-year work permit. It was possible that they had not realised that these services are critical because of their belief in traditional healing methods to meet their health needs. According to Norma, one of the research participants, her husband has traditional healing skills for asthma, sore throat and other types of common sickness affecting children. Whenever their children got sick, her husband massaged them using his traditional knowledge and skills. Being on a visitor visa during the short-term period prior to approval of permanent residency, she was not worried about not having free access to healthcare services. None of her children had any health issues requiring healthcare services before they received their permanent residency. Another research participant, Nickie, also believed in her traditional healing skills, which initially made her not worry about not having free access to healthcare services. However, she realised that the traditional healing skills she has do not seem to be suitable for illnesses associated with the cold weather in New Zealand. This made her and her family, especially her children, vulnerable especially when the traditional healing method has certain limitations.

It requires research and development to understand how individuals navigate their way to meet their health needs, without having to see a professional medical doctor or nurse. While most of the traditional healing methods are preventative in nature, women 
still have a high health risk when surgery or any type of medical intervention is required. Access to healthcare services is paramount.

\subsection{NEW ZEALAND'S HEALTH SYSTEM}

The New Zealand's Ministry of Health (The Ministry) strategy supports the achievement of good health outcomes for all New Zealanders. The strategy acknowledges that,

Our system can struggle to give all New Zealanders equitable access to health services: some population groups continue to benefit less from the health system than the population as a whole. We have to rise to the challenge of achieving better outcomes for everyone, within the resources we have. This means we must find new ways of working to deliver the services we need (Ministry of Health, 2016, p. 1).

The Ministry recognises that some population groups, especially minority ethnic and migrant groups, have had inadequate access to healthcare services. This is notable amongst new migrants such as Kiribati PAC migrants, who have been disadvantaged because they are new to the culture and environment, and they do not know what to do, how and where to go when they need healthcare. Even if they do, some cannot afford to meet the cost of healthcare.

Recognising the importance of the health of children from an early age, the strategy also states that "[b]efore birth and throughout childhood, adolescence and adulthood, all factors including economic, political, environmental and social factors affect an individual to live well, stay well, get well and ultimately, to experience a good end to life" (Ministry of Health, 2016, p. 4). The Ministry adds that "good health, starting in childhood and continuing throughout the life course, requires investment in prevention and interventions that make the environment in which children grow, learn and play a healthy one" (Ministry of Health, 2016, p. 4). While investment in child health makes perfect sense, understanding the community well would help the Ministry identify and respond to the needs of various community groups. This issue is of interest to this thesis and it is addressed to an extent by uncovering the issues of successful Kiribati PAC migrants, during the early stage of their settlement. Kiribati PAC migrants make up one group that needs free access to healthcare and translation support services especially during the early phase of their settlement. This would achieve good health outcomes and reduce costs on the health system in the long run. 
As health is affected by many factors, the Ministry works in collaboration with other government agencies to achieve good health outcomes for everyone by implementing various initiatives including:

-Providing healthier homes and addressing factors such as overcrowding to reduce the risk of illnesses like rheumatic fever and respiratory conditions.

-Putting families and whanau at the centre of service delivery through Whanau Ora (Ministry of Health, 2016, p. 6).

Successful PAC migrants have to work independently to meet the requirements for permanent residency with limited support from the New Zealand government. This has resulted in many socio-economic problems related to unemployment, overcrowded housing and limited access to healthcare and other services. These outcomes are in contrast to the objectives of the Ministry of Health's policy, which rather aims to improve health outcomes by, for example, reducing overcrowding.

Another important theme of the Ministry's health strategy is 'People-powered' (Ministry of Health, 2016, p. 16). It is the responsibility of the health system, which involves all organisations such as District Health Boards and Health Service Providers to empower people to be aware and understand the health information, and how to access healthcare services, and manage their own healthcare. Service providers are expected to work with Service users or people using the service to help them remain healthy (Ministry of Health, 2016). While 'People-powered' is a significant theme for the health of Pacific people, obviously this is a significant gap in the PAC. In Chapter 3 , the women's stories articulated the need for more awareness and understanding of important information before migrating or during their initial settlement in New Zealand. It is crucial that someone is responsible for ensuring that PAC migrants are aware of these services.

Recognising that the Pacific population have poorer health status than the non-Pacific population, the 'Ala Mo'ui: Pathways to Pacific Health and Wellbeing 2014-2018 strategy (henceforth referred to as 'Ala Mo'ui ${ }^{14}$ ) aims to improve health outcomes of Pacific peoples. The Ministry has put in place key performance indicators (KPIs) that

\footnotetext{
14 'Ala Mo'ui is a combination of a number of Pacific languages meaning 'pathways to the essence of life force'. It represents the holistic view of health and wellbeing, encompassing the physical, mental, cultural and spiritual dimensions that are important to Pacific people: Tongan ('Ala Mo'ui), Niuean (Ala Moui), Samoan (Ala), Cook Island Māori (Ara), Tokelauan (Ala), Tuvaluan (Ala).
} 
include (i) reducing the Ambulatory Sensitive Hospital admissions rate for Pacific people; (ii) increased life expectancy; and (iii) increased health expectancy. Figure 7.1 shows that there is high rate of Pacific people admitted to hospitals. Hutt Valley had the highest hospital admissions of 4,149 per 100,000. The Ministry aims to positively influence these KPIs. These are "long-term measures but in order to reach health equity, all three indicators need to reflect positive health trends for Pacific families and communities" (Ministry of Health, 2014a, p. 15). In other words, when these KPIs are delivered, the health benefits of investment in Pacific families and communities would be achieved.

Figure 7.1: Ambulatory Sensitive Hospital admissions.

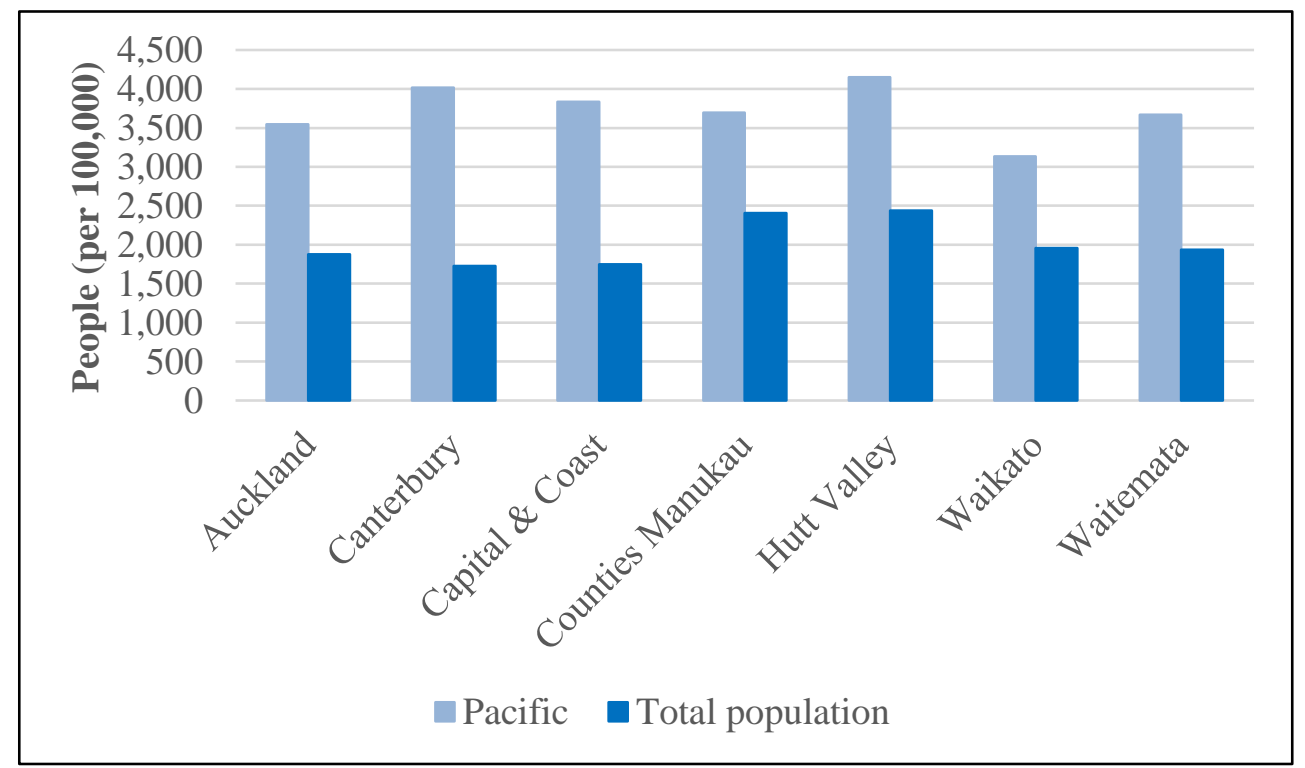

Source: Ministry of Health (2014a).

'Ala Mo'ui sets out the priority outcomes and actions for the four years that should contribute to achieving the government's long-term outcomes for health. "That is, all New Zealanders, including Pacific peoples, will lead healthier and more independent lives; high-quality health services will be delivered in a timely and accessible manner; and the future sustainability of the health and disability sector will be assured" (Ministry of Health, 2014a, p. 2). 'Ala Mo'ui also seeks to achieve the following four priority outcomes:

i) Systems and services meet the needs of Pacific peoples; ii) More services are delivered locally in the community and in primary care; iii) Pacific peoples are better supported to be healthy; and iv) Pacific peoples experience improved broader determinants of health (Ministry of Health, 2014a, p. 13). 
Recognising that health is rooted in culture, 'Ala Mo'ui regards Pacific cultures as an integral part of the strategy, and weaves in the Pacific principles including respecting Pacific culture, valuing family and communities, quality healthcare and working together.

\subsubsection{Respecting Pacific culture}

Individuals and organisations in the health and disability sector recognise that Pacific families' experience of healthcare is influenced by Pacific world views, cultural beliefs and values (Taumoefolau 2012). Culture has been identified as 'expressions of knowledge, beliefs, customs, morals, arts and personality' (Ministry of Social Development 2012a). Moreover, as Nga Vaka o Kaiga Tapu (Ministry of Social Development 2012a) recognises, while Pacific 'cultures' share some similarities in principles and concepts, they each have specific and independent world views...

Given the dynamic nature of the Pacific population in New Zealand, these cultural world views, beliefs and values are diverse and evolving. In general, Pacific peoples in New Zealand maintain strong links with the Pacific Islands through family, culture, history and language...(Ministry of Health, 2014a, p. 6).

Many Pacific people have beliefs about individual health, family and community needs and realities that are different from those of other New Zealanders (Southwick et al., 2012). These beliefs can influence health choices and behaviours. For instance, the financial priorities of many Pacific individuals centre on maintaining relationships, meeting their immediate family needs, donating to the Church, and making contributions to family, both in New Zealand and in Pacific Island countries of origin (Tait, 2009). Such financial obligations can impact on families' ability to pay for health services. Their use of traditional Pacific medicine and healing can also influence the way that Pacific peoples use healthcare services in New Zealand (Tiatia-Seath, 2008). In the case of Kiribati PAC migrants, their lack of access to free healthcare before becoming permanent residents would have made some of them rely on their traditional health knowledge.

In addition, whilst I agree with the above quote that there are similarities as well as differences across Pacific cultures, I argue further that within each Pacific island culture, people have different world views that would influence their healthcare. The 'Ala Mo'ui strategy faces the challenge of accommodating differences within each cultural group in order to help health and disability service providers become responsive to the health needs of the different groups within each culture. 'Ala Mo'ui 
gives priority to Pacific people who experience poorer health status compared to other non-Pacific people. However, the strategy needs to identify the most vulnerable groups to be targeted. Successful PAC migrants, particularly the newly migrant group, are the most vulnerable group within the Kiribati community in New Zealand. Many of them have experienced problems that are discussed in the following stories. However, most of the women who participated in my research expressed their appreciation of the quality of healthcare services that they can access after becoming permanent residents. For many of them, it comes as a great relief that they do not have to pay much (if any) for healthcare when a family member needs to see a GP or is hospitalised.

Pacific peoples are also unique in that they have strong family links, which make a significant contribution to the health and wellbeing of individuals. This is their cultural asset that they bring with them to New Zealand and the rest of the world. It is a challenge for policy makers to ensure that their cultures are well nurtured and not undermined by policy initiatives that are driven by neoliberalism that promotes privatisation and self-responsibility. The lack of integration of Pacific cultures in such policy initiatives would marginalise Pacific people who are completely new to these concepts.

\subsubsection{Family and communities}

The Ministry of Health (2014a, p. 6) acknowledges that,

Workers in the health and disability sector are aware that, for most Pacific peoples, 'āiga, kāiga, magafaoa, kōpū tangata, vuvale, fāmili (family) is the centre of the community and way of life. Family provides identity, status, honour, prescribed roles, care and support (Tiatia and Foliaki 2005). Care for family members with disabilities or for older family members is often informally provided within the family (Huakau and Bray 2000). Pacific peoples have a holistic view of health and wellbeing (Ministry of Social Development 2012a. Whānau ora is a holistic and strengths-based approach to developing and maintaining strong and vibrant families. The initiative supports Pacific families through the development of 'navigators', who facilitate increased access to existing systems and services.

Earlier in Section 2.4.1, te utu (parents, children and grand-children, daughter and son in law), or te kainga were explained. It is for this reason that many Kiribati women do a very good job in the healthcare sector. It is already an important part of their culture to care and support members of the family. Pacific peoples appear to be more connected socially than many other population groups in New Zealand (Tait, 2009). 
For example, many Pacific families are strong participants in church and community activities, which create and reinforce strong social connections and therefore resilience (Tait, 2009). A number of recent health initiatives have successfully built on the strengths of Pacific communities, such as the immunisation campaigns for Pacific children, and Pacific church initiatives to promote physical activity and healthy eating. Because of these unique Pacific factors and strengths, Pacific peoples are more strongly engaged in identifying and developing effective approaches that will work for them. Pacific participation helps to spread knowledge, awareness and understanding of Pacific health issues and encourages collective ownership of and action on health issues.

The role of navigators is exactly what is required by my research participants, so the challenge for Immigration New Zealand managing the PAC programme is to connect successful PAC migrants to such services. Chapter 4 explained that the role of Kiribati families in New Zealand has become crucial for the wellbeing of PAC migrants by playing the role of an informal service broker.

\subsubsection{Quality healthcare}

The key dimensions of quality - access, equity, cultural competence, safety, effectiveness, efficiency and patient-centredness - are implicit in the delivery of health and disability services to Pacific peoples (Minister of Health 2003). Quality healthcare is delivered from a strengths-based approach and is apparent at individual, family, community, organisation and overall system levels (Ministry of Health, 2014a, p. 6).

Improved quality of healthcare would be a great investment return for Pacific peoples, but the question is how this would reach out to vulnerable migrants who are new to New Zealand. They do not know where to go or who to ask for help if they need healthcare support. I argue that this is another grey area within the PAC policy. There is no clear orientation to successful PAC migrants about how they would manage their healthcare when they arrive New Zealand. This is discussed further in the following women's stories.

\subsubsection{Working together - integration}

The health and disability sector works together to provide seamless and integrated quality care to Pacific peoples. The sector focuses on the social, environmental, economic and cultural factors that impact on Pacific health outcomes. The health and disability sector partners with 
education, housing and social development to prioritise and focus on Better Public Service targets (Ministry of Health, 2014a, p. 6).

This service is something that the women in this research would greatly benefit from if someone like a navigator as mentioned above is able to track PAC migrants and connect them to the right service provider. As discussed in Chapter 3, Teiti (the PAC host) was able to connect the PAC family staying with her to a service provider in their local area. The service provider was able to assist the family in accessing a house within a short period of time. Recognising that Kiribati host families are already busy with their own lives, the New Zealand government is urged to identify ways to relieve the burden on these existing families by providing much needed assistance to newly PAC migrants during the early stages of their settlement.

The women's stories raise the question of an opportunity to change the PAC policy to ensure that the Ministry's overarching health strategy that is supported by the 'Ala Mo'ui sub-strategy are responsive to the healthcare needs of PAC migrants and their families upon arrival in New Zealand. It is a question of how Pacific health services will become more responsive to the needs of new immigrants who have arrived under the PAC policy. It also creates opportunities for greater partnership between the PAC team and the Pacific health team responsible for implementing the 'Ala Mo'ui strategy to ensure that the services are delivered to the targeted population including PAC migrants.

\subsection{WOMEN'S HEALTH EXPERIENCES}

The PAC has attracted many Kiribati people since the policy came into effect in 2001, but only 75 individuals get selected each year (as discussed in Chapter 1). The PAC policy is clear that successful applicants must meet certain criteria, one of which is to have a suitable job offer. Clearly, it cannot be expected that these migrants will be given a job automatically by an employer in New Zealand, without a face-to-face interview. An employer must interview an applicant and have the confidence in them before they offer them a job. Likewise, a person applying for a job needs to meet the employer to ensure they are the right employer and the organisation is a good place to work (Gibson, McKenzie, \& Stillman, 2009). It is unrealistic for PAC migrants to expect to obtain a job offer without making contact with New Zealand employers or physically coming to New Zealand and applying for a job that is acceptable to 
Immigration New Zealand. It is for this reason that most of my participants travelled to New Zealand on a visitor visa to look for a job offer.

Based on a feminist oral history researcher's approach (e.g. Anderson \& Jack, 1991; Reinharz et al., 1992; Scanlon, 1993; Theobald, 2014) my research gave Kiribati PAC migrant women the opportunity to have their voice heard by sharing their health experience since arriving in New Zealand. Most of the studies that have been conducted on Pacific migration to New Zealand (e.g. Gibson et al., 2009; Ramasamy et al., 2008) have not looked specifically at how immigration policies have impacted on the health of migrant women and their families. Williams (2010) observed that there is limited research done to understand women's issues within the contemporary forms of migration. My participants' stories contribute to knowledge in this area.

Of the thirty participants, twenty-nine came on a visitor visa to look for a job offer that is acceptable for permanent residency. Knowing that they are not eligible to access public health and disability services, they tried to avoid visiting a GP or any healthcare service provider because of the fear of the cost of such a visit. In this situation is likely some of them would use their traditional healing practices. Some migrants were fortunate to get their work permit and permanent residency in less than three months of their arrival in New Zealand, whilst others took much longer (refer to Table 1-2 in Chapter 1). Saving money for their permanent residency applications was a key priority for these migrant women as well as saving towards living costs and other expenses whilst staying with family or friends. When these migrants moved to their own places, they still had to pay rent, utility bills, children's school fees and uniforms, and meet other basic needs. Other key barriers to accessing quality health services included shift work, limited knowledge of the New Zealand health system, lack of transport, language, financial constraint and cultural beliefs around their healthcare. In the next section, I present the stories shared by two women about their health experience when they were pregnant before they were granted their permanent residency.

\subsection{CULTURE AND GENDER}

As explained in the story before this chapter, Ann shared the detrimental and emotional health experience of losing her child through still birth. This demonstrates the disarticulation of the PAC with the health service provision. It also shows the 
significant impact of the lack of cultural competency and gender integration in the design of the PAC on the health and wellbeing of these migrant women and their family.

Ann was still traumatised from the loss of her child. When she said "I a kainnano ma I bon keiaki" (Even though I was feeling unwell, I still tried). It illustrates being disadvantaged because of her non-resident status. She had no other means of financial support, but her work so she could earn enough money to put food on the table and meet other basic needs. When she said "ao ngai naba I maka naba boon te mena tera arei ba are e tuai naba n tia ara bai," (I could not afford to pay the full cost because our residency had not yet been approved), Ann referred to health costs, which she did not have a budget for, and was prepared to take a risk by not having a family doctor. This may also reflect that many Kiribati people rely on traditional healing practices to meet their health needs. As discussed in Section 7.3, Kiribati women rely on traditional midwives until they give birth. Some prefer home birth, and others prefer to give birth in hospital. When Ann knew she was pregnant, and was convinced by her relative, who had been living in New Zealand longer, to have a family doctor, she did not have anyone to seek help from but her cousin. When she said "buokau au katin," (it was my cousin, who helped me) she affirmed that the role of te kainga (extended family), rooted in the Kiribati maneaba system, is critical for the wellbeing of Kiribati PAC migrant families. It is a reflection of the richness of the Kiribati culture, which puts families at the centre. When someone is ill, members of te utu and te kainga take responsibility. Chapter 4 has more details of te maneaba system, which shapes the role of te utu and te kainga. Whilst 'Ala Mo'ui recognises the significance of Pacific cultures, Immigration New Zealand should arguably take more responsibility for ensuring that the health needs of newly arrived Kiribati migrants coming under the PAC are met. In the following statement by the former President of the Republic of Kiribati, Teburoro Tito, at the United Nations Special Session on Children, the Kiribati government acknowledges the family and cultural values for nurturing the health and wellbeing of children.

Children represent the best, the purest and the loveliest part of humanity in every family, village and society. According to our Kiribati tradition, which goes back to mythological times, the world, comprising sky, ocean and land, belongs to a super spiritual being, called Nareau, and all human beings are his descendants through the half spirit half human beings ('anti ma aomata'), that he created at the beginning of time to 
help him mould and take charge of the world. Every human being born into the world is therefore considered sacred (tabu) and supreme over other creations and its needs and requirements for life are above all other considerations. Guided and influenced by these traditional beliefs blended with Christian values, every stage of the child's development is celebrated as a significant event and an essential part of the child's preparation and initiation into the adult world, and the needs of the child take precedence over all other needs...

In Kiribati, the Government, in partnership with the parents, families, the island councils, the churches, various community based organisations, NGOs and development partners, is doing its very best, within its available resources, to improve the wellbeing of children as an essential part of its 'quality of life improvement' policy. As part of the aim to improve the social, physical and economic environment for children, the Government is enhancing the revival of important family and cultural values and investing more and more of its resources and money in the health, education, sports and other children and youth related activities (Tito, 2002, p. 1).

In this statement, Tito (2002) reminded the United Nations that Kiribati as a nation remains strong in its culture and tradition, and that the needs of Kiribati children are nurtured by such cultural values of respecting, caring and sharing with others from a very young age. The key message from his United Nations address is that to "build a better world for our children and for all humanity", cultural values are an essential component of a global, regional and national policy. This statement was not only reminding the United Nations but I believe that it is a strong message and reminder to Immigration New Zealand to put in place better policies that will protect the healthcare of PAC migrant children. They are the leaders of tomorrow. If they live in a poor environment, they will not reach their full potential for this country.

From the Kiribati cultural perspective, Ann and her family were hurt and claimed that the real cause of her stillbirth was the fact that her registered clinical midwife did not provide enough information about the health of her child. When she said "ngaia are $e$ a roko ao e a karaua nanou ao ngai I aki I rang un (so she came and tried to comfort me, but I was very furious)", this arguably demonstrates the pain Ann went through as a result of self-healthcare, which was a new concept for her. Coming from a collectivist culture where family wellbeing is at the centre (Ministry of Health, 2014a; Southwick et al., 2012; Tito, 2002) Ann considered that the midwifery service was appalling. The poor health experience and the pain she went through demonstrates the PAC policy gap in cultural competency in healthcare delivery that resulted in poor health outcomes (Ghiasuddin et al., 2015). It contradicts the goal of the Ministry of Health in achieving 
positive health outcomes for Pacific peoples. As other researchers (e.g. Bassett et al., 2012; Ghiasuddin et al., 2015; Su'a, 2017) argued, cultural competency in healthcare requires a good understanding of the patient's culture and beliefs to be able to provide the best healthcare. Based on the neoliberal notion of self-responsibility Ann was expected to take responsibility for her own health and her unborn child. In contrast, Pacific cultures including that of Kiribati are centred on the health needs of the individual, allowing everyone including members of te utu, te kainga and the health worker or traditional healer to take responsibility. As Ann said, it was her family who convinced her to look for a family doctor. She did not take the initiative to get one in the first place. Using the traditional health approach, the healer and her utu or kainga are responsible to meet the needs of a sick person, in preparing the traditional medicines, or providing special food. When Ann blamed the midwife for being unhelpful, it revealed her misunderstanding of the neoliberal notion of self-healthcare. This was not solely Ann's fault nor the midwife's, but it is the impact of the PAC policy gaps on the health and wellbeing of migrants. It also demonstrates the midwife's lack of cultural competency in understanding the potential challenges faced by Ann so as to provide a better health service tailored to Ann's needs. Ann's experience demonstrated the need for a translation service in the PAC scheme for Kiribati PAC women in need, so a professional health or other service provider could better meet the health and social needs of Kiribati PAC migrants. Su'a (2017) argues that when you speak English, it does not mean that you will automatically understand health information. Churchward (2011, p. 194) highlights the needs for cultural competent health service provders who are comfortable speaking in the mother tongue of clients and their families.

[S]ome of the midwives interviewed believed that shared ethnicity, culture and language was an advantage to working with minority ethnicities. Some said that it enhanced the relationship due to shared background and allowed the midwife to communicate fully not only with the mother but her wider family, particularly with older members such as the grandmothers, who may prefer communicating in their mother tongue.

This means that if midwives understand their client's culture and beliefs or a family with good health literacy could be an interpreter for the client, they would be able to provide better health service. 
Health literacy is the degree to which individuals have the capacity to obtain, process and understand basic health information and services needed to make appropriate health decisions. Health education is directed towards improving health literacy. It is the process through their health and how to improve it through skill and knowledge development. The format can vary through verbal, printed and electronic material, and should be educationally, culturally and linguistically appropriate. Health literacy is therefore a key outcome of health education (New Zealand Guidelines Group, 2011, p. 4).

Aside from such cultural barriers, Ann's case also demonstrates the gender gap in the PAC's scheme. Ann was given two options: (1) to have an operation to surgically remove the stillborn baby from her womb, or (2) have a natural birth. Both methods and their costs were explained to her. Both options were quite costly and were both beyond her budget. Option 1 was more expensive, costing up to $\$ 10,000$, but is a more comfortable experience. Option 2 was less expensive, costing $\$ 4,000$, but it is a painful experience, as it comes with the pain of vaginal delivery. Ann had no choice but to pick the more affordable option. This demonstrates a significant gender gap in the PAC policy, which resulted in health inequality and poverty for women and children. Silva and Dawson (2004) stated the key outcomes of their study on the impact of international migration on the health of Brazilian women living in Melbourne, Australia was that there was an association between women's health problems and the lack of social support and barriers to accessing healthcare services.

Ann's case and others discussed in this chapter show that successful PAC applicants need to understand New Zealand's health system. This raises the question about who is responsible for ensuring this. Is this a component of the PAC package? As discussed in Section 1.4.4, when refugees arrive in New Zealand, they are housed at the Mangere Refugee Resettlement Centre for six weeks to ensure that they are well informed about the health system and other important things that they need to know in their daily life. The women's powerful stories in this research evidently articulate the need for this kind of support service, but based on the cultural principles of the Kiribati maneaba system. This responsibility had been shouldered by friends and families living in New Zealand and no one would complain about it because it is taken as the norm that puts the needs of the family at the centre. Despite the aim of 'Ala Mo'ui to achieve health equity for all Pacific peoples, these women's stories demonstrate that new PAC migrants have not accessed sufficient healthcare, showing that the PAC policy has been disarticulated from health policies and cultural protocols of PAC migrants. Under 
the current state of the PAC policy, individuals are expected to come to New Zealand and know where and how to register with health service providers, and where to go in case of any emergency. Although the Ministry of Health acknowledges the cultural competency framework as a tool to assist health services to be responsive to Pacific people, Māori and other ethnic groups (Tiatia-Seath, 2008), it appears that this has not yet reached minority groups such as PAC migrant women. Whilst Kiribati migrant women meet the English requirement to be accepted under the PAC, they still require a translator who has adequate health literacy. This is a significant barrier to accessing quality healthcare that evidently results in poor health outcomes (Ministry of Health, 2014a, 2016). Kvamme and Ytrehus (2015, p. 13) argued that "inability to pay, administrative problems, lack of knowledge or understanding of the healthcare system and one's right, and language barrier - can result in delayed care". Ethnic minorities, particularly people who speak English as a second language, tend to have lower health literacy (Zanchetta \& Poureslami, 2006). A culturally competent workforce helps healthcare providers understand how and why different belief systems, ethnic origins, family structures and other culturally determined factors influence people's illness, or response to treatment. In other words, this good relationship and understanding between a provider and a patient improves the delivery of culturally competent care (Cohen, Gabriel, \& Terrell, 2002).

The Ministry of Health has good health policies in place to protect the rights of patients and values their cultural diversity. For example, the Ministry also sets its policy in line with 'Your rights under the Substance Addiction (Compulsory Assessment and Treatment) Act 2017' (Ministry of Health, 2018b). Despite the role of the policy to protect the rights of patients and respect cultural diversity, it does not appear to link to what is happening on the ground. Under this legislation, the Ministry outlined a list of rights of the patient. One of them is "your cultural and ethnic identity, language and personal beliefs are recognised and respected as are your ties with your family, whānau, hapū, iwi and extended family" (Ministry of Health, 2018b). Whilst this policy should be beneficial to Kiribati PAC migrants, they would not know about it unless they have someone advising them of their rights as patients. Those who live with families who have a good understanding of the New Zealand health system are fortunate. It is important that all migrants have equal access to health information and services. It is obvious in the women's stories that none of them ever used a medical 
interpreter, instead they used their families. Some family members may not have the health literacy to convey the advice of a healthcare professional in a way that the patient would understand. Using Ann's case, if her midwife had recognised and understood Ann's cultural background and belief, she would have delivered a better service. It was Ann's first time being pregnant and she did not understand the symptoms. She probably did not really understand her midwife and therefore did not understand which risk factors to manage, or signs of when to go to the hospital and thereby avoid delayed care.

\section{7 $\quad$ SENSE OF BELONGING}

In the following story, Lily shared her experience, which is similar to that of Ann, except that she had a safe delivery. She came on a visitor visa in order to look for a job offer, and she and her husband were granted a one-year work permit based on their job offers. This did not give them eligibility for access to free health services.

\section{Lily [selected in the PAC ballot in 2009 and came to New Zealand in the same year]}

E tuai tia ara bai ao e kanga arora ma te oo n aoraki ti aki ata arona ba ti na nakea, I aki roko $n$ te nako $n$ tutuo iroun au midwife ba are I aki ata arona ao mwina e na kaboaki ke kanga ngaia kanga I maaku ni mena ngaia I a bon tiku naba inanon are I bikoukou ao I a tiba tutuo n au kawaniua ke au kaitiua.

We were worried that we had not received our permanent residency. We had no idea about where and how to go to the hospital. I never saw a midwife as I didn't know if I had to pay, so I never visited one until I was seven or eight months pregnant.

Researcher

Ko nakon te midwife?

Did you ever go to see a midwife?

Lily

Eng ba are I a bon kaungaki I a bon tuoaki ba are tao imwina ngke tao iai te kanganga iroun natiu ngaia anne, e tei nangin are tao te mane ko na manga kabaka ke tera ao are e tuai tia ara bai ba ti bon still work permit. E ti kareke mane buu ba are ngai I a manga bikoukou. E tekeraoi ba I bung raoi ao e otinako ara PR n te...e otinako ara $P R n$ Aokati ao I bung $n$ Okitoba.

Yes, I was encouraged by my relatives to go for a health check in case there were complications with my child. The fear of the cost was the real factor as we were still on a work permit. My husband was the only one working as I was pregnant. I was lucky that I gave birth after the approval of our permanent residency...the permanent residency came out in August and I gave birth in October. 
Further to her story discussed in Chapter 4, this chapter shares her experience when she was pregnant while her permanent residency was still being processed. When Lily said "kanga ti raraoma ba e tuai otinako ara $P R$ " (we were worried because our permanent residency was not yet approved) it shows that there was no sense of belonging or feeling of freedom. The PAC was designed to give successful applicants the opportunity to become New Zealand permanent residents and a sense of belonging to their new country. With the lack of access to free healthcare, the lack of information about where and how to seek help from a midwife, the limited budget for healthcare, and cultural barriers as discussed in the previous chapter, she decided to take the risk not to seek antenatal services during her pregnancy. She felt isolated or imprisoned and did not know where to go or how to access healthcare services. Lily also felt distressed and homesick, and she sadly missed her son who stayed behind in Kiribati with their parents. Their son was once very ill, but the grandparents decided not to tell the parents until after the child was well. Lily wanted to return home, but she was stuck as she had no money to pay for her airfare. Feeling helpless, she could not do anything, but wait for her birth delivery. She finally had a health check-up at her seventh or eighth month, when her relatives were pressuring her to go for a check-up in case of any unexpected complications. If her relatives, who had been living in New Zealand longer than her, were not pushing her to see the midwife, Lily might have not seen one until she gave birth. It also shows that neoliberalism, which supports self-healthcare, creates health risks for Kiribati PAC women. Most women coming to New Zealand under the PAC are young and are more likely to get pregnant. Issuing a short-term work permit to Lily and the rest of these women was the major bottleneck for accessing healthcare. As stated earlier in Chapter 1, New Zealand health policy clearly states that a work visa holder of at least two years, and his/her partner and children under 18, are eligible to publicly-funded health and disability services (Ministry of Health, 2018a). Based on the stories of these women, the desire to find a job offer has made these Kiribati applicants including Lily come to New Zealand prior to obtaining permanent residency approval, without receiving good advice from Immigration New Zealand offshore officials, or their relatives and friends in New Zealand about real life experience and costs in New Zealand. The lack of health information and more importantly lack of access to healthcare for these mothers means that it also denies the rights of children to access quality healthcare. This is a significant health gap in the PAC. 
According to Anya (2007), in the UK, access to healthcare for vulnerable migrants is significant and it supports the human rights' argument that these services should be available and accessible. The author also argues that under the Italian law, since 1999 migrants regardless of their immigration status had the right to access healthcare without being reported to the Immigration Authority. However, a study on 770 migrants in 2004 shows that about 89 percent of illegal immigrants were not benefiting from any healthcare. Anya (2007) argues that changing the law does not automatically lead to improved access but requires appropriate legislation, strong political commitment, cultural understanding and outreach programmes. The UN and EU have made the following joint statement.

We urge all EU country governments to acknowledge explicitly their responsibilities for the healthcare of each person residing on their soil and to guarantee their individuals' rights to necessary healthcare. If such responsibilities are not accepted, serious human rights violations will continue and further harm will be done to vulnerable people who not only have a right to health, but to social inclusion (Anya, 2007, p. 827).

The Kiribati PAC migrant women's stories are critical to ensure that the PAC scheme does not violate the human rights of Kiribati migrant women and their children by not ensuring equal opportunities to access healthcare services to achieve good health outcomes. Similarly, Ruiz-Casares et al. (2012) raise the question on "who is responsible for the cost of healthcare services" which often make it hard for visitors. They argue that by excluding certain migrants from access to healthcare, the state not only breaches international human rights' law, but this also has a negative impact on medical practice and the integrity of the national health system. For example, these women and children can become unwell and affect/infect other people leading to more burden on the health system.

\subsection{THE DEMON OF MONEY}

It is evident from the following and previous women's stories that one of the key problems affecting most of the PAC migrants is lack of financial resources. Some of the participants were on a two-year work permit, but were not aware that they had free access to healthcare services. The majority were on a work permit of less than one year, which did not allow them to access publicly-funded healthcare services. Nancy said she never consulted the doctor when she felt sick because of the cost. 


\section{Nancy [selected in the PAC ballot in 2007 and arrived in New Zealand in the same year]}

$N$ aron ae bon ngai ngkana iai te aoraki ae reke e rang kanganga nakou nakon norakin te taokita ke tera ba iaan are...e tuai reke am $P R$ ao $e$ rang bobuaka aron kawarakin te taokita (Ngke e moan tabeka ana karaki, ao e baka ran matana).

When I became sick, I never consulted a doctor because of the fear of the cost of consultation and I had not got my permanent residency at the time. (When she started telling her story, she was in tears).

When she said, "e rang bobuaka aron kawarakin te taokita" (fear of the cost of the consultation) it reinforces the significant impact of the PAC on health inequality for PAC migrant women and their families. Nancy must have found it so difficult when she felt unwell with no treatment, and her children remained in the islands waiting for her papers to come through. This undermines the Ministry of Health's aim of ensuring that all people have equal access to healthcare. Whilst many of them might have used traditional healing in Kiribati, they do not have access in New Zealand to traditional plants that they would use on their home island.

In the following story Julia articulated the Kiribati ways of life that are inappropriate and could create health risks because of the different environment in New Zealand. Julia was a senior health professional in Kiribati before coming to New Zealand, so she had a good knowledge of the health impact of other cultural practices. Julia was fortunate to have known a local doctor whom she could consult for advice when necessary.

Julia

Iai ae ti kina ae doctor ae kain abara... (e ngarenage man oki nanona)...ngaia are ngaia anne are $n$ tabetai ti a bon nako nae kan...ao tao bukina naba are iai teutana ae I ataia...Aa e aki tangira moa te oo $n$ aoraki karaoi moa $n$ anne ke are ti karaua moa $n$ baronga te...i main ae ti nang bon nako naba $n$ access ao tera ao $n$ aekakin are e a bon korakora kan kakauongoa moa neiei ke tao antai.

Sometimes we take advantage of seeking medical advice from a local doctor ... (she laughed with relief) ....and plus my background in nursing, so I know whether or not it is necessary to access health services.

ma eti ngai I a bon tia $n$ baka $n$ aoraki ae I a bon...baka $n$ aoraki ae tao e a kan ae tao 3 te wiiki $i$ aon te flu...eng kanga irou anne e rawata nae buokara ba are ti tekeraoi ba iai ae ti kina ae taokita.

I had also been down with the flu for three weeks, yes, I personally felt that we received great support from a local Kiribati doctor, whom we knew very well. 
Having a good knowledge of health, she was able to monitor the health of her family and herself without going to a hospital.

\subsection{HOUSING}

Generally there is evidence that improved health and wellbeing go together with improved housing and the Ministries of Social Development and Health have a strong shared interest in reducing overcrowded housing (New Zealand Guidelines Group, 2011). Pacific people are used to living with extended families, so living in overcrowded housing is not uncommon. With the inflow of new immigrants under the PAC and in the absence of housing support, it is a challenge for these Ministries to address this issue. Most Kiribati PAC migrants have to stay with members of their $u t u$, kainga or friends before they can find or afford to move to a house of their own. For some PAC migrants, it takes a very long time before they can afford to leave their host family:

\section{Julia}

ao $n$ aekakin tabetai ti a bane nae $n$ maeka $n$ ae e crowded e tiraua ao ti a kabongana na tao ti a turn nae tao te karati ba te auti...e rang kaoraki ao ngaira iroura arei e bon rang normal ba are e bon raoiroi ba kae e tikiraoi taraia ai tikiraoira ami tabo aei ao ngaia e a noraki te curtain e a mould aana ao ngaira ti aki ataia ngaia ai bon anne te bai ae e a rang aoraki iai te aba.

Sometimes we were crowded in one house so we turned the garage into a living area, which is very unhealthy for us. The place looks alright and normal, but when you look behind the curtain, you could see mould, which demonstrates the unhealthy condition of the place. None of us was even aware that this is a critical and unhealthy condition.

The issue around affordability of accommodation has pushed many of the PAC migrant families to live with their relatives and friends in New Zealand. They did not have a job and secure income to afford renting their own place, so they took the risk of living in crowded houses, or even turn the garage into a living area without realising the mould behind curtains that could lead to asthma and other health issues for the children. The Ministry of Health (2014a) aims to deliver three key performance indicators to contribute to good health outcomes of Pacific peoples and communities. One of these indicators is the reduction in hospital admissions. Whilst the PAC has provided opportunities for Kiribati PAC migrants to live and work in New Zealand, it has contributed to poor health outcomes where some of these migrants have no choice but to accept living in overcrowded houses until they can afford to get a place of their 
own. In addition, many Kiribati families hosting these PAC migrants have ignored this problem as it is their cultural responsibility under Kiribati hospitality to put the needs of these newly migrant families before theirs. In Kiribati, the weather is tropical so people are used to living in an open house that allows circulation of air. While this way of living is appropriate in Kiribati, it is not suitable for New Zealand's colder weather. Again, this shows that Kiribati PAC migrant women need to be well aware of issues around the poor housing conditions and different weather conditions, and the impact on their families' health.

\title{
7.10 LACK OF FREE ACCESS TO HEALTHCARE
}

In the following story, Nickie, shared the story of her child being admitted to Starship Hospital for a serious illness.

\begin{abstract}
Nickie
Natiu naba are te ikawai arei I kabaka naba e kan te bwina tenga ibukin boon ana on aoraki ngke e moan roko ao ti aki ataia ba nanona ana tutuo $i$ Kiribati a bane $n$ raraoi ao ngke e a roko ao iai ana kanganga ba e babobo ti aki ataia naba ma e a bon roko naba angin te aoraki irouna ae korakora ao a bane n babobo bain rabatana e a kakibaaki $n$ te erekabuta nakon te starship, e reke aio imain ae I PR, ao I a pay te te bwina te ngaa ao tii aua ana bong. I a nako n kakaea buokana nakon te social worker, ba irarikina naba natiu e a rang kainnano $n$ te oo $n$ aoraki ba akea te bai ae karaoaki ba e a bon ti ananaki naba rarana $n$ katoa bong. E kona $n$ reke anakin rarana tao teniua te tai $n$ teuana te bong ngaia e a bon taetae natiu akea buokana ae reke, ti tabo e a kainnano riki $n$ are e a waewaraki $n$ te nei ran. (Ngke e karaki, ao ko namakina ba e tuai nako betin te maraki arei).
\end{abstract}

One of my children, the eldest, suddenly got very sick when they first arrived in New Zealand and I had to pay around \$10,000 for her hospitalisation. The child's medical check-up in Kiribati was fine. But after arriving in New Zealand, she got very sick, her skin was all yellow, she was flown by helicopter to Starship. This happened before we were granted permanent residency, and I paid $\$ 10,000$ for the 4 days she stayed in the hospital. I went to seek help from a social worker, because my child was suffering in the hospital as there was no treatment given to her, but the blood test was done every day. There were about three blood tests done in one day, my child said she was not getting any better, it is like she suffered more from being poked with needles. (When she told her story, she looked angry and I could feel that the root cause of the pain had not yet healed).

As reported in Chapter 1, Kiribati is a poor country and it is expected that most of these women emigrate with limited income. Most of them only have enough money to cover the cost of processing their applications with Immigration New Zealand. Nickie was 
on a visitor visa when her daughter was admitted to Starship Hospital. Nickie had no choice but to pay around $\$ 10,000$ for her daughter's hospitalisation. She was very stressed, thinking about how she would afford to pay for their documentation relating to their permanent residency, and the cost of her child's treatment. This affected the wellbeing of the whole family. This story provides evidence that the lack of access to public health services is a real challenge and has caused poverty and health inequality for PAC migrant women and their children. Nickie and her family completed their medical check-ups before coming to New Zealand, but not long after they arrived her daughter became very ill. This suggests that the medical facilities in Kiribati, and this could be the same in other Pacific countries, do not have the capability to do a full and thorough medical examination. This is a health gap in the PAC scheme that needs critical attention to support the wellbeing of Kiribati PAC migrant women and children.

In the following story, Dora experienced a miscarriage and was charged the full cost of the healthcare service.

\section{Dora [came to New Zealand in 2007 and selected in the PAC ballot in 2012]}

Aorakiu ngkanne are te aekaki are I urakinanako te rara eng ma ngke I a tuoaki ao te aekaki ae e baka natiu, iai natiu I bikoukou ma I aki ataia ba I bikoukou ngaia anne ngaia are a tuoai taokita ao a taku ba $e$ nang bon riai ni baka ngaia are e a mamaraki e aki kona $n$ toki marakina ma inanon iraua te aoa tao bon tii uoua te aoa ao e a toki ao I otinako naba $n$ te tai anne... ao I a tuangaki boon au oo $n$ aoraki te aekaki ae tao $\$ 700$ tabun ke, te aekaki anne $\$ 700$ tabun ae nna kabaka. (Ngke e karaki ao e oti ae e rang tabeaianga n te tai arei).

I had heavy menstruation so after my check up, it was confirmed that I had a miscarriage. I was pregnant, but I didn't know it. When the doctors checked me, they told me that I had a miscarriage hence I was in pain, which continued for a number of hours, perhaps it was two hours before the pain stopped, and I was discharged on the same day...the bill came later, which was around $\$ 700$ or more. (There was a visible sign of stress when she told this story).

Most of the PAC migrants started on the minimum wage and coupled with a large family, they are amongst the poorest families in New Zealand. Over time, they worked their way up and had undertaken courses to be able to do better with higher paying jobs. But within the first year of settlement, they needed health and social support. Dora had a large family. She was already on a tight budget covering school fees for her children, who all attended the Catholic primary and secondary schools, food, bills 
and other expenses for their basic needs. On top of such expenses, she had to pay the hospital bill for her treatment. She had no choice but to make part-payment until the bill was paid off. Dora did not expect that she would have to pay for the treatment because in Kiribati healthcare is free to everyone. What Dora went through was a natural health problem for women, however, the lack of access to free healthcare services by migrants prior to the approval of their permanent residency is evidence of a significant gap in the PAC.

The next stories show how the PAC created unnecessary poverty, inequality and hardship for women prior to gaining their residency.

\subsection{INEQUALITY}

Most of the women interviewed had no choice but to accept low skilled jobs, which involved working long and odd hours. Josephine shared her experience of working odd hours, which did not give her enough time to attend to the health needs of her children. The need for income to meet the fees for their application and other financial needs forced Josephine and her husband to take these shifts.

\section{Josephine}

(Ngke e moan karaki Josephine, ao e bon ruru banana man rotaki $n$ te nanokawaki)

E bon affect ba ngai ngke e aoraki naba natiu are te mane arei e bon aoraki ibukin ae ti a bon aki tabeakinia kanga ngai irou, ti nako ni kaitiaki $n$ te aoa 2 ni karokoa te karangaina ti oki ti a bon oki naba ni kabakaia, $n$ oki ni matu $n$ uti $n$ nako $n$ anaia $n$ taon nako $n$ reirei..ao ngai natiu arei tao e bon aoraki tao e a bekobeko e maraki buana ao ngaira iroura akea tarakin te itera arei ba are ti na nako ni makuri ba tia manga aki nako ni makuri ao are ti work permit ba ti angoa ara PR ba e na reke ti na riai ni karaoi ba akekei ni kabane ao a manga baini kirinira taan makuri ba tao a kanga a rang desperate ti na kanakoia ba a na kaitiaki i...are bon akea ae kan nako ao ngaira iroura aa te bwaka mai $i$ karawa anne..... e raoiroi ti nako naba tao bon iraua ara namakaina ngke e bon reke ara $P R$ ao ti aki naba nanora ba ti na resign...(ngke e karaki ao e ngarengare ma te oki $n$ nano)... ti aki nanora ba ti na resign ma are e rin natira $n$ te oo ao I a bon tangiraki ba $n$ na tiku irarikiaa ataei...ao raou e ririanna e nako $n$ noria.. e a rang too much ibukira ao ti a resign naba. Ma ngai irou anne akea are ko taraia raoi tera ae riki irouia ngkai ngke e a bon tiba kangai naba temanna, e maraki buau na kabaea moa ana mena natiu ba e na nako bon akea ngai ngkai irou bon akea te kabane tai kanga a bon aoraki naba, kanga e maraki matau mummy, ngaia am appointment arei ko na nako te aoa iraua ngkoa ngai irou tao a bon bon taetae ma tiaki tabe irouia ba e rang kakawaki riki ara makuri are ti na manga karaoia arei 
ba are reken ara mane ba are ngkana ti aki nako ni makuri e aki reke ara mane ba are ti aki eligble nakon te benefit $n$ te tai arei ba are ti work permit ai bon maiura naba ara mane are e reke are korakorara ni katoa bong..

(When she first told me her story, her voice was shaky and she looked sad). I feel that my child was sick because we just did not have enough time for him. We went to do our cleaning around $2 \mathrm{pm}$ until early the next morning. We came back after work, took our children to school. After that, we went straight to sleep. When we woke up, we went to pick them up from school. My child got sick, he coughed, he had sore throat and we did not have time to monitor his health condition because we had to go to work. We had no other choice. We could not afford not to work as we were on a work permit and tried our best to achieve our permanent residency. At work, at times, we felt mistreated because they knew we were desperate for money. They sent us to do cleaning in..., a place that no one would like to go because it was far away. For us at the time, it was a gift from heaven...so we took it. We worked there for a few months. When our permanent residency was approved, we stopped working... (Josephine laughed with relief) ...we did not mean to resign because we got our PR, but our child was admitted to hospital and I needed to be with him. My husband continued to work, but it was too much for him, so we decided to resign. From my perspective, that was the cause. You had no adequate time to provide good healthcare for your children. Now, as soon as one of them said, "I have a sore throat...." and "mummy I have a sore eye", I arranged their appointment. I told them "your appointment has been arranged, make sure you go at whatever time". Before the approval of our PR, they probably needed good care, but we could not do anything about it, our job was a priority as we needed money to meet our basic needs. If we didn't work, we were not eligible for the unemployment benefit at the time. We were on a work permit, we earned our living from an income that we earned each day.

When Josphine said "maiura naba ara mane are e reke are korakorara ni katoa bong are ti nako ni makuria (we earned our living from an income that we earned each day)", this articulated the critical healthcare gap in the PAC for migrant women and their children. Josephine knew her responsibility was to her children, but had no choice. If she did not work, they had nothing to eat or could not meet financial obligations for their children's education. Whilst she recognised her critical role as a mother and caregiver to her children, there was no family support system like the one they had in Kiribati. The family support in New Zealand is available in terms of providing temporary accommodation, transport, or a service broker between migrants and service providers or Immigration New Zealand. Looking after children, and taking them to school or a doctor are vital responsibilities that new migrant couples with 
children have to do. Mothers who did not work in Kiribati now have to work together with their husbands so that they can both meet the minimum income requirement for permanent residency under the PAC. Most of these women started with low skilled jobs despite having good qualifications or holding high positions back in Kiribati. For this reason, some couples decided to leave their children behind until they had secured their permanent residency.

\subsection{HEALTH RISK}

In the following story, Josephine explained how it was less stressful when her child was admitted to the hospital after they had received their permanent residency. They did not have to worry about paying for their child's hospitalisation. It also became evident from her narratives that this illness could have been prevented if she had attended earlier to the health needs of her child. However, the nature of her work, and the lack of access to free healthcare services in the first instance had made it difficult to provide quality healthcare for her children:

\section{Josephine}

...bon te moan $n$ tai ngke ti rin tia bon tuangaki naba ae kaini ikai ngkami ke ti aki ao ngke ti kangai nakoia ngaira ao ngaia ti kona n nora te proof of everything ao ngaira iroura nanona e a bon tiba out ara PR ni banen Beberuare ao te aekaki are two weeks riki ao e rin natira ao ti a bon itaramata ti taku ti a kuri kangara ao...ma a bon kabarabara kam na riai $n$ raa ni provide ami PR nakoira ba te cost of the bed of one night e kan ngaa ao eng ao ngaira ti aki tabara ao kai ti na uotia ni ngabong ao ngke ti a oki ao ti a taku ti a kuri kanga ao tera riki ae ti na karaoia ao imagine riki ake ... ao eng are ti a manga tuangaki kanga e na bon tiku ni maan tao bon teuana te week.... Ao ko nang kanga ni kaboa ao at that stage are ko a bon rang struggle e tuai reke am tabo ni maeka ao a tuai n settle ataei ao riki ngkana e tiraua natim ke. (Ngke e karaki ao e ngarengare man oki nanona).

The first thing we were asked on arrival at the hospital was proof of being a New Zealand citizen or permanent resident. Our permanent residency just come out in February, two weeks before our child was admitted to the hospital. So, we looked at each other and said, we could have paid so much if we were non-residents. They explained to us that you must show proof of your permanent residency because the cost of the bed per night was about $\$ 1000$. We responded quickly, telling them that we would bring it the next day. We came home and shared our story. What else could we have done if we were non-residents... when they told us that our child would have to stay for about a week... and how could we afford that when we were still struggling. We don't even have our own place to live and our children were not yet settled, 
especially when we have many children. (When she told her story, she laughed with relief).

When Josephine and her husband were told of the cost of hospitalisation for about a week, they looked at each other with a great relief. She knew that if this had happened before the approval of their permanent residency, they would have faced a huge financial problem. They would not have been able to afford to meet the basic needs of their children. Josephine thought of large families like hers who were in the same situation, but had not yet received permanent residency.

Given high healthcare costs, the language barrier, a lack of social support and the type of unskilled work they did whilst waiting for their permanent residency to be granted, these PAC migrant families often had little choice but to disregard minor health issues and more significantly those of their children, which thus led to serious illnesses later on. At the time of this maroro, Josephine had completed her nursing degree, and totally understood and agreed that accessing health services was critical for the health and wellbeing of Kiribati PAC migrants. In sharing her story, she affirmed that had this happened before they received their permanent residency, they would not have been able to afford to pay the cost of their child's hospitalisation, which lasted about a week where the cost of one bed was around $\$ 1,000$ per night, plus the cost of other treatment and medications. Whilst the Ministry of Health aims to reduce hospital admissions for Pacific people, the poor conditions of the PAC policy exacerbate poor health conditions.

In the following story, Faustina also shares her experience and the challenges of not having access to free healthcare services.

Faustina [selected in the PAC ballot in 2009 and came to New Zealand in 2010]

E reke anne naba iroura ba natira anne e a kaman baka $n$ aoraki ao ti tuai ataia ba...ngaia ngkana a wene $n$ aoraki ba ai tera te wene $n$ aoraki...kam na riai...tao a bon baki ke aera an nako amarake ba ngkana kam rang taningaroti $n$ amarake kam tangiria ba kam na wene $n$ aoraki ao ai te bobuaka riki te bai n aoraki ao ngkanne natira akekei ngkana ti kangai kam na nakon te oo $n$ aoraki a rang maaka te oo $n$ aoraki...Eng are ti tabo ma a rang maaku ibukin ara taeka arei...are e a wewene $n$ aoraki ao tao ngkana ti kangai ti nang nikiriko $n$ te oo $n$ aoraki I aki I raoiroi, I rang... a taekinna ngkanne e rang bobuaka te bai n aoraki ti a manga bure ba ti tabo ma ti a menaia are kanga a nang kain aorakiia $n$ aki kaotinakoa...ao a ongongo ara taetae are e rang bobuaka te bai n aoraki ti tuai ataia ba iraua boona ma iaan ae ti a bon 


\section{ongongo naba ae bobuaka. (Ngke e karaki ao e rotaki $n$ angin te nanokawaki).}

That also happened to us. One of our children was ill. When they were feeling unwell...I told them "you must not..." perhaps they were hungry or whatever reasons, I told them, "go and have something to eat because if you are too lazy to eat then you will get sick and healthcare is expensive". I feel that when my children were actually sick and needed to see a doctor, they would refuse because they already knew that the medicine was expensive. They started to get frightened to be referred to a doctor when someone was sick. As soon as we said, "we will take you to the hospital", the child responded by saying, "no, I am alright...". They said, "the cost of medicine is very expensive". We realised we were being unfair to our children as we had influenced their perception that healthcare is expensive and they prefer not to discuss their sickness. They have heard from us many times that healthcare is expensive, even though we don't know yet the real cost, but this is what we have heard from others. (She was very emotional when she told her story).

One of Faustina's children was admitted to hospital with a serious illness not long after their permanent residency was granted. Faustina asserted that if they were not faced with financial constraints and healthcare was free, perhaps her daughter's health problem could have been avoided or treated much earlier. Before they received their permanent residency, they could not afford to access healthcare services so they tried their very best to avoid seeking medical attention when it was needed. Whenever her children became unwell, although she knew she should to take them to be seen by a doctor, instead she would try to treat them at home by encouraging them to stay active and eat healthily, with the hope that they would get better. The children were made aware that the cost of healthcare was very expensive, and that it was very important not to get sick.

Faustina recounted, "ti kangai ti nang nikiriko n te oo n aoraki, I aki I raoiroi (we said, we will take you to the hospital, the child responded by saying, no, I am alright)". This shows that the child was in denial of her health needs because she was aware that her parents were struggling and knew that they could not afford the cost of healthcare. The financial constraint and the lack of access to free healthcare created a sense of insecurity, lack of freedom and health inequality for the children. Faustina's child had a serious illness and was admitted to hospital, but there was no cost of hospitalisation to them at the time because they were permanent residents. I argue that the poor conditions of the PAC policy had disadvantaged Faustina who has a large family. She had to manage her scarce resources to ensure that they were able to meet their bills and 
other basic needs. Whilst she felt relieved when she did not have to pay for her daughter's hospitalisation, it was now a burden on the public health system. Again, 'Ala Mo'ui's objectives of reducing hospital admissions and improving health outcomes of Pacific people are undermined by the poor health condition of the PAC policy.

Early and regular child health check-ups could have prevented these serious health cases. The experiences of PAC migrant women align with the findings of other researchers such as Kvamme and Ytrehus (2015), who demonstrate that undocumented migrant women have been disadvantaged by situations where they have ignored minor illnesses, thus resulting in serious health problems.

\subsection{LACK OF HEALTH INFORMATION}

In the following story, Sally articulated the importance of educating the PAC migrant women about the importance of bringing their children's immunisation records. Sally and her children waited in Kiribati while her husband who was already working in New Zealand was processing their papers. They travelled to New Zealand after the approval of their permanent residency application. Compared with the rest of the participants, Sally was fortunate because she could access free healthcare at any time after arrival.

\section{Sally}

Teuana mai ibuakon... are nanona ba ngkana a roko ikai, e kanganga a na access aia information... a tangiria ba a tia $n$ immunise $i$ aon tera natim arei, ao angiina ... ba are ngke ngkana ko nakomai kanga...iroum akea bongan baai ake... ko a bon roko naba n aki tabe ma te bai ngaia are ngke ko a roko, kai e a bon tia...n aron ae I kangai e a bon tia $n$ immunise natiu n te miitira ao te bai arei, a manga kakeweko ba a kan kakoaua ba are ikai bon iai te boki.

It is important that they bring information about their children, because when they get here, it is difficult to access such information. Health workers here like to know if your children have been immunised against important sicknesses. You think it is not important, but when you get here, it is something that is required because even when I said my child has been immunised, they still required a copy of my child's health records.

Whilst Sally did not experience as many challenges as the rest of the participants, she still acknowledged the gap in the PAC relating to awareness of important health information when she said, "ana tuangaki ana karekei aia information ibukin natiaa 
(it is important they are advised to bring health information, e.g. immunisation, about their children)". No one provides awareness and advice to PAC migrants. Having completed her nursing degree at the time of our maroro, Sally strongly stressed that this is one of the real health gaps in the PAC, which has a significant impact on the health of children. Hence, she advised the need for more awareness among those coming under the PAC of the importance of bringing with them their health records such as their children's immunisation records.

A number of researchers (e.g. Kvamme \& Ytrehus, 2015; Meadows, Thurston, \& Melton, 2001; Ruiz-Casares et al., 2012; Silva \& Dawson, 2004) have identified similar barriers including the lack of social support for women in accessing healthcare services in other countries.

In the following story, Sandy indicated that she depended on Kiribati friends to connect them to a Pacific health service provider who offered free healthcare services.

\begin{abstract}
Sandy
Ngai I marurung ma ti buu ae e aoraki ngaia ti a manga nako $n$ kakai taabo aika a free, ba kanga e ulcer ngaia e tekeraoi $n$ te [oo $n$ aorake teuana] ...Angin buokana ibukin atakin taabo, bon mairouia raora $n$ Kiribati.

I was fine but my husband had a health problem so we had to look for places that offered free health services. He had an ulcer but we were lucky to get help from one of the [Pasifika service providers]. He mainly knew contacts for other places through our Kiribati network.
\end{abstract}

The cost of a medical check-up related to immigration papers was beyond Sandy's limited budget. She was lucky as through the network of other Kiribati friends, her husband was able to access free health services from a Pasifika service provider, which was a big help. This information was not something that other participants were aware of, so there was inconsistency in how the PAC migrants receive information about free healthcare services leading to unequal distribution of benefits amongst these migrants.

\title{
7.14 STRESSFUL LIFE
}

In Kiribati, one hardly hears the word 'stress'. Those who do not work, but have a financial commitment, would bubuti members of their utu or kainga for help (refer to Ruuti's story in Section 4.7. Those who do not have any savings do not have to worry because their utu or kainga will support them when they are in need. In the following stories, it is evident that whilst the PAC has given Kiribati people the opportunity to 
live a better life in New Zealand, it has not provided enough information to migrants about New Zealand's way of life and and prepare them to address some of the challenges they may face when they arrive.

Whilst Sally was appreciative of the opportunity to live permanently under the PAC, she felt that her health status has deteriorated.

\section{Sally}

Ngai ngkanne I aki aoraki are bon te aoraki ma ti tabo ma I rang stress kanga ngkai I kataia ni compare ma are bon au life ngkoa i abau i main ae I nakomai. $N$ aron are I taku I rang kukurei ngke I a reke $n$ te PAC ibukin au iango are a na bon rang tamaroa baai ni kabane ikai ma ngkai $n$ ae I a bon maan ao I a kataia ni iaiangoia ba tera te kaokoro ae I namakinna ao I taku ba I rang stress ikai ao ngaia kanga e birirake rietatan rarau ae I bon aki ririetata n rara i abau ao I a roko ikai ao ti tabo e a rietata raarau kanga te aekaki anne ma tao e bon rawata baai aika e contribute nako iai...ba are bon iai bebeten reken te amarake ma tao e a kanga ngkanne e a nakon naba are $i$ abara ngkoa tao i abara ngkoa a rang bebete aron baai ba are ti maeu ma tamara tinara tarira manera ara aunty ma ara extended family ao akea tabetabera (tabetaben am iango) ngaia anne kanga e rang rawata...are ko aki tabeakini ikekei $n$ aron are ko uti kanga ko a bon uti nae $n$ nako ni makuri n akea am kanganga ba ko a katikui naba are kanga natim ma tera ma te mwenga iroun tamam tinam am aunties ao ngkanne ngkai ti a roko ikai ai bon ngaira baai ni kabane ti a bon bane $n$ tobai ao ni kotaki ma are...ikekei I bon makuri...I kataia ni compare ba ikai. I bon makuri naba ngke I mena i Kiribati ma I aki rang stress ao kai I a roko ikai I a rang stress ao e a rietata rarau ao I a tangira te batin ba e na control I taku ba akanne eti ba are I bon makuri naba i Kiribati ao ikai naba I makuri ma are akea au supporters akekei are e aki rarawata au iango ba I a bon kangai naba...ni kakioi ake tabeua ao I a katikui ake tabeua nakon tinau ke tariu ao au aunty ao kai tia roko ikai ai bon akea ara utu ba are tia roko $n$ te aba are ti aki abara ngaia ara kanganga ake... a buokaki... a bane ni baka iaora ba are ai bon tii ngaira ngkai $n$ tobai kanga te aekaki anne kanga irou anne, eng eti are ti aki aoraki tao tera ma kanga ngaia are ma ti a stress ao ti a rietata $n$ rara (A uaia ni ngarengare Sally ao te tia kakae).

I don't feel ill but I feel very stressed if I compare my life in Kiribati before coming to New Zealand and after. As said earlier, I am very happy that I got selected under the PAC to fulfil my plan to live a better life here, but after living here for a long time and when I try to think of the difference in my health status, I feel very stressed here and have experienced high blood pressure, which I never had in Kiribati...I have to take pills to control it... This could be caused by various factors...food is easier to get here, but in my home island, we live with our father and mother, sisters and brothers, our aunts and our extended family. We had no worries there. For example, there are no worries when you get ready for work, as you can leave any responsibilities with 
your parents and members of your extended family, to take care of your children and other domestic work. When we came here, we had to deal with everything whilst also working. I also worked in Kiribati but I was not stressed...I can easily do certain things and leave the rest of the responsibility to my mother, sister or aunty. When we came here, we had no family members to rely on..., so all our responsibilities fell on us because we are on our own. It is something like that. It is not that I am sick, but we are stressed and have high blood pressure (Sally and the researcher both laughed).

Sally's key message articulates the important role of te utu and te kainga in supporting members who are working. This includes taking responsibility for the healthcare of children. Before adapting to the New Zealand way of life, Sally felt homesick and missed the support provided by her parents, siblings and other family members. This is the beauty of the Kiribati culture, which is treasured and missed when Kiribati people are away from their parents and extended family. On the other hand, the Kiribati way of life does not prepare its people for life in an individualistic society such as that in New Zealand. For my generation, our parents did not envisage that their children would one day be living in a different part of the globe, where life is very different from the one that they knew. Thus, the Government of Kiribati needs to be strategic and forecast the movement of its citizens beyond its borders, and determine the skills required to prepare them for life and work abroad. As mentioned in Chapter 4, te utu and te kainga play a significant role in supporting the career of women. Our parents wanted their children to advance their careers. From Sally's story, when she was working in Kiribati, most of her domestic responsibilities were taken up by her parents and extended family so she could perform well at work. In New Zealand, on top of taking on domestic responsibilities Sally also had to work. Without work, her family would not meet their everyday expenses. These PAC migrant women have to work and be responsible for the healthcare of their children. As Sally claims, the increased responsibilities have escalated her stress and high blood pressure.

In the following story, Sali said that she struggled to meet the cost of medical consultations with a PAC medical specialist and other medical doctors.

\section{Sali}

E tauira te aoraki e rang rawata te cholesterol. Bon akea ngkekei nanona ngke ti moan roko ikai ao a tikiraoi aia mena buu ao natiu aia tutuo ao tii ngai. Nanoa bon te bae ae na moantai n tia ara PR ma e a tuai I a roroko iroun te specialist are I pay $\$ 300$ tabun...ao e rang rawata naba au tai are I nanako n pay te tutuo. Are I tuoaki 3 months 
ao I a manga tuoaki naba. E kan $\$ 50$ n teuana te tutuo (Ko namakina ae e rang stress $n$ te tai arei ngke e karakina arona).

I had high cholesterol, I never had it before. When we came, my husband and children had their medical examinations cleared. Our PR could have been issued much earlier, but it was pending my medical clearance. I went to see a specialist who charged over $\$ 300$ per hour and I paid a lot more for additional medical check-ups. I had my medical check-up every three months. Each time, I paid almost $\$ 50$ per consultation. (There was sign of visible stress when she told this story).

When Sali said "Bon akea ngkekei", she meant that she was feeling well before coming to New Zealand. Since arriving in New Zealand, she suffered from high cholesterol, which she never experienced before. As mentioned in Section 1.3.2, health is affected by socio-economic factors. Sali and her husband had nine children together. Most of their children remained in Kiribati with their grandparents until they had settled in New Zealand. Sali helped shoulder their financial responsibilities by working, and remitting money to Kiribati for their children. Her anxieties about when her medical tests would clear and when she would be reunited with her children, may have all contributed to her poor health. Being separated from her children for the first time, as a mother Sali was always worried about her children's welfare. Prior to coming to New Zealand, her family received limited information and advice about how to look for a job and process their applications. However, with the support of members of their kainga who had already settled in New Zealand, Sali and her husband were able to acquire a job offer and subsequently their work permits quite quickly. This allowed them to work and earn enough money to meet the costs of processing their applications, including the cost of medical consultations.

\subsection{PSYCHOLOGICALLY AFFECTED}

\section{Tally}

Kanga physically kanga ti bon rang kukurei i abara ke ma are ngke ti a roko ao ti tabo ma are emotially...e a rang ni mena e a rang affect ara health riki ba ... are mentally kanga e aera e a bon affect ao mentally ao e a bon roota naba korakoram, te aekaki ae are ti tabo ma are ko na kanga ko aki amamarake ke ao ti tabo ma I a mama $n$ ira nanou $n$ amarake ke ba tera ke kanga te aekaki aio ao ti tabo ma am apetitite ai akea ba ti tabo ma ko na manga taraia ba ningabong tera ngkanne ae $n$ na manga karaoia ao n na manga nakea...I a nimarakiraki e a tau ai manga te batin e a manga rang bobouaka ke tao terana kee ai manga ...te aekaki anne ngaia te aekaki are ti tabo ba are...(e toki moa ni iango)...ti aki kona ti a aki kona riki n manga explain more ba te 
aekaki are kanga e a roko iroura te regret.... (Ngke e karaki ao e rang mata $n$ nanokawaki $n$ aron te bai are e a tia $n$ rinanona).

Physically, we were happy in our own country, but when we came, we felt emotional... it had a great impact on our health. Mentally, it affected your strength to the extent that you lost your appetite, you started counting days, what you will do the next day and where to go. I started to feel the pain throughout my body, the medicines were expensive or things like that... (she paused and recollected her ideas) ... we can't explain it further. It's as if we have regretted coming considering our health. (When she told this story, Tally looked sad recounting what she had gone through).

Tally felt constrained by many factors including being new to the New Zealand environment, lack of understanding of the English culture, and lack of networks and New Zealand work experience. She was worried that she would not find a job offer within the limited time that she had. This had affected her physically, emotionally and mentally. She lost her appetite and felt her body ache. Tally could not afford the cost of medicines, so she preferred to bear the pain. Her husband and children remained in Kiribati. This made it worse for her as she could not share her pain with her family. This reinforces the need for further support services by Immigration New Zealand so that when these PAC migrants arrive in New Zealand, they can easily find work and find a house quickly. At the time of our maroro, Tally had completed her nursing degree and was working as a registered nurse. When she first arrived in New Zealand, Tally was inexperienced and lacked the confidence to liaise with employers to find work. She came with only a secondary school qualification. Despite this, it provided her with a foundation to undertake studies towards a nursing degree. Her story shows that many PAC migrants with only a secondary education have the potential to further their education and obtain a profession. They deserve to be well supported so that they can easily find work, access health and social services and settle well in their adopted country.

In the following section, I look at best practice options that could be considered to improve the healthcare of PAC migrants.

\subsection{OTHER BEST PRACTICE INITIATIVES}

\subsubsection{Refugees}

It is evident from these women's stories that New Zealand's health policy has been disarticulated in the design process and implementation of the PAC. Interestingly, as discussed in Chapter 1, the status of refugees in New Zealand provides a useful 
comparison for understanding the health experience of PAC migrant women and their children. The study by Mortensen (2011) on refugees in New Zealand shows that services that were available to refugees included health promotion, mental health, community-based health, and that cultural diversity training are needed for the Kiribati migrants as well as other migrants from other eligible Pacific Islands.

\subsubsection{New Zealand's Recognised Seasonal Employers (RSE) scheme}

According to Johnson and Maguire (2016), the RSE employers have taken seriously the responsibility to ensure the wellbeing of their Pacific RSE workers by providing a number of services including access to medical insurance, language translation, and pastoral care. The RSE scheme involves recruitment of seasonal workers from eligible Pacific countries including Kiribati. Fiji, Samoa, Tonga, Tuvalu, Solomon Islands, Vanuatu, Papua New Guinea and Nauru. The RSE scheme has largely been successful by employing young workers, both men and women from these countries (Immigration New Zealand, 2019a). It contributes to meeting the demand for workers when the domestic demand is not met by local labour supply. As discussed in Chapter 1, the scheme has a good process and system in place, caring for the welfare and health needs of these seasonal workers. For instance, under this scheme, it is mandatory for RSE employers to arrange health insurance cover for their workers coming from overseas. The availability of health insurance is crucial for covering the costs of unexpected hospitalisation. In addition, the RSE employers provide pastoral care and support for these workers. Most member countries that participate in the scheme have a liaison officer based in New Zealand to also provide pastoral care for these workers by bridging any language and cultural barriers. This raises the question of what is limiting the New Zealand government from providing the same healthcare support to PAC migrant families that is provided for RSE workers. Doing so would support the health and wellbeing of the latter group, so that they can become productive and active New Zealanders.

\subsection{CONCLUSION AND DISCUSSION}

As consistently discussed in both the present and previous chapters, the poor health experiences of most of these women had been contributed to by a complex set of factors. The key factor is the mismatch between neoliberalism and te maneaba system that created stress, anger, loneliness, hopelessness and cultural gaps affecting the 
mental health, healthcare and wellbeing of Kiribati PAC migrants. Labonté and Stuckler (2016) argued that neoliberalism was a political response to economic crises in the 1970s, which first started in Chile in 1973. Neoliberalism as an economic policy has created health issues including unemployment, poverty and homelessness, because of the reduction in the budget for health and social protection. Arguably, the PAC had given these women the opportunity to be economically independent and live permanently in New Zealand, but with minimal healthcare and social support until they obtained permanent residency. As Szenassy (2016) stated, during an interview with Susanna Trnka, a social and medical anthropologist of Czech-American heritage, Trnka argued that when comparing responsibilities for childhood asthma in the Czech Republic and New Zealand, it is clear that the two countries have very different concepts about the responsibility of the individual and the family in coping with chronic health conditions. Being at the forefront of neoliberal reform of healthcare, in New Zealand it is very much the responsibility of individuals and families, whereas in the Czech Republic it is focussed on the expertise of professionals such as doctors (Szenassy, 2016).

The PAC women were given the responsibility for looking after their own health and healthcare, without any access to such services and other support from government. This does not work for many Kiribati PAC migrants especially those who have never been to New Zealand or any other country, who not only lack the understanding of the New Zealand health system, but have a unique culture around their healthcare rooted in their traditional maneaba system. Members of te utu and te kainga take responsibility for the health of a sick woman or child. There is strong evidence from the above women's stories that the PAC has caused poverty and health inequality amongst many Kiribati PAC migrant families. For example, one woman had a stillbirth, one woman ended up paying a large hospital bill, which was beyond her budget, and two mothers had their children admitted to the hospital for preventable illnesses. Coming to New Zealand on a visitor visa and short-term work permit does not give PAC migrants access to healthcare services. Coupled with financial constraints, fear of the cost of healthcare, the language barrier, and the lack of health information, most of these women were in denial of their health needs as well as the needs of their children. The fact that these women were very attached to their culture and identity, a part of which is traditional healing, as indicated by two research 
participants and another non-research participant, could be something they used to help meet their health needs. This is an area that requires future research and development. In addition, Nickie had a sick child admitted to hospital at the time when she was still a non-resident. This had hurt the family, not only because of their concern for the wellbeing of the child, but because of the amount of money they had to pay. On top of that, they needed the money to meet the cost of their immigration papers. This created financial stress, which affected family wellbeing. Dora was also admitted in relation to a menstruation issue, a problem that is unavoidable for women. It is therefore critical that women should have a form of health security to protect their health and wellbeing. The unequal opportunities to access quality health services is a significant gap in the current PAC policy. It is evident from the women's challenging and courageous stories that there is a real need for PAC migrants to be given equal opportunity to access health services and housing that is freely available for New Zealand permanent residents, citizens or refugees as soon as they arrive in New Zealand. Most of these women were permanent residents and working at the time of te maroro so they played a key role as tax-payers. They were denied free access to health services and some had unfortunately gone through difficult situations or paid the full price for their healthcare needs. This caused unnecessary poverty amongst the Kiribati PAC immigrants.

Being on a limited budget, many of these migrants had sought temporary accommodation with other Kiribati relatives, thus causing overcrowding and poor housing conditions. As reported in Section 1.4.6, it took more than a year for many of these migrants to receive their permanent residency. For some, it took three to six years. The long waiting period and their insecurity of not yet being a resident of New Zealand have affected their health and wellbeing. As reported in the 'Ala Mo'ui Pacific health strategy, family commitments are accorded high priority in Pacific cultures, and overcrowding is a key issue affecting Pacific people. Southwick et al. (2012), who also covered a Kiribati group in their study, affirmed that poor and overcrowded housing, housing affordability, language barrier, transportation issues, poor health literacy and low income, all contribute to poor health outcomes for Pacific peoples. Their research also reported that even for those with good English, medical jargon was beyond their understanding. Wright (2009, p. 2) argues that "[w]e have plenty of evidence that household overcrowding is a risk factor for acute rheumatic fever (ARF) and New Zealand has done quite badly in that area". Statistics New Zealand (2010, p. 12) adds 
that "Pacific children and young people (aged 0 to 24) are nearly 50 times more likely than European children (and twice as likely as Māori) to be admitted to the hospital with acute rheumatic fever (ARF)".

After being granted permanent residency, Kiribati PAC migrants obtain free access to public and disability healthcare services. Arguably, these women had to forego the benefits of accessing free healthcare services in Kiribati in order to receive the benefits that come with permanent residency in New Zealand. In Kiribati, there is a saying, 'te kabwaia itinanikun te kanganga (prosperity is achieved after having gone through hardship and challenges)'. The people on Tabiteuea Island in South Kiribati, have a proverb that says, 'E aki kakatantan ba te riringa', which means that people strive to work, no matter how extremely hard it is. Such strong motives have been one of the determining factors for these women in pursuing their long-term goal of settling in New Zealand despite the hardship and challenges that they faced.

From the women's stories above, it is evident that the New Zealand PAC policy disarticulates from the humanitarian principles of health and wellbeing for migrants, resulting in expectations of self-responsibility that disadvantage Pacific migrants. On the other hand, the PAC policy may also contribute to long-term costs to the New Zealand government, especially in the health sector. By not providing free healthcare and social services to PAC migrants in the short term, illnesses that could have been prevented may occur in the future. The Ministry of Health's policy clearly protects the rights of patients and respects Pacific culture. One of the Ministry of Health's objectives is "your cultural and ethnic identity, language and personal beliefs are recognised and respected as are your ties with your family, whānau, hapū, iwi and extended family". In other words, the Ministry acknowledges that culture influences health and wellbeing. Whilst this policy should be beneficial to Kiribati PAC migrants, many of them would not know of it unless they have someone advising them of their rights as patients.

Children of two mothers were admitted to hospital after they had received their residency. These hospital admissions and related costs paid by the government could have been avoided if the conditions of the PAC policy were favourable. Such illnesses could have been prevented if the mothers had free access to healthcare services earlier in their settlement period when the child first showed signs of being ill. In addition, PAC migrant women may also require training before they come to New Zealand or 
when they arrived in New Zealand about their rights in relation to sick leave and family care when one of their children is unwell.

It is also crucial that a support system, gender integration in the PAC and work-permits that have access to health services should be a right for all migrants (not just PAC). Immigration New Zealand should work closely with the Ministry of Health to provide a culturally appropriate care service to PAC migrants. They should acknowledge the health and housing needs of the Kiribati PAC migrants, and their traditional cultures around healthcare. Similar to other Pacific cultures, the use of traditional healers in Kiribati remains a significant part of the lives of their people. New Zealand government's assistance to the RSE in securing jobs, housing and health insurance could be considered as a good model for successful PAC applicants.

The analyses in Chapters 3 to 6 have clearly shown that a hybrid of neoliberalism and te maneaba system is required to be integrated in a residency model that would contribute to improved health outcomes and wellbeing of the PAC migrants. This type of residency model will be discussed in the concluding chapter. While I support the aim of empowering Kiribati immigrants to be economically independent, the PAC policy needs to articulate the humanitarian principles of health and wellbeing. Arguably, neoliberalism should be integrated with the ideology and principles of te maneaba system that puts the health and wellbeing of individuals and families at the centre, as opposed to placing the market at the heart of the development of an economy. This would facilitate access and rights to healthcare, resulting in good health and wellbeing of migrants, and their having a sense of belonging in New Zealand as a new home. This would not only benefit Kiribati immigrants, but other Pacific island groups participating in the PAC. To align with te maneaba governmentality, where family responsibility is key in the lives of Kiribati people, family healthcare service would be culturally appropriate for new Kiribati PAC migrants. As McCalman et al. (2017, p. 2), elaborates on Australia, Canada and New Zealand's context "[p]rimary healthcare services have embraced the concept of family-centred models of care as one approach to improve health and preventative services for Indigenous children.....[F]amilycentred care approaches provide support and care for the whole family, their lives and wellbeing concerns, often at the family's home". This would improve health information to these migrants and avoid health complications and hospital admissions. As an additional measure, the number of hospital admissions "could be used as a 
management tool to monitor and identify possible problems in the coverage, access, and quality of primary healthcare", as Dourado et al. (2011, p. 583) have argued with regard to a Brazilian context. 


\section{Chapter 8 Conclusions, limitations and recommendations}

\subsection{INTRODUCTION}

In this thesis, I have argued, based on the stories of 30 Kiribati women, who have migrated to New Zealand under the PAC as principal applicants or dependents, that New Zealand's PAC has created unnecessary inequality, unfairness, hardship, and poverty. This has had a significant impact on most of these women and their children, and members of their utu and kainga in Kiribati and New Zealand, as evidenced in their stories. Using the lens of governmentality, critiques of neoliberalism, a gender perspective and my understanding of these women as both a New Zealander and IKiribati researcher, helped uncover the issues impacting on their health and wellbeing. This thesis makes the following new contributions to academic scholarship as well as to the development of better migration policies. In this concluding chapter I also discuss limitations of the study that provide potential areas for future research, and offer recommendations to Immigration New Zealand staff and other interest groups.

\subsection{DRAWBACKS OF THE POLITICAL AND ECONOMIC SYSTEMS}

This thesis has articulated drawbacks of the neoliberal governmentality and te maneaba governmentality, which largely contributed to the challenging experiences of the 30 Kiribati PAC migrant women. There is strong empirical data that the PAC policy is largely dominated by neoliberal governmentality in the sense that the central focus is around economic incentives with minimum state intervention in the health and wellbeing of PAC migrants. Whilst te maneaba governmentality has contributed to the successful migration of the Kiribati PAC migrant women by infilling gaps in service provision, this was largely so at the expense of extended family members or wider community networks. These drawbacks highlight areas for improvement to the PAC policy. 


\subsection{NEOLIBERAL GOVERNMENTALITY}

\subsubsection{Self-responsibility}

When analysed through the lens of governmentality, there is strong empirical data that the PAC policy has many features based on the principles of neoliberalism especially around minimum state intervention, and self-care and responsibility. Neoliberalism as a policy marks the major change from full state responsibility for the welfare of its citizens to self-responsibility (Golub, 2014; Kingfisher \& Goldsmith, 2001; Larner, 2000a, 2000b; Lemke, 2002; Murray \& Overton, 2011; Suaalii, 2006; Trnka \& Trundle, 2014). The spread of neoliberal state governance is associated with "radical reform, restructuring and diminishing the role of states in order to place the market at the centre of development strategies" (Murray \& Overton, 2011, p. 1). Lemke (2002) highlights three main areas of critique of neoliberalism as an ideology, economicpolitical reality and its impact on individuals - how an individual is being governed. The third criticism of neoliberalism is relevant to this thesis.

The third line of criticism is levelled against the destruction effects of neo-liberalism on individuals. We could cite the devaluation of traditional experiences neo-liberalism promotes, the process of individualisation endangering collective bonds, the imperatives of flexibility, mobility and risk taking that threaten family values and personal affiliations: neo-liberalism as ['practical anti-humanism'] (Lemke, 2002, p. 6).

There is strong empirical data that such principles of neoliberalism have influenced the focus of the PAC. It thus causes the PAC to create hardships for Kiribati PAC migrants. The hardships are in the form of unnecessarily poor child healthcare, poor access to health and other services, overcrowded housing, and financial stress. These have affected the health and wellbeing of most of the women engaged in my research. Women are the primary caretakers of children and the family, and therefore, women and children are most affected.

These women experienced this hardship before they were granted permanent residency and achieved a better life. An important question for the Kiribati government and New Zealand government is 'why should these women suffer before they achieve their residency?' The migration of these families has benefitted the economies of both countries. The Kiribati government has a policy goal of finding employment opportunities for its growing young population. Not only, that, but these families have contributed to its economy in sending remittances and other in-kind assistance to their 
families remaining behind. While this research did not touch on remittances, it is widely acknowledged that Kiribati people, like other Pacific people, put the needs of families first before the needs of individuals. This involves sending remittances to less affluent members of a family. With high population and limited land mass, thus causing high population density and pressure on the environment in Kiribati, migration of Kiribati people benefits siblings remaining behind by relieving population pressure. Investment by the Kiribati government in preparing PAC migrants well before they leave Kiribati would generate returns to the Kiribati economy.

On the other hand, these migrants have become an asset to the New Zealand economy. During my maroro with these women, all except three who had a small child to look after at the time, were working in different sectors of the economy including aged care, nursing, teaching, and farming. They had contributed significantly to New Zealand's workforce. Some of these women who claimed that they struggled with a language barrier to communicate with authorities (e.g. employer, officials from Immigration New Zealand), had completed their nursing degree and public policy degree, and had worked in different areas such as health professional positions. This proves that Immigration New Zealand had made the right selection. It also shows that the Kiribati education provided a good foundation. However, these women had a strong need for initial English language training and other support to get PAC migrants familiar with the English culture, and to settle quickly.

Gender analysis provides another lens through which to analyse how these women, particularly those with children, have been disadvantaged because the PAC policy is largely driven by neoliberal governmentality. The lack of free access to healthcare and child support had affected mainly women. Those who worked night shift also had the primary responsibility for the children. This affected the quality of healthcare for children. Others experienced difficulty in finding a job offer because they had a small child to look after. Being a Kiribati researcher, I have the advantage of communicating openly with these women in the language we all speak, to listen wholeheartedly, and build a strong partnership with them.

Being self-responsible for their own healthcare had affected the health and wellbeing of the 28 women, who arrived on a visitor visa. Based on empirical data, some women could not afford to see a doctor, and had lived with the pain. Some children ended up being admitted to hospital. This could have been avoided if they had free access to 
healthcare and or had someone with health literacy to support them when visiting a health professional. Some had used their traditional healing knowledge to treat their children, as an alternative cheap option. There was no evidence whether this resulted in quality healthcare for the children. Nickie believed that her traditional healing method did not seem to work for her children probably because of the difference in weather. However, Norma's husband has traditional healing skills, which worked for her children when they became sick. While traditional healing skills are important for preventive measures, women still require free access to healthcare in times of emergency. Being unable to afford the cost of healthcare, and having no free access to health services, most of them were in denial of their health needs including the need to consult a GP, midwife or other health professional, buy medicines from a pharmacy, and/or visit the emergency department when necessary. For example, Ann and Lily did not see a midwife until they were in their seventh or eighth month of pregnancy. Ann experienced a stillbirth, which could possibly have been prevented if there had been a good support system for the healthcare of PAC migrants. Nickie's child had a chronic health condition and was taken to Starship Children's Hospital. She had no choice but to pay a substantial amount of money. This created a financial burden on Nickie and the family as they were not eligible for family assistance. Tally experienced stress and body pain, but could not afford to buy any medicine from a pharmacy as she was still waiting for a work permit and not earning money at the time. Nancy avoided taking medicines or seeing a GP when she was unwell because she could not afford the cost. Sali struggled to meet the high cost of seeing a specialist, whilst trying to save money for her nine children waiting in Kiribati for the approval of their residency.

\subsubsection{Family separation}

Looking for a job offer was stressful, thus impacting on the health and wellbeing of PAC migrants, particularly those with large families. They left their children behind with the aim of bringing them to New Zealand later after they were settled. Most of them had taken more than a year before they received their residency. Others took almost a year before they were able to find a job offer and work. They then ran out of money, which they had saved for their residency application. The women who left their children behind felt lonely, homesick, and worried. Lily was very homesick and wanted to go back when she heard that her child remaining with her family in Kiribati was ill. She could not go because she had no money, and she was still waiting for her 
permanent residency to be issued. Julia was stressed when looking for a job offer, with no support from families and Immigration New Zealand. She sent her job applications to many prospective employers, and finally found one. Nancy was stressed by the fact that her children were left behind, and it had taken so long before she received her permanent residency. She repeatedly got rejected from Immigration New Zealand because her job offer did not meet the income threshold. Sally experienced high blood pressure, which she never had before coming to New Zealand. She assumed that this could have been escalated by stress due to many factors, including taking full responsibility of looking after the wellbeing of her children, and working at the same time. She greatly missed the extended family support system she had when she was in her homeland.

\subsubsection{Lack of health information}

During my maroro with other women, they had just become aware of the purpose and benefits of the New Zealand Accident Compensation Corporation. One of the ladies had an injury at work, but had tried to continue working as she needed money. Molly had been very careful to look after her children so they did not get sick as she was scared of the fact that she did not know of any health centres to go to. Sally identified an information gap for PAC migrants of not being aware of the importance of bringing their children's health information such as immunisation records. For example, if a child had been immunised for measles in Kiribati, a nurse in New Zealand still needs to see evidence that the child has been immunised. Such information is crucial for the health and wellbeing of PAC migrants, and they must be aware of such health information before coming to New Zealand. Whilst it is evident that many of these women were not aware of important health information, interestingly, the Ministry of Health as discussed in Section 6.6 (Ministry of Health, 2018b) explicitly states that it values peoples cultural diversity and protects the rights of patients.

\subsubsection{Lack cultural competency}

The mismatch of neoliberalism and te maneaba system affects the health and wellbeing of Kiribati PAC migrant women. The women's stories provide strong evidence that te maneaba system and the neoliberal model are talking past each other or have different communication practices and understandings. Thus, this creates stress and hardship for both successful PAC applicants and the New Zealand based Kiribati families supporting them. For example, the misunderstanding and communication 
between Ann and her midwife was a classic example of the mismatch in cultures that had a significant impact on health and wellbeing. Together with other factors such as the lack of free access to healthcare and other social support services, such misunderstanding resulted in a stillbirth which could have been avoided if there was appropriate support for PAC migrants, especially for pregnant mothers and mothers with young children. These examples illustrate that a culturally competent service is important to bridge communication between the two economic and political systems (Blauner, 1992; Brach \& Fraserirector, 2000; Metge \& Kinloch, 1984; Ortactepe, 2013; Tone, 2005).

With minimum state intervention and the expectation placed on successful PAC migrants to be self-responsible to meet the necessary requirements for residency and settlement in New Zealand, these women and children had experienced many social and economic issues which impacted negatively on their health and wellbeing. Not only that, but it created a burden on the host families in New Zealand as well as caretakers in Kiribati, the latter referring to families who look after children, when the parents leave to go to New Zealand to look for a job offer and process their permanent residency

\subsubsection{Inequality/poverty}

I have discussed at length in the previous chapters, the negative impact of the PAC policy on the wellbeing of migrant women and their families. The stress in finding work and the cultural barrier to liaise with authorities such as employers, health service providers, housing and other social services affects their health and wellbeing. The participants who were mostly disadvanged were those with limited social capital, and a lower socio-economic background. Most of them took a long time and went through a cycle of pain, stress and financial hardship before they were granted permanent residency. Others who had a higher socio-economic status or powerful siblings or extended family or friends in New Zealand, were better prepared to achieve permanent residency without going through many stressful challenges.

The women's stories provide strong evidence demonstrating the risks of neoliberalism on the health and healthcare of immigrants. Their experiences are consistent with arguments put forward by critiques of neoliberalism (e.g. Kingfisher, 1999; Larner, 2000a; Lemke, 2002; Murray \& Overton, 2011; Navarro, 2007). As Navarro (2007) argues, some initiatives led by international organisations such as the Poverty 
Reduction Strategy introduced by the World Bank resulted in the reduction of health service expenditure. Evidently, neoliberalism exacerbates poverty and health inequality. When political factors are given minor consideration within public health and epidemiological research, they have significant consequences for health policy and, ultimately, health outcomes. Labonté and Stuckler (2016) reported on the health impact of the rise of neoliberalism "across Europe, reveal[ing] a marked rise in food insecurity since 2010, when austerity began. The rise corresponds to 13.5 million additional Europeans who are unable to afford a healthy diet. Suicide rates since the crisis indeed have increased by 12 to $15 \%$ in the worst affected European countries. Healthcare budgets were cut by $20 \%$ or more in several countries" (Labonté \& Stuckler, 2016, p. 314). In the case of PAC migrants, neoliberal notions involving minimal state support and self-responsibility mean that individuals bear excessive burdens on social risks such as illness, unemployment, overcrowded housing, and poverty. These burdens are distributed also to families and communities forced to fill the PAC gap in service provision. There are also cost implications of the PAC gap for service provision, especially in the public health sector.

The PAC is an excellent initiative for eligible Pacific islanders as a way to seek a better life in New Zealand, provided they comply with the policy and criteria. Whilst the PAC gives individuals the freedom and choice to apply, PAC migrants are being governed in terms of having to comply with the policy requirements for residency. Thus, individual applicants take the responsibility and accountability if they are unsuccessful. This is what is understood as neoliberalism, where responsibility and risks are transferred to families and individuals. From the perspective of te maneaba governmentality, the PAC agent staff are not being supportive to migrants. Using various lenses of governmentality, critiques of neoliberalism, gender, and the voices of women participating in my research, the key driving problem is the mismatch of the Kiribati maneaba system and the neoliberal-influenced PAC policy.

\subsubsection{Lack of social housing services}

There are no housing facilities for successful PAC migrants. All of these 30 women had to live with members of their families in New Zealand until they found work and could afford to rent their own house. Some did not take long before they found a place. Others, like Sandra and her husband, took a long time because of the large size of their family, so it was difficult to find the right house with affordable rent. Other women, 
especially a single mother like Runga, could not afford to rent a house on her own. She had been living with families or friends who live close to her workplace. As noted from my communication with a Kiribati woman (not named), who has been hosting many successful PAC families for many years, housing is a critical health issue. She said that she has been receiving requests not only from members of her own kainga or friends, but others she has neither known nor met before. Culturally, she invited them to her home. Although it was not the original focus of my research to talk with host families, the Kiribati community is small and members are well connected. I have observed other families, who had kindly been providing shelter to other new successful PAC families. Housing is a critical health issue for Kiribati people living in New Zealand as acknowledged by other researchers (e.g. Gillard \& Dyson). The size of a Kiribati family is considered large by New Zealand standards as it consists of seven members on average. Overcrowded housing has an impact on the development and wellbeing of children (Dockery et al., 2010). As implied in Julia's shared experience, due to a lack of government support, other PAC migrants are forced to live in overcrowded housing where some garages have been turned into extra living space.

\subsubsection{Lack of a service broker}

All of these women met the minimum English requirement, but did not have sufficient English language or culture and the networks to be able to find work, visit a GP, look for a house, or do day-to-day activities when they first arrived. Most of them had to rely on their families and friends in New Zealand, thus transferring responsibilities to these families. This is the same for other Pacific migrants. They rely on their families and own communities because of insufficient government support (Gillard \& Dyson). As discussed in Section 4.2.6, in the Kiribati moral economy te kainga has the responsibility and cultural obligations to help other members in times of difficulty. In the New Zealand environment, where cost of living is relatively high, with minimum government support, the PAC policy has affected the health and wellbeing of Kiribati PAC migrants and families or friends who were assisting. Whilst most Kiribati people are concentrated in a low income bracket, culturally these families had to meet the needs of PAC migrants as well as their own needs. To make things worse, many of the new migrant women and their husbands did not find work straight away when they arrived in New Zealand. Riri did not get the right support at the right time from the family she stayed with, and ended up being without documentation. Through her 
perseverance and strong belief that she did not intend to break New Zealand law, she sought legal help and finally regained her PAC status and received her residency. During the seven years, she suffered mentally, physically, and emotionally. She also felt socially excluded with no sense of belonging. While the 'Ala Mo'ui strategy aims to facilitate increased access to existing systems and services through the development of 'navigators' (Ministry of Health, 2014a), this has not had an impact on the wellbeing of PAC migrants. This is an area most in need of improving for new PAC migrants.

\subsubsection{Lack of good environment and support system}

A combination of all factors including the mismatch of the Kiribati and New Zealand's culture, lack of health education and awareness, lack of a service broker, and overcrowding housing, has implications not only on the health and wellbeing of these women, but on the health system itself. Two children, Faustina's child and Josephine's child were admitted to hospital after they had gained residency. The cost of these cases and others which may have been experienced by other families who did not engage in my research, could have been avoided if these families were better supported by a good environment and support system.

\subsection{TE MANEABA SYSTEM AS GOVERNMENTALITY}

No matter where people go, their culture travels with them. The physical maneaba does not exist in New Zealand, but its principles create power and knowledge that continue to influence and govern the beliefs, mind, the behaviour, and the action of an I-Kiribati. The teachings of the Christian Church further embedded these cultural behaviours around respect, peace and unity within these different units. The teaching of these principles strengthens collectivism, connectedness and a sense of belonging which put forward the needs of vulnerable families before the needs of individuals. Such power and knowledge made up of these cultural values have influenced PAC migrants' health and wellbeing.

In New Zealand, the principles of te maneaba are strongly practised within each family unit, religious groups, and general communities that encompass all I-Kiribati regardless of their religion, age, and gender. The challenge for Kiribati people who were born in the islands is to preserve the language and culture based on te maneaba system that embraces everyone and puts in place the needs of families before individuals. Other Pacific cultures also influence the way their people think and act. 
For instance, Su'a (2017, p. 7) explained that "Fa'a Samoa is an expression of who Samoan people are and what they do to reflect their language, identity, beliefs, values, and traditions". Suaalii (2006, p. 232) added that "Fa'a Samoa invokes powerful techniques of both self- and collective-government through the institutions and/or principles of aiga, faamatai, alofa, faaloalo, tautua, va fealoaloa'i and so forth as 'technologies' of governing". These researchers' findings are consistent with the findings of this thesis, in that there is a need for acknowledging the power and knowledge of the Kiribati government, te maneaba, the family, and the church, which all influence the behaviour and actions of PAC migrants.

Kiribati migrant women claim that agents of the nation-state have not supported them while implementing the PAC. These are understandable when viewed through the various lenses of governmentality, critiques of neoliberalism, and gender, and expectations of the Kiribati maneaba system. The lack of integration of the eligible Pacific islands' culture in the implementation of the PAC thus results in the lack of appropriate support systems for successful applicants as discussed in the previous sections. The women's lack of understanding and awareness of neoliberal expectations of self-responsibility and self-healthcare that govern the PAC causes many challenges for migrants as they settle in New Zealand.

\subsubsection{Family care}

In te maneaba system, when someone is sick, it is the responsibility of the family as opposed to self-health care. It is widely observed and written in the literature that traditional healing is considered a significant part of the lives of people in many cultures (e.g. Fiedeldey-Van Dijk et al., 2017; Ghiasuddin et al., 2015; Hurdle, 2002; Serbulea \& Payyappallimana, 2012; Su'a, 2017). However, there is limited literature on traditional healing specific to Kiribati, which could have enriched the findings of my research in confirming the assumption of the importance of Kiribati traditional healing in the lives of I-Kiribati. It is observed that as part of their culture and heritage, many Kiribati people still maintain their traditional healing knowledge and skills in various areas including te kabung (birth delivery), karawataan te ran ni mama (helping breast feeding mothers with no breast milk), te riring $n$ te maoto (fixing bone fractures), tarou (muscle sprains), te kabuebue (high temperatures), and te bakabua (sore throats). In my conversation with some Kiribati people with first-hand experience in traditional Kiribati healing (T. Kabutaiti, personal communication, August 1, 2018; 
K. Kautu, personal communication, December 30, 2018; T. Tebouaki, personal communication, September 1, 2018), they confirmed that some Kiribati people were still using traditional healing methods to help meet their health needs.

\subsubsection{Respect - shyness and silence are not appropriate}

Te mama and te aki kakarongoa are Kiribati ways of demonstrating respect. Family reputation is significant, so a child is brought up to be respectful and become a good ambassador for his/her family. Munniksma, Flache, Verkuyten, and Veenstra (2012, p. 576) state that "family reputation vulnerability refers to the extent to which parents think that the behavior of their child affects the reputation of the family within their ethnicity". There is a traditional belief in Kiribati that when a child is brought up to be respectful and obedient, he/she would not be a trouble-maker when they become an adult. Coupled with Church teachings on peace and respect, children are taught to be respectful to their parents so they will receive many blessings in life. Such cultural understandings and knowledge about not only Kiribati but other eligible Pacific countries under the PAC should be integrated in the future improvement in the PAC policy and its service provision.

A lack of cultural understanding of the Kiribati culture of te mama (shyness) and te aki kakarongoa (silence) has become a critical risk to the successful implementation of PAC policy. If such aspects of the Kiribati cultures were understood by an implementing agency of PAC, appropriate workshops could have been initiated to address such cultural barriers. By allowing successful PAC applicants to fulfil requirements for their residency with minimum intervention and self-responsibility, Immigration New Zealand unintentionally created many problems affecting the health and wellbeing of these women.

\subsubsection{Burden on host families}

There is strong empirical evidence that the PAC places strain on host families. Julia, Josephine and Nickie for example, arguably stated the need for more state responsibility and support by both New Zealand and Kiribati to reduce stress and burden on host families. The Kiribati government could invest in preparing future migrants for migration, which has the risks of neoliberalism as discussed above, which leads to the emergence of the new responsibility for Kiribati families in New Zealand and could therefore bridge the so-called 'PAC gaps'. These include housing, 
healthcare, transport, relationship with employers, and other important areas of successful settlement. The Kiribati culture and values that shape the connectedness amongst te utu (the family unit) and te kainga (the extended family), have compelled Kiribati families in New Zealand to take responsibility for helping new Kiribati migrants to settle permanently in New Zealand. Similar experiences were shared by other researchers for other Pacific Islanders migrating to New Zealand under the PAC scheme (Gibson \& McKenzie, 2006; Simati, 2009). Having lived in New Zealand long enough, they have gained the knowledge of the New Zealand system, have strong networks with potential employers and other key contacts, and have had the experience of looking for work. They have acted as unimane (elders) within te maneaba', who act as proxy parents to support the wellbeing of new migrants, who are young in terms of knowledge, skills and experience in the New Zealand system and environment. Kiribati families in New Zealand act as a social welfare scheme in meeting, for instance, the housing needs of most PAC migrants. They do this whole-heartedly and of their own free will, with no expectation of being compensated for hosting new Kiribati migrant families because it is part of the Kiribati moral economy. Coming from Kiribati, considered to be a poor country but with a rich culture, many of these migrants could not afford to rent their own place when they first arrived in New Zealand. The women participating in the research had no other choice but to stay with families or friends until they secured a job and could afford their own accommodation. Some took more than a year before they could afford to rent their own place.

\subsubsection{Acknowledgement of other services}

It was reported in Section 1.4.7 that about 94 percent of Kiribati people living in New Zealand follow a religion. The majority are Catholics followed by the Kiribati United Church (KUC) and Kiribati Protestants Church (KPC) and other religions. The role of these Churches has complemented the role of te maneaba in circulating and maintaining the Kiribati cultural identity of love and respect, and they maintain the connectedness amongst members. The church services are conducted in the Kiribati language and thus have encouraged children and young people to learn and maintain their culture and identity. The religious activities within these main Church groups have provided informal support services that meet the spiritual needs of PAC migrants. For example, while Julia was capable of finding work because of her good educational background and work experience, she strongly believed that her spiritual faith helped 
her find a job offer. Molly also acknowledged the role of the church in helping them find a house when they first arrived in New Zealand. As an active member of the Kiribati community in New Zealand, I am aware that the availability of church services in the Kiribati language provide a good source of spiritual support for many successful PAC applicants. It provides a safe space or outlet where they share their emotions and issues, and seek support and advice from other Kiribati friends. Other researchers suggest the Church complements the role of families and friends in meeting the survival and social needs of their congregations (Gillard \& Dyson; Walls, 1992).

\subsection{ASPECTS OF TE MANEABA THAT RELATE TO WELLBEING (TRADITIONAL SETTING)}

This thesis has defined and used the cultural values rooted in te maneaba system in a new way to examine how the PAC policy has impacted on the health and wellbeing of Kiribati people as explained throughout this thesis. As examined under the govermentality framework, these values shape and define the way Kiribati people think, act, behave and view the world. The culture of respect that has a strong connection with hospitality and the bubuti system has compelled members of the families to help each other. Utu and kainga are a small version of te maneaba system that maintain and put such cultural values into practice. Arguably, te maneaba governmentality has defined family members to operate as an informal welfare agencies for "the long-term welfare and status of families" (Connell, 2014, p. 75). The richness of te maneaba system would not be realised had another policy not properly taken into consideration such values and adapted them appropriately into a new environment. This thesis also proposes a new maneaba system that would better position the traditional maneaba system in the New Zealand society and would avoid the many challenges the Kiribati PAC migrants and other migrants from other Pacific Island countries have faced.

\subsection{NEO-MANEABA HEALTH AND WELLBEING MODEL IN THE NEW ZEALAND SOCIETY}

It is not the intention of this thesis to overlook the traditional setting of te maneaba system, but to blend its principles into a policy that will benefit not only Kiribati PAC migrants but migrants from other Pacific Island countries. 
Figure 8.1: Neo-maneaba health and wellbeing model.

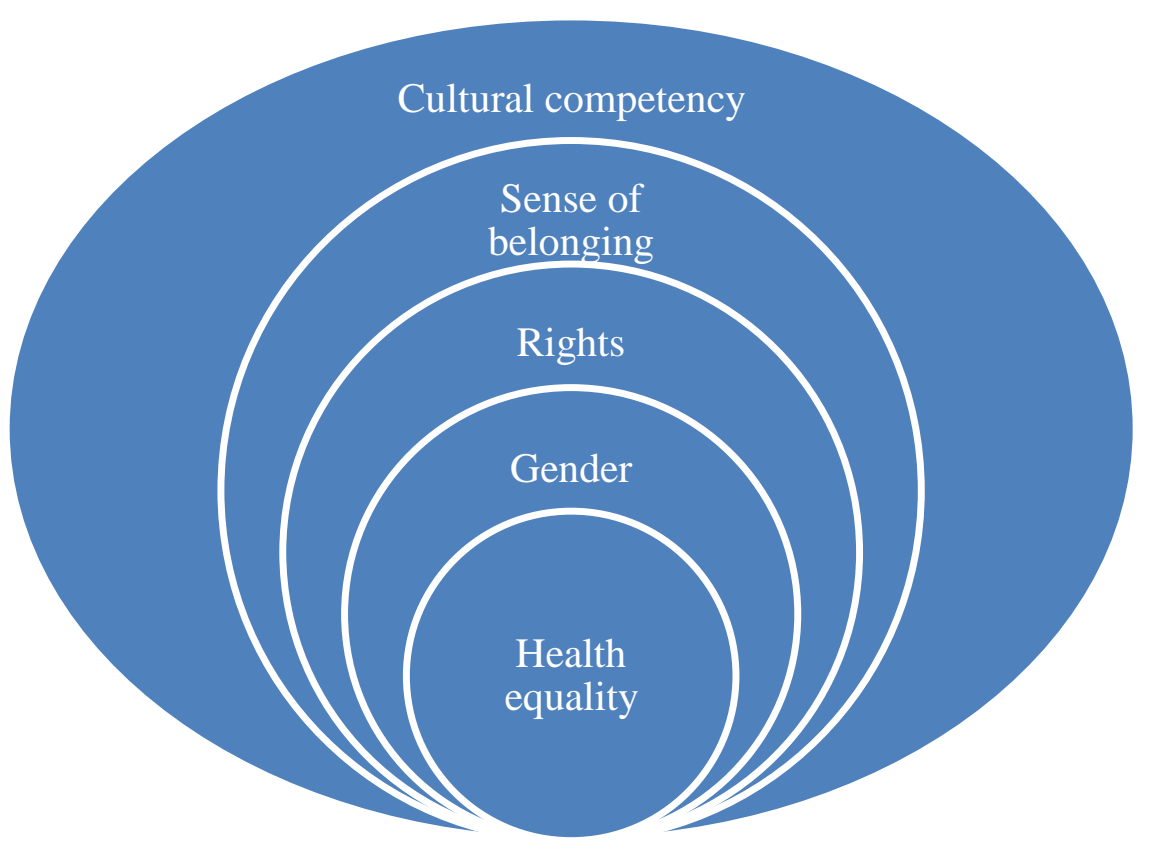

\subsubsection{Cultural competency}

It is important that future reviews of the PAC scheme use the Pacific ethnic group's cultural lens to better understand and service needs of future PAC migrants, and establish support services to close the PAC gaps in these areas. These include health information, job search, temporary accommodation, pre-departure training, settlement training, language support, and healthcare services.

\subsubsection{Sense of belonging}

Using the principle of te maneaba of embracing everyone, future improvement to the PAC policy would be achieved by addressing the PAC gaps so future migrants would have a sense of belonging.

\subsubsection{Rights}

By attending culturally appropriate training, migrants would build awareness about important aspects of day-to-day living in New Zealand, including where and how to access healthcare, housing, and language support, and find work. This would enable migrants to get settled and become toronibwai. They would be able to support not only their immediate families but other members of their kainga remaining behind, and thus strengthen their connections with their land and people. 


\subsubsection{Gender}

Whilst women understand their position and space in te maneaba and home environment under te maneaba governmentality, they also need training about their changed role in New Zealand. This is more relevant for women from lower economic social status, as most of them would be working for the first time. They would need to understand their rights as in New Zealand they would be mothers in a new working environment. They would need to know what strategies they need in order to cope with managing their children and working at the same time. Future improvements to the PAC policy would consider support services available for women with children or pregnant women that align with te maneaba governmentailiy based on family and group responsibility.

\subsubsection{Health equality}

Future policy changes should enable future PAC migrants to access not only healthcare but other services including housing, employment, language support as included in Section 8.7.1 to improve health outcomes.

\subsection{LIMITATION OF THE RESEARCH}

\subsubsection{Views of stakeholders}

This research did not take into account the views of Kiribati and New Zealand officials managing international and regional labour mobility to understand how the PAC policy setting was designed in the first place, or what were the original political interests and intended benefits of the scheme, and who were the key stakeholders consulted at that time.

The design of this research did not involve formally conducting te maroro more widely with the Kiribati families in New Zealand to seek their experiences when assisting successful PAC applicants. However, in the course of the research it became apparent that it is important to consider their views on how the policy could better serve the interests of new PAC migrants and the New Zealand government, without transferring unnecessary responsibility to te utu and te kainga already resident in New Zealand. Realising the need to hear the views of host families, I have included the views of three other hosts as well as my own observations. While the views of three host families and my observations indicate many problems relating to the health and wellbeing of the host families, future research is required to look into this in more detail. 
The research did not take into account the views of the caretakers in Kiribati. Their views would be useful to understand the impact of PAC on the families in Kiribati. Caring for children is an important role of an extended family in a cultural setting particularly for parents who work and remain in Kiribati. The PAC has separated mothers from their children ranging from short-term to long-term periods, depending on how quickly they achieved their permanent residency. Future research would be useful to find out how the separation of children from their parents impacts on the health of all involved - the children, parents and caretakers.

The research did not look at other policies similar to PAC being implemented in other countries. Future research could look at comparing lessons learnt from other models to address some of the PAC gaps.

\subsection{RECOMMENDATIONS}

These stories articulate a consistent requirement for a hybrid neoliberalism-maneaba system, to create a residency model that works for successful PAC applicants, the government of New Zealand and Kiribati, and Kiribati families living in both countries. This would also benefit other eligible countries (Fiji, Tonga, and Tuvalu) participating under the PAC scheme. This would avoid repeating the stress and pain most of these PAC migrant women had experienced because of lack of government support as perceived from the lens of te maneaba system. The model must include the following:

- Having PAC agent(s), in the sending country and in New Zealand, to help successful PAC applicants find work and housing immediately and avoid overcrowded housing and related health impacts. The priority needed most is having a job which would help them find a house and meet the health and economic needs of family. While the Kiribati host families provide support as part of the moral economy, at the same time, this would reduce a social and economic burden on the host families. The experiences of composite Woman 3 and Woman 4 provide a good benchmark for everyone. They started working and could afford to rent their own place within three months of arriving in New Zealand.

- Considering the health risks of being on a visitor visa or a short-term work visa, it is recommended that Immigration New Zealand should review its 
PAC policy and include a two-year open work visa. This should enable successful PAC migrants to be eligible for publicly-funded disability and health services including maternal health services for expectant mothers.

- With the experience of composite Woman 7 and Woman 11, the views of the three host families and my observations, waiting off-shore for the approval of a residency is a better option for the health and wellbeing of PAC migrants. They do not have to experience what many PAC migrants had gone through related to overcrowding, limited healthcare for children and unemployment. An agent in New Zealand could look for a suitable job offer, which they can use to support their application for residency from offshore. An agent in the sending country is required to assist them in processing their application forms. After the approval of their residency, the families would be able to travel on a one-way ticket, rather than a return ticket for each member of the family. This would benefit most Kiribati people who are on a low income. In addition, Teiti's shared experience is a good model to use.

- A responsible person in New Zealand is still required to assist families after arrival in looking for a house, getting them registered with a service provider, English courses to help them carry out their day-to-day activities, how to get a New Zealand driver's licence, how to go to the bank, and complete IRD forms. A partnership between Immigration New Zealand and other government agencies such as the Ministry of Social Development and the Ministry of Health is strongly recommended to look into this area for improvement. Based on what I have learned from others and even one of my participants, Faustina, some successful PAC applicants did not get a job offer because they did not know anyone in New Zealand who could help them. Consequently, they remained in Kiribati and did not take the PAC offer to apply for New Zealand's residency. Other Kiribati people in New Zealand, who had been asked by other successful PAC applicants in Kiribati were not able to help because they could not find a job offer either. These examples show that the state must take more responsibility to support future successful PAC applicants. 
- The Kiribati government is required to integrate pre-departure training, targeting RSE workers and PAC migrants to prepare them before they come to New Zealand. Some women shared in te maroro that before they left and were told what they were supposed to do when they come to New Zealand, did not make sense until they arrived and started living in New Zealand. In view of this, it is recommended that upon arrival, another workshop is organised for PAC migrants to cover important issues to help them set their goals and get settled quickly. This would enhance their health and wellbeing for both themselves, their families and the host families. Understanding how the Kiribati culture of te mama and te aki kakarongoa could impede their aspirations should be an important part of these workshops in Kiribati and New Zealand.

- It is therefore critical that Immigration New Zealand staff or people assisting successful PAC migrants must understand both the New Zealand neoliberal notion of self-care and responsibility, and the Kiribati maneaba system of collectivism and family centricity. In this way, they would be able to provide useful advice to PAC migrants and help them liaise with health, and social service providers and potential employers in New Zealand.

- The assisting person must have the ability to connect new immigrants to existing English courses or facilitate culturally appropriate training that would help migrants to quickly overcome cultural behaviours, e.g. te mama (shyness), and te aki kakarongoa (silence), in order to adjust to their new environment and settle well in New Zealand.

- Whilst successful PAC applicants meet the English requirements, they still require the PAC forms to be translated into the Kiribati language. Migrating to a new country is a big change in the lives of many Kiribati people, which makes them nervous and not confident. If the forms are written in the Kiribati language, this will reduce the need to ask others to help them when completing forms for residency. It also helps in-country workshops make sense to them.

- English culture (see Sections 6.5. p161) needs to be a critical component of the education system in Kiribati to empower I-Kiribati migrants to be more 
competitive in the world market for jobs and entrepreneurship, not only in New Zealand but across the globe.

- Some successful applicants cannot afford the cost of the airfare and do not know anyone in New Zealand who could help with accommodation and finding a job offer. This is an area where both the New Zealand and Kiribati governments must consider finding ways to support these disadvantaged groups. This is an affordability issue.

- Given the lack of access to free healthcare for PAC migrants when on a visitor visa and short-term work visa, it is expected that women prefer traditional healing remedies to meet their health needs as it costs less. This is a possible area to be explored in future research to inform quality healthcare services and health policies for Pacific people, as part of this population are Kiribati people living in New Zealand.

- To extend the findings of this research, a further area for future study could seek the views of the agents managing the PAC regarding how the successful PAC applicants and their family could access healthcare services in the future, prior to being granted New Zealand residency. This is similar to the point above and both bullet points might need to be integrated.

- Future research would assess the impact of PAC migration on the lives of people living and supporting PAC migrants in New Zealand.

All the above recommendations, based on the needs discussed by the research participants, would ensure that the neo-maneaba health and wellbeing model addresses gender inequality, poverty, hardship, and makes settlement in New Zealand easier for PAC migrants. Ultimately, this would contribute to improved health outcomes and the healthcare and wellbeing of future PAC migrants. 



\section{Bibliography}

Aizawa, Y., \& Whatley, M. A. (2006). Gender, Shyness, and IndividualismCollectivisim: A Cross Cultural Study. Race, Gender and Class, 13(1/2), 7-25. Retrieved from https://www.jstor.org/stable/41675217

Akau, I. (1946). Kirilyrics (E a katau te nako Orona). Retrieved from https://www.kirilyrics.com/lyrics/author/Iuta-Akau-(Kaain-Beru\%2C-1946)

Allen, A. J., Davey, M. P., \& Davey, A. (2010). Being examples to the flock: The role of church leaders and African American families seeking mental health care services. Contemporary Family Therapy, 32(2), 117-134. doi: 10.1007/s10591-009-9108-4

Alzayed, N. N. Y. (2015). Preserving immigrants native language and cultural identity in multilingual and multicultural societies. International Journal of Humanities and Social Science, 5(2), 263-267.

Anae, M. (2010). Research for better Pacific schooling in New Zealand: Teu le va - a Samoan perspective. MAI Review (1).

Anderson, K., \& Jack, D. (1991). Learning to listen: Interview techniques and analysis. In S. B. Gluck \& D. Patai (Eds.), Women's Words: The feminist practice of oral history (pp. 11-26). New York: Routledge.

Anya, I. (2007). Vulnerable migrants have a right to health. The Lancet, 370(9590), P2. doi: 10.1016/S0140-6736(07)61020-4

Apelu, J. (2008). Pacific Community Mental Health Nurses' Experiences of Working for a District Health Board in New Zealand (Master's thesis, Victoria University of Wellington). Retrieved from http://hdl.handle.net/10063/684

Asian Development Bank. (2018). Kiribati, Key Indicators 2018 [Excel file]. Retrieved from https://data.adb.org/dataset/kiribati-key-indicators

Askola, H. (2010). Illegal Migrants: Gender and Vulnerability: The Case of the EU's Return Directive. Feminist Legal Studies, 18(2), 159-178. doi: 10.1007/s10691-010-9153-2

Atkinson, R., \& Flint, J. (2001). Accessing Hidden and Hard-to-Reach Populations: Snowball Research Strategies. Social Research Update, 33, 1. Retrieved from http://sru.soc.surrey.ac.uk/SRU33.html

Attride-Stirling, J. (2001). Thematic networks: an analytic tool for qualitative research. Qualitative research, 1(3), 385-405. doi: 10.1177/146879410100100307

Auckland Regional Public Health Service. (2019). Refugee Health. Retrieved from http://www.arphs.health.nz/health-professionals/refugee-health/

Autio, P. (2010). Hard custom, hard dance: Social organisation (un) differentiation and notions of power in a Tabiteuean community, Southern Kiribati (PhD thesis, University of Helsinki). Retrieved from http://urn.fi/URN:ISBN:978952-10-6151-6

Awumbila, M. (2015). Women moving within borders: Gender and internal migration dynamics in Ghana. Ghana Journal of Geography, 7(2), 132-145.

Bailey, J. (2008). First steps in qualitative data analysis: transcribting. Family Practice, 25(2), 127-131. doi: 10.1093/fampra/cmn003

Baker, M., McDonald, A., Zhang, J., \& Howden-Chapman, P. (2013). Infectious diseases attributable to household crowding in New Zealand: A systematic review and burden of disease estimate (HP number 5662). Retrieved from University of Otago, He Kainga Oranga/Housing and Health Research 
Programme website: $\quad$ http://www.healthyhousing.org.nz/wpcontent/uploads/2010/01/HH-Crowding-ID-Burden-25-May-2013.pdf

Balcazar, F. E., Suarez-Balcazar, Y., \& Taylor-Ritzler, T. (2009). Cultural competence: Development of a conceptual framework. Disability and rehabilitation, 31(14), 1153-1160. doi: 10.1080/09638280902773752

Barr, N. (2012). Economics of the welfare state (5 ed.). Oxford, UK: Oxford University Press.

Bassett, D., Tsosie, U., \& Nannauck, S. (2012). "Our culture is medicine": perspectives of native healers on posttrauma recovery among American Indian and Alaska Native patients. The Permanente Journal, 16(1), 19-27. Retrieved from https://www.ncbi.nlm.nih.gov/pmc/articles/PMC3327107/

Bauer, T. K., Lofstrom, M., \& Zimmermann, K. F. (2001). Immigration Policy, Assimilation of Immigrants, and Natives' Sentiments towards Immigrants: Evidence from 12 OECD Countries (Working Paper No. 33). Retrieved from Center for Comparative Immigration Studies website: https://escholarship.org/content/qt1m58x0z3/qt1m58x0z3.pdf

Bedford, R. (1994). Pacific Islanders in New Zealand. Espace Populations Sociétés, 12(2), 187-200. Retrieved from https://www.persee.fr/doc/espos_07557809_1994_num_12_2_1639?pageid=t1_200

Bedford, R. (2015). Tangata o te Moana. New Zealand and the people of the Pacific. New Zealand Sociology, 30(1), 215-231. Retrieved from https://search.informit.com.au/documentSummary; $\mathrm{dn}=359490044900184 ;$ res $=$ IELNZC

Bedford, R., \& Bedford, C. (2010). International migration and climate change: A post-Copenhagen perspective on options for Kiribati and Tuvalu. In B. Burson (Ed.), Climate change and migration: South Pacific perspectives (pp. 89 -134). doi: 10.13140/RG.2.1.2910.2166

Bedford, R., \& Hugo, G. (2008). International Migration in a Sea of Islands: Challenges and Opportunities for Insular Pacific Spaces. Paper presented at the Connecting Worlds: Emigration, Immigration and Development in Insular Spaces, Azores, Portugal. Retrieved from https://researchcommons.waikato.ac.nz/bitstream/handle/10289/966/PSC-dp69.pdf? sequence $=1 \&$ is Allowed $=\mathrm{y}$

Bedford, R., \& Macdonald, B. (1982). The population of Kiribati: A review of some myths about migration and depopulation.

Bedford, R., Macdonald, B., \& Munro, D. (1980). Population estimates for Kiribati and Tuvalu, 1850-1900: Review and speculation. The Journal of the Polynesian Society, 89(2), 199-246.

Belich, J. (2001). Paradise Reforged: A History of the New Zealanders from the 1880s to the Year 2000. Auckland, New Zealand: Allan Lane; Penguin.

Bell, B., \& McDonald, G. (2013). Cost Benefit Analysis and Economic Impact Analysis of the Kiribati Marine Training Centre. Retrieved from Ministry of Foreign Affairs and Trade website: https://www.mfat.govt.nz/assets/Aid-Progdocs/Evaluations/2013/May-2013/Kiribati_MTC_costbenefit_study_May_2013.pdf

Bennett, A. (2017). Tourism bisnis and "making ples" An ethnography of ni-Vanuatu bungalow and tour owners on Malekula (Masters thesis, Victoria University of Wellington). Retrieved from http://hdl.handle.net/10063/6739

Bertram, G. (2012). Trade and Exchange: Economic Links between the Pacific and New Zealand in the Twentieth Century. In S. Mallon, K. U. Māhina-Tuai \& D. 
I. Salesa (Eds.), Tangata o te Moana. New Zealand the People of the Pacific (pp. 201-220). Wellington: Te Papa Press.

Bevir, M. (2010). Rethinking governmentality: Towards genealogies of governance. European Journal of Social Theory, 13(4), 423-441. doi: $10.1177 / 1368431010382758$

Blauner, B. (1992). Talking past each other: Black and white languages of race. The American Prospect, (Summer), 55-64. Retrieved from http://jonsenglishsite.info/Class\%20Docs\%205/2_Talking\%20Past\%20Each \%200ther.pdf

Bönisch-Brednich, B. (2016). What to do with Stories? Fabula, 57(3-4), 11-25. doi: 10.1515/fabula-2016-0035

Borovnik, M. (2009). Remittances: an informal but indispensable form of income for seafarer families in Kiribati (Working Paper No 8/2005). Retrieved from Massey University, Centre for Indigenous Governance and Development website: http://hdl.handle.net/10179/933

Brach, C., \& Fraserirector, I. (2000). Can Cultural Competency Reduce Racial and Ethnic Health Disparities? A Review and Concept Model. Medical Care Research and Review, 57(1_suppl), 181-217. doi: 10.1177/1077558700057001S09

Brewis, A. (1996). Lives on the line: women and ecology on a Pacific atoll. Fort Worth, TX: Harcourt Brace College Publishers.

Bulley, B. S. (2014). Governmentality: notes on the Thought of Michel Foucault. Critical Legal Thinking Law and the Political. Retrieved from http://criticallegalthinking.com/2014/12/02/governmentality-notes-thoughtmichel-foucault/

Burchell, G., Gordon, C., \& Miller, P. (1991). The Foucault Effect: Studies in Governmentality.

Bush, A., Collings, S., Tamasese, K., \& Waldegrave, C. (2005). Samoan and psychiatrists' perspectives on the self: Qualitative comparison. Australian \& New Zealand Journal of Psychiatry, 39(7), 621-626. doi: 10.1080/j.14401614.2005.01635

Cambridge Business English Dictionary. (2019). Definition of 'welfare state'. Retrieved from https://dictionary.cambridge.org/dictionary/english/welfare$\underline{\text { state }}$

Cameron, D. (1998). The feminist critique of language: A reader: London.

Campbell, C. E. (2003). Sociology of Shyness: A Self Introduction. Human Architecture: Journal of the Sociology of Self-Knowledge, 2(1), 58-64. Retrieved from https://scholarworks.umb.edu/cgi/viewcontent.cgi?referer=https://scholar.goo gle.com/\&httpsredir=1\&article $=1037 \&$ context=humanarchitecture

Carballo, M., \& Mboup, M. (2005). International migration and health. Retrieved from Global Commission on International Migration website: http://www.iom.int/jahia/webdav/site/myjahiasite/shared/shared/mainsite/poli cy_and_research/gcim/tp/TP13.pdf

Cervatiuc, A. (2009). Identity, Good Language Learning, and Adult Immigrants in Canada. Journal of Language, Identity and Education, 8(4), 254-271. doi: 10.1080/15348450903130439

Churchward, M. E. (2011). Sophisticated Mediators: New Zealand-born Samoan firsttime mothers and strategies for their health and wellbeing (Master's thesis, 
Victoria University of Wellington). Retrieved from http://hdl.handle.net/10063/1551

Clifford, J. (2003). On the edges of anthropology: Interviews. Chicago: Prickly Paradigm Press.

Cohen, J. J., Gabriel, B. A., \& Terrell, C. (2002). The case for diversity in the health care workforce. Health Affairs, 21(5), 90-102. doi: 10.1377/hlthaff.21.5.90

Cole, R. V., \& Parry, T. G. (1986). Selected Issues in Pacific Island Development: Papers from the Islands/Australia Project. Canberra, ACT: National Centre for Development Studies, Australian National University.

Condron, M. L. (2007). When You Come to a Fork in the Road, Pick It Up: A Case Study in Managing by Self-Responsibility. Cataloging \& Classification Quarterly, 44(3-4), 363-375. doi: 10.1300/J104v44n03_13

Connell, J. (2010). Pacific islands in the global economy: Paradoxes of migration and culture. Singapore Journal of Tropical Geography, 31(1), 115-129. doi: $10.1111 / \mathrm{j} .1467-9493.2010 .00387 . \mathrm{x}$

Connell, J. (2014). The two cultures of health worker migration: A Pacific perpective. Social Science \& Medicine 116, 73-81. doi: 10.1016/j.socscimed.2014.06.043

Cowley, E. T., Paterson, J., \& Williams, M. (2004). Traditional gift giving among Pacific families in New Zealand. Journal of family and economic issues, 25(3), 431-444. doi: 10.1023/B:JEEI.0000039949.35285.20

Cressey, J. (1998). Making a Splash in the Paci c: Dolphin and Whale Myths and Legends of Oceania. Rapa Nui Journal: Journal of the Easter Island Foundation, 12(3), 75-84. Retrieved from https://kahualike.manoa.hawaii.edu/rnj/vol12/iss3/4

Denzin, N. K., \& Lincoln, Y. S. (2005). Introduction: The Discipline and Practice of Qualitative Research. In N. K. Denzin \& Y. S. Lincoln (Eds.), The Sage handbook of qualitative research (pp. 1-32). Thousand Oaks, CA: Sage Publications Ltd.

Dockery, A., Kendall, G., Li, J., Mahendran, A., Ong, R., \& Strazdins, L. (2010). Housing and children's development and wellbeing: A scoping study (Final Report No. 149). Retrieved from Australian Housing and Urban Research Institute website: https://www.ahuri.edu.au/_data/assets/pdf_file/0023/1994/AHURI_Final_R eport_No149_Housing-and-childrens-development-and-wellbeing-a-scopingstudy.pdf

Dourado, I., Oliveira, V. B., Aquino, R., Bonolo, P., Lima-Costa, M. F., Medina, M. G., . . Macinko, J. (2011). Trends in primary health care-sensitive conditions in Brazil: the role of the Family Health Program (Project ICSAP-Brazil). Medical care, 577-584. doi: 10.1097/MLR.0b013e31820fc39f

Edelman, M. (2005). Bringing the moral economy back in.... to the study of 21st century transnational peasant movements. American Anthropologist, 107(3), 331-345. Retrieved from https://www.jstor.org/stable/3567019

Fairbairn-Dunlop, P. (2005). Gender, culture and sustainable development - the Pacific way. In A. Hooper (Ed.), Culture and sustainable development in the Pacific (pp. 62-76). Canberra, ACT: ANU E Press.

Farrelly, T., \& Nabobo-Baba, U. (2014). Talanoa as empathic apprenticeship. Asia Pacific Viewpoint, 55(3), 319-330. doi: 10.1111/apv.12060

Fiedeldey-Van Dijk, C., Rowan, M., Dell, C., Mushquash, C., Hopkins, C., Fornssler, B., . . . Shea, B. (2017). Honoring Indigenous culture-as-intervention: Development and validity of the Native Wellness Assessment. Journal of 
ethnicity in substance abuse, 16(2), 181-218. doi: 10.1080/15332640.2015.1119774

Foucault, M. (1991). Governmentality. In G. Burchell, C. Gordon \& P. Miller (Eds.), The Foucault effect: studies in governmentality: with two lectures by and an interview with Michel Foucault (pp. 87-104). Chicago: University of Chicago Press.

Fozdar, F., \& Torezani, S. (2008). Discrimination and Well-being: Perception of Refugees in Western Australia. International Migration Review, 1(Spring), 3063. doi: 10.1111/j.1747-7379.2007.00113.x

Galloway, R., \& New Zealand Foundation for Character Education. (2008). Making Sense of Managing Self Teaching Responsilibility to Improve Student Learning and Behaviour in New Zealand Schools. Alexandra, NZ: New Zealand Foundation for Character Education Inc.

Geiringer, C., \& Palmer, M. (2007). Human rights and social policy in New Zealand. Social Policy Journal of New Zealand, 12(30), 12-41. Retrieved from https://papers.ssrn.com/sol3/papers.cfm?abstract_id=983041

Ghebreyesus, T. A. (2017). Health is a fundamental human rights [Press release]. Retrieved

from

https://www.who.int/mediacentre/news/statements/fundamental-humanright/en/

Ghiasuddin, A., Wong, J., \& Siu, A. M. (2015). Ethnicity, traditional healing practices, and attitudes towards complementary medicine of a pediatric oncology population receiving healing touch in Hawaii. Asia-Pacific journal of oncology nursing, 2(4), 227-231. doi: 10.4103/2347-5625.158015

Gibson, J., \& McKenzie, D. (2006). How does an ex-ante job offer requirement on labor mobility work? The New Zealand-Tongan experience. BREAD Policy Paper No, 13, 1-27.

Gibson, J., McKenzie, D., \& Stillman, S. (2009). The impacts of international migration on remaining household members: omnibus results from a migration lottery program. Review of Economics and Statistics, 93(4), 1-42. doi: $10.2307 / 41349113$

Gillard, M., \& Dyson, L. Kiribati migration to New Zealand: experience, needs and aspirations. Retrieved from Presbyterian Church of Aotearoa New Zealand website:

http://presbyterian.org.nz/sites/default/files/gmo/kiribati/Kiribati_migration_t o_New_Zealand.pdf

Glasford, A., \& Huang, P. (2008). Immigrant Women's Health a Casualty in the Immigration Policy War. The Women's Health Activist, 33 (2), 1-7.

Golub, A. (2014). Competing responsibilities: An Interview with Susanna Trnka and Catherine Trundle. Retrieved from http://savageminds.org/2014/08/07/competing-responsibilities-an-interviewwith-susanna-trnka-and-catherine-trundle/

Gordon, C. (1991). Governmental Rationality: An Introduction. In G. Burchell, C. Gordon \& P. Miller (Eds.), The Foucault effect: studies in governmentality: with two lectures by and an interview with Michel Foucault. Chicago: University of Chicago Press.

Government of Kiribati. (2006). Digest of education statistics 2006. Retrieved from https://drive.google.com/file/d/0B23LvIfM4VgkcV82UnZhYTZTY1E/view 
Government of Kiribati. (2016a). Digest of education statistics 2016. Retrieved from https://drive.google.com/file/d/1jKvjIQ2R0EgEFbQ8Q4eCJzZMqGWNMH Ab/view

Government of Kiribati. (2016b). Kiribati Development Plan 2016-2019. Retrieved from

http://www.mfed.gov.ki/sites/default/files/Kiribati\%20Development\%20Plan \%202016\%20-\%2019.pdf

Governnment of Kiribati. (2005). Kiribati Islands. A situation analysis of children, women and youth. from https://www.unicef.org/pacificislands/Kiribati_Sitan.pdf

Griffen, V. (1989). Women, Development and Empowerment: A Pacific Feminist Perspectiv Retrieved from http://nzetc.victoria.ac.nz/tm/scholarly/teiGriWom2-c5.html

Haggerty, J., Campbell, H., \& Morris, C. (2009). Keeping the stress off the sheep? Agricultural intensification, neoliberalism, and 'good'farming in New Zealand. Geoforum, 40(5), 767-777. doi: 10.1016/j.geoforum.2008.12.003

Halapua, S. (2008). Talanoa process: The case of Fiji. Retrieved from United Nations Public Administration Network website: http://unpan1.un.org/intradoc/groups/public/documents/un/unpan022610.pdf

Halcomb, E. J., \& Davidson, P. M. (2006). Is verbatim transcription of interview data alsways necessary? Applied Nursing Resesarch, 19(1), 36-42. doi: 10.1016/j.apnr.2005.06.001

Hall, L. K. (2009). Navigating Our Own" Sea of Islands": Remapping a Theoretical Space for Hawaiian Women and Indigenous Feminism. Wicazo Sa Review, 24(2), 15-38.

Hammersley, M. (2013). What is qualitative research? London, UK: Bloomsbury.

Hang, D. L. (2011). O uiga 'ese'ese ma o'oōga o le lè-tautala the multiple meanings of silence in the Samoan classroom: implications for teachers of Samoan students. Paper presented at the Samoan Conference II, National University of Samoa, Apia, Samoar from http://samoanstudies.ws/storage/2014/02/LEE-HANG-multiple-meanings-ofsilence.pdf

Hewagodage, V., \& O’Neill, S. (2010). A case study of isolated NESB adult migrant women's experience learning English: A sociocultural approach to decoding household texts. International Journal of Pedagogies and Learning, 6(1), 2340. doi: 10.5172/ijpl.6.1.23

Holmes, F. (2004). The Quest for Security and Welfare in New Zealand 1938-1956. Wellington, NZ: Institute of Policy Studies, Victoria University of Wellington.

Hurdle, D. E. (2002). Native Hawaiian traditional healing: Culturally based interventions for social work practice. Social Work, 47(2), 183-192. doi: $10.1093 / \mathrm{sw} / 47.2 .183$

Immigration New Zealand. (2018a). English Language Information (INZ 1060). Retrieved from https://www.immigration.govt.nz/documents/forms-andguides/inz1060.pdf

Immigration New Zealand. (2018b). Immigration New Zealand Operational Manual. Retrieved from https://www.immigration.govt.nz/opsmanual/\#46618.htm

Immigration New Zealand. (2019a). Recognised Seasonal Employer (RSE) scheme. Retrieved from https://www.immigration.govt.nz/about-us/research-andstatistics/research-reports/recognised-seasonal-employer-rse-scheme 
Immigration New Zealand. (2019b). Refugee and protection. Retrieved from https://www.immigration.govt.nz/about-us/what-we-do/our-strategies-andprojects/supporting-refugees-and-asylum-seekers/refugee-and-protection-unit

International Monetary Fund. (2019). Kiribati : 2018 Article IV Consultation -Press Release; Staff Report; and Statement by the Executive Director for Kiribati. Retrieved from International Monetary Fund website: https://www.imf.org/en/Publications/CR/Issues/2019/01/24/Kiribati-2018Article-IV-Consultation-Press-Release-Staff-Report-and-Statement-by-the$\underline{46546}$

Johnson, M., \& Maguire, J. (2016). Recognised Seasonal Employers Survey 2016. Retrieved from Immigration New Zealand website: https://www.immigration.govt.nz/documents/statistics/rse-monitoring-survey2016-report.pdf

Johnstone, I., \& Powles, M. (2012). New flags flying: Pacific leadership: Huia Publishers.

Kazama, K. (2015). Tabiteuea Kiribati (pp. 607-609): JSTOR.

Kelsey, J. (1993). Rolling back the state: privatisation of power in Aotearoa/New Zealand. Wellington, NZ: Bridget Williams Books.

Kingfisher, C. P. (1999). Rhetoric of (Female) Savagery: Welfare Reform in the United States and Aotearoa/New Zealand. NWSA Journal, 11(1), 1-20. Retrieved from https://www.jstor.org/stable/4316626

Kingfisher, C. P., \& Goldsmith, M. (2001). Reforming women in the United States and Aotearoa/New Zealand: A comparative ethnography of welfare reform in global context. American Anthropologist, 103(3), 714-732. doi: 10.1525/aa.2001.103.3.714

Kopper, H., Teixeira, A. R., \& Dorneles, S. (2009). Cognitive performance of a group of elders: influence of hearing, age, sex, and education. International Archives of Otorhinolaryngology, 13(1), 39-43.

Koser, K. (2012). Environmental change and migration: Implications for Australia. Retrieved from Lowy Institute website: https://www.lowyinstitute.org/sites/default/files/koser_environmental_change and_migration_web_0.pdf

Krishnan, V., Meleisea, P. S., \& Warren, J. (1994). The challenge of change: Pacific Island communities in New Zealand, 1986-1993. Wellington, NZ: NZ Institute for Social Research \& Development.

Kvamme, E., \& Ytrehus, S. (2015). Barriers to health care access among undocumented migrant women in Norway. Society, Health and Vunerability, 6(1), 28668. doi: 10.3402/shv.v6.28668

Labonté, R., \& Stuckler, D. (2016). The rise of neoliberalism: how bad economics imperils health and what to do about it. Journal of Epidemiol and Community Health, 70(3), 312-318. doi: 10.1136/jech-2015-206295

Lamb, C., \& Officer, S. M. P. (1996). Barriers to work for refugee women. Paper presented at the Second Women in Migration Conference, Wesley Centre Sydney. Retrieved from

Larner, W. (2000a). Neo-liberalism: Policy, Ideology, Governmentality. Studies in Political Economy, 63(1), 5-25. doi: 10.1080/19187033.2000.11675231

Larner, W. (2000b). Post-Welfare State Governance: Towards a Code of Social and Family Responsibility. Social Politics: International Studies in Gender, State \& Society, 7(2), 244-265. doi: 10.1093/sp/7.2.244 
Larner, W., \& Craig, D. (2005). After neoliberalism? Community activism and local partnerships in Aotearoa New Zealand. Antipode, 37(3), 402-424.

LeClair, K. L., \& Saunders, J. E. (2019). Meeting the educational needs of children with hearing loss. Bulletin of the World Health Organization, 97(10), 722. doi: http://dx.doi.org/10.2471/BLT.18.227561

Lemke, T. (2002). Foucault, Governmentality, and Critique. Rethinking Marxism, 14(3), 49-64. doi: 10.1080/089356902101242288

Lemke, T. (2007). An indigestible meal? Foucault, governmentality and state theory. Distinktion: Scandinavian Journal of Social Theory, 8(2), 43-64. doi: 10.1080/1600910X.2007.9672946

Linscott, J., Randolph, A. L., \& Mayle, T. (2016). The Impact of Spirituality on Wellness for Appalachian Older Adults. Adultspan Journal, 15(2), 96-108. doi: 10.1002/adsp. 12024

Llácer, A., Zunzunegui, M. V., del Amo, J., Mazarrasa, L., \& Bolůmar, F. (2007). The contribution of a gender perspective to the understanding of migrants' health. Journal of epidemiology and community health, 61(Suppl 2), ii4-ii10. doi: 10.1136/jech.2007.061770

Ludwig, G., \& Stefanie, W. (2009). Governmentality and gender: Current transformations of gender regimes revisited from a Foucauldian perspective". Paper presented at the ECPR Conference on Gender and Politics, Belfast, Northern Ireland. Retrieved from

Maclellan, N. (2011). Kiribati's policy for "migration with dignity". Inside Story. Retrieved from http://insidestory.org.au/kiribatis-policy-for-migration-withdignity/

Maclellan, N. (2017). Grappling with the Bomb: Britain's Pacific H-bomb tests. Action, ACT: Australian National University Press.

Maher, L., \& Dertadian, G. (2018). Qualitative research. Addiction, 113(1), 167-172. doi: 10.1111/add.13931

Māhina-Tuai, K. (2012). FIA (Forgotten in Action): Pacific Islanders in the New Zealand Armed Forces. Tangata o te Moana: New Zealand and the People of the Pacific, 139-159.

Mallon, S., Māhina-Tuai, K. U., \& Salesa, D. I. (2012). Tangata o le Moana: New Zealand and the people of the Pacific: Te Papa Press.

Mallon, S., Māhina-Tuai, K. U., \& Salesa, D. I. (2012). Tangata O Le Moana: New Zealand the People of the Pacific. Wellington, NZ: Te Papa Press.

Mansfield, H. A. H. K. (2013). Discourses of Vulnerability: Kiribati, I-Kiribati Women and Forced Migration Due to Climate Change. (Victoria University of Wellington).

Martinez, E., \& Garcia, A. (1997). What is neoliberalism? A brief definition for activists. National Network for Immigrant and Refugee Rights, 1 .

Martinez, E., \& Garcia, A. (2001). What is neoliberalism? A brief definition. Retrieved from http://www.ewb.org.au/resources/download/2316P2011-1221_18:19:48

Masoe, P., \& Bush, A. (2009). A Samoan perspective on infant mental health. Pacific health dialog, 15(1), 148-155. Retrieved from https://pdfs.semanticscholar.org/d91c/242b70b4354d712dc001cc6ce8e85442 4fb8.pdf

Maude, H. (1952). The colonization of the Phoenix Islands. The Journal of the Polynesian Society, 61(1/2), 62-89. 
Maude, H. E. (1961). The Evolution of the Gilbertese Boti: An Ethnohistorical Interpretation; a Paper Prepared for the Symposium on Ethnohistory in the Pacific at the Pacific Science Congress, Honolulu, Hawaii, USA, August 21September 6, 1961 (Vol. 72): Australian National University.

McAdam, J. (2009). Environmental migration governance. UNSW Law Research Retrieved from https://ssrn.com/abstract $=1412002$

McCalman, J., Heyeres, M., Campbell, S., Bainbridge, R., Chamberlain, C., Strobel, N., \& Ruben, A. (2017). Family-centred interventions by primary healthcare services for Indigenous early childhood wellbeing in Australia, Canada, New Zealand and the United States: a systematic scoping review. BMC pregnancy and childbirth, 17(1), 71. doi: 10.1186/s12884-017-1247-2

McGregor, J. (2014). The human rights framework and equal pay for low paid female carers in New Zealand. New Zealand Journal of Employment Relations, 38(2), 4-16.

Meadows, L. M., Thurston, W. E., \& Melton, C. (2001). Immigrant women's health. Social science \& medicine, 52(9), 1451-1458. doi: 10.1016/S02779536(00)00251-3

Metge, J., \& Kinloch, P. (1984). Talking past each other: problems of cross cultural communication. Wellington, NZ: Victoria University Press.

Ministry of Business, Innovation and Employment. (2018). Pacific migration trends and settlement outcomes report. Retrieved from https://www.mbie.govt.nz/assets/902b9b1dcc/inz-pacific-migrant-trends-andsettlement-outcomes-november-2018.pdf

Ministry of Business, Innovation and Employment. (2019). Migration Data Explorer. https://mbienz.shinyapps.io/migration_data_explorer/

Ministry of Finance and Economic Development. (2018). National statistics series [Excel file].

Ministry of Health. (2011). Work visa holder eligible to be in NZ for two years or more. Retrieved from https://www.health.govt.nz/new-zealand-healthsystem/eligibility-publicly-funded-health-services/guide-eligibility-publiclyfunded-health-services/work-visa-holder-eligible-be-nz-two-years-or-more

Ministry of Health. (2014a). 'Ala Mo'ui: Pathways to Pacific Health and Wellbeing 2014-2018. Retrieved from https://www.health.govt.nz/system/files/documents/publications/ala-mouipathways-to-pacific-health-and-wellbeing-2014-2018-jun14-v2.pdf

Ministry of Health. (2014b). Analysis of Household Crowding based on Census 2013 data. Retrieved from https://www.health.govt.nz/publication/analysishousehold-crowding-based-census-2013-data

Ministry of Health. (2016). New Zealand Health Strategy: Future direction. Retrieved from https://www.health.govt.nz/new-zealand-health-system/new-zealandhealth-strategy-future-direction

Ministry of Health. (2018a). Who is eligible for publicly funded maternity services? Retrieved from https://www.health.govt.nz/new-zealand-healthsystem/publicly-funded-health-and-disability-services/pregnancy-services

Ministry of Health. (2018b). Your rights under the Substance Addition (Compulsory Assessment and Treatment) Act $2017 . \quad$ Retrieved from https://www.health.govt.nz/our-work/mental-health-andaddictions/preparing-commencement-substance-addiction-compulsoryassessment-and-treatment-act-2017/your-rights-under-substance-addictioncompulsory-assessment-and-treatment-act-2017 
Ministry of Labour and Human Resources Development. (n.d). Information \& Guide for Kiribati Seasonal Workers Retrieved from http://oit.org/wcmsp5/groups/public/---asia/---ro-bangkok/---ilosuva/documents/publication/wcms_502118.pdf

Ministry of Social Development. (2015). Boutokaan te mweeraoi: A Conceptual Framework for enhancing I-Kiribati wellbeing. Retrieved from http://www.pasefikaproud.co.nz/assets/Resources-fordownload/PasefikaProudResource-Nga-Vaka-o-Kaiga-Tapu-PacificFramework-Kiribati.pdf

Ministry of Social Development. (2016). Three Year Maneaba Strategic Action Plan Mortensen, A. (2011). Public health system responsiveness to refugee groups in New Zealand: activation from the bottom up. Social Policy Journal of New Zealand, 37, 1-12. Retrieved from https://www.msd.govt.nz/about-msd-and-ourwork/publications-resources/journals-and-magazines/social-policyjournal/spj37/37-public-health-system-responsiveness-to-refugee-groups-innew-zealand.html

Moy, S. (2008). The importance of incorporating education for sustainable development (ESD) into the secondary curriculum in order to minimise the problems of waste on South Tarawa (Master's thesis, Victoria University of Wellington). Retrieved from http://hdl.handle.net/10063/1017

Munniksma, A., Flache, A., Verkuyten, M., \& Veenstra, R. (2012). Parental acceptance of children's intimate ethnic outgroup relations: The role of culture, status, and family reputation. International Journal of Intercultural Relations, 36(4), 575-585.

Murray, W. E., \& Overton, J. D. (2011). Neoliberalism is dead, long live neoliberalism? Neostructuralism and the international aid regime of the 2000s. Progress in Development Studies, 11(4), 307-319. doi: $10.1177 / 146499341001100403$

Navarro, V. (2007). Neoliberalism, globalization, and inequalities: Consequences for health and quality of life: Baywood Pub.

New Zealand Government. (2001). Government announces Pacific access scheme [Press release]. Retrieved from https://www.beehive.govt.nz/release/government-announces-pacific-accessscheme- 0

New Zealand Government. (2004a). Management of Pacific quotas to be improved [Press release]. Retrieved from https://www.beehive.govt.nz/release/management-pacific-quotas-beimproved

New Zealand Government. (2004b). Speech to Northland Business and Employment Law Conference [Press release]. Retrieved from https://www.beehive.govt.nz/speech/speech-northland-business-andemployment-law-conference

New Zealand Government. (2018). Increasing the cap for the Recognised Seasonal Employer scheme. Retrieved from https://www.mbie.govt.nz/assets/2778593410/cabinet-paper-increasing-thecap-for-the-recognised-seasonal-employer-scheme.pdf

New Zealand Guidelines Group. (2011). RapidE: Rheumatic Fever A system review of the literature on health literacy, overcrowding and rheumatic fever. Retrieved from 
https://www.health.govt.nz/system/files/documents/publications/rf20systemat ic20review20w20nz20case20studies20included.pdf

New Zealand Treasury. (2018). The New Zealand Pacific Economy. Retrieved from https://reasury.govt.nz/sites/default/files/2018-11/nz-pacific-economynov18.pdf

Office of Te Beretitenti, \& T'Makei Services. (2012). Republic of Kiribati Island Report Series: Butaritari. Retrieved from http://www.climate.gov.ki/aboutkiribati/island-reports-2012/butaritari/

Ongley, P., \& Pearson, D. (1995). Post-1945 International Migration: New Zealand, Australia and Canada Compared. International Migration Review, 29(3), 765793. doi: $10.2307 / 2547504$

Ortactepe, D. (2013). "This is called Free-Falling Theory not Culture Shock": A Narrative Inquiry on Second Language Socialization. Journal of Language, Identity and Education, 12(4), 215-229. doi: 10.1080/15348458.2013.818469

Pe-Pua, R. (2006). From decolonizing psychology to the development of a crossindigenous perspective in methodology: the Philippine experience. In U. Kim, K.-S. Yang \& K.-K. Hwang (Eds.), Indigenous and Cultural Psychology: understanding people in context. (pp. 109-137). New York, NY: Springer

Prescott, S. M. (2009). Pacific business sustainability in New Zealand: a study of Tongan experiences ( $\mathrm{PhD}$ thesis, Auckland University of Technology). Retrieved from http://hdl.handle.net/10292/745

Prince, R., Kearns, R., \& Craig, D. (2006). Governmentality, discourse and space in the New Zealand Health Care System. Health \& place, 12(3), 253-266. doi: 10.1016/j.healthplace.2004.09.003

Ramasamy, S., Krishnan, V., Bedford, R., \& Bedford, C. (2008). The Recognised Seasonal Employer policy: seeking the elusive triple wins for development through international migration. Pacific Economic Bulletin, 23(3), 171-186. Retrieved from http://hdl.handle.net/1885/157917

Raymond, L. (2006). Book Review: Environmentality: Technologies of Government and the Making of Subjects. Comparative Political Studies, 39(2), 261-265. doi: 10.1177/0010414005283293

Reinharz, S., Davidman, L., \& Conochie, J. (1992). Feminist methods in social research. New York, NY: Oxford University Press

Repo, J. (2016). Gender Equality as Biopolitical Governmentality in a Neoliberal European Union. Social Politics, 23(2), 307-328. doi: https://doi.org/10.1093/sp/jxu028

Robinson, D., \& Williams, T. (2001). Social capital and voluntary activity: Giving and sharing in Maori and non-Maori society. Social Policy Journal of New Zealand(17), 52-71.

Royal, T. A. C. (2005a). 'Māori', Te Ara - the Encyclopedia of New Zealand. Retrieved from https://teara.govt.nz/en/maori

Royal, T. A. C. (2005b). 'Maori - The Arrival of Europeans', Te Ara - the Encyclopedia of New Zealand. Retrieved from http://www.TeAra.govt.nz/en/maori/page-3

Rudnyckyj, D. (2004). Technologies of servitude: governmentality and indonesian transnational labour migration. Anthropological Quarterly, 77(3), 407(428.

Ruiz-Casares, M., Rousseau, C., Laurin-Lamothe, A., Rummens, J. A., Zelkowitz, P., Crepeau, F., \& Steinmetz, N. (2012). Access to health care for undocumented migrant children and pregnant women: the paradox between values and attitudes of health care professionals. Maternal and Child Health Journal, 17(2), 292-298. doi: 10.1007/s10995-012-0973-3 
Ryan, L. (2011). Migrants' social networks and weak ties: accessing resources and constructing relationships post-migration. The Sociological Review, 59(4), 707-724. doi: 10.1111/j.1467-954X.2011.02030.x

Sanga, K. F. (2004). Making philosophical sense of indigenous Pacific research. In T. Baba, O. Mahina, N. Williams \& U. Nabobo-Baba (Eds.), Researching the Pacific and indigenous peoples: issues and perspectives (pp. 41-52). Auckland, NZ: Centre for Pacific Studies, University of Auckland.

Scanlon, J. (1993). Challenging the imbalances of power in feminist oral history: Developing a take-and-give methodology. Women's Studies International Forum, 16(6), 639-645. doi: 10.1016/S0277-5395(08)80008-8

Schmidt-Busby, J., Wiles, J., Exeter, D., \& Kenealy, T. (2019). Self-management action and motivation of Pacific adults in New Zealand with end-stage renal disease. PloS one, 14(9), 1-18. doi: https://doi.org/10.1371/journal.

pone. 0222642

Schouler-Ocak, M., Graef-Calliess, I. T., Tarricone, I., Qureshi, A., Kastrup, M. C., \& Bhugra, D. (2015). EPA guidance on cultural competence training. European Psychiatry, 30(3), 431-440.

Scott, C. D. (1994). Reform of the New Zealand health care system. Health Policy, 29(1-2), 25-40. doi: 10.1016/0168-8510(94)90005-1

Scott, J. (1997). Communication campaign and the neo-liberal policy agenda. Media Culture and Society, 19, 183-199.

Serbulea, M., \& Payyappallimana, U. (2012). Onsen (hot springs) in JapanTransforming terrain into healing landscapes. Health \& place, 18(6), 13661373.

Sigley, G. (2006). Chinese governmentalities: Government,governance and thesSocialist market economy. Economy and Society, 35(4), 487-508. doi: https://doi.org/10.1080/03085140600960773

Silva, A. L. d., \& Dawson, M. T. (2004). The impact of international migration on the health of Brazilian women living in Australia. Texto \& Contexto-Enfermagem, 13(3), 339-350.

Silvius, R. (2016). Neo-liberalization, devolution, and refugee well-being: A case study in Winnipeg, Manitoba. Canadian Ethnic Studies, 48(3), 27-44. doi:

https://doi.org/10.1353/ces.2016.0024

https://muse.

Simati, S. P. (2009). The effect of migration on development in Tuvalu: a case study of PAC migrants and their families: a thesis presented in partial fulfilment of the requirements for the degree of Master of Philosophy in Development Studies at Massey University, New Zealand.

Singh, P. (2001). Speaking about Cultural Difference and School Disadvantage. An Interview study of 'Samoan' Paraprofessionals in Designated Disadvantaged Secondary Schools in Australia. British Journal of Sociology of Education, 22(3), 317-337. doi: 10.1080/01425690120067953

Slack, J. D. (1996). The theory and method of articulation in cultural studies. In D. Morley \& K.-H. Chen (Eds.), Stuart Hall: Critical dialogues in cultural studies (pp. 112-127). New York: Routledge.

Slack, J. D. (2006). Communication as Articulation. In G. J. Shepherd, J. St John \& T. Striphas (Eds.), Communication as perspectives on theory. Thousand Oaks: Sage Publications, Inc.

Smith, J., \& Firth, J. (2011). Qualitative data analysis: the framework approach. Nurse researcher, 18(2), 52-62. 
Smith, L. T. (2004). Building research capability in the Pacific, for the Pacific and by Pacific peoples. Researching the Pacific and indigenous peoples: Issues and perspectives, 4-16.

Southwick, M., Kenealy, T., \& Ryan, D. (2012). Primary care for pacific people: a Pacific and health systems approach.

Statistics New Zealand. (2010). Health and Pacific peoples - Pacific Progress. Retrieved from

Statistics New Zealand. (2013a). 2013 Census ethnic group profiles: Kiribati. Retrieved from http://archive.stats.govt.nz/Census/2013-census/profile-andsummary-reports/ethnicprofiles.aspx ?request_value $=24717 \&$ parent $\mathrm{id}=24706 \&$ tabname $=\# 24717$

Statistics New Zealand. (2013b). 2013 Census: Birthplace (detailed overseas born) and years since arrival in New Zealand by sex, for the overseas born census usually resident population count, 2001, 2006, and 2013 Censuses (RC, TA)]. Retrieved

from http://nzdotstat.stats.govt.nz/wbos/Index.aspx ?DataSetCode=TABLECODE8 $\underline{021 \#}$

Statistics New Zealand. (2019a). 2013 Census QuickStats about culture and identity. Retrieved from http://archive.stats.govt.nz/Census/2013-census/profile-andsummary-reports/quickstats-culture-identity.aspx

Statistics New Zealand. (2019b). NZ.Stat. Retrieved 22 March 2019 http://nzdotstat.stats.govt.nz/wbos/index.aspx\#

Statistics New Zealand. (2019c). Occupancy Rate by Ethnic Group. Retrieved from http://nzdotstat.stats.govt.nz/wbos/index.aspx\#

Stehr, N., \& Adolf, M. S. (2018). Society, 55, 193-198.

Stevens, G., Flaxman, S., Brunskill, E., Mascarenhas, M., Mathers, C. D., \& Finucane, M. (2013). Global and regional hearing impairment prevalence: an analysis of 42 studies in 29 countries. The European Journal of Public Health, 23(1), 146152.

Su'a-Tavila, A. (2019). Contemporary Pacific values and beliefs. In J. Ravulo, T. Mafile'o \& D. Bruce (Eds.), Pacific Social Work: Navigating Practice, Policy and Research: Taylor \& Francis eBooks

Su'a, T. T. (2017). Samoan People's Knowledge and Understanding of Cardiovascular Disease (Victoria University of Wellington).

Suaalii-Sauni, T., \& Fulu-Aiolupotea, S. M. (2014). Decolonising Pacific research, building Pacific research communities and developing Pacific research tools: The case of the talanoa and the faafaletui in Samoa. Asia Pacific Viewpoint, 55(3), 331-344.

Suaalii, T. M. (2006). Le Matuamoepo: competing'spirits of governing'and the management of New Zealand-based Samoan youth offender cases (ResearchSpace@ Auckland).

Svalastog, A. L., Donev, D., Kristoffersen, N. J., \& Gajović, S. (2017). Concepts and definitions of health and health-related values in the knowledge landscapes of the digital society. Croatian medical journal, 58, 431.

Szenassy, E. (2016). Understanding care, pain and responsibilization-making sense of policy and practice. An Interview with Susanna Trnka. Cargo Journal, 9(1-2), 179-187.

Retrieved

from http://www.cargojournal.org/index.php/cargo/article/viewFile/60/66

Tabe, T. (2011). Sapon Riki Ba Kain Toromon: A Study of the I-Kiribati Community in Solomon Islands (UNIVERSITY OF HAWAII AT MĀNOA). 
Tabokai, N. (1993). Atoll Politics The Republic of Kiribati. Christchurch [New Zealand] Macmillan Brown Centre for Pacific Studies, University of Canterbury, and Institute of Pacific Studies, University of the South Pacific, Suva [Fiji]. Macmillian Brown Centre for Pacific Studies, University of Cantebury and Institute of Pacific Studies University of the South Pacific.

Tait, R. (2009). An Outcomes Framework for Pacific Peoples in New Zealand: Report for the Ministry of Pacific Island Affairs. Retrieved from www. mpia. govt. nz/resources/pdfs/news-publications/Framework\% 20report

Tamasese, K. P., Carmel, Waldegrave, Charles; Bush, Allister. (2005). Ole Taeao Afua, the new morning: A qualitative investigation into Samoan

perspectives on mental health and culturally appropriate services. Australian and New Zealand Journal of Psychiatry 39 (4), 300-309.

Tamasese, T. K., Parsons, T. L., Sullivan, G., \& Waldegrave, C. (2010). A qualitative study into pacific perspectives on cultural obligations and volunteering. Wellington: Pacific Section and the Family Centre Social Policy Research Unit.

Teaiwa, K. M. (1999). Tirawata irouia: Re-presenting Banaban stories (University of Hawai'i).

Teaiwa, K. M. (2018). Pacific nations aren't cash-hungry, minister, they just want action on climate change. Retrieved from https://theconversation.com/pacificnations-arent-cash-hungry-minister-they-just-want-action-on-climate-change$\underline{105206}$

Teaiwa, T. K. (2010). For or before an Asian Pacific studies agenda? Specifying Pacific studies. Remaking area studies: Teaching and learning across Asia and the Pacific, 110-124.

Teaiwa, T. K. (2014). The ancestors we get to choose: White influences I won't deny. Theorizing native studies, 43-55.

Teaiwa, T. K., \& Henderson, A. K. (2009). Humanities and Communities: A Dialogue in Pacific Studies. Pacific Studies, 32(4), 421-438.

Tebano, T., Barako, E., Auatabu, T., Kakau, E., \& Kiata, R. (2008). Republic of Kiribati Island Report Series for KAP II (Phase 2): Butaritari. Retrieved from https://web.archive.org/web/20111106060656/http://www.climate.gov.ki/libr ary.html

Thaman, K. H. (2007). Partnerships for progressing cultural demogracy in Teacher Education in Pacific Island Countries (T. T. a. R. B. (eds.) Ed.): Springer.

Theobald, J. (2014). Feminist Oral History and the Victorian Domestic Violence Services Movement. Australian Feminist Studies, 28(78), 364-374. doi: 10.1080/08164649.2013.858654

Thompson, M. A. (2016). The Settlement Experiences of Kiribati Migrants Living in New Zealand (University of Otago). Retrieved from http://hdl.handle.net/10523/6144

Tiatia-Seath, S. (2008). Pacific cultural competencies: A literature review: New Zealand Ministry of Health.

Tito, T. (2002). Kiribati Statement. New York. Retrieved from http://www.janeresture.com/kiribati_un_speech/index.htm

Tone, K. (2005). Talking past each other: the impact of cross-cultural communication on construction project management in Samoa (Queensland University of Technology).

Trease, H. V. (1993). Atoll Politics The Republic of Kiribati. University of the South Pacific, Suva: Christchurch [New Zealand] Macmillan Brown Centre for 
Pacific Studies, University of Canteburry, and Institute of Pacific Studies, University of the South Pacific.

Trnka, S., \& Trundle, C. (2014). Competing Responsibilities: Moving Beyond Neoliberal Responsibilisation.

doi: https://www.wcaanet.org/downloads/dejalu/feb2016/Anthropological\%20For $\underline{\text { um.pdf }}$

Tukuitonga, C. (2012). Pacific Island health: Causes of poor health. Te Ara-The Encyclopedia of New Zealand.

Uakeia, T. (2017). Political System in Kiribati Pacific ways, government and politics in the Pacific Islands [Book Review] (pp. 118 - 131). Victoria University of Wellington: Victoria University of Wellington.

UNESCO. (2019). Literacy. Retrieved from https://en.unesco.org/themes/literacy

United Nations. (2018). United Nations Pacific Strategy 2018-2022. Retrieved from https://unsdg.un.org/resources/united-nations-pacific-strategy-2018-2022

United Nations. (2019). The Sustainable Development Goals Report 2019. Retrieved from website: https://unstats.un.org/sdgs/report/2019/The-SustainableDevelopment-Goals-Report-2019.pdf

United States Department of Labour's Bureau of International Labour Affairs. (2012). Kiribati: 2012 Findings on the Worst Forms of Child Labour. Retrieved from http://www.refworld.org/pdfid/5268e58f2.pdf

Uriam, K. K. (2017). In their own words: History and society in Gilbertese oral tradition: Canberra, ACT: Division of Pacific and Asian History, Research School of ....

Vaioleti, T. M. (2006). Talanoa research methodology: a developing position on pacific research.

Volunteer Service Abroad. (2019a). AMAK (Aia Maea Ainen Kiribati). Retrieved from https://vsa.org.nz/what-we-do/countryregion/kiribati/kiribati-partnerorganisations/amak-aia-maea-ainen-kiribati/

Volunteer Service Abroad. (2019b). English Language Trainer. Retrieved from https://vsa.org.nz/volunteer/volunteer-vacancies/english-language-trainer41180/

Walls, C. T. (1992). The role of church and family support in the lives of older African Americans. Fam Aging, 33-36.

Wesley-Smith, T. (1995). Rethinking Pacific Islands Studies. Pacific Studies, 18(2), 115-136.

Whincup, T. (2009). Bwai ni Kiribati Artefacts of Experience. National Library New Zealand: Steele Roberrts Publishers.

WHO, \& Ministry of Health and Medical Services, G. o. K. (2012). Health Services Delivery Profile Kiribati. Retrieved from website: http://www.wpro.who.int/health_services/service_delivery_profile_kiribati.p $\underline{\mathrm{df}}$

Williams, A. (2010). The Experiences of the Recognised Seasonal Employer scheme and Ni-Vanuatu Temporary Workers in Te Puke, New Zealand (Otago University).

Woolley, F. R. (1993). The Freminist challenge to neoclassical economics. Cambridge Journal of Economics, 17, 485-500.

Wright, M. (2009, 3 August 2009). Maori and Pacific peoples face increasing rates of acute rhematic fever. 
Zanchetta, M. S., \& Poureslami, I. M. (2006). Health literacy within the reality of immigrants' culture and language. Canadian Journal of Public Health/Revue Canadienne de Sante'e Publique, S26-S30. 


\section{Appendices}

\section{Appendix A}

\section{Appendix for Chapter 1}

\section{A.1 NON-RESIDENCE VISA CATEGORIES}

Table A-1: Temporary work and study visa policies most commonly granted to Pacific people.

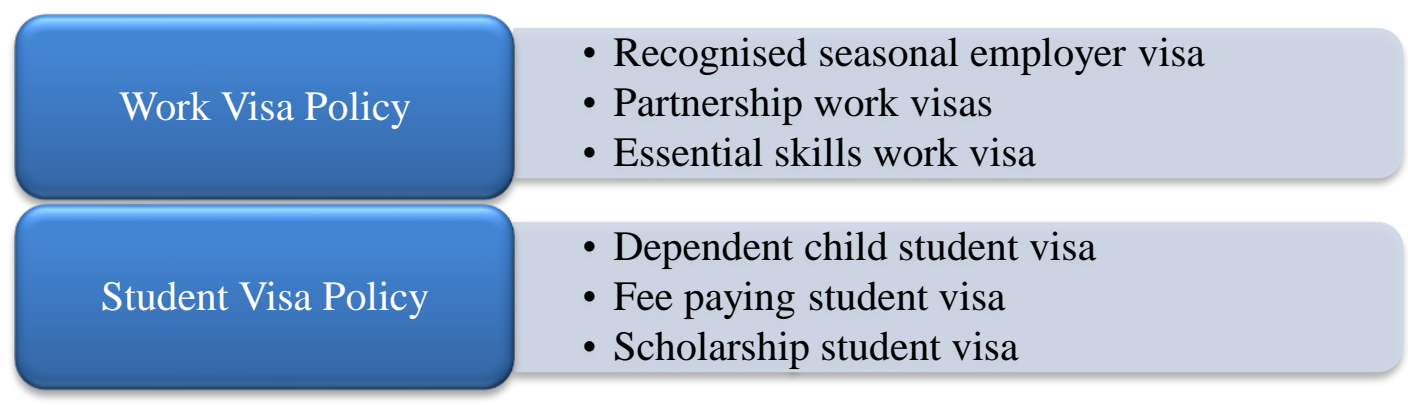

Source: Ministry of Business, Innovation and Employment (2018).

\section{A.2 SUPPLEMENTARY DATA}

Table A-2: Pacific residence approvals by stream.

\begin{tabular}{|l|lllll|}
\hline \multirow{2}{*}{ Application stream } & \multicolumn{5}{|c|}{ Financial year decided } \\
\cline { 2 - 6 } & 2013 & 2014 & 2015 & 2016 & 2017 \\
\hline Business/Skilled & 1,074 & 1,113 & 1,054 & 1,137 & 1,025 \\
Family & 2,413 & 2,514 & 2,409 & 2,568 & 2,260 \\
International/Humanitarian & 1,540 & 1,563 & 1,802 & 1,771 & 1,958 \\
\hline Total & 5,027 & 5,190 & 5,265 & 5,476 & 5,243 \\
\hline
\end{tabular}

Source: Ministry of Business, Innovation and Employment (2018). 
Table A-3: Approved temporary workers from the Pacific by work visa policies.

\begin{tabular}{|l|rrrrr|}
\hline \multirow{2}{*}{ Application sub-stream } & \multicolumn{5}{c|}{ Financial year decided } \\
\cline { 2 - 6 } & \multicolumn{1}{c|}{2013} & 2014 & 2015 & 2016 & \multicolumn{1}{c|}{2017} \\
\hline RSE & 6,151 & 6,563 & 7,171 & 7,894 & 9,120 \\
Partner & 3,064 & 3,000 & 2,867 & 2,910 & 2,592 \\
Essential skills & 1,921 & 2,056 & 2,249 & 2,434 & 2,171 \\
Specific purpose or event & 173 & 184 & 231 & 366 & 329 \\
Study to work & 351 & 201 & 214 & 258 & 230 \\
Work to residence & 83 & 76 & 70 & 77 & 157 \\
Other & 1,027 & 1,011 & 932 & 765 & 664 \\
\hline Total & 12,641 & 12,973 & 13,634 & 14,593 & 15,173 \\
\hline
\end{tabular}

Source: Ministry of Business, Innovation and Employment (2018).

Table A-4: Recognised Seasonal Employer work visa approvals by eligible country.

\begin{tabular}{|c|c|c|c|c|c|c|c|c|c|c|}
\hline \multirow{2}{*}{ Eligible countries } & \multicolumn{10}{|c|}{ Financial year decided } \\
\hline & 2009 & 2010 & 2011 & 2012 & 2013 & 2014 & 2015 & 2016 & 2017 & 2018 \\
\hline Fiji & & & & & & & 30 & 102 & 384 & 381 \\
\hline Kiribati & 42 & 63 & 171 & 171 & 171 & 147 & 159 & 174 & 192 & 243 \\
\hline Nauru & & & & & & & 18 & 21 & 18 & 18 \\
\hline Papua New Guinea & & & 6 & 12 & 30 & 60 & 102 & 69 & 123 & 123 \\
\hline Samoa & 1,383 & 1,092 & 1,347 & 1,305 & 1,215 & 1,224 & 1,329 & 1,551 & 1,761 & 1,995 \\
\hline Solomon Islands & 330 & 285 & 273 & 450 & 537 & 513 & 546 & 651 & 633 & 651 \\
\hline Tonga & 1,443 & 1,341 & 1,551 & 1,677 & 1,689 & 1,785 & 1,770 & 1,767 & 2,004 & 2,127 \\
\hline Tuvalu & 63 & 60 & 60 & 117 & 60 & 72 & 81 & 66 & 81 & 81 \\
\hline Vanuatu & 2,655 & 2,244 & 2,448 & 2,580 & 3,111 & 3,249 & 3,816 & 3,930 & 4,398 & 4,665 \\
\hline Total & 5,916 & 5,085 & 5,856 & 6,312 & 6,813 & 7,050 & 7,851 & 8,331 & 9,594 & 10,284 \\
\hline
\end{tabular}

Source: Ministry of Business, Innovation and Employment (2019). 
Table A-5: Key economic data for Kiribati.

\begin{tabular}{|c|c|c|c|c|c|c|c|c|c|c|c|c|c|}
\hline & 2005 & 2006 & 2007 & 2008 & 2009 & 2010 & 2011 & 2012 & 2013 & 2014 & 2015 & 2016 & 2017 \\
\hline \multicolumn{14}{|l|}{ Population $\uparrow$} \\
\hline Total population & 92,533 & & & & & 103,058 & & & & & 110,136 & & \\
\hline Population density (persons $/ \mathrm{km}^{2}$ ) & 127 & & & & & 142 & & & & & 152 & & \\
\hline Urban population ( $\%$ of total population) & 43.6 & & & & & 48.7 & & & & & 51.2 & & \\
\hline \multicolumn{14}{|l|}{ Gross Domestic Product (GDP, A\$ millions) $\dagger$} \\
\hline Nominal GDP & 147 & 146 & 159 & 168 & 170 & 170 & 176 & 184 & 192 & 199 & 228 & 240 & 242 \\
\hline Gross national income & 208 & 205 & 226 & 245 & 234 & 249 & 245 & 278 & 320 & 379 & 467 & 467 & 475 \\
\hline Gross national disposable income & 252 & 233 & 257 & 276 & 267 & 278 & 275 & 321 & 361 & 453 & 512 & 535 & 522 \\
\hline Real GDP & 146 & 146 & 149 & 146 & 147 & 146 & 148 & 155 & 162 & 161 & 178 & 187 & 187 \\
\hline Real GDP growth rate $(\%)$ & 4.95 & -0.05 & 2.04 & -2.09 & 0.80 & -0.92 & 1.59 & 4.71 & 4.21 & -0.70 & 10.40 & 5.13 & 0.33 \\
\hline Real GDP per capita (A $\$$ ) & 1,583 & 1,548 & 1,546 & 1,482 & 1,462 & 1,417 & 1,421 & 1,468 & 1,510 & 1,480 & 1,612 & 1,672 & 1,656 \\
\hline \multicolumn{14}{|l|}{ External Trade (A\$ millions) $\diamond$} \\
\hline Current account balance & -48 & -19 & -9 & -11 & -23 & 0 & -17 & 3 & 38 & 106 & 105 & 47 & 34 \\
\hline Trade balance & -92 & -76 & -68 & -75 & -76 & -70 & -75 & -91 & -94 & -100 & -121 & -130 & -142 \\
\hline Balance on services & -45 & -39 & -44 & -47 & -44 & -43 & -53 & -50 & -52 & -82 & -90 & -77 & -76 \\
\hline Balance on factor income & 61 & 63 & 70 & 77 & 65 & 80 & 67 & 95 & 128 & 181 & 242 & 192 & 219 \\
\hline Fishing license fees* & & & & & & & & & & & 197 & 144 & 151 \\
\hline Investment income* & & & & & & & & & & & 32 & 35 & 54 \\
\hline Remittances and compensation of employees* & & & & & & & & & & & 16 & 16 & 16 \\
\hline Balance on current transfers & 28.3 & 33.1 & 33.7 & 33.8 & 32.6 & 33.2 & 43.4 & 49.3 & 55.8 & 107.6 & 74.1 & 62.4 & 33 \\
\hline \multicolumn{14}{|l|}{ External Sector (A\$ millions) $\dagger$} \\
\hline Balance of trade & -94 & -79 & -72 & -79 & -81 & -75 & -81 & -98 & -104 & -108 & -124 & -135 & -131 \\
\hline Total exports & 6 & 3 & 12 & 9 & 8 & 4 & 8 & 7 & 7 & 11 & 13 & 14 & 20 \\
\hline
\end{tabular}




\begin{tabular}{|c|c|c|c|c|c|c|c|c|c|c|c|c|c|}
\hline & 2005 & 2006 & 2007 & 2008 & 2009 & 2010 & 2011 & 2012 & 2013 & 2014 & 2015 & 2016 & 2017 \\
\hline Total imports & 100 & 82 & 84 & 88 & 89 & 80 & 89 & 105 & 111 & 119 & 137 & 150 & 151 \\
\hline \multicolumn{14}{|l|}{ Migration $\uparrow$} \\
\hline Net migration & 1,422 & 434 & 424 & -218 & -770 & 570 & 197 & $-1,600$ & -33 & $-1,168$ & $-3,357$ & $-2,504$ & -622 \\
\hline Arrivals & 7,845 & 4,724 & 8,064 & 8,112 & 6,831 & 7,688 & 8,146 & 7,613 & 8,394 & 6,995 & 3,918 & 9,236 & 15,260 \\
\hline Departures & 6,423 & 4,290 & 7,640 & 8,330 & 7,601 & 7,118 & 7,949 & 9,213 & 8,427 & 8,163 & 7,475 & 11,740 & 15,882 \\
\hline \multicolumn{14}{|l|}{ Education $(15$ yrs +$) \dagger$} \\
\hline Achieved secondary education or higher (\%) & & & & & & 59.6 & & & & & 74.9 & & \\
\hline Male & & & & & & 59.7 & & & & & 73.5 & & \\
\hline Female & & & & & & 59.5 & & & & & 78.3 & & \\
\hline Literacy rate & & & & & & 97.7 & & & & & 79.6 & & \\
\hline Male & & & & & & 97.7 & & & & & 79.8 & & \\
\hline Female & & & & & & 97.8 & & & & & 79.4 & & \\
\hline
\end{tabular}

Sources: $\uparrow$ Ministry of Finance and Economic Development (2018), *International Monetary Fund (2019) and $\diamond$ Asian Development Bank (2018) 


\section{A.3 EXTRACTIONS FROM THE PAC OPERATIONAL MANUAL (IMMIGRATION NEW ZEALAND, 2018B)}

\section{S1.40.5 Criteria for a resident visa}

1. To qualify for a resident visa under the Pacific Access Category, the principal applicant must:

1. be a citizen of Fiji, Tonga, Tuvalu, or Kiribati; and

2. have their Pacific Access Category registration drawn from the relevant Fiji, Tonga, Tuvalu, or Kiribati pool of the Pacific Access Category; and

3. lodge their application for a resident visa under the Pacific Access Category within eight months of written advice from Immigration New Zealand that their registration has been drawn from the relevant Fiji, Tonga, Tuvalu, or Kiribati pool of the Pacific Access Category; and

4. have been aged between 18 and 45 (inclusive) at the registration closing date; and

5. have an acceptable offer of employment or have a partner, included in the application, who has an acceptable offer of employment (see S1.40.30 below); and

6. (if they have dependent children) meet the minimum income requirement set out at $\mathrm{S} 1.40 .35$ below; and

7. meet a minimum level of English language ability (see S1.40.45 below); and

8. meet health and character requirements (see $\underline{\mathrm{A} 4}$ and $\underline{\mathrm{A} 5}$ ).

2. Principal applicants who are citizens of Fiji:

1. must be either in Fiji or lawfully in New Zealand at the time their application under the Pacific Access Category is made; and

2. must have been born in Fiji or born overseas to a Fijian citizen who was born in Fiji.

3. Principal applicants who are citizens of Tonga:

1. must be either in Tonga or lawfully in New Zealand at the time their application under the Pacific Access Category is made; and

2. must have been born in Tonga or born overseas to a Tongan citizen who was born in Tonga.

4. Principal applicants who are citizens of Kiribati:

1. must be either in Kiribati or Fiji or lawfully in New Zealand at the time their application under the Pacific Access Category is made; and

2. must have been born in Kiribati or born overseas to a Kiribati citizen who was born in Kiribati.

5. Principal applicants who are citizens of Tuvalu:

1. must be either in Tuvalu or Fiji or lawfully in New Zealand at the time their application under the Pacific Access Category is made; and

2. must have been born in Tuvalu or born overseas to a Tuvaluan citizen who was born in Tuvalu.

6. Partners and dependent children included in applications under the Pacific Access Category must also meet health and character requirements (see A4 and $\underline{\mathrm{A} 5}$ ). 
7. An immigration officer may extend the eight-month timeframe referred to in paragraph (a)(iii) if the officer believes the special circumstances of the applicant justify such an extension.

8. An Assistant General Manager, Visa Services may extend the eight-month timeframe referred to in paragraph (a)(iii) in relation to a class of applicants if the Assistant General Manager believes the special circumstances of the class of applicants justify such an extension.

\section{S1.40.30 Acceptable offers of employment}

1. Acceptable offers of employment may be in either a skilled or unskilled occupation but must be for on-going and sustainable employment. On-going and sustainable employment is:

1. an offer of employment or current employment with a single employer which is permanent, or indefinite, and of which the employer is in a position to meet the terms specified; or

2. an offer of employment or current employment, with a single employer for a stated term of at least 12 months.

Note: When assessing whether employment is sustainable, officers may consider, but are not limited to, such factors as the residence status of the employer, the period for which the employing organisation has been established as a going concern, and the financial sustainability of the employing organisation.

Where an offer of employment or current employment is for a stated term of at least 12 months, the stated term must be valid both at the time the application is lodged and when the application is decided, in particular:

$\sim$ if the applicant has current employment, he or she must be in that employment, or

$\sim$ if the applicant has an offer of employment, the offer must continue to be valid.

2. Acceptable offers of employment must also be:

1. for full-time employment (employment is full-time if it amounts to, on average, at least 30 hours per week) unless S1.40.35.1 (c) applies; and

2. current at the time of assessing the application and at the time of grant the visa; and

3. genuine; and

4. for a position that is paid by salary or wages (ie, positions of selfemployment, payment by commission and/or retainer are not acceptable); and

5. accompanied by evidence of professional or technical registration if this is required by law to take up the offer; and

6. compliant with all relevant employment law in force in New Zealand.

3. An acceptable offer of employment must be from an employer who complies with all relevant employment and immigration law in force in New Zealand. Compliance with relevant New Zealand employment and immigration law 
will be assessed on the basis of past and current behaviour, and includes, but is not limited to:

1. paying employees no less than the applicable minimum wage rate; and

2. meeting holiday and leave entitlements and other minimum statutory requirements; and

3. meeting occupational safety and health obligations; and

4. only employing people who are entitled to work in New Zealand.

4. An employer is considered to not have a history of compliance with employment law if it fails to meet the requirements set out at R5.110 or if it is included on a list of non-compliant employers maintained by the Labour Inspectorate (see Appendix 10).

5. For the purposes of S1.40.30(a)(ii), Immigration New Zealand must be satisfied that the employer:

1. has genuine reasons based on reasonable grounds for specifying that the employment is for a stated term; and

2. has advised the employee of when or how their employment will end and the reasons for their employment ending; and

3 . is in a position to meet the terms specified.

6. 'Genuine reasons' for the purposes of SM6.30.(c)(i) do not include reasons:

1. that exclude or limit the rights of a person under employment law; or

2. ito determine the suitability of a person for permanent or indefinite employment.

Note: In order meet employment law, employment agreements that are for a stated term must specify in writing the way in which the employment will end and the reasons for ending the employment.

7. If the principal applicant has dependent children, the offer of employment must also meet the minimum income requirement set out at $\mathrm{S} 1.40 .35$ below. 


\section{Appendix B}

\section{Appendix for Chapter 2}

\section{B.1 SUPPLEMENTARY DOCUMENTS}

\section{B.1.1 Ethics approval}

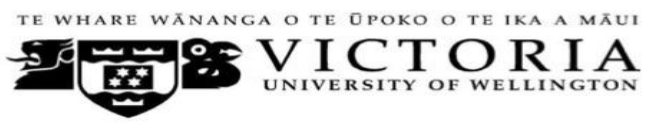

MEMORANDUM

\begin{tabular}{l|l}
\hline TO & Rose Namoori-Sinclair \\
\hline COPY TO & Teresia Teaiwa \\
\hline FROM & AProf Susan Corbett, Convener, Human Ethics Committee \\
\hline DATE & 8 November 2015 \\
\hline PAGES & 1 \\
\hline & $\begin{array}{l}\text { Ethics Approval: } 22105 \\
\text { SUB impact of Immigration on Pacific women's health: The } \\
\text { experiences of Kiribati migrants }\end{array}$
\end{tabular}

Thank you for your application for ethical approval, which has now been considered by the Standing Committee of the Human Ethics Committee.

Your application has been approved from the above date and this approval continues until 30 November 2016. If your data collection is not completed by this date you should apply to the Human Ethics Committee for an extension to this approval.

Best wishes with the research.

Kind regards

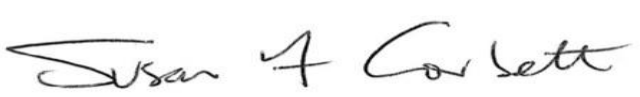

Susan Corbett

Convener, Victoria University Human Ethics Committee 


\title{
B.1.2 Information sheet
}

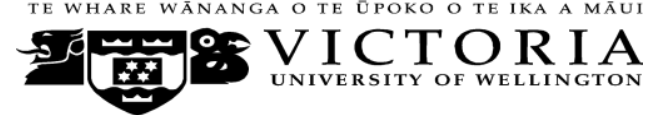

\section{INFORMATION SHEET}

The impact of Immigration on Pacific women's health: The experiences of Kiribati migrants

\author{
Researcher: \\ Rose Namoori-Sinclair, PhD student, Pacific Studies Programme, \\ Va'aomanū Pasifika Victoria University of Wellington (VUW) \\ Email sinclarose@myvuw.ac.nz; home line: 063642332
}

\section{Kam na mauri ao ana tangira Te Uea nakoimi ni kabane. Greetings and the Lord's peace with you all.}

\begin{abstract}
Who am I?
My name is Rose Namoori-Sinclair. I am a PhD student in Pacific Studies at Victoria University of Wellington. I am of Kiribati ancestry, my father and mother are both from Tabiteuea Island (North and South). I am female, married to a part European Fijian, with two children and one grandson, and live in New Zealand. I received VUW Human Ethic Committee ethics approval on 8 November 2015.
\end{abstract}

What is my research about?

As a Kiribati national, I migrated to New Zealand under the Skilled Migrant in 2001 category. I have since then worked closely with a number of people within the Kiribati community in Wellington. Many of them have recently migrated to New Zealand under the Pacific Access Category (PAC). I am aware that some I-Kiribati women who had been on temporary visas while waiting for their permanent residency to be processed under the PAC have experienced problems with healthcare services under the existing health policy. As part of my research, I raise the following research questions:

- Whose responsibility is it to ensure that PAC immigrants receive healthcare and social services?

- How does the PAC immigration policy articulate responsibility for PAC immigrants' healthcare?

- What health conditions have PAC I-Kiribati women faced since arriving in New Zealand?

What do you need to do in this research?

1. Participate in an individual maroro session with me.

And/or

2. Participate in a focus group maroro session with me and other research participants. 
In individual maroro sessions you and I will maroro (talk) together about your experiences of migration and healthcare since arriving in New Zealand. You may say as much or as little as you like. It is up to you. You will only need to do one maroro session. This will last for about 1 hour. We will hold our individual maroro session at any place that suits you best. I can visit you where you live, or pick you up and bring you to where I am based or find a mutually convenient place for both of us.

In focus group maroro session, we will maroro about experiences of migration and health that participants feel comfortable sharing with each other. Focus group maroro sessions will be held in a venue that I have pre-arranged. I will provide transport to the venue for participants.

In both individual maroro and focus group maroro sessions, I will also ask you for your permission to audio record our maroro session and to take handwritten notes. This is so I can capture your words as accurately as possible.

Your participation is voluntary, so you are able to withdraw your information from the study up until 31 July 2016.

\section{Who will access your information?}

Only the researcher (myself) will access your information. No other government agencies will access your information so your immigration status will not be affected.

What am I going to do with your information?

I will transcribe your maroro session and then give you the option of having a sound recording of the session or a written transcript of what was said. All our maroro sessions will be held in the Kiribati language. I will not use your real name but would ask you to either give me a code name or pseudonym or I will allocate one to you. This ensures that anything you say is kept anonymous so that no harm can come to you because of what you said.

I will store your information as an electronic file in a password secured file in a computer housed in my personal computer at home. I will store this for 5 years and then after that time will delete it.

Who do you speak to if you have any questions about the research/ or the ethical conduct of the research?

If you have any questions about my research you can make contact with me by email or phone one of my academic supervisors using the addresses and numbers provided below.

Primary Academic Supervisor: Dr Teresia Teaiwa, Senior Lecturer, Pacific Studies Programme, Va'aomanū Pasifika, VUW; email: Teresia.Teaiwa@ vuw.ac.nz; Ph: 04 4635110 
Secondary Academic Supervisor: Dr. Tamasailau Suaalii-Sauni, Senior Lecturer, Pacific Studies Programme, Vaaomanū Pasifika Unit, VUW; Contact details: Email sailau.suaalii-sauni@vuw.ac.nz; Ph: 044636867

If you have any concerns about the ethical conduct of the research you may contact the Victoria University Human Ethic Committee Convener: Associate Professor Susan Corbett. Email susan.corbett@ vuw.ac.nz or telephone +64-4-463 5480.” 


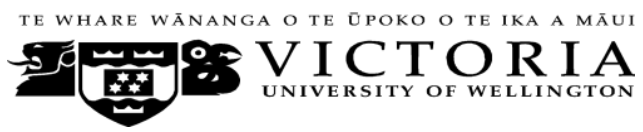

Rongorongo aika a kakawaki

\title{
Atun te kakae: Te kakae i aon marurungia aine ake a eweati mai Kiribati nako Niutiran: Aia karaki i aon baai aika a tia n rinanona
}

\author{
Te tia kakae: \\ Rose Namoori-Sinclair, te tia kakae, Reirein te Betebeke, \\ Va'aomanū Pasifika ibukin te reirei ae rietata ae Victoria University of Wellington \\ (VUW) \\ Email sinclarose@ myvuw.ac.nz; tarebon: 063642332
}

\section{Kam na mauri ao ana tangira Te Uea nakoimi ni kabane.}

\section{Antai te tia kakae?}

Arau Nei Rose Namoori-Sinclair. I karaoa au beba $n$ taokita i aon te rabakau $(\mathrm{PhD})$ ni mangan te reirei ae rietaata ae Victoria University of Wellington (VUW) are i bukin te betebeke. Bon kain Kiribati ngai, tamau ao tinau kain Tabiteuea Meang ao Maiaki. I a tia ni ieien, kain abau bon te itera ni Biiti ao I-Matang, uoman natiu ao temanna tibuu, ao I maeka I Niutiran. E a tia $n$ kariakaki au kakae man te komete are e tabe ma te itera aio ae te VUW Human Ethic Committee $\mathrm{n} 8$ bongin te namakaina ae Nowemba 2015.

\section{Tera ae nna kakae i aona?}

I roko i Niutiran iaan te itera are tabe ma rabakau mai i tinaniku aika a kainnanoaki i aon Niutiran (Skilled Migrant) i nanon 2001. Man moan rokou i Niutiran ao I a tia n mamakuri ma kain Kiribati i aon Wellington. A rangi maiti mai i buakoia te koraki aikai aika a roko I Niutiran iaan te Pacific Access Category (PAC). I a tia naba $n$ ataia ae tabeman aine ake a roko $i$ aon te visa ae uarereke imain ae a kaina te aba, a rang maiti aia kanganga i aon kainnanoan te buoka man te botaki ni kuakua. Mangan au kakae aio, nna kataia ni kakaea kaekaan raoi titiraki aikai:

- Antai tabena ba ana nabaeaki raoi naake a roko iaan te PAC ni kaineti ma kainnanoia i aon katoki aoraki?

- Tera te anga ae e na kona riki te tua i aon te PAC n kamatata raoi an tai tabena kateimatoan marurungia?

- Tera bitaki nakon marurungia aine ake a roko i niutiran iaan te PAC?

$\underline{\text { Tera ae ko na riai ni karaoia n te kakae aei ngkana ko kukurei? }}$ ke

1. Ko na maroro $\mathrm{n}$ ti ngkoe ma ngai

2. Ko na ira te maroro ma uoman riki tabeman ainen Kiribati

Te boto ni iango i aon maroro aikai bon baai ake kam a tia ni kaitibo ma ngaai ni moan rokomi I Niutiran ni kaineti ma tararuan marurungimi. Bon nanom ngkana ko kan kananaua ke kauarerekea am maroro i aon baai aikai. Bon teuana te tai ni maroro. Maanin te maroro aio tao bon teuana te aoa. Ngkana ko rinea te maroro are 
ngai ao ngkoe, ko kona $\mathrm{n}$ rinea te tabo are ko mwengaraoi iai. I kona ni kawariko $\mathrm{n}$ te tabo are ko maeka iai, ke I kona $\mathrm{n}$ anaiko nakon au tabo ke te tabo riki teuana are ko mwenagaraoi iai. Ngkana ko rinea te maroro ma are uoman riki aine, iai te tabo ae I a tia ni katauraoia I bukimi. I tauraoi naba $\mathrm{n}$ anaiko nakon te tabo aio.

I bukin maroro aika uoua aikai, na kainnanoa am kariaia ba nna rawea kanoan te maroro ao na koroi naba tabeua boto ni iango man te maroro. I kani karaoa aio ibukin ae I aonga $\mathrm{n}$ rawea raoi muin ami maroro $\mathrm{n}$ aki kaburei.

Ko aki kabaeaki ni karaoa te maroro aio, ngaia are ko inaomata ni bubai man te kakae aio imain 30 Nowemba 2016

\section{Antai ae kona n nora muin ami maroro?}

Bon tii te tia kakae (ngai) ae na kona nori muin ami maroro. Akea taabo n makuri man te tautaeka ae na kona n nora am rongorongo ngaia are e aki kona n rootaki tikum I Niutiran iaan te tua.

\section{Tera ae na karaoia ma am rongorongo?}

$\mathrm{N}$ na korei baa aika ko taekin $\mathrm{n}$ aron raoi taekinana iroum ni manga anganiko nanom ngkana ko tangira katotongan te bana ke are I a tia n koroia. Ara maroro ana bane ni karaoaki $n$ te taetae ni Kiribati. $\mathrm{N}$ aki kabongana oin aram ma ko na anganai aram ni karaba ke nna anganiko teuana. Aio are e na totokoa reken te kanganga ibukin te bai ae ko taekinna ni kaineti ma am maroro.

Na kawakina am rongorongo aio inanon au computer $\mathrm{n}$ akea ae na roko iai ba bon tii ngai. Na kawakinna inanon nimaua te ririki I main ae I a kamaunai.

Antai ae ko na reitaki mangaia ngkana iai am titiraki ibukin te kaka ke i bukin rinanoakin karaoan te kakae?

Ngkana iai am titiraki i aon au kakae, ko kona $n$ reitaki mangai $\mathrm{n}$ te email, ke $\mathrm{n}$ tarebonia temanna mai irouia au mataniwi i aon taian namba aika oti i nano.

Te moan mataniwi: Dr Teresia Teaiwa, tia reirei, te Betebeke, Va'aomanui Pasifika Unit, VUW: meeri ao tareboon: email: Teresia.Teaiwa@vuw.ac.nz: Ph: 044635110

Kauoman n mataniwi: Dr Tamasailau Suaalii-Sauni, tia reirei, te Betebeke, Vaaomanū Pasifika Unit, VUW: meeri ao tareboon: Email sailau.suaaliisauni@ vuw.ac.nz; Ph: 044636867

Ngkana iai am kanganga $\mathrm{n}$ aron karaoan te kakae aio irou, ko kona $\mathrm{n}$ reitaki ma are te tia tei man te komote ae tara te itera aio ae te Human Ethic Committee man te reirei ae rietata i Victoria. Ana meeri: susan.corbett@ vuw.ac.nz ke tareboon +64-4-463 5480 .

Ko bati n raba are ieta am ibuobuoki ao te Uea i manera $n$ taai nako. 


\section{B.1.3 Consent form}

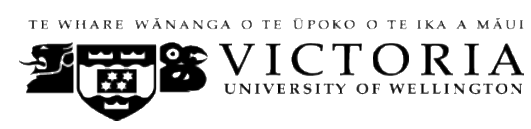

\section{CONSENT TO PARTICIPATE IN RESEARCH}

Research Project Title: The impact of Immigration on Pacific women's health: the experiences of Kiribati migrants

I have been given an information sheet by Rose Namoori-Sinclair and understand the purpose of her research project. I have had an opportunity to ask her questions and have had them answered to my satisfaction.

I understand that I may withdraw my audio-recording (or any information derived from it) from this research by 30 November 2016 without having to give reason and without penalty of any kind.

I understand that all audio recordings will be used by the researcher for her research project. I understand that the data that I provide will not be used by the researcher for any purposes other than those specified on the information sheet.

I have been informed by Rose (the researcher) that I will give a pseudonym or code name, or one will be given to me to use during the talanoa/maroro (maroro) so that all data collected during Te maroro, or quotations used by the researcher from Te maroro will be anonymised.

I also understand that unless I request otherwise the audio recording of this maroro session will be stored as an electronic file in a password secured file in the researcher's personal computer at her home, at the conclusion of this research. On expiry of 5 years, my personal information will be deleted.

\begin{tabular}{|l|l|}
\hline $\mathbf{Y} \square \mathbf{N} \square$ & $\begin{array}{l}\text { I consent to information or opinions that I have provided being } \\
\text { attributed to me by code name in any reports on this research. }\end{array}$ \\
\hline $\mathbf{Y} \square \mathbf{N} \square$ & $\begin{array}{l}\text { I consent to the audio recordings of my maroro session being given to } \\
\text { and maintained by Rose Namoori-Sinclair at the conclusion of this } \\
\text { research. }\end{array}$ \\
\hline $\mathbf{Y} \square \mathbf{N} \square$ & $\begin{array}{l}\text { I consent to the handwritten notes of my maroro session being given to } \\
\text { and maintained by Rose Namoori-Sinclair at the conclusion of this } \\
\text { research. }\end{array}$ \\
\hline $\mathbf{Y} \square \mathbf{N} \square$ & $\begin{array}{l}\text { I would like to receive an audio sound, or a transcript, or a summary } \\
\text { of the findings from } \text { Te maroro session. }\end{array}$ \\
\hline $\mathbf{Y} \square \mathbf{N} \square$ & I agree to take part in this research. \\
\hline
\end{tabular}

Name of Research Participant:

Signature of Research Participant:

Date:

VA'AOMANŪ PASIFIKA - Programmes in Pacific Studies \& Samoan Studies, 6 Kelburn Parade, PO Box 600, Wellington New Zealand Telephone: +64-4-463-5830, Website: www.victoria.ac.nz/pasifika 


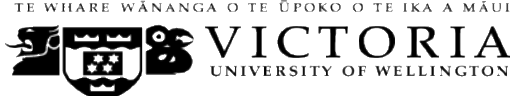

CONSENT TO PARTICIPATE IN RESEARCH

Atun te kakae: Te kakae iaon marurungia aine ake a eweati mai Kiribati nako

Niutiran: Aia rongorongo iaon baai aika a tia $\mathrm{n}$ rinanona

I anganaki te beeba iroun Rose Namoori-Sinclair are e kabarabaraaki iai bukin te kakaaei aio ao I oota iai. I anganaki naba au tai n titiraki ao a tia ni kaekaaki au titiraki.

I oota ba I kona ni katoka te rawerawe ma $\mathrm{n}$ anai muin au maroroo ma $\mathrm{n}$ te kakaei aio i maain 30 Novemba $2016 \mathrm{n}$ akea au kabarabara ke rekeni kaiu iai.

I oota ba e na kabonganaaki au maroroo ae raweaki bon tii i roun te tia kakaaei i bukin ana makuri ni kakaaei aio. I ota naba ba e na aki kaboonganaaki au rongorongo iroun te tia kakaei $\mathrm{i}$ bukin baai aika a ri tinanikun bukin te kakae aio.

E a tia ni kabarabaraaki nakoiu iroun Rose, te tia kakaaei, ba e na aki oti arau n au maroroo ni kabane ke ni kabonganaaki arau iroun te tia kakaaei ngkana e na kabongana raoi au taekae are I taekinna $\mathrm{n}$ tain te maroro, ma e na kaabongana arau ni karaba are nna kabongana $\mathrm{n}$ tain te kakae, $\mathrm{n}$ te aro ae akea ae kona $\mathrm{n}$ ataia ba antai ae anga rongorongo $\mathrm{n}$ tain te kakae.

I oota naba ba au maroroo are e raweaki, e na kawakinna te tia kakaaei ni mweengana n ana kaombiuta ae roka ao akea ae na kona $\mathrm{n}$ roko iai, ma ti ngkana I tangiria ba e na kawakinaki $\mathrm{n}$ te tabo are I tangiria. A na bane ni kamaunaaki au maroroo ake a raweaki i muin nimaua te ririki.

\begin{tabular}{|l|l|}
\hline Eang $\square$ Tiaki $\square$ & $\begin{array}{l}\text { I anga au kariaia ba a na kanikinaeaki muin au maroroo ni } \\
\text { kaineti ma te kakaei aio iaan arau ni karaba are e kabonganaki } \\
\text { n tain te maroro. }\end{array}$ \\
\hline Eang $\square$ Tiaki $\square$ & $\begin{array}{l}\text { I anga au kariaia ba e na anganaki Rose muin au maroroo ake a } \\
\text { raweaki n te bai n rawe bana ba e na tararuai ngkana e a toki te } \\
\text { maakuri ni kakaei aio. }\end{array}$ \\
\hline Eang $\square$ Tiaki $\square$ & $\begin{array}{l}\text { I anga au kariaria ba e na anganaki Rose muin au maroroo ake a } \\
\text { koreaki i aon te beeba ngkana e tia te makuri ni kakaei aio. }\end{array}$ \\
\hline Eang $\square$ Tiaki $\square$ & $\begin{array}{l}\text { I tangiria ba n na anganaki katotoon au maroroo are e raweaki n } \\
\text { te bai n rawe bana, ke n anganaki are e a tia ni koreaki n aron } \\
\text { are I bon taekinna, ke katoton taian boto ni iango ake a reke } \\
\text { man au maroro. }\end{array}$ \\
\hline Eang $\square$ Tiaki $\square$ & \begin{tabular}{l} 
I kariaia bwa n na ira te waaki i aon te kakaei aio. \\
\hline
\end{tabular}
\end{tabular}

Aran te tia maroroo:

Ana tiaaina te tia maroroo:

Te bong:

VA'AOMANŪ PASIFIKA - Programmes in Pacific Studies \& Samoan Studies, 6 Kelburn Parade, PO Box 600, Wellington, New Zealand Telephone: +64-4-463-5830, Website: www.victoria.ac.nz/pasifika 


\section{B.1.4 Confidentiality form}

\section{VICTORIA UNIVERSITY OF WELLINGTON \\ Te Whare Wānanga o te Ûpoko o te Ika a Māui

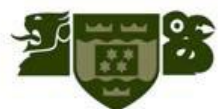

Research Project Title:

The impact of Immigration on Pacific women's health:

The experiences of Kiribati migrants

\section{CONFIDENTIALITY AGREEMENT}

I

(Full Name - printed)

agree to keep everything discussed at the talanoa session confidential . I understand that confidentiality means to not disclose any information at all about anything that was discussed during the talanoa session by any of the members of the talanoa to anyone outside of that group.

Signature:

Date:

VA'AOMANŪ PASIFIKA - Programmes in Pacific Studies \& Samoan Studies, 6 Kelburn Parade, PO Box 600 , 


\section{VICTORIA UNIVERSITY OF WELLINGTON}

Te Whare Wānanga o te Ûpoko o te Ika a Mãui

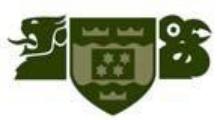

Atun te Kakae:

Te kakae iaon marurungia aine ake a eweati mai Kiribati nako Niutiran: Aia rongorongo iaon baai aika a tia $n$ rinanona

\section{TE BORARAOI}

Ngai ae (Korea Aram ae aki mantikitiki)

I kariaia ba na kawakin rongorongo aika a maroroakinaki n te maroro aio iaon te kakae ae e a tuunaki ieta, ba a rang taburoroko. I oota ae e rang kakawaki ba $\mathrm{n}$ aki manga maroroakini kanoan ara maroro aio ma aomata tabeman i tinanikun te kurubu aio.

Tiaina:

Te bong:

VA'AOMANŪ PASIFIKA - Programmes in Pacific Studies \& Samoan Studies, 6 Kelburn Parade, PO Box 600 , 


\section{B.1.5 Topic guide}

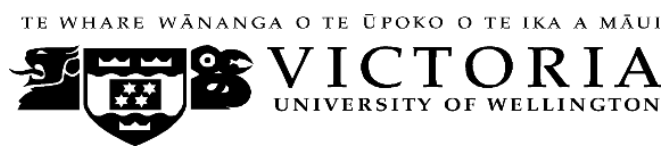

TOPIC GUIDE

The impact of Immigration on Pacific women's health: The experiences of Kiribati migrants

The following are topic areas for our maroro session: Explore each topic area by probing what participants know or have experienced.

- Identifying and evaluating where responsibility for Pacific Access Category (PAC) immigrant health lies;

- Describing and analysing the health experiences of PAC migrant women, using Kiribati women as a case study to comment on issues of responsibility;

- Providing evidence for an argument for more state responsibility in the facilitation of access to appropriate health services for PAC migrant women.

To achieve the stated goals above, I will collect information along the following research questions, which form the evaluation criteria for reviewing policy documents and shaping Te maroro sessions for research participants.

Migration (2002 to present

- What was it like for PAC I-Kiribati women coming from Kiribati to Aotearoa NZ under the PAC Scheme?

- What sorts of interactions did PAC I-Kiribati women have with public, private and/or indigenous healthcare services in their home country?

\section{Resettlement}

- Where did they settle when they arrived in New Zealand? Is there anything they missed about Kiribati?

\section{Work life}

- Did they have work set up before they came? What was it like when they got here?

\section{Health status}

- Have they used any health services here? What about other services? What was that like?

- Whose responsibility is it to ensure that PAC immigrants receive healthcare and services?

- How does the PAC immigration policy articulate responsibility for PAC immigrants' healthcare? 
- How do immigration officials articulate responsibility for PAC immigrants' healthcare?

- What health conditions did PAC I-Kiribati women face before coming to New Zealand?

- What beliefs did PAC I-Kiribati women have about responsibility for healthcare before coming to New Zealand?

- What did PAC I-Kiribati women understand about what the PAC's conditions in relation to their access to healthcare and social services in New Zealand?

What health conditions have PAC I-Kiribati women faced since arriving in New Zealand? 